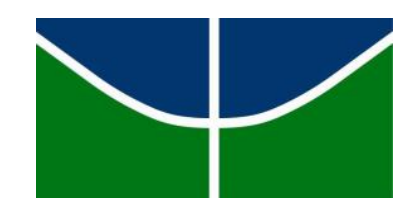

UNIVERSIDADE DE BRASíLIA
FACULDADE DE CIÊNCIAS DA SAÚDE
PROGRAMA DE PÓS-GRADUAÇÃO EM CIÊNCIAS DA SAÚDE

HEIKO THEREZA SANTANA

APLICAÇÃO DA LISTA DE VERIFICAÇÃO DE SEGURANÇA CIRÚRGICA DA ORGANIZAÇÃO MUNDIAL DA SAÚDE:

Análise da segurança do paciente cirúrgico em serviços de saúde do Distrito Federal

BRASÍLIA 


\section{UNIVERSIDADE DE BRASÍLIA \\ FACULDADE DE CIÊNCIAS DA SAÚDE \\ PROGRAMA DE PÓS-GRADUAÇÃO EM CIÊNCIAS DA SAÚDE}

HEIKO THEREZA SANTANA

\section{APLICAÇÃO DA LISTA DE VERIFICAÇÃO DE SEGURANÇA CIRÚRGICA DA ORGANIZAÇÃO MUNDIAL DA SAÚDE:}

Análise da segurança do paciente cirúrgico em serviços de saúde do Distrito Federal

Tese apresentada como requisito parcial para a obtenção do Título de Doutor em Ciências da Saúde pelo Programa de Pós-Graduação em Ciências da Saúde da Universidade de Brasília.

Orientadora: Prof ${ }^{a}$. Dr . Maria do Socorro Nantua Evangelista.

BRASÍLIA 
HEIKO THEREZA SANTANA

\title{
APLICAÇÃO DA LISTA DE VERIFICAÇÃO DE SEGURANÇA CIRÚRGICA DA ORGANIZAÇÃO MUNDIAL DA SAÚDE: \\ Análise da segurança do paciente cirúrgico em serviços de saúde do Distrito Federal
}

Aprovado em

\begin{abstract}
Tese apresentada como requisito parcial para a obtenção do Título de Doutor em Ciências da Saúde pelo Programa de Pós-Graduação em Ciências da Saúde da Universidade de Brasília.

Orientadora: Prof ${ }^{\text {a }}$. Dr ${ }^{\text {a }}$. Maria do Socorro Nantua Evangelista.
\end{abstract}

BANCA EXAMINADORA

Prof $^{a}$. Dr ${ }^{\mathrm{a}}$. Maria do Socorro Nantua Evangelista (Presidente)

Universidade de Brasília

Prof ${ }^{a}$. Dr ${ }^{\mathrm{a}}$. Maria Cristina Soares Rodrigues (Membro)

Universidade de Brasília

Prof ${ }^{a}$. Dr ${ }^{\mathrm{a}}$. Helena Eri Shimizu (Membro)

Universidade de Brasília

Prof ${ }^{a}$. Drª . Maria Raquel Gomes Maia Pires (Membro)

Universidade de Brasília

Prof ${ }^{a}$. Dr ${ }^{\mathrm{a}}$. Ivone Kamada (Membro)

Universidade de Brasília 
Dedico este trabalho...

Aos meus pais, com toda admiração e respeito, pelo amor, dedicação e estímulo à busca do conhecimento.

Aos meus queridos filhos, Yuzo, Yuri, Yann e Yasmin, muitas vezes usurpados da minha presença, mas não do meu imenso amor.

Ao nosso precioso Arthur, que tanta alegria nos proporcionou com sua recente chegada em nossas vidas. 


\section{AGRADECIMENTOS}

A Deus, o Todo de tudo. Se existem a Vida, a Beleza, a Sabedoria e o Amor, é porque Ele está sempre presente.

Aos meus pais, queridos incentivadores, que sempre incitaram minha busca do conhecimento.

Aos meus filhos Yuzo, Yuri, Yann e Yasmin e afilhados, Yumi e Leonardo, pelo amor, estímulo e por toda ajuda e incentivo.

À Thayanne e Arthur, pelo carinho, apoio e pelo entendimento das constantes ausências.

Aos meus queridos irmãos Clayton e Iwace, cunhadas Marilene e Fernanda e sobrinhos Juliano, Sheila, Murilo e Amanda, pela presença e apoio recebido.

A toda minha família (Santana e Iwasse), pelo carinho, importante presença e constante incentivo.

Ao Cleuto, pelo apoio, carinho e compreensão, indispensáveis para a execução deste trabalho.

À querida Prof $\underline{\text { a }}$ Drạ. Maria do Socorro Nantua Evangelista, pela orientação, dedicação, apoio, carinho, encorajamento e por todo auxílio prestado durante a realização deste estudo.

A todos os amigos que pertencem ou pertenceram ao quadro de servidores da GGTES/ANVISA (desde 2012): André Anderson, André Paes, André Sinoti, André Rezende, Adjane, Andressa, Nice, Benefran, Cássio Marques, Chiara, Cleide, Eduardo, Fabiana Petrocelli, Gabriel, Helen, Humberto, Janaína, Karla, Letícia, Mara, Marcelo, Dolores, Rafael, Rosângela, Tatiana, Bete, Dandara, Fernanda e Ceiça e estagiários, Guilherme, Daniel, Dhandara, Luene, Marília e Manoela. Em especial à Angela, Magda, Fabiana Sousa, Suzie, Paulo, Luana, Ana Clara, Sâmia, João Henrique e Eliane, por todo auxílio prestado. E a todos os amigos da ANVISA, em especial à Rosa Aires, Patrícia Fernanda, Luna, Rodrigo Taveira, Cristiano Fernandes, Tiago Carvalho, Átila Correa, Ethel Freitas e Anne Jéssica.

À Dra. Diana Oliveira, pela força durante esta trajetória e que deixou muitas saudades.

Ao Silvano, Julie, Leila Kusano, por toda ajuda recebida.

Ao Prof. Wilson e à Profa. Dra. Regina Maria Dias Buani dos Santos, pela presteza e auxílio que contribuíram para a execução deste trabalho. 
A todos os professores do Programa de Pós-Graduação da Faculdade de Ciências da Saúde.

Aos Professores Doutores da UnB, Luiz Augusto Casulari, Maria Cristina Soares Rodrigues, Leila Gottems e Mauro Niskier Sanchez, pelas valiosas contribuições durante o exame de qualificação.

Ao Prof. Dr. Wildo Navegantes de Araújo, pelas prestimosas colaborações.

À Prof ${ }^{a}$. Dr ${ }^{a}$. Eliete Guerra, sempre prestativa e disposta em ajudar.

Aos Professores Doutores Edmundo Ferraz, Marise Freitas, Maria Clara Padoveze, Adriana Oliveira, Maria Harada e Julia Kawagoe, pela preciosa colaboração neste trabalho.

Às Professoras Doutoras Maria do Socorro Nantua Evangelista, Maria Cristina S. Rodrigues, Helena Eri Shimizu, Maria Raquel Gomes Maia Pires e Ivone Kamada, pela valiosa participação na banca examinadora.

A todos os amigos do Curso e de pesquisa, pelo grande auxílio prestado, em especial à Tatiana Lofti, Maria Cristina Santos, Lígia Cantarino, Cássio Costa e Rogério Lima, e pelos momentos de estudo.

A todos os funcionários administrativos do Programa de Pós-Graduação da Faculdade de Ciências da Saúde. Em especial à Edigrês, Ingrid, Bruna, Douglas e Fabiana.

A todos os pesquisadores envolvidos, que muito auxiliaram nesta pesquisa.

Aos diretores e todos os profissionais de saúde dos hospitais envolvidos neste estudo.

À ANVISA, pelo apoio técnico e por possibilitar a realização deste Curso.

\section{A todos, MUITO OBRIGADA!}


"A maior riqueza do homem é a sua incompletude. Nesse ponto sou abastado. Palavras que me aceitam como sou - eu não aceito..." “....Perdoai

Mas eu preciso ser Outros. Eu penso renovar o homem usando borboletas." 


\section{RESUMO}

\section{SANTANA, HT. Aplicação da lista de verificação de segurança cirúrgica da}

Organização Mundial da Saúde: Análise da segurança do paciente cirúrgico em serviços de saúde do Distrito Federal. 2015. 267p. Tese (Doutorado) - Faculdade de Ciências da Saúde, Universidade de Brasília, Brasília - DF.

Frente ao problema da elevada morbimortalidade nos procedimentos cirúrgicos, em 2008, a Organização Mundial de Saúde lançou o programa Cirurgia Segura Salva Vidas, recomendando o uso da Lista de Verificação de Segurança Cirúrgica (LVSC) para minimizar riscos nas cirurgias. Em 2010, o Ministério da Saúde e a Agência Nacional de Vigilância Sanitária lançou o Programa Cirurgias Seguras Salvam Vidas, sendo que um projeto piloto foi desenvolvido para avaliar a aplicação da LVSC (PréPós-intervenção) em hospitais públicos do Distrito Federal. O estudo transversal prospectivo foi realizado entre 2012-2014. Além da avaliação da aplicação da LVSC, analisou-se as atitudes e opiniões de segurança das equipes cirúrgicas e da atenção anestésico-cirúrgica e segurança do paciente. Os profissionais dos Centros Cirúrgicos foram treinados para a LVSC, sendo que 19 itens de segurança foram avaliados (antes da indução anestésica, da incisão cirúrgica e antes da saída do paciente da sala operatória). Utilizou-se também o Safety Attitudes QuestionnaireOperating Room com 504 profissionais, avaliando as atitudes e opiniões das equipes na sala operatória, além da autoavaliação anestésico-cirúrgica e segurança do paciente (149 profissionais). Na análise estatística utilizaram-se os testes de Kruskal-Wallis, Mann-Whitney e Qui-quadrado com significância de 5,0\%. Na formação do banco de dados utilizou-se o software SPSS, versão 16.0. Para a aplicação da LVSC, estudou-se 1.141 pacientes (Pré-intervenção) e 1.052 (Pósintervenção), totalizando 2.193 pacientes. Quanto à adesão à LVSC (Pósintervenção), "antes da indução anestésica" observou-se que na "identificação do paciente", a "colocação do oxímetro de pulso" e "funcionamento do oxímetro", a adesão foi superior a 95,0\%. Na "verificação de alergias", "avaliação de dificuldade aérea" e "avaliação de perda sanguínea", foi baixa a adesão. Os itens "antes da incisão cirúrgica" apresentaram adesão superior a 90,0\%, exceto "eventos críticos previstos pelo anestesista" (86,7\%) e "disponibilização de exames de imagem" 
(80,0\%). Na etapa "antes do paciente sair da sala operatória", houve baixa contagem de instrumental. As complicações e óbitos foram baixos. Quanto às atitudes e opiniões, a sensação de segurança e concordância da integração da equipe após capacitação foi significativa entre a equipe de enfermagem e anestesiologistas. Ainda, a LVSC apresenta fácil preenchimento, ajuda a evitar erros e contribui para melhor comunicação na sala operatória. $\mathrm{Na}$ avaliação da atenção anestésicocirúrgica e segurança do paciente, relatou-se ausência de controle de temperatura e pressão positiva na maioria das sala operatória. A maioria não reconhece o duplo mecanismo de identificação do paciente, do monitoramento do tempo de atraso da cirurgia e tempo na Recuperação Anestésica. A taxa de reinternação não é monitorada $(82,2 \%)$ e a vigilância pós-alta, em $72,2 \%$ não é realizada. Concluiu-se que houve bons níveis de conformidade à maioria dos itens da LVSC, mas estudos qualitativos devem ser realizados para compreensão das razões para a adesão variável aos itens da lista. Com relação às atitudes e opiniões das equipes sobre a LVSC, percebeu-se dificuldade de aceitação do instrumento pelos cirurgiões. Por último, a investigação aponta fragilidades na estrutura físico-operacional dos Centros Cirúrgicos e nos itens de segurança do paciente, sinalizando para possível descumprimento de determinados regulamentos sanitários.

Palavras-chave: Segurança do Paciente; Eventos Adversos; Cirurgia Segura; Serviços de Saúde; Vigilância Sanitária. 
SANTANA, HT. Application of the World Health Organization (WHO) surgical safety checklist: Analysis of surgical patient safety in health services in the Brazilian Federal District. 2015. 267p. Thesis (PhD) - Health Sciences College, University of Brasilia, Brasilia, Federal District.

\begin{abstract}
Due to elevated rates of morbidity and mortality in surgical procedures, in 2008 the World Health Organization launched the program "Safe Surgery Saves Lives", recommending the use of the Surgical Safety Checklist to minimize the risks of surgery. In 2010 the Ministry of Health and the National Health Surveillance Agency then launched the program Safe Surgery Saves Lives with a pilot project that was developed in order to evaluate the process of utilizing the checklist (Pre- and Postintervention) in public hospitals in the Federal District. The prospective transversal study was conducted in three hospitals between 2012 and 2014. In addition to evaluating checklist use, the study evaluated the attitudes and opinions of the surgical teams regarding patient safety. The professionals in the Surgery Centers were trained to use the checklist; 19 safety items on the checklist pertained to the stages: Before induction of anesthesia, Before skin incision, and Before patient leaves operating room were evaluated. Also, the Safety Attitudes QuestionnaireOperating Room was given to 504 professionals to evaluate the attitudes and opinions of teams in the operating room, in addition to the self-evaluation on patient safety, which 149 professionals responded to. The Kruskal-Wallis, Mann-Whitney, and Chi-square tests were used in the statistical analyses with $5.0 \%$ significance. SPSS version 16.0 was used to compile the data bank. The checklist was used with 1,141 patients in the Pre-intervention phase and 1,052 patients in the Postintervention phase, for a total of 2,193 patients. Regarding adherence to the checklist in the Post-intervention stage, "Before induction of anesthesia", it was observed that adherence was higher than 95\% for "Patient identification", "Pulse oximeter placement", and "Pulse oximeter functioning". "Allergy verification", "Airway obstruction verification", and "Risk of blood loss assessment" had low adherence in all three hospitals. The items included in the stage "Before skin incision" revealed $90 \%$ or greater adherence, except for "Anticipated critical events" by the anesthetist
\end{abstract}


$(86.7 \%)$ and "Essential imaging displayed" (80.0\%). In the stage "Before patient leaves operating room", there were low levels of instrument counts. Complications and deaths were low. Regarding to attitudes and opinions, feelings of safety and agreement on team integration after the training program were significant between nursing teams and anesthesiologists. Moreover, surgical team reported that the checklist is easy to fill out, helps to avoid errors, and contributes to better communication in the operating room. In the evaluation of the anesthetic-surgical care and patient safety, the absence of temperature control and positive pressure in the majority of operating rooms was observed. A secondary means of identifying the patient, monitoring surgical delay, or time in the anesthesia recovery room are not recognized by most of the respondents. The readmission rate is not monitored $(82.2 \%)$ and post-release follow up on surgical patients is not conducted $(72.2 \%)$. It was concluded that there were good levels of compliance with the majority of the items on the checklist, but qualitative studies should be conducted in order to better understand the reasons for variable adherence to items on the checklist. Regarding to the attitudes and opinions by surgeons on the checklist, were observed difficulties found in the acceptance of the instrument. Finally, the study identifies weaknesses in the physical and operational structure of the Surgical Centers as well as with some of the items in relation to patient safety, which could be a possible indication that certain health regulations are not being followed.

Keywords: Patient Safety; Adverse Events; Safe Surgery; Healthcare Services; Healh Surveillance. 


\section{LISTA DE FIGURAS}

Figura 1 Modelo do queijo suíço proposto por Reason......................... 84

Figura 2 Lista de verificação de segurança cirúrgica (LVSC) da OMS ..................................................................... 95

Figura 3 Linha do tempo do estudo e implementação da LVSC nos hospitais avaliados.

\section{Artigo 1}

Figure 1 Pareto chart for the least frequently adhered to items in relation to the total and per hospital in the Federal District. Brazil, 2012- 2014 


\section{LISTA DE QUADROS}

Quadro 1 Principais legislações que apresentam interface com a segurança cirúrgica

Quadro 2 Dez objetivos essenciais da OMS para a segurança cirúrgica. 


\section{LISTA DE TABELAS}

\section{Artigo 1}

Table 1 Features of public hospitals participating in the study - Federal District, 2015

Table 2 Constant variables in the Surgical Safety Checklist

Patient and surgical procedure characteristics according to Table 3 checklist intervention phase (Period I - Pre and Period II - Post), in hospitals in the Federal District. Brazil, 2012 2014

Pre-operatory control item assessment and specialties according

Table 4 to checklist intervention period (Period I - Pre and Period II - Post) by hospital in the Federal District. Brazil, 2012 2014

Table 5

Safety items marked on the checklist for Period II in hospitals in the Federal District. Brazil, 2012 - 2014

\section{Artigo 2}

Table 1 Socio-demographic characteristics of surgery teams according to period of intervention using the Surgical Safety Checklist.

Table 2 Surgical team safety attitudes on surgical safety checklist according to intervention period.

Table 3 Surgical team opinions towards the Surgical Safety Checklist implementation in participating hospitals. 


\section{Artigo 3}

Tabela 1 Distribuição dos participantes do estudo por categoria profissional e por hospital. Distrito Federal, Brasil. 2013 hospital.

Tabela 2 Percepção da equipe relativa à estrutura física e operacional mínima para a segurança do paciente na atenção anestésicocirúrgica nos hospitais do Distrito Federal, Brasil. 2013

Tabela 3 Percepção da equipe quanto à permanência de membros da equipe na atenção anestésico-cirúrgica, por categoria profissional e por hospital do Distrito Federal, Brasil. 2013

Tabela 4 Percepção da existência de barreiras frente às metas nacionais para a segurança do paciente na atenção anestésico-cirúrgica, por hospital do Distrito Federal, Brasil. 2013. 


\section{LISTA DE ABREVIATURAS}

AES

AHRQ

AMBEAS

AMSP

ANS

ANVISA

ASA

CBA

$\mathrm{CBC}$

$\mathrm{CCIH}$

CDC

CEBAS-SAÚDE

CECIH

CEP

CFF

CFM

CFO

CFT

$\mathrm{CHG}$

CIPNSP

$\mathrm{CMCIH}$

CME

CNCIRAS

CNES

CNQPS

COFEN

CONASEMS

CONASS
Adverse Events

Agency for Healthcare Researt and Quality

Eventos adversos na atenção ambulatorial nos países da América Latina

Aliança Mundial para a Segurança do Paciente

Agência Nacional de Saúde Suplementar

Agência Nacional de Vigilância Sanitária

American Society of Anesthesiologists

Consórcio Brasileiro de Acreditação

Colégio Brasileiro de Cirurgiões

Comissão de Controle de Infecção Hospitalar

Centers for Disease Control and Prevention

Certificado de Entidade Beneficiente de Assistência Social em Saúde

Coordenação Estadual de Controle de Infecção Hospitalar

Comitê de Ética em Pesquisa

Conselho Federal de Farmácia

Conselho Federal de Medicina

Conselho Federal de Odontologia

Comissão de Farmácia e Terapêutica

Clorexidina

Comitê de Implementação do Programa Nacional de Segurança do Paciente

Coordenação Municipal de Controle de Infecção Hospitalar Centro de Material Esterilizado

Comissão Nacional de Controle de Infecção Relacionada à Assistencia à Saúde

Cadastro Nacional de Estabelecimentos de Saúde

Comissão Nacional de Qualidade e Produtividade em Saúde

Conselho Federal de Enfermagem

Conselho Nacional de Secretários Municipais de Saúde

Conselho Nacional de Secretários de Saúde 
CSP

CVC

DF

DICOL

DOU

DSN

EA

EUA

FIOCRUZ

GGTES

GM

GT

GVIMS

HEPA

HICC

$\mathrm{HM}$

HMPS

IBEAS

ICC

ICPS

IHI

IOM

IPCS

IQR

IRAS

ISC

JCAHO

LVSC

MCR

MERCOSUL

MRSA

MS
Conferência Sanitária Pan-Americana

Cateter Venoso Central

Distrito Federal

Diretoria Colegiada

Diário Oficial da União

Dialysis Surveillance Network

Eventos Adversos

Estados Unidos da América

Fundação Oswaldo Cruz

Gerência Geral de Tecnologia em Serviços de Saúde

Gabinete do Ministro

Grupo de Trabalho

Gerência de Vigilância e Monitoramento em Serviços de Saúde

High Efficiency Particulate Air

Hospital Infection Control Committee

Higiene das Mãos

Havard Medical Study Practice

Estudo Ibero-Americano de eventos adversos na Atenção

Insuficiência Cardíaca Congestiva

International Classification for Patient Safety

Institute for Healthcare Improvement

Institute of Medicine

Infecção Primária da Corrente Sanguínea

Interquartile Deviation Range

Infecção Relacionada à Assistência à Saúde

Infecção do Sítio Cirúrgico

Joint Commission on Accreditation of Hospitals

Lista de Verificação de Segurança Cirúrgica

Micobactéria de Crescimento Rápido

Mercado Comum do Cone Sul

Staphylococcus aureus resistente à meticilina

Ministério da Saúde 
$\mathrm{NaSH}$

NHS

NHSN

NNIS

NOTIVISA

NPSA

NQF

NSP

OMS

OPAS

OR

PBQP

$\mathrm{PCIH}$

PDCA

PNASS

PNCIRAS

$\mathrm{PNH}$

PNHOSP

PNSP

PNSST

POP

PROADESS

PROADI-SUS

Proqualis

PSP

PVPI

QAHCS

QUALISS

QUALISUS- Red

RDC

RE

REBRAENSP

RENISS
National Surveillance System for Healthcare Workers

National Healthcare Service

National Healthcare Safety Network

Nosocomial National Infection Surveillance

Sistema Nacional de Notificações para a Vigilância Sanitária

National Patient Safety Agency

National Quality Forum

Núcleo de Segurança do Paciente

Organização Mundial da Saúde

Organização Pan-Americana de Saúde

Operating Room

Programa Brasileiro de Qualidade e Produtividade

Programa de Controle de Infecção Hospitalar

Plan-Do-Check-Act

Programa Nacional de Avaliação de Serviços de Saúde

Programa Nacional de Controle de Infecção Relacionada à Assistencia à Saúde

Programa Nacional de Humanização

Política Nacional de Atenção Hospitalar

Programa Nacional de Segurança do Paciente

Política Nacional de Segurança e Saúde no Trabalho

Procedimento Operacional Padrão

Projeto de Avaliação de Desempenho de Sistemas de Saúde Programa de Apoio ao Desenvolvimento Institucional do SUS

Centro Qualidade do Cuidado e Segurança do Paciente

Plano de Segurança do Paciente

Polivinilpirrolidona lodo

Quality in Australian Health Care Study

Programa de Monitoramento da Qualidade dos Prestadores de Serviços na Saúde Suplementar

Qualidade da Rede de Atenção à Saúde

Resolução de Diretoria Colegiada

Resolução

Rede Brasileira de Enfermagem e Segurança do Paciente Rede Nacional de Investigação de Surtos e Eventos 
Adversos em Serviços de Saúde

RM

Resistência Microbiana

$\mathrm{RN}$

Resolução Normativa

$\mathrm{SP}$

SAQ-OR

São Paulo

SAS

SCIP

SGT

SIASUS

Safety Attitudes Questionnaire - Operating Room

Secretaria de Atenção à Saúde

Surgical Care Improvement Project

Subgrupos de Trabalho

SNVS

Ambulatory Information System

SOBECC

Sistema Nacional de Vigilância Sanitária

Sociedade Brasileira de Enfermeiros de Centro Cirúrgico,

SPSS Recuperação Anestésica e Centro de Material e Esterilização

SRE

SSI

SUS

TCLE Statistical Package for the Social Sciences

Serious Reportable Events

Surgical Site Infection

Sistema Único de Saúde

UFPE

Termo de Consentimento Livre e Esclarecido

UnB

Universidade Federal de Pernambuco

UPP

Universidade de Brasília

Úlcera por Pressão

UTI

VIGIPÓS

Unidade de Terapia Intensiva

VISA

Sistema de Notificação e Investigação em Vigilância Sanitária

Vigilância Sanitária

WHA

World Health Assembly

WHO

World Health Organization 


\section{SUMÁRIO}

1.

INTRODUÇÃO.

25

2.

REVISÃO BIBLIOGRÁFICA.

30

2.1

SEGURANÇA DO PACIENTE

BREVE HISTÓRICO

2.1.2 PRINCIPAIS INICIATIVAS INTERNACIONAIS E NACIONAIS PARA A PROMOÇÃO DA SEGURANÇA DO PACIENTE.

MARCO INTERNACIONAL

SEGURANÇA DO PACIENTE E QUALIDADE EM SERVIÇOS DE SAÚDE.

SEGURANÇA DO PACIENTE E VIGILÂNCIA SANITÁRIA DE SERVIÇOS DE SAÚDE.

2.1.4.1 PRINCIPAIS LEGISLAÇÕES QUE APRESENTAM INTERFACE COM A SEGURANÇA CIRÚRGICA ........................................... 54

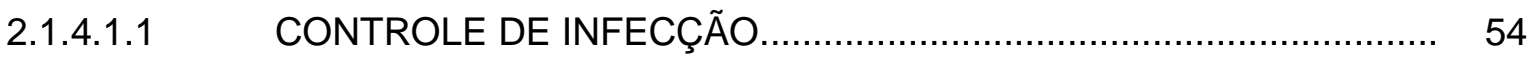

2.1.4.1.2 INFRAESTRUTURA DO CENTRO CIRÚRGICO............................ 55

2.1.4.1.3 REPROCESSAMENTO DE PRODUTOS PARA A SAÚDE............... 56

2.1.4.1.4 CONTROLE DE MICOBACTERIOSES $\quad$ C.......................................... 57

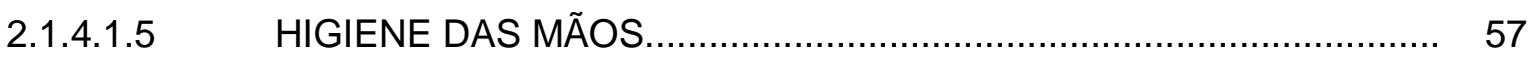

2.1.4.1.6 QUALIDADE EM SERVIÇOS DE SAÚDE.................................... 58

2.1.4.1.7 CENTRO DE MATERIAL E ESTERILIZAÇÃO................................ 59

2.1.4.1.8 SEGURANÇA DO PACIENTE $\quad$ S.............................................. 60

2.1.4.1.8.1. PROGRAMA NACIONAL DE SEGURANÇA DO PACIENTE............. 60 
2.1.4.1.8.2. AÇÕES DE SEGURANÇA DO PACIENTE EM SERVIÇOS DE SAÚDE.

2.1.4.1.8.3. PROTOCOLOS BÁSICOS PARA A SEGURANÇA DO PACIENTE.... 65

2.1.4.2 FERRAMENTAS NACIONAIS PARA A SEGURANÇA DO PACIENTE CIRÚRGICO 69

2.1.4.2.1 NOTIFICAÇÃO 69

2.1.4.2.2 MATERIAIS EDUCATIVOS 70

2.1.4.3 GESTÃO DE RISCO. 72

SEGURANÇA DO PROCEDIMENTO CIRÚRGICO. 74

EPIDEMIOLOGIA DO EVENTO ADVERSO CIRÚRGICO 74

\subsection{2}

2.2 .3 EPIDEMIOLOGIA DA INFECÇÃO DO SíTIO CIRÚRGICO. 77 EPIDEMIOLOGIA DO ERRO HUMANO.. 83

2.2.3.1

FATORES HUMANOS E FATORES DE EQUIPE. 85

2.2.4 A SALA OPERATÓRIA.

FATORES ASSOCIADOS A RESULTADOS CIRÚRGICOS DESFAVORÁVEIS.

LISTA DE VERIFICAÇÃO DE SEGURANÇA CIRÚRGICA DA ORGANIZAÇÃO MUNDIAL DA SAÚDE.

2.2.6.1.1 OBJETIVO 1: A EQUIPE OPERARÁ O PACIENTE CERTO E O LOCAL CIRÚRGICO CERTO..

OBJETIVO 2: A EQUIPE USARÁ MÉTODOS CONHECIDOS PARA IMPEDIR DANOS NA ADMINISTRAÇÃO DE ANESTÉSICOS, $\begin{array}{lll}\text { ENQUANTO PROTEGE O PACIENTE DA } & \end{array}$ DOR.

2.2.6.1.3 OBJETIVO 3: A EQUIPE RECONHECERÁ E ESTARÁ EFETIVAMENTE PREPARADA PARA PERDA DE VIA AÉREA OU DE FUNÇÃO RESPIRATÓRIA QUE AMEACEM A VIDA.

2.2.6.1.4 OBJETIVO 4: A EQUIPE RECONHECERÁ E ESTARÁ EFETIVAMENTE PREPARADA PARA O RISCO DE GRANDES PERDAS SANGUÍNEAS..

2.2.6.1.5 OBJETIVO 5: A EQUIPE EVITARÁ A INDUÇÃO DE REAÇÃO ADVERSA A DROGAS OU REAÇÃO ALÉRGICA SABIDAMENTE DE RISCO AO PACIENTE. 
2.2.6.1.6 OBJETIVO 6: A EQUIPE USARÁ DE MANEIRA SISTEMÁTICA, MÉTODOS CONHECIDOS PARA MINIMIZAR O RISCO DE INFECÇÃO DO SÍTIO CIRÚRGICO.

2.2.6.1.7 OBJETIVO 7: A EQUIPE IMPEDIRÁ A RETENÇÃO INADVERTIDA DE INSTRUMENTAIS OU COMPRESSAS NAS FERIDAS CIRÚRGICAS.

2.2.6.1.8 OBJETIVO 8: A EQUIPE MANTERÁ SEGURO E IDENTIFICARÁ PRECISAMENTE TODOS OS ESPÉCIMES CIRÚRGICOS.

OBJETIVO 9: A EQUIPE SE COMUNICARÁ EFETIVAMENTE E TROCARÁ INFORMAÇÕES CRÍTICAS PARA A CONDUÇÃO SEGURA DA OPERAÇẪO.

2.2.6.1.10 OBJETIVO 10: OS HOSPITAIS E OS SISTEMAS DE SAÚDE PÚBLICA ESTABELECERÃO VIGILÂNCIA DE ROTINA SOBRE A CAPACIDADE, VOLUME E RESULTADOS CIRÚRGICOS.

OUTROS ESTUDOS ENVOLVENDO A APLICAÇÃO DA LISTA DE VERIFICAÇÃO DE SEGURANÇA.

2.2.6.3

PRINCIPAIS DESAFIOS PARA A APLICAÇÃO DA LISTA DE VERIFICAÇÃO DE SEGURANÇA CIRÚRGICA NOS SERVIÇOS DE SAÚDE.

2.2.6.4 LISTA DE VERIFICAÇÃO DE SEGURANÇA CIRÚRGICA $X$ EFEITOS ADVERSOS.

FATORES CONTRIBUINTES PARA A IMPLEMENTAÇÃO EXITOSA DA LISTA DE VERIFICAÇÃO DE SEGURANÇA CIRÚRGICA NOS SERVIÇOS DE SAÚDE.

2.2.6.5.1 PARTICIPAÇÃO DOS PACIENTES E FAMILIARES NOS CUIDADOS CIRÚRGICOS.

OBJETIVOS.

GERAL

ESPECÍFICOS 
4.3.1.3 COLETA DE DADOS E INTERVENÇÃO $\quad$ C.................................. 125

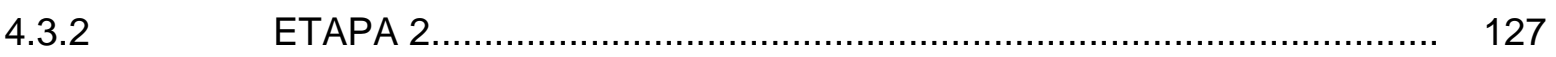

4.3.2.1 CRITÉRIOS DE INCLUSÃO $\quad$ C................................................... 127

4.3.2.2 CRITÉRIOS DE EXCLUSÃO $\quad$ C..................................................... 127

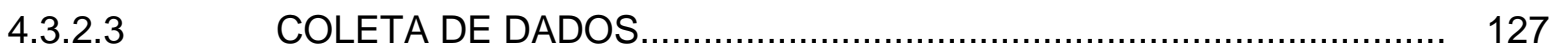

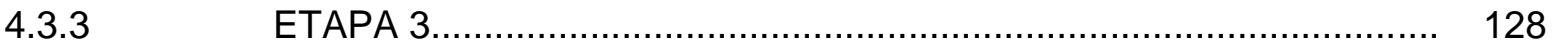

4.3.3.1 CRITÉRIOS DE INCLUSÃO $\quad$ C................................................... 128

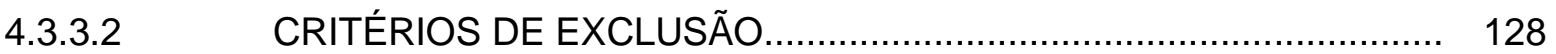

4.3.3.3 COLETA DE DADOS $\quad$ C................................................................... 129

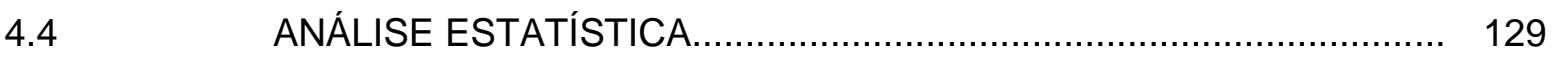

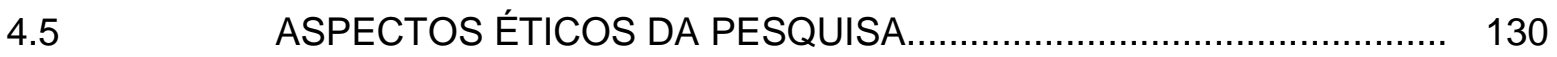

$5 \quad$ RESULTADOS E DISCUSSÃO......................................................

5.1 RESULTADOS DA ETAPA 1 - AVALIAÇÃO DA APLICAÇÃO DA LISTA DE VERIFICAÇÃO DE SEGURANÇA CIRÚRGICA DA ORGANIZAÇÃO MUNDIAL DA SAÚDE EM HOSPITAIS PÚBLICOS DO DISTRITO FEDERAL, BRASIL

5.2 RESULTADOS DA ETAPA 2 - AVALIAÇÃO DAS ATITUDES DE SEGURANÇA E OPINIÕES DAS EQUIPES SOBRE SEGURANÇA CIRÚRGICA EM HOSPITAIS PÚBLICOS DO DISTRITO FEDERAL, BRASIL

5.3 RESULTADOS DA ETAPA 3 - ANÁLISE DA ATENÇÃO ANESTÉSICO-CIRÚRGICA E SEGURANÇA DO PACIENTE A PARTIR DA PERCEPÇÃO DAS EQUIPES CIRÚRGICAS EM HOSPITAIS PÚBLICOS DO DISTRITO FEDERAL, BRASIL.............. 180 
APÊNDICES............................................................................. 239

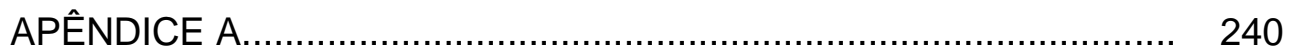

APÊNDICE B................................................................... 251

APÊNDICE C ............................................................... 253

APÊNDICE D................................................................ 256

APÊNDICE E ................................................................. 259

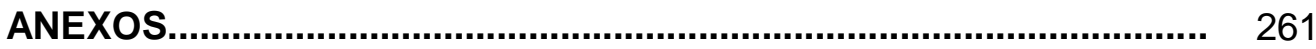

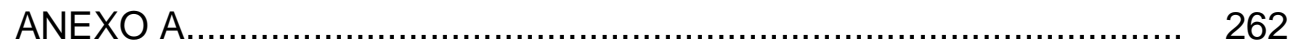

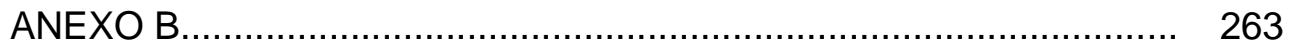

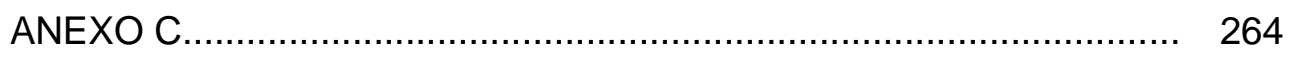

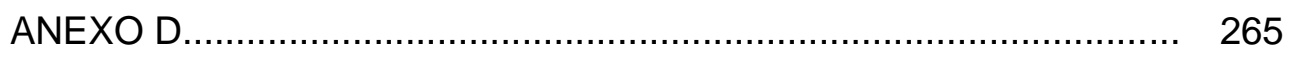

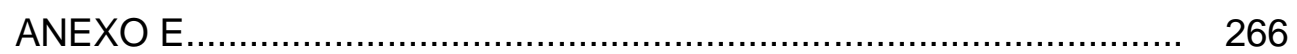

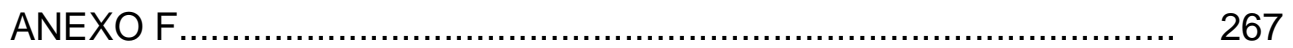


Diversas medidas de prevenção dos riscos relacionados à assistência e à melhoria da qualidade em saúde vêm sendo desenvolvidas pelos serviços de saúde em favor da segurança do paciente ${ }^{(1)}$.

Tais medidas visam à promoção da segurança do paciente, inserindo-a no centro das políticas relevantes mundiais de saúde pública. Entende-se por segurança do paciente, "[...] redução, a um mínimo aceitável, do risco de dano desnecessário associado à atenção à saúde"(2). Logo, a segurança do paciente envolve todos os elementos da cadeia de atenção à saúde (governo, serviços de saúde, profissionais de saúde, pacientes e familiares).

Outro aspecto de crucial importância são os eventos adversos (EA), conhecidos como incidentes que resultam em dano ao paciente ${ }^{(2)}$, podendo ser ocasionados quando o paciente recebe cuidados em um estabelecimento de saúde. Assim, os EA envolvem todos os riscos a que o paciente está exposto nos processos de assistência à saúde, derivados de uma multiplicidade de fatores, destacando-se a qualidade técnica dos profissionais que 0 atendem ${ }^{(3)}$.

Estudos mostram que a ocorrência de EA no processo de atendimento aos pacientes hospitalizados acarreta complicações na evolução de sua recuperação, aumento das taxas de infecções e do tempo médio de internação ${ }^{(4-7)}$. Entretanto, a ocorrência de EA não provoca apenas custos de danos físicos e psíquicos para os pacientes (as suas primeiras vítimas), mas afeta ainda a reputação de profissionais e de instituições (as suas segundas vítimas), predispondo ao litígio e à quebra de confiança entre as partes ${ }^{(8)}$.

Estima-se que 1 em 150 pacientes admitidos em estabelecimento de saúde vai a óbito em consequência de EA e que cerca de dois terços destes eventos estão associados a procedimentos cirúrgicos ${ }^{(9)}$. Desta forma, medidas de prevenção destes eventos precisam ser adotadas com vistas a reverter tal panorama.

Até recentemente, os erros relacionados à assistência à saúde eram considerados inevitáveis pela medicina moderna ou um infortúnio advindo de maus prestadores desses serviços ${ }^{(10)}$.

Não se reconhecia a gravidade do problema até cerca de 10 anos quando foi publicado o relatório "Errar é humano: construindo um sistema de saúde mais seguro", divulgado em 2000, pelo Comitê para a Qualidade do Cuidado à Saúde na América (Committee on Quality of Health Care in América), do Instituto de Medicina 
(Institute of Medicine - IOM) dos Estados Unidos da América (EUA) ${ }^{(3)}$. O documento reportou que aproximadamente 98 mil americanos vão a óbito a cada ano como resultado de falhas evitáveis em serviços de saúde. Esta estimativa foi baseada em estudos realizados no final da década de 1980 e início da de 1990, envolvendo o Harvard Medical Practice Study (HMPS) $)^{(3,11)}$ e em trabalhos posteriormente publicados nos EUA, usando a revisão retrospectiva de prontuários em hospitais de Utah e Colorado sobre a avaliação da incidência de $\mathrm{EA}^{(12,13)}$.

O relatório do IOM apontou, ainda, o grave prejuízo financeiro provocado pela ocorrência de EA. No Reino Unido e na Irlanda do Norte, o prolongamento do tempo de permanência no hospital devido aos EA custou cerca de dois bilhões de libras ao ano e o gasto do Sistema Nacional de Saúde com questões litigiosas associadas à ocorrência de EA foi de 400 milhões de libras ao ano. Nos EUA, os custos provocados por EA foram estimados entre 17 e 29 bilhões de dólares anuais ${ }^{(13)}$.

Diversos estudos sobre a incidência e a prevalência de EA, incluindo os cirúrgicos, têm sido realizados em vários países ${ }^{(14-19)}$. Os EA cirúrgicos ou complicações cirúrgicas são considerados como "um evento que é atribuível a um procedimento cirúrgico e pode ocorrer em qualquer momento no pós-operatório tão longo quanto a ocorrência é ainda atribuível a uma precedente intervenção cirúrgica anteriormente realizada"(20). Em particular, a maior parte dos erros cirúrgicos ocorre na sala operatória ${ }^{(21-23)}$ e são de natureza técnica ${ }^{(24,25)}$.

Avanços internacionais significativos foram alcançados em 2004 por meio da criação da World Alliance for Patient Safety (Aliança Mundial para a Segurança do Paciente - AMSP), pela Organização Mundial da Saúde (OMS), e de políticas para se concentrar maior atenção no temário segurança do paciente ${ }^{(26)}$.Um elemento central do trabalho da Aliança é a formulação dos Desafios Globais para a Segurança do Paciente, sendo que a cada dois anos, um novo desafio é formulado pela $\mathrm{OMS}^{(27)}$.

Em 2008, a OMS e a Universidade de Harvard dos EUA, desenvolveram diretrizes para tornar os procedimentos cirúrgicos mais seguros, definindo um conjunto de padrões universais de segurança que pudessem ser aplicados nos países membros da OMS para a prevenção e a redução dos danos cirúrgicos, e constituindo o segundo desafio global para a segurança do paciente, Cirurgias Seguras Salvam Vidas ${ }^{(9)}$. 
Esses padrões de segurança foram estabelecidos para as equipes cirúrgicas durante suas atividades na sala operatória, sendo operacionalizados pela aplicação de uma Lista de Verificação de Segurança Cirúrgica (LVSC) ou checklist no ato cirúrgico, e pela criação de medidas preventivas básicas nos serviços cirúrgicos ${ }^{(9)}$, que podem funcionar como importante barreira para prevenir ou reduzir a ocorrência de dano ao paciente cirúrgico nos serviços de saúde. A LVSC pode ser adaptada ao contexto local e aborda a segurança em 19 itens, aplicáveis a todas as cirurgias, em três etapas: 1) antes da indução anestésica; 2) antes da incisão cirúrgica; e 3) antes da saída do paciente da sala operatória ${ }^{(9)}$.

Após a introdução da LVSC da OMS para uso em sala operatória em 2008, estudos realizados em diferentes países relataram redução nas complicações pósoperatórias, na morbidade e na mortalidade ${ }^{(28-31)}$. Ademais, a capacitação da equipe cirúrgica com a incorporação de uma LVSC, juntamente com o emprego de estratégias de comunicação foi associada à significativa redução da mortalidade

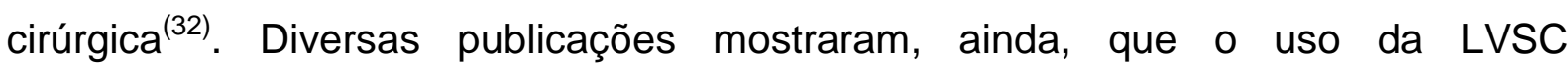
proporciona melhorias nas atitudes de segurança de profissionais que atuam na sala operatória dos serviços de saúde ${ }^{(33-36)}$.

Aliado ao contexto, práticas de autoavaliação da atenção anestésico-cirúrgica podem aprimorar as boas práticas de cuidado assistencial, com vistas a conhecer as perspectivas das equipes cirúrgicas quanto ao seu ambiente de trabalho, os padrões sanitários estabelecidos e a interação com os demais profissionais dentro das salas operatórias. Desta forma, a autoavaliação no Centro Cirúrgico pode subsidiar as inspeções sanitárias ${ }^{(37)}$, além de contribuir na compreensão das ocorrências nas salas operatórias, entre elas as advindas da própria comunicação no processo de trabalho.

Apesar dessas evidências, a aceitação da LVSC como uma ferramenta de segurança cirúrgica universal tem sido criticada, conforme relatado recentemente em estudos realizados $^{(38,39)}$ e a plena incorporação de boas práticas na sala operatória, contudo, ainda não se tornou realidade. A implementação de uma LVSC carece de prática cirúrgica ampla nos serviços de saúde, assim como de inúmeras iniciativas por parte das instituições de saúde para prevenir e reduzir os erros decorrentes de falhas no sistema ${ }^{(1)}$. 
Ressalta-se que uma das ações da Agência Nacional de Vigilância Sanitária (ANVISA) para a segurança do paciente cirúrgico é a implementação do Projeto Cirurgias Seguras Salvam Vidas em estabelecimentos de saúde do país ${ }^{(40)}$, o qual contempla o uso da LVSC da OMS nas salas operatórias. Não obstante, há poucos estudos publicados no país sobre a aplicação da LVSC da OMS e da situação de aceitação do instrumento pelas equipes cirúrgicas nos serviços de saúde, especialmente nos hospitais de ensino.

No caso de procedimentos cirúrgicos, embora a cirurgia possa evitar a perda de vida e preservar a integridade física, também está associada a complicações póscirúrgicas e óbitos em serviços de saúde ${ }^{(9)}$.

Este cenário evidencia a magnitude da problemática dos danos advindos dos procedimentos cirúrgicos nos serviços de saúde e promove uma reflexão sobre a dimensão desta problemática no Distrito Federal (DF), suscitando os questionamentos: Qual é o nível de adesão aos distintos itens de segurança da LVSC? Em que medida as atitudes e opiniões de segurança das equipes cirúrgicas corrobora para a melhoria ou redução da segurança na sala operatória? Existem barreiras que impedem a aceitação da LVSC da OMS pelas equipes cirúrgicas? Como os profissionais das equipes cirúrgicas percebem as condições da estrutura físico-operacional dos Centros Cirúrgicos e dos itens de segurança do paciente?

O presente estudo objetiva conhecer aspectos referentes à segurança do procedimento cirúrgico em hospitais públicos do DF, envolvendo: avaliar os resultados da implementação da LVSC nas salas operatórias; conhecer as atitudes e opiniões sobre segurança cirúrgica das equipes cirúrgicas antes e após a aplicação da LVSC; e depreender os níveis de percepção das equipes cirúrgicas sobre os elementos da atenção anestésico-cirúrgica e a segurança do paciente.

Os achados podem contribuir com o delineamento de estratégias direcionadas à minimização de riscos nos Centros Cirúrgicos e à melhoria na prestação da qualidade do cuidado, promovendo a segurança do paciente cirúrgico, além de colaborar com o desenvolvimento de uma cultura de segurança nos serviços de saúde avaliados. 
2. REVISÃO BIBLIOGRÁFICA 


\subsection{Segurança do Paciente}

\subsubsection{Breve Histórico}

Hipócrates (460 a 370 a.C.) cunhou o postulado Primum non nocere, que significa - primeiro não cause o dano. O pai da Medicina tinha a noção, desde essa época, que o cuidado prestado ao paciente poderia causar algum tipo de dano ${ }^{(41)}$.

Ao longo da história, diversos profissionais contribuíram com a melhoria da segurança e da qualidade em saúde. Na enfermagem, desde 1855, a inglesa Florence Nightingale recomendava a prevenção de riscos e alertava para a segurança do paciente, enunciando como primeiro dever de um hospital não causar dano ao paciente ${ }^{(42)}$.

O trabalho desenvolvido por Nightingale durante os anos desastrosos que o exército britânico experienciou durante a Guerra da Criméia, entre 1854 e 1857, decorreu em grande parte do resultado de sua preocupação com o saneamento e da relação deste com a mortalidade, bem como de sua capacidade de liderança, organização, e realização de tarefas. Ela foi uma das primeiras na Europa a compreender os princípios da ciência da estatística e aplicá-los durante os cuidados prestados aos soldados no hospital militar em Scutari, na Turquia Otomana ${ }^{(43)}$. Com o auxílio de 38 mulheres (irmãs anglicanas e católicas) organizou um hospital de 4000 soldados internos, baixando a mortalidade local de $40 \%$ para $2 \%{ }^{(42)}$.

As medidas inovadoras preconizadas por Nightingale que resultaram na redução do número de óbitos dos pacientes internados foram importantes para o campo da saúde pública ${ }^{(43)}$. Sua preocupação com o "cuidar" estabeleceu as diretrizes e o caminho para a Enfermagem moderna.

O médico húngaro Semmelweis também trouxe contribuições valiosas à área da saúde quando demonstrou, em 1847, que a higiene apropriada das mãos podia prevenir infecções puerperais e evitar mortes maternas ${ }^{(44)}$.

O químico francês Louis Pasteur (1822-1895) realizou vários experimentos contrários à teoria da geração espontânea e descobriu que os micro-organismos tinham a capacidade de propagar-se entre as pessoas ${ }^{(45)}$. 
A história da cirurgia contou com a importante contribuição do cirurgião inglês, Joseph Lister. Em 1865, ele pesquisou um modo de manter as incisões cirúrgicas livres de contaminação por micro-organismos. Associando a conhecida propriedade do fenol de destruir bactérias, ele passou a utilizar compressas cirúrgicas banhadas nessa solução, borrifando também a sala operatória com ácido carbólico (fenol) e obtendo bons resultados. As taxas de mortalidade após amputação reduziram de $46 \%$, antes da antissepsia, para $15 \%$ após os experimentos de Lister $^{(45,46)}$.

Ernest Codman, cirurgião americano, no início do século $X X$, foi pioneiro na avaliação científica do resultado da cirurgia ao considerar o resultado final para o paciente como o princípio fundamental para justificar uma intervenção cirúrgica ${ }^{(47)}$.

Codman propôs o primeiro método de monitoramento do resultado do cuidado com o argumento de que é fundamental verificar se o cuidado prestado foi efetivo. As categorias propostas por Codman para avaliar as falhas no tratamento envolviam: erro por falta de conhecimento técnico ou habilidade; erro por falta de julgamento cirúrgico; erro por falta de atendimento ou equipamento; erro por falta de habilidade diagnóstica; a doença é intratável; o paciente recusa o tratamento e calamidades cirúrgicas ou acidentes e complicações que não podem ser controladas. De 1911 a 1916, 337 pacientes receberam alta do hospital de Codman, com 123 erros registrados. Além dos erros, Codman registrou calamidades cirúrgicas, sobre as quais ele não tinha controle, mas acreditava que deveriam ser reconhecidas e divulgadas para conhecimento público ${ }^{(48)}$

O cirurgião conseguiu influenciar positivamente o Colégio Americano de Cirurgiões, que criou em 1917 o primeiro elenco de padrões hospitalares, conhecido como "padrões mínimos"(48, 49). Em 1918, o Colégio Americano de Cirurgiões iniciou as inspeções e o resultado da primeira avaliação mostrou que apenas 89 dos 692 hospitais avaliados preencheram os requisitos dos padrões mínimos ${ }^{(50)}$.

Os padrões mínimos foram usados até 1952, quando se tornaram ultrapassados após a criação da Comissão Conjunta de Acreditação de Organizações Hospitalares (Joint Comission on Accreditation of Hospitals) ${ }^{(47)}$.

Na Medicina, a área de Anestesiologia foi pioneira na cultura da segurança. Em junho de 2010, o compromisso com a segurança nesta área foi reafirmado com a "Declaração de Helsínquia sobre a Segurança do Paciente em Anestesiologia" (Helsinki Declaration on Patient Safety in Anaesthesiology) ${ }^{(51)}$, proposta pelo 
Conselho Europeu de Anestesiologia para as salas operatórias e unidades de recuperação pós-anestésica, sendo aprovada pela OMS e Federação Mundial das Sociedades de Anestesiologistas e endossada pela Confederação Latino-americana de Sociedades de Anestesiologia ${ }^{(52)}$.

Cabe ressaltar que o cirurgião Lucian Leape vem se destacando pelo desenvolvimento de pesquisas na área de segurança do paciente ${ }^{(10)}$. É importante lembrar que outros profissionais contribuíram com a melhoria da qualidade em saúde, destacando-se Avedis Donabedian, John E. Wennberg e Archibald Leman Cochrane, entre outros ${ }^{(41)}$.

\subsubsection{Principais iniciativas internacionais e nacionais para a promoção da segurança do paciente}

\subsubsection{Marco Internacional}

Durante a década de 1990 e no início do século XXI, houve inúmeras estatísticas sobre o erro e as lesões provocadas em pacientes, uma série de casos verdadeiramente trágicos de falhas no sistema de atendimento hospitalar e um número cada vez maior de importantes relatórios governamentais e de sociedades profissionais sobre a necessidade de tornar o atendimento mais seguro ${ }^{(47)}$. A melhoria dos processos de cuidado com foco na segurança passou a ser o principal componente da qualidade nos serviços de saúde.

Em 1999, o pediatra inglês Cyrill Chantler chamou atenção ao afirmar que a medicina antes era mais simples, entretanto mais inefetiva e relativamente segura, e passou a ser mais complexa, efetiva, mas potencialmente perigosa ${ }^{(53)}$.

Sequentemente, diversas publicações relataram tacitamente as falhas na atenção à saúde e a partir deste reconhecimento, trabalhos mostrando a incidência de EA começaram a ser divulgados ${ }^{(54)}$.

O movimento moderno em prol da segurança do paciente se iniciou com a publicação do HMPS no New England Journal of Medicine em fevereiro de 1991. Os resultados do estudo revelaram que $3,7 \%$ dos pacientes hospitalizados sofreram EA, dos quais dois terços foram considerados evitáveis e $14 \%$ resultaram em óbitos ${ }^{(55)}$. 
Como desdobramento, a segurança do paciente tornou-se uma prioridade de saúde pública, expressada nas políticas de diversas organizações internacionais que velam pela segurança e qualidade dos serviços de saúde, tais como o IOM, o National Healthcare Service (NHS), a OMS, o Institute for Healthcare Improvement (IHI), o National Quality Forum (NQF) e a Joint Commission on Accreditation of Healthcare Organization (JCAHO). Outras principais iniciativas envolvem as contribuições do National Healthcare Safety Network (NHSN) e da Agency for Healthcare Research and Quality (AHRQ) ${ }^{(10)}$.

Em 1998, o IOM iniciou um projeto denominado Qualily of Healh Care in America para promover a melhora significativa da qualidade da atenção à saúde e em 2000 disponibilizou a publicação na qual foi abordado o problema dos erros médicos nos EUA e a necessidade de se ter serviços de saúde mais seguros ${ }^{(3)}$. Utilizando-se dos dados do HMPS $^{(11)}$, o IOM derivou sua estimativa de 44.000 98.000 óbitos/ano nos $E \cup A^{(3)}$, resultado de falhas evitáveis em serviços de saúde. $A$ publicação desse relatório foi, isoladamente, o estímulo mais importante para o desenvolvimento da segurança do paciente, lançando-a para a atenção pública e instituindo uma política de segurança de alto nível nos EUA ${ }^{(47)}$.

No mesmo ano, a publicação de outro relatório semelhante no Reino Unido, intitulado An Organisation with a Memory, também destacou as temáticas do erro humano e dos EA relacionados à assistência à saúde ${ }^{(56,57)}$.

A partir das publicações supraexpostas, a preocupação com os cuidados inseguros se estendeu rapidamente por todo o mundo e diversos países começaram a desenvolver políticas e estratégias para reduzir os erros e melhorar a segurança do paciente nos serviços de saúde.

Em 2001, o Reino Unido desenvolveu um plano governamental para promover a segurança do paciente, sendo que uma das ações definidas no documento foi o estabelecimento da obrigatoriedade de notificação de EA e de complicações decorrentes da atenção à saúde. Foi criada a National Patient Safety Agency (NPSA), encarregada de avaliar as questões de segurança do paciente, encontrar soluções apropriadas, conduzir investigações, além de propor recomendações e regulações. Entretanto, suas atividades foram recentemente encerradas, sendo as funções principais da divisão de segurança do paciente da NPSA transferidas ao NHS da Inglaterra ${ }^{(58,59)}$. 
Os resultados dos estudos sobre a magnitude e tipo de dano a pacientes decorrentes da assistência à saúde, realizados por pesquisadores, agências governamentais e organismos não governamentais serviram de apoio técnico para que a OMS colocasse o tema da qualidade e da segurança do paciente na agenda da 55aㅗ Assembleia Mundial da Saúde. Durante a assembleia realizada em maio de 2002, em Genebra, foi aprovada a Resolução World Health Assembly (WHA) 55.18, a qual recomendava à própria OMS e aos Estados-membros, dispor maior atenção ao problema da segurança do paciente e estabelecer programas e políticas para a melhoria da segurança e da qualidade do cuidado ${ }^{(9,60)}$.

Em novembro de 2003, durante reunião com representantes das regiões da OMS com o objetivo de discutir o futuro da cooperação internacional em segurança do paciente, foi aprovada a proposta de criação da AMSP e na oportunidade, foram definidos grupos de trabalho (GT) para os seguintes temas específicos: 1) desenvolvimento e acompanhamento de políticas de segurança do paciente; 2) sistemas de relato e aprendizagem; 3) investigação; 4) taxonomia e 5) envolvimento de pacientes na segurança ${ }^{(61)}$.

Um ano após, em 2004, foi estabelecida a AMSP, a qual congrega países membros, organismos interessados e especialistas com o propósito de coordenar ações de abrangência internacional e concentrar esforços para o enfrentamento do problema de segurança do paciente ${ }^{(1,27)}$. São contemplados temas que apresentam risco significativo à saúde para a consequente instituição de ações pelos Estadosmembros da $\mathrm{OMS}^{(1)}$.

As questões principais no biênio 2005 - 2006 foram a redução das infecções relacionadas à assistência à saúde (IRAS) nos serviços de saúde e a necessidade de maior segurança nos procedimentos realizados nos serviços de saúde ${ }^{(60)}$. Desta forma, o primeiro desafio global da OMS para a segurança do paciente enfatizou a prática da higiene das mãos como medida primordial para a prevenção das infecções com o tema "Uma Assistência Limpa é uma Assistência mais Segura"(26, 62). As seguintes ações foram previstas para este desafio: 1) práticas limpas higiene das mãos e segurança dos procedimentos clínicos, cirúrgicos e de urgências; 2) ambiente limpo - segurança da água, saneamento e gerenciamento de resíduos; 3) produtos limpos - segurança nas transfusões sanguíneas e hemoderivados e 4) equipamentos limpos - vacinação e injeção seguras ${ }^{(26)}$. 
A segurança dos pacientes nos blocos cirúrgicos recebeu grande atenção da OMS e o segundo desafio global para a segurança do paciente, Cirurgias Seguras Salvam Vidas, foi lançado em 2008, dentro do marco de ações prioritárias da AMSP. O desafio tem o objetivo de promover a melhoria da segurança cirúrgica e reduzir os óbitos e complicações cirúrgicas de quatro maneiras ${ }^{(9,63)}: 1$ ) fornecendo informação para médicos, administradores de hospitais e profissionais da saúde sobre a importância dos padrões da segurança cirúrgica na saúde pública; 2) definindo um conjunto mínimo de indicadores cirúrgicos para a vigilância nacional e internacional da assistência cirúrgica; 3) identificando um conjunto simples de padrões de segurança cirúrgica que seja aplicável em todos os países e cenários de saúde e que esteja compilado em uma LVSC para uso nas salas operatórias; 4) avaliando e difundindo a LVSC e as medidas de vigilância inicialmente em centros pilotos de cada região da OMS e posteriormente em hospitais de todo o mundo.

Recentemente, outras soluções para a segurança do paciente têm sido estimuladas pela OMS, tais como ${ }^{(27,41)}$ : evitar erros de medicamentos com grafias e sons parecidos; evitar troca de pacientes ao administrar qualquer cuidado; garantir uma correta comunicação durante a transmissão do caso; criar mecanismos de controle de soluções eletrolíticas concentradas; garantir a medicação correta em transições dos cuidados; evitar má conexão de tubos cateteres e seringas e usar seringas descartáveis.

O IHI é uma organização sem fins lucrativos e em 2005, lançou a campanha para salvar 100 mil vidas, com a promoção de seis práticas orientadas para a segurança nos hospitais norte-americanos - prevenir a pneumonia associada à ventilação mecânica; prevenir a infecção de corrente sanguínea associada a cateter venoso central (CVC); prevenir a infecção de sítio cirúrgico (ISC); melhorar o cuidado para infarto agudo do miocárdio; prevenir EA de medicamentos por meio da reconciliação medicamentosa e empregar equipes de resposta rápida (10). A campanha objetivou a prevenção de mortes de pacientes por EA em um período de dois anos, com término em 2006 (55). As novas práticas adotadas pelos hospitais participantes resultaram na redução da mortalidade de 122.000 pacientes ${ }^{(10,55)}$.

Ainda em 2006, foi lançada pelo IHI, a campanha para prevenir 5 milhões de danos, por meio de seis práticas adicionais: prevenir úlceras por pressão (UPP), reduzir infecções por Staphylococcus aureus resistente à meticilina (MRSA); prevenir dano causado por medicamentos de alta vigilância; reduzir complicações cirúrgicas 
gerais; prestar cuidado consistente baseado em evidência para pacientes com insuficiência cardíaca congestiva (ICC) e engajar a alta administração das instituições de saúde nesta iniciativa ${ }^{(10)}$.

O NQF, estabelecido em 1999, é uma organização não governamental com sede em Washington DC, nos EUA. Em 2002, o NQF publicou uma lista de Never Events (eventos que nunca deveriam ocorrer em serviços de saúde). Esta lista é atualmente conhecida como Serious Reportable Events - SRE. Além da lista SRE, o NQF também elaborou a lista de práticas de segurança, baseadas em evidências ${ }^{(10)}$.

A Joint Commission on Accreditation of Hospitals foi criada nos EUA em 1952, contando com a participação de associações profissionais e de hospitais dos EUA e do Canadá. Em função da ampliação de seu escopo de avaliação passou a se chamar JCAHO e, mais recentemente, simplesmente The Joint Commission ${ }^{(50)}$.

Com o intuito de promover melhorias específicas em áreas que são problemáticas na assistência à saúde, a Joint Commission, desde 2003, propõe que hospitais implementem uma lista de práticas de segurança desenvolvida pelo $\mathrm{NQF}^{(55)}$. Em 2006, a Joint Commission propôs 6 metas internacionais relacionadas com a segurança do paciente: 1) identificar os pacientes corretamente; 2) melhorar a efetividade da comunicação entre os profissionais da assistência; 3) melhorar a segurança de medicamentos de alta vigilância; 4)' assegurar cirurgias com local de intervenção, procedimento e paciente corretos; 5) reduzir o risco de IRAS nos serviços de saúde e 6) reduzir o risco de lesões aos pacientes, decorrentes de quedas $^{(64)}$.

O CDC's National Healthcare Safety Network (NHSN), uma rede de informações administrada pelos Centers for Disease Control and Prevention (CDC), foi criado para integrar os três sistemas de vigilância do CDC: o Nosocomial National Infection Surveillance (NNIS), a National Surveillance System for Healthcare Workers (NaSH) e a Dialysis Surveillance Network (DSN). O banco de dados do NHSN foi organizado em três componentes para a prevenção e controle das IRAS, a saber: segurança do paciente, segurança dos profissionais de saúde e biovigilância (65). Desde 2006, os CDC já vinham trabalhando em conjunto com o Centers for Medicare \& Medicaid Services e organizações cirúrgicas em um programa denominado Projeto de Melhoria do Cuidado Cirúrgico - Surgical Care Improvement Project (SCIP) para reduzir as complicações cirúrgicas ${ }^{(55,66)}$. 
Por sua vez, a $A H R Q$, dos EUA, lidera esforços para pesquisas e promoção da segurança do paciente para o desenvolvimento e a disseminação de melhores práticas de segurança, baseadas em evidências. Após a aprovação da Lei da Segurança do Paciente e Melhoria da Qualidade pelo Congresso Americano, em 2005, autorizando a criação das Organizações de Segurança do Paciente, a AHRQ foi encarregada de supervisionar as organizações que aderiram às iniciativas de melhoria da segurança e da qualidade do cuidado ao paciente ${ }^{(10)}$. Recentemente, o relatório Making Health Care Safer II, publicado em março de 2013, pela AHRQ, confirmou a implementação eficaz da LVSC da OMS, incluindo-a entre as 10 práticas altamente recomendáveis para melhorar a segurança do paciente em serviços de saúde e que deve ser implantada, sem hesitação, por estes serviços ${ }^{(67)}$.

Diante do exposto, cabe ressaltar que as diferenças existentes entre os países, inevitavelmente, significam que as abordagens para a segurança do paciente devem ser adaptadas localmente, a fim de garantir a sua relevância. No entanto, há também muitos desafios comuns para os sistemas de saúde de países que buscam estabelecer programas e iniciativas de segurança do paciente, como: 1) impedir que os pacientes sejam prejudicados durante o atendimento de saúde; 2) detectar precocemente o dano ao paciente decorrente de cuidados inseguros; 3) instituir estratégias para amenizar os efeitos de tais danos em pacientes, familiares e profissionais de saúde e 4) promover a aprendizagem dos profissionais envolvidos no cuidado, impedindo danos a outros pacientes a partir da detecção de fontes de risco semelhantes ${ }^{(1,26,27)}$. 


\subsubsection{Marco Latino Americano}

Durante a $27^{\text {a }}$ Conferência Sanitária Pan-Americana (CSP), da Organização Pan-Americana da Saúde (OPAS/OMS), realizada em outubro de 2007, foi emitida a Resolução CSP27.R.10, Política e Estratégia Regional para a Garantia da Qualidade da Atenção Sanitária, incluindo o tema segurança do paciente. Esta resolução tratou, entre outros, de instar os Estados-membros a priorizar a segurança do paciente e a qualidade da atenção nas políticas de saúde e programas setoriais, incluindo a promoção de uma cultura organizacional e pessoal de segurança do paciente e da qualidade dos cuidados prestados aos pacientes ${ }^{(68,69)}$. A resolução se baseou na CSP27.R.16, onde foram delineadas cinco linhas estratégicas de ação a serem implementadas na Região: 1) posicionar a qualidade da atenção de saúde e a segurança do paciente como prioridade setorial; 2) promover a participação da cidadania em temas de qualidade; 3) gerar informação e evidência em matéria de qualidade; 4) desenvolver, adaptar e apoiar a implantação de soluções sobre qualidade e 5) elaborar uma estratégia regional para o fortalecimento da qualidade da atenção de saúde e da segurança do paciente ${ }^{(68,70)}$.

Desde então, esforços têm sido direcionados pela OPAS/OMS para posicionar a qualidade na atenção e a segurança do paciente na agenda dos governos da região, apoiando a inclusão das ações da AMSP, especialmente em relação ao desenvolvimento de pesquisas neste tema ${ }^{(68)}$.

Em novembro de 2007, durante a XXII Reunião de Ministros da Saúde do Mercado Comum do Cone Sul (MERCOSUL) houve o primeiro movimento oficial do bloco de apoio ao primeiro desafio global da OMS. Os países do bloco assumiram o compromisso internacional de desenvolver e aplicar os respectivos Planos Nacionais de Segurança do Paciente para atender, não somente à redução do risco a que o paciente está exposto, mas também às questões amplas do direito à saúde. Nessa reunião, ocorrida em Montevidéu, no Uruguai, os ministros dos Estados-membros assinaram a Declaração de Compromisso na Luta Contra as IRAS, com a presença das delegações da Argentina, Brasil, Paraguai, Uruguai, Bolívia, Chile e Equador ${ }^{(71,}$ 72). 
A Portaria $n^{\circ}$. 1.323 de 8 de junho de 2011 tornou pública a proposta do Projeto de Resolução "Diretrizes para Disponibilização de Preparação Alcoólica para Fricção Antisséptica das Mãos pelos Serviços de Saúde", aprovado na XXXVI Reunião Ordinária do Subgrupos de Trabalho (SGT) 11, realizada em abril de 2011, em Assunção, no Paraguai, com a íntegra de um regulamento em vigor no Brasil desde 2010, a Resolução da Diretoria Colegidada (RDC) da ANVISA n. 42, de 25 de outubro de 2010 , voltada para a prevenção das IRAS e segurança do paciente ${ }^{(71}$, 73).

O estudo Ibero-Americano de Eventos Adversos na Atenção à Saúde (IBEAS) ${ }^{(74)}$ foi realizado no período 2007 - 2009, com participação de 58 hospitais de cinco países da América Latina (Argentina, Colombia, Costa Rica, México e Peru). O trabalho mostrou que $10,5 \%$ dos pacientes hospitalizados sofrem algum tipo de EA, e destes, $58,9 \%$ poderiam ter sido evitados ${ }^{(68,74)}$. Ainda, o estudo permitiu conhecer a magnitude do problema em alguns países da região.

A partir de 2010, houve um aumento do interesse nas investigações sobre segurança do paciente na atenção ambulatorial. Um estudo com o objetivo de conhecer a frequência e a evitabilidade dos EA na atenção ambulatorial nos países da América Latina (AMBEAS) foi iniciado em 2012, com a participação do Brasil, Colômbia, México e Peru ${ }^{(68)}$. Outros propósitos do estudo piloto incluem a validação de ferramentas utilizadas no estudo e a mobilização dos países participantes para a questão da segurança do paciente. Dados preliminares nos 22 centros participantes mostram que os EA relacionados com medicação e prescrição foram os mais frequentes $^{(68)}$.

Em paralelo às pesquisas desenvolvidas, por intermédio da OMS e OPAS, tem-se promovido outras atividades como o desenvolvimento de sistemas de notificação de EA, com a finalidade de conhecer as causas desses eventos e propor recomendações para sua prevenção(68). 


\subsubsection{Marco Nacional}

No Brasil, os órgãos e os serviços responsáveis por transfusões de sangue, pelo controle e prevenção das IRAS e pelos serviços de anestesiologia podem ser considerados pioneiros no que tangem às medidas que promovem a segurança do paciente, garantindo a segurança dos processos de cuidado ${ }^{(41)}$.

Cabe destacar, no Brasil, a contribuição da vigilância sanitária (VISA), principalmente em relação ao licenciamento de estabelecimentos de saúde e a inspeção nestes serviços como importantes estratégias de melhoria da qualidade desses estabelecimentos, desde que os roteiros de inspeção sanitária sejam abrangentes, com itens referentes à totalidade dos atos normativos vigentes ${ }^{(41)}$.

A ANVISA tem atuado fortemente na área da segurança do paciente. Diante da priorização da política de segurança do paciente pela OMS, a ANVISA vem reforçando as ações relacionadas à segurança do paciente e à qualidade nos serviços de saúde, tanto como país signatário à OMS, quanto no âmbito do MERCOSUL, em especial, após o compromisso assinado pela pasta governamental brasileira da saúde ${ }^{(71)}$. A partir de então, um conjunto de ações de práticas da VISA circunscritas em políticas, normas, técnicas, regulamentações, fiscalizações, monitoramento, entre outros instrumentos sanitários foi delineado e desenvolvido em prol da assistência cirúrgica nos estabelecimentos assistenciais de saúde ${ }^{(2,75-77)}$.

A adoção de compromisso para a redução das IRAS pode ser considerada como um dos primeiros compromissos da Agência voltados para a segurança do paciente em âmbito nacional ${ }^{(1)}$. Em 2008, a ANVISA aderiu ao desafio "Uma Assistência Limpa é uma Assistência mais Segura", quando foram implantados no país os "sítios de testes complementares", aplicando-se a estratégia multimodal da OMS para a higiene das mãos em cinco hospitais localizados nas cinco diferentes regiões do país ${ }^{(78)}$. O trabalho, previsto no Projeto Higienização das Mãos em Serviços de Saúde, da ANVISA, foi coordenado pela Agência em conjunto com a OPAS/OMS e contou com a participação de hospitais da Rede Sentinela ${ }^{(40)}$. 
Vale ressaltar que a Rede Sentinela, inicialmente na forma de projeto da ANVISA, foi desenvolvida em parceria com hospitais, hemocentros e serviços de saúde com o objetivo de construir uma rede de serviços preparada para notificar EA e queixas técnicas de produtos de saúde, insumos, materiais e medicamentos, saneantes, kits para provas laboratoriais e equipamentos médico-hospitalares em uso no Brasil. Atualmente, é facultado a todo e qualquer estabelecimento de saúde solicitar credenciamento à Rede Sentinela, em qualquer tempo, de acordo com os critérios para credenciamento e permanência das instituições na Rede, de acordo com a Portaria n‥523, de 04 de abril de 2012, que dispõe sobre acréscimos à composição da Rede Sentinela ${ }^{(79)}$.

Devido à necessidade de promover a identificação precoce de problemas relacionados a serviços e produtos sob VISA, comercializados ou não, a fim de eliminar ou minimizar os riscos decorrentes de uso destes, foi instituído o Sistema de Notificação e Investigação em Vigilância Sanitária (VIGIPÓS) no âmbito do Sistema Nacional de Vigilância Sanitária (SNVS), como parte integrante do Sistema Único de Saúde (SUS), por meio da Portaria $n^{\circ}$. 1.660, de 22 de setembro de $2009^{(80)}$. As informações dos serviços de saúde são encaminhadas à ANVISA, por meio do Sistema Nacional de Notificações para a Vigilância Sanitária (NOTIVISA), ou por outras vias, como formulários, mensagem eletrônica, telefone e fax, com a finalidade de subsidiar a Agência nas ações de regulação desses produtos no mercado ${ }^{(78)}$.

O segundo desafio global para a segurança do paciente, Cirurgias Seguras Salvam Vidas, foi lançado no Brasil em 13 de maio de 2010, pela Secretaria de Atenção à Saúde (SAS), do Ministério da Saúde (MS), com a presença de representantes da ANVISA, OPAS/OMS, Coordenação Estadual de Controle de Infecção Hospitalar (CECIH), VISA's Estaduais e Distrital, Colégio Brasileiro de Cirurgiões $(\mathrm{CBC})$, entre outros ${ }^{(40)}$. As atividades relacionadas a este desafio vêm sendo trabalhadas em parceria com a SAS/MS, Fundação Oswaldo Cruz (Fiocruz), Agência Nacional de Saúde Suplementar (ANS) e OPAS/OMS ${ }^{(1,49)}$.

Em 2012, a ANVISA iniciou o desenvolvimento do Projeto Cirurgias Seguras Salvam Vidas, cujas ações previstas envolvem a melhoria da segurança e da qualidade do atendimento prestado pela equipe cirúrgica na sala operatória e a aplicação da LVSC, um instrumento essencial para a assistência cirúrgica segura, de acordo com a $\mathrm{OMS}^{(9)}$. O Projeto envolve as seguintes fases: 1) Fase Préimplantação (Fase 1), envolvendo o planejamento e a preparação das unidades, 
além da avaliação de dados epidemiológicos basais de segurança cirúrgica nos serviços de saúde participantes. Nesta fase foram disponibilizados materiais educativos da ANVISA sobre a temática da cirurgia segura, tais como guia de implementação da LVSC, plano de ação, LVSC revisada pela OMS e aulas sobre Cirurgia Segura; 2) Sensibilização e Implantação do Projeto (Fase 2), sendo assinados, localmente, os Termos de Compromisso, pelos diretores dos hospitais participantes, para o desenvolvimento do Projeto. Foram também realizadas, palestras sobre Cirurgia Segura para as equipes hospitalares e as lotadas nas Secretarias de Saúde do DF. A capacitação foi, ainda, direcionada às Equipes condutoras (formadas no mínimo por cirurgião, anestesiologista, enfermeiro, representante da CCIH ou da Gerência de Risco, ou da Comissão/Núcleo de Segurança do Paciente ou da Gerência de Qualidade) e aos Coordenadores locais, incluindo chefes de departamento, serviço e equipes de saúde (enfermeiros, chefes de cirurgia, equipes cirúrgicas e equipes do Centro de Recuperação Anestésica); 3) Implementação (Fase 3), com a aplicação das ferramentas da OMS de cirurgia segura nos Centros Cirúrgicos dos serviços de saúde participantes, incluindo a LVSC; 4) Avaliação (Fase 4), abrangendo a discussão dos dados obtidos com a implantação do Projeto e elaboração de documento técnico contendo os principais resultados da intervenção. Ainda, nesta fase, foram propostas medidas corretivas para o SNVS direcionadas à segurança do paciente cirúrgico e melhoria da qualidade em serviços de saúde; e 5) Ampliação (Fase 5), na qual são previstas estratégias para a sustentação da intervenção nos serviços de saúde participantes e ampliação do projeto piloto da ANVISA para outros serviços de saúde do país.

Em continuidade, a ANVISA decide compor um GT de Segurança do Paciente, coordenado pela Agência e formalizado por meio da Portaria ํ‥ 1.443, de 11 de outubro de $2012^{(77)}$. O GT integrou representantes de conselhos profissionais como os de medicina, enfermagem e farmácia, técnicos da ANVISA, além de profissionais com notável saber no tema segurança do paciente e qualidade em serviços de saúde. O principal objetivo do GT foi discutir e indicar estratégias para a elaboração e implementação do "Plano de Ação para a Segurança do Paciente e Qualidade em Serviços de Saúde". Somado a isso, auxiliar no monitoramento dos EA relacionados à assistência à saúde e prestar assistência na elaboração e revisão de materiais educativos para a Segurança do Paciente e Qualidade em Serviços de Saúde. Cabe ressaltar que o GT foi responsável pela elaboração da publicação da 
ANVISA intitulada "Assistência Segura: uma Reflexão Teórica Aplicada à Prática" a qual trata dos principais EA relacionados à assistência à saúde bem como da prevenção e do controle destes eventos ${ }^{(1)}$.

O marco nacional de extrema relevância para a segurança do paciente foi a instituição do PNSP, por meio da publicação da Portaria no. 529, do Gabinete do Ministro (GM), do MS, de $1^{\circ}$ de abril de $2013^{(75)}$. O PNSP foi lançado no dia $1^{\circ}$ de abril pelo MS e pela ANVISA, visando prevenir, monitorar e reduzir a incidência de EA nos atendimentos prestados, promovendo melhorias relacionadas à segurança do paciente e a qualidade em serviços de saúde do país ${ }^{(75)}$.

Importante lembrar que os objetivos específicos do PNSP são: 1) implantar a gestão de risco e os Núcleos de Segurança do Paciente (NSP) nos estabelecimentos de saúde; 2) envolver os pacientes e familiares nas ações; 3) ampliar o acesso da sociedade às informações; 4) produzir, sistematizar e difundir conhecimentos; e 5) fomentar a inclusão do tema segurança do paciente no ensino técnico e de graduação e pós-graduação na área da saúde ${ }^{(75)}$.

A partir da criação do PNSP, outro importante marco regulatório para a melhoria da segurança do paciente no país foi a publicação da RDC n. 36/2010 que institui as ações para a segurança do paciente em serviços de saúde ${ }^{(2)}$ e a instituição dos Protocolos Básicos de Segurança do Paciente, incluindo o protocolo para cirurgia segura( ${ }^{(81)}$.

Outros programas e políticas do MS, em parceria com as Secretarias Estaduais e Municipais de Saúde contribuem com o PNSP, a saber: o conjunto de iniciativas da ANVISA, em especial a Rede Sentinela; o Programa Nacional de Avaliação de Serviços de Saúde (PNASS); o Programa de Apoio ao Desenvolvimento Institucional do SUS (Proadi-SUS); a parceria entre o MS e as entidades de Saúde detentoras do Certificado de Entidade Beneficente de Assistência Social em Saúde (Cebas-Saúde); o Projeto de Formação e Melhoria da Qualidade da Rede de Atenção à Saúde (QualiSUS-Rede); a Política Nacional de Humanização $(\mathrm{PNH})$; o processo de certificação dos Hospitais de Ensino, sob a coordenação do MS e do Ministério da Educação, a Política Nacional de Segurança e Saúde no Trabalho (PNSST) e a Política Nacional de Atenção Hospitalar (PNHOSP), que estabelece as diretrizes para a reorganização do componente 
hospitalar da Rede de Atenção à Saúde, recentemente pactuada na comissão intergestora tripartite ${ }^{(41)}$.

Ainda nas propostas das metas de segurança preconizadas pela OMS, o país avançou nos termos da AMSP, em especial nas ações desenvolvidas pela ANVISA, no que se refere ao monitoramento e prevenção dos EA relacionados à assistência à saúde, incluindo as IRAS, Rede Nacional de Monitoramento da Resistência Microbiana (Rede RM), Rede Nacional de Investigação de Surtos e Eventos Adversos em Serviços de Saúde (Reniss) e NOTIVISA, voltado para o Vigipós e queixas técnicas ${ }^{(71)}$.

$\mathrm{Na}$ área da Enfermagem, a Rede Brasileira de Enfermagem e Segurança do Paciente (Rebraensp) vem trabalhando em articulação e cooperação técnica com instituições diretas e indiretamente ligadas à saúde e educação de profissionais em saúde. Os objetivos da Rebraensp são disseminar e sedimentar a cultura de segurança do paciente nas organizações de saúde, escolas, universidades, organizações governamentais, usuários e seus familiares ${ }^{(41)}$.

Alguns centros de ensino e pesquisa têm realizado pesquisas e publicado trabalhos sobre o tema. O portal do Centro Colaborador para a Qualidade do Cuidado e a Segurança do Paciente (Proqualis) tem cumprido o papel de disseminação de conhecimento em duas áreas, informação clínica e segurança do paciente $^{(82)}$. Por sua vez, o hotsite "Segurança do Paciente", da ANVISA, divulga ações de regulamentação e controle sanitário, auxiliando os serviços de saúde na identificação da ocorrência de eventos que afetam a segurança do paciente, corroborando para a redução do dano e a prevenção de riscos futuros ${ }^{(83)}$.

Atualmente, a ANVISA, em conjunto com as VISA's Estaduais, Municipais e Distrital, vem executando o Plano Integrado para a Gestão Sanitária da Segurança do Paciente em Serviços de Saúde - Monitoramento e Investigação de EA e Avaliação de Práticas de Segurança do Paciente, cujo objetivo é integrar as ações do SNVS para a gestão da segurança do paciente em serviços de saúde do país visando à identificação e redução de riscos relacionados à assistência à saúde ${ }^{(84)}$. Ressalta-se que o Plano envolve, entre outros, o monitoramento da conformidade da LVSC nos hospitais brasileiros.

Com a instituição da recente política de segurança do paciente no país, outras medidas direcionadas à instituição e à sustentação da cultura de segurança do paciente nos serviços de saúde ainda são necessárias ${ }^{(1)}$. 


\subsubsection{Segurança do paciente e qualidade em serviços de saúde}

O interesse pelo tema qualidade nos serviços de saúde vem despertando a atenção de muitos estudiosos. Segundo Avedis Donabedian, cuidado de boa qualidade é "aquele que proporciona ao paciente o bem estar máximo e mais completo, após ter sido considerado o equilíbrio previsto entre ganhos ou benefícios e perdas ou danos que acompanham o processo de cuidado em toda a sua extensão"(85).

Donabedian publicou na década de 1960 os conceitos que podem ser considerados como a base fundamental para a avaliação moderna da qualidade dos sistemas de saúde. Inicialmente, atribuiu três dimensões à qualidade: conhecimento técnico-científico, relações interpessoais entre os profissionais e o paciente e amenidades, isto é, condições de conforto e estética das instalações e equipamentos no local onde a prestação do cuidado ocorre ${ }^{(86,87)}$.

De acordo com Donabedian, a qualidade na saúde baseia-se na sistematização do conhecimento das organizações, por meio de três fatores ${ }^{(88,89)}$ : estrutura, processo e resultado. A estrutura corresponde às características mais estáveis da assistência de saúde. Envolve desde estrutura física e disponibilidade de equipamentos até a capacitação dos indivíduos que prestam a assistência, passando pela organização dos serviços. O processo abrange as atividades desenvolvidas entre os profissionais de saúde e os pacientes. Fornece as bases para a valoração da qualidade uma vez que, por meio dessas relações se obtém os resultados da assistência. Inclui as atividades do paciente na procura e recebimento do cuidado; as atividades do pessoal na realização do diagnóstico; as recomendações ou implementação do tratamento. O resultado é a consequência da assistência realizada, refletindo as mudanças observadas no estado de saúde do paciente. Envolvem a melhoria do conhecimento, as mudanças de comportamento que venham a melhorar este estado de saúde, o grau de satisfação do paciente.

A segurança constitui uma das dimensões da qualidade ${ }^{(90)}$. Por sua vez, a segurança bem como a qualidade do cuidado cirúrgico constituem elementos 
cruciais da prática cirúrgica moderna, e vêm despertando um interesse crescente por parte dos usuários, gestores e profissionais que atuam em serviços de saúde.

Transpondo a teoria supra exposta de Donabedian para a unidade do Centro Cirúrgico, o modelo de avaliação da qualidade do serviço cirúrgico poderia ser assim tratado $^{(10,91)}$ : estrutura - como o cuidado é organizado (instalações físicas, materiais e equipamentos disponíveis, recursos humanos e suas habilitações); processo - o que foi feito (esterilização de material, preparação da sala operatória, anestesiologia e cirurgia) e resultados - o que aconteceu com o paciente (produtos e serviços decorrentes desses processos).

Exemplos de indicadores de estrutura que podem ser monitorados no Centro Cirúrgico envolvem a presença de enfermeiro durante todo o processo de funcionamento e horas de treinamento de funcionários. Para indicadores de processo têm-se ${ }^{(92)}$ : cirurgias suspensas por fatores hospitalares extrapaciente; tempo médio de atraso no início da cirurgia; tempo médio de permanência na Recuperação Anestésica e percentual de procedimentos operacionais padrão (POP) descritos. Os indicadores de resultados abrangem, por exemplo, a taxa de ISC, o número de reintervenções cirúrgicas não programadas e a taxa de mortalidade operatória $^{(92)}$.

Em outro modelo publicado, Donabedian ampliou o conceito de qualidade, utilizando o que denominou de "sete pilares da qualidade": eficácia, efetividade, eficiência, otimização, aceitabilidade, legitimidade e equidade ${ }^{(93)}$. Esses atributos ajudaram a compreender melhor o conceito de qualidade em saúde ${ }^{(41)}$.

De acordo com Wennberg ${ }^{(48,94)}$, variações indesejáveis no cuidado de saúde são comumente observadas, podendo diferir em três categorias de cuidado de saúde: cuidado efetivo/necessário; cuidado sensível às preferências dos pacientes e cuidado sensível à oferta.

O cuidado efetivo/necessário é aquele para o qual existem evidências científicas razoavelmente robustas, indicando que ele responde melhor do que qualquer outra alternativa e que os benefícios para os pacientes excedem os riscos de possíveis danos. Como, neste caso, todos os pacientes com indicação para o procedimento devem recebê-lo, o problema de qualidade que se destaca é a subutilização. Um exemplo deste tipo de situação é uma baixa cobertura vacinal ${ }^{(48)}$. 
As situações em que existem mais de uma opção de cuidado e que os resultados variam segundo a opção adotada estão relacionadas com o cuidado sensível às preferências dos pacientes. Entretanto, grande parte das decisões terapêuticas é delegada aos médicos, que nem sempre escolhem o procedimento que seria de preferência do paciente. Variações no cuidado sensível às preferências dos pacientes apontam para a importância de se avançar no conhecimento sobre a eficácia dos procedimentos, mas, em particular, para a necessidade de mudança da cultura médica vigente. Esses são requisitos para uma maior participação do paciente na decisão sobre o seu cuidado, decisão esta que deve ser baseada em informação consistente sobre as alternativas existentes e seus potenciais riscos e benefícios $^{(48)}$.

Por fim, o cuidado sensível à oferta geralmente resulta em sobre utilização. Para reduzir essa variação, o conhecimento científico sobre o impacto de procedimentos diagnósticos e terapêuticos específicos tem de avançar, de modo a possibilitar decisões terapêuticas orientadas por evidências científicas e pelas preferências dos pacientes ${ }^{(48)}$.

Desde 2001, o IOM recomendava o cumprimento de seis domínios específicos de melhoria da qualidade na área da saúde no século $21^{(90)}$ : 1) segurança - prevenção de lesões e danos aos pacientes durante a prestação de cuidado que tem como objetivo ajudá-los; 2) efetividade - prestação de cuidados baseados no conhecimento científico para todos que delem possam se beneficiar, evitando seu uso por aqueles que não estão propensos a se beneficiar (evitando-se a subutilização e a sobreutilização, respectivamente); 3) aceitabilidade ou foco no paciente - prestação de cuidados que respeite e seja sensível às preferências necessidades e valores individuais dos pacientes, assegurando que os valores do paciente orientem todas as decisões clínicas; 4) acesso ou oportunidade - redução do tempo de espera e de atrasos potencialmente danosos tanto para quem recebe como para quem presta o cuidado; 5) eficiente - cuidado sem desperdício, incluindo o desperdício associado ao uso de equipamentos, suprimentos, ideias e energia e 6) equidade - prestação de cuidados que não variam em decorrência de características pessoais, como gênero, etnia, localização geográfica e condição socioeconômica.

Interessante ressaltar que um dos domínios supraexpostos para um sistema de saúde de qualidade envolve a segurança, tornando-a, em essência, um subconjunto da qualidade. Ainda, a definição do IOM é muito ampla e inclui assuntos 
que são de particular importância para os pacientes (centralidade e acesso) e para a sociedade (equidade). Sob esse ponto de vista, qualidade é mais do que prestação de assistência baseada em evidências científicas e inclui aspectos que são de particular importância para os pacientes e a sociedade ${ }^{(10)}$.

Donald Berwick, pediatra americano envolvido no gerenciamento da qualidade, adaptou para a saúde os conceitos utilizados na indústria, oferecendo exemplos de efetiva aplicação das ferramentas da qualidade. Em seu livro traduzido para o português sob o título "Melhorando a Qualidade dos Serviços Médicos, Hospitalares e da Saúde", apresenta como princípios que ${ }^{(95)}:$ 1) o trabalho produtivo é realizado através de processos; 2) relações sólidas entre cliente e fornecedor são imprescindíveis para uma segura administração da qualidade; 3) a principal fonte de falhas de qualidade são os problemas nos processos; 4) a má qualidade é cara; 5) a compreensão da variabilidade dos processos é a chave para melhorar a qualidade; 6) o controle de qualidade deve concentrar-se nos processos; 7) a abordagem contemporânea de qualidade está fundamentada no pensamento científico e estatístico; 7) o envolvimento total do funcionário é crucial; 8) estruturas organizacionais diferentes podem ajudar a obter melhoria da qualidade; 9) a administração da qualidade emprega três atividades básicas, estreitamente interrelacionadas - planejamento da qualidade, controle da qualidade e melhoria da qualidade ${ }^{(95) .}$

O primeiro passo para a melhoria da qualidade começa com a mensuração da qualidade. A maioria das instituições de saúde utiliza vários ciclos PDCA (Plan-DoCheck-Act), reconhecendo que as atividades de melhoria da qualidade devem ser mensuradas, e que os resultados dessas atividades devem ser retornados para 0 sistema em um processo contínuo e interativo de melhoria ${ }^{(10)}$.

As estratégias para a melhoria da qualidade envolvem a divulgação do desempenho dos profissionais ou sistemas e ainda, a transparência, ou seja, a divulgação dos resultados das medidas de qualidade para os principais interessados - os pacientes (ou seus representantes, como as fontes pagadoras). Outra estratégia implantada por muitos países é o sistema de notificação de EA em serviços de saúde ${ }^{(10)}$.

Iniciativas de qualidade e de segurança devem ser abordadas em conjunto. Modernamente, e de modo mais simples, a qualidade na saúde define-se hoje numa 
triangulação de: efetividade (eficácia e eficiência); experiência dos pacientes (satisfação) e segurança (ausência de complicações) ${ }^{(96)}$.

Muitos requisitos relacionados à segurança dos pacientes foram incluídos entre os critérios para acreditação de serviços de saúde, visando a reduzir os riscos de $E A^{(97)}$.

No Brasil, a acreditação surgiu como estratégia para a melhoria da qualidade hospitalar no início da década de 1990. Em 1994, o MS estabeleceu o Programa Brasileiro de Qualidade e Produtividade (PBQP) e a Comissão Nacional de Qualidade e Produtividade em Saúde (CNQPS), que desempenharam importante papel na instituição da acreditação no país. A avaliação e a certificação de serviços de saúde foram consideradas estratégicas e prioritárias pelo MS nos anos de 1997 e 1998. No entanto, até a presente data, o número de serviços de saúde acreditados no país ainda é incipiente ${ }^{(48)}$.

Atualmente, existem três instituições atuando como acreditadoras no Brasil: a Organização Nacional de Acreditação, a Joint Commission International, representada pelo Consórcio Brasileiro de Acreditação (CBA) e a Canadian Council on Healthcare Services Accreditation, representada pelo Instituto Qualisa de Gestão $^{(41)}$.

O Projeto de Avaliação de Desempenho de Sistemas de Saúde (PROADESS) tem como objetivo propor uma metodologia de avaliação de desempenho do sistema de saúde no país, considerando as dimensões: acesso, efetividade, eficiência, adequação, continuidade, segurança, aceitabilidade e direitos dos pacientes. A equidade deve ser considerada em todas as demais dimensões da avaliação de desempenho do sistema de saúde previstas na matriz conceitual ${ }^{(98)}$.

Em 2011, a ANS publicou a Resolução Normativa (RN) $n^{\circ} .275$, que dispõe sobre a instituição do Programa de Monitoramento da Qualidade dos Prestadores de Serviços na Saúde Suplementar, conhecido como QUALISS ${ }^{(99)}$. O programa foi desenvolvido pela ANS em parceria com os representantes dos prestadores, dos consumidores, das operadoras, de instituições de ensino e pesquisa, da ANVISA e do MS. O QUALISS está estruturado em dois componentes ${ }^{(100)}:$ 1) Divulgação da Qualificação dos Prestadores de Serviços e 2) Monitoramento da Qualidade dos Prestadores de Serviços. A mensuração de indicadores que possuem validade, comparabilidade e capacidade de discriminação de resultados permitirá avaliar a qualidade dos prestadores de serviço na saúde suplementar. 


\subsubsection{Segurança do Paciente e Vigilância Sanitária de Serviços de Saúde}

A segurança do paciente vem permeando as ações desenvolvidas pelo SNVS desde sua criação, cooperando com a missão da VISA de proteger a saúde da população e intervir nos riscos advindos do uso de produtos e dos serviços a ela sujeitos, por meio de práticas de vigilância, controle, regulação e monitoramento sobre os serviços de saúde e o uso das tecnologias disponíveis para o cuidado ${ }^{(101,}$ 102).

No campo da VISA, a regulação consiste no modo de intervenção do Estado para impedir possíveis danos ou riscos à saúde da população. A VISA atua por meio da regulamentação, controle e fiscalização das relações de produção e consumo de bens e serviços relacionados à saúde ${ }^{(103,104)}$.

A VISA deve ser entendida como tecnologia relevante na verificação das condições de funcionamento dos estabelecimentos de saúde e sobre os produtos, medicamentos e outros insumos utilizados no cuidado à saúde, à medida que esses estão disponíveis para o uso nos pacientes. As ações da vigilância possibilitam a verificação in loco da situação e a identificação de fontes potenciais de danos, além de constituir uma prática de observação sistemática, orientada por conhecimentos técnico-científicos, destinada a examinar a conformidade com padrões e os requisitos que visam à proteção da saúde individual e coletiva ${ }^{(41)}$.

No Brasil, a ANVISA, criada em $1999^{(104)}$, é responsável por elaborar normas de funcionamento, observar seu cumprimento, estabelecer mecanismos de controle e avaliar riscos e EA relacionados a serviços prestados por hospitais, clínicas de hemodiálise, postos de atendimento, entre outros. A Agência exerce suas competências em ação coordenada com os estados, os municípios e o DF, de acordo com os princípios do SUS, para a melhoria da qualidade de vida da população brasileira(105).

Portanto, as intervenções da VISA são norteadas pela noção de risco. Uma vez que a VISA lida com permanente incorporação tecnológica e saberes de diversas áreas do conhecimento, as várias faces do conceito de risco se alargam e 
se articulam, seja com noções e conceitos inerentes à esfera da proteção da saúde - tais como finalidade, eficácia, efetividade, nocividade, qualidade, segurança - seja com princípios que resguardam a ética sanitária - princípio bioético do benefício - e a responsabilidade pública. Além disso, quando o conhecimento científico é insuficiente para identificar e estimar os riscos é possível se apropriar do princípio da precaução $^{(106)}$.

As medidas relacionadas à segurança do paciente e a redução da exposição ao risco e minimização do dano à saúde abrange um quantitativo considerável de serviços de saúde, que são estabelecimentos de saúde destinados a prestar assistência à população na prevenção de doenças, no tratamento, recuperação e na reabilitação de pacientes ${ }^{(76)}$. Atualmente, o Brasil possui mais de 200 mil estabelecimentos de saúde, nos quais os pacientes são expostos rotineiramente às tecnologias em saúde e às intervenções de profissionais de saúde, estando sujeitos às ocorrências de erros e $E A^{(71)}$.

Sobre os serviços de saúde incidem multiplicidade de riscos, de origens e naturezas diversas. Uma vez identificados os riscos, uma gama de mecanismos e instrumentos de regulação à disposição do SNVS podem ser utilizados, como legislação, educação e orientação sanitária, inspeção da prestação de serviços, sistema de informação, monitoramento de EA relacionados à assistência à saúde e participação popular, entre outros ${ }^{(107)}$.

As não conformidades encontradas nas inspeções reorientam o planejamento dos estabelecimentos de saúde e constituem uma oportunidade de implementação de medidas de melhoria da qualidade e da segurança do paciente. Entre essas medidas, inclui-se a adoção da rotina de realização de auditorias internas periódicas ${ }^{(41)}$. Ainda, é importante o uso do instrumental epidemiológico pela VISA como referência para a sua ação, visto que o enfoque de risco é parte de sua própria definição.

A concepção ampliada de risco vem redirecionando o processo atual de regulação pela VISA. Assim, há necessidade crescente de mudança no perfil policialesco e cartorial que ao longo dos anos vem caracterizando as ações de VISA no país. Contribuindo para esta mudança de cultura, uma questão importante na década de 1970 foi a incorporação do termo "vigilância" em substituição à 
"fiscalização", o que aponta para a construção de um novo conceito para essas ações. A adoção do termo VISA na legislação e na denominação do espaço institucional remete às ações voltadas para precaução, cuidado e prevenção e constitui uma noção mais abrangente do que apenas a de controle e punição, antes atribuída a estes serviços, rotulados com o termo "fiscalização"(108, 109).

Entretanto, riscos e danos também podem resultar da insuficiente produção de conhecimentos ou de dificuldades de acesso ao saber já produzido, à medida que as ações de VISA lidam diretamente com o conhecimento científico e o desenvolvimento tecnológico, que são fundamentais para o estabelecimento e a permanente atualização das normas, técnicas e jurídicas ${ }^{(107)}$. Assim, é esperado que as equipes das VISA's que trabalham em prol da prevenção de riscos e danos estejam devidamente qualificadas em segurança do paciente e qualidade em serviços de saúde.

A VISA de serviços de saúde busca elevar a qualidade dos estabelecimentos com instrumentos que promovam a melhoria da assistência prestada aos pacientes. Com a instituição da recente política de segurança do paciente ${ }^{(75)}$, as VISA's vêm percebendo o grande desafio de apoiar a implantação e a implementação dos princípios e diretrizes previstos no PNSP nos serviços de saúde do país.

Logo, um aspecto crucial na vigilância, no monitoramento e na investigação de falhas nos serviços de saúde é a disseminação do conceito de segurança do paciente nestes serviços para a prevenção de riscos e danos. Isto envolve a aprendizagem com erros e falhas, não por meio de punições individuais, mas pelo redesenho do sistema para a redução de erros, criando uma cultura de segurança que permita a contínua possibilidade de gerenciar riscos nos serviços de saúde ${ }^{(49)}$. Orientar a criação de um ambiente seguro favorável à notificação de incidentes relacionados à assistência à saúde é um desafio importante para o SNVS ${ }^{(102)}$. 


\subsubsection{Principais legislações que apresentam interface com a segurança cirúrgica}

\subsection{Controle de infecção}

O controle de infecção hospitalar no Brasil foi regulamentado pela Portaria ํㅡ․ 196, de 24 de junho de $1983^{(110)}$, que tornou obrigatória a implantação de Comissão de Controle de Infecção hospitalar $(\mathrm{CClH})$ nos hospitais. Posteriormente, foi revogada e substituída pela Portaria ํㅡ. 930, de 27 de agosto de $1992^{(111)}$.

A Lei $n^{\circ} .9 .431$ foi promulgada em 1997, e definiu o Programa de Controle de Infecção Hospitalar (PCIH), como o "conjunto de ações desenvolvidas, deliberada e sistematicamente, com vistas à redução máxima possível da incidência e da gravidade das infecções hospitalares"(112).

A Portaria $n^{\circ}$. 2.616, de 12 de maio de 1998(113) regulamentou o $\mathrm{PCIH}$ e a exigência de manutenção das $\mathrm{CCIH}$ 's, de $\mathrm{CECIH}$ e de Comissão Municipal de Controle de Infecção Hospitalar $(\mathrm{CMClH})$, determinando as competências das três esferas de governo na prevenção das infecções. De acordo com a Portaria, o PCIH é um conjunto de ações desenvolvidas deliberada e sistematicamente, com vistas à redução máxima possível da incidência e da gravidade das infecções hospitalares. A norma define diversas competências visando à eficiência do controle de infecção, incluindo a prevenção de ISC, o estabelecimento da taxa de ISC, de acordo com o potencial de contaminação e o levantamento destas taxas, por cirurgião e por especialidade ${ }^{(113)}$.

Interessante lembrar que o SNVS tem como atribuição legal a competência para monitorar e coordenar as ações para o controle de IRAS desde $1999^{(1,104)}$.

Recentemente, foi publicada a Portaria no. 1.218, que instituiu a Comissão Nacional de Prevenção e Controle de Infecção Relacionada à Assistência à Saúde (CNCIRAS). A finalidade é assessorar a Diretoria Colegiada (DICOL) da ANVISA na elaboração de diretrizes, normas e medidas para prevenção e controle de infecções $^{(114)}$, ampliando a segurança do paciente em serviços de saúde. A CNCIRAS é formada por representantes da ANVISA, do MS, das Coordenações Estaduais/Distrital e Municipais de Controle de Infecção Hospitalar, especialistas em 
controle de IRAS, entidades representativas da área de infectologia, universidades e profissionais que atuam na prevenção e controle de IRAS.

Um dos objetivos principais do Programa Nacional de Prevenção e Controle de Infecções Relacionadas à Assistência à Saúde (PNPCIRAS), considerando-se o período de 2013-2015, é reduzir as ISC em serviços de saúde. As estratégias de atuação envolvem 0 desenvolvimento de atividades junto às Coordenações Estaduais e Distrital de Prevenção e Controle de IRAS, como a implantação de sistema de vigilância epidemiológica de ISC, com o escopo definido para infecções em parto cesário, tendo como alvo preliminar os serviços de saúde que já notificam infecção primária da corrente sanguínea (IPCS) ${ }^{(115)}$.

\subsection{Infraestrutura do Centro Cirúrgico}

A RDC nº. 50, de 21 de fevereiro de $2002^{(116)}$ dispõe sobre o regulamento técnico para planejamento, programação, elaboração e avaliação de projetos físicos de estabelecimentos assistenciais de saúde. De acordo com a RDC, estabelecimento assistencial de saúde é definido como "denominação dada a qualquer edificação destinada à prestação de assistência à saúde à população, que demande o acesso de pacientes, em regime de internação ou não, qualquer que seja o seu nível de complexidade".

O regulamento técnico trata das construções novas de estabelecimentos assistenciais de saúde de todo o país, das áreas a serem ampliadas de estabelecimentos assistenciais de saúde já existentes, e das reformas de estabelecimentos assistenciais de saúde já existentes e os anteriormente não destinados a estabelecimentos de saúde.

De acordo com a RDC n. 50/2002, Centro Cirúrgico é definido como "unidade destinada ao desenvolvimento de atividades cirúrgicas, bem como à recuperação pós-anestésica e pós-operatória imediata"(116).

A estrutura física das unidades de Centro Cirúrgico deve apresentar as características dispostas nos regulamentos vigentes da $\operatorname{ANVISA}^{(116,117)}$. Algumas práticas recomendadas pela Sociedade Brasileira de Enfermeiros de Centro Cirúrgico, Recuperação anestésica e Central de Material Esterilizado (SOBECC), envolvem ${ }^{(118)}$ : 
1) Acabamento de paredes, pisos e tetos: os materiais adequados para 0 revestimento de paredes, pisos e tetos de ambientes e áreas críticas e semicríticas devem ser resistentes à limpeza e ao uso de desinfetantes;

2) Local de fácil acesso às unidades de pacientes, tais como ambulatório, emergência, unidade de internação, Unidade de Terapia Intensiva (UTI), e as unidades de suporte, almoxarifado, farmácia, lavanderia, banco de sangue, laboratórios, raio X e Centro de Material Esterilizado (CME);

3) Planta física com barreiras que minimizem a entrada de micro-organismos, delimitando-se três áreas para movimentação de pacientes e equipe: irrestritas, semi-restritas e restritas;

4) Vestiário como uma barreira física de acesso ao Centro Cirúrgico;

5) Lavabos cirúrgicos exclusivos para degermação de mãos e antebraços e para higiene das mãos, que devem ter profundidade suficiente para a realização do procedimento sem o contato com as torneiras (comando automático ou acionamento com os pés) e as bordas;

6) Lâmpadas fluorescentes no teto e existência de iluminação direta com foco cirúrgico;

7) Sistema de emergência com gerador próprio, capaz de assumir automaticamente o suprimento de energia em no máximo meio segundo e mantê-lo por no mínimo uma hora;

8) Rota de fuga para emergência que deve ser de conhecimento dos usuários e estar sinalizada nas dependências do setor;

9) Sala operatória com controle individual de temperatura, filtros de ar específicos e pressão positiva para prevenir a entrada de ar contaminado;

10) Janelas lacradas, com persianas recobertas por vidros;

11) Portas de correr na sala operatória para eliminar a turbulência de ar, com visores de vidro.

\subsection{Reprocessamento de produtos para a saúde}

Os problemas relacionados ao reprocessamento de produtos para a saúde são numerosos, incluindo infecção, presença de endotoxinas, biofilmes, perda da integridade do material e outros ${ }^{(119)}$. 
No país, o reprocessamento destes produtos foi fortemente marcada em 2006 com as publicações das Resoluções da ANVISA: RDC n‥ 156, de 11 de agosto de 2006, que dispõe sobre o registro, rotulagem e reprocessamento de produtos médicos, e dá outras providências ${ }^{(120)} ; \mathrm{RE}$ №. 2605, de 11 de agosto de 2006, que estabelece a lista de produtos médicos enquadrados como de uso único proibidos de ser reprocessados ${ }^{(121)}$ e RE №. 2606, de 11 de agosto de 2006, que dispõe sobre as diretrizes para elaboração, validação e implantação de protocolos de reprocessamento de produtos médicos e dá outras providências ${ }^{(122)}$, atendendo aos requisitos de segurança e eficácia consensuais na literatura para a prática do reprocessamento.

\subsection{Controle de micobacterioses}

Com o surgimento de casos de micobacterioses de crescimento rápido em todo país em 2009, a ANVISA publicou a RDC №. 8, de 27 de fevereiro, que dispõe sobre as medidas para redução da ocorrência de infecções por Micobactérias de Crescimento Rápido (MCR) em serviços de saúde ${ }^{(123)}$. Segundo a RDC, permanece suspensa a esterilização química por imersão, utilizando agentes esterilizantes líquidos, para o instrumental cirúrgico e produtos para saúde utilizados nos procedimentos cirúrgicos e diagnósticos por videoscopias com penetração de pele, mucosas adjacentes, tecidos subepiteliais e sistema vascular, cirurgias abdominais e pélvicas convencionais, cirurgias plásticas com o auxílio de ópticas, mamoplastias e procedimentos de lipoaspiração.

\subsection{Higiene das mãos}

A RDC n. 42/2010, dispõe sobre a obrigatoriedade de disponibilização de preparação alcoólica para friç̧ão antisséptica das mãos, pelos serviços de saúde do país. Segundo a RDC, todos os pontos de assistência ao paciente, por exemplo, UTI, salas de triagem, ambulatórios, serviços de atendimento móvel e unidades de urgência e emergência e outros, deverão ter a preparação alcoólica à disposição dos profissionais, em local visível e de fácil acesso ${ }^{(73)}$. 
De acordo com a RDC $n^{\circ} \cdot 42 / 2010^{(73)}$, a preparação alcoólica para higiene das mãos sob a forma líquida deve apresentar concentração final entre $60 \%$ a $80 \%$, com a finalidade de reduzir o número de micro-organismos. Já a preparação alcoólica para higiene das mãos sob as formas gel, espuma e outras deve apresentar concentração final mínima de $70 \%$ com atividade antibacteriana comprovada por testes de laboratório in vitro (teste de suspensão) ou in vivo, destinadas a reduzir o número de micro-organismos. Ambas as preparações alcoólicas devem conter emolientes para evitar o ressecamento da pele. Cabe lembrar que a RDC $n^{\circ}$. 42/2010 ${ }^{(73)}$ não contempla o procedimento de antissepsia cirúrgica ou preparo pré-operatório das mãos, o qual constitui uma medida importante, entre outras, para a prevenção da ISC.

Os antissépticos mais utilizados nos serviços de saúde para a antissepsia cirúrgica das mãos são a clorexidina (CHG) e o polivinilpirrolidona iodo (PVPI) ${ }^{(124)}$. Produtos alcoólicos também têm sido recomendados para a realização da friç̧ão cirúrgica das mãos devido à eficácia antimicrobiana, facilidade de aplicação, menor dano à pele e economia de tempo ${ }^{(124-126)}$.

Ressalta-se que as preparações alcoólicas destinadas à higiene das mãos nos serviços de saúde devem estar devidamente regularizadas na $\operatorname{ANVISA}^{(127,128)}$.

\subsection{Qualidade em serviços de saúde}

A RDC $n^{\circ} .63$, de 25 de novembro de $2011^{(76)}$, dispõe sobre os requisitos de boas práticas de funcionamento para os serviços de saúde no país, sejam instituições públicas, privadas, filantrópicas, civis ou militares, incluindo aquelas que exercem ações de ensino e pesquisa. De acordo com a RDC, serviço de saúde é o "estabelecimento de saúde destinado a prestar assistência à população na prevenção de doenças, no tratamento, recuperação e na reabilitação de pacientes".

O regulamento técnico possui o objetivo de estabelecer os requisitos de boas práticas para o funcionamento de serviços de saúde, fundamentados na qualificação, na humanização da atenção e gestão, e na redução e controle de riscos aos usuários e meio ambiente ${ }^{(76)}$. Segundo a norma, os serviços devem 
utilizar a Garantia da Qualidade como ferramenta de gerenciamento e desenvolver a qualidade envolvendo a tríade de gestão estrutura, processo e resultado ${ }^{(1,76)}$.

A RDC em questão abrange pontos importantes para a prática segura nos serviços de saúde, como o gerenciamento da qualidade, a segurança do paciente, as condições organizacionais, o prontuário do paciente, a gestão de pessoal, a gestão de infraestrutura, a proteção à saúde do trabalhador, a gestão de tecnologias e processos e o controle integrado de vetores e pragas urbanas ${ }^{(76)}$.

Com o propósito de interferir na gestão administrativa dos estabelecimentos de saúde para a prevenção de EA cirúrgicos que agravam a condição base do paciente, uma das diretrizes importantes para a segurança do paciente cirúrgico foi estabelecida no art. $8^{\circ}$ da RDC, como referência à obrigação de prestar serviços de qualidade. De acordo com o referido artigo, o serviço de saúde deve estabelecer estratégias e ações voltadas para Segurança do Paciente, a saber ${ }^{(76)}$ :

I. Mecanismos de identificação do paciente;

II. Orientações para a higienização das mãos;

III. Ações de prevenção e controle de eventos adversos relacionados à assistência à saúde;

IV. Mecanismos para garantir segurança cirúrgica;

V. Orientações para administração segura de medicamentos, sangue e hemocomponentes;

VI. Mecanismos para prevenção de quedas dos pacientes;

VII. Mecanismos para a prevenção de úlceras por pressão;

VIII. Orientações para estimular a participação do paciente na assistência prestada.

\subsection{Centro de Material e Esterilização}

Em 2012, a ANVISA publicou a RDC n. 15 que dispõe sobre requisitos de boas práticas para o processamento de produtos para saúde e dá outras providências. O objetivo do regulamento técnico é estabelecer os requisitos de boas práticas para o funcionamento dos serviços que realizam o processamento de produtos para a saúde visando à segurança do paciente e dos profissionais envolvidos $^{(129)}$. 
O regulamento técnico é aplicado ao CME dos serviços de saúde públicos e privado, civil e militar, e às empresas processadoras envolvidas no processamento de produtos para saúde. Encontram-se excluídos do escopo desse regulamento o processamento de produtos para saúde realizados em consultórios odontológicos, consultórios individualizados e não vinculados a serviços de saúde, unidades de processamento de endoscópios, serviços de terapia renal substitutiva, serviços de assistência veterinária ${ }^{(129)}$.

De acordo com a RDC, o processamento de produto para saúde é definido como o "conjunto de ações relacionadas à pré-limpeza, recepção, limpeza, secagem, avaliação da integridade e da funcionalidade, preparo, desinfecção ou esterilização, armazenamento e distribuição para as unidades consumidoras"(129).

\subsection{Segurança do Paciente}

\subsection{Programa Nacional de Segurança do Paciente}

Apesar de a preocupação com a segurança do paciente sempre permear as legislações sanitárias, o principal marco sobre o tema foi o lançamento oficial do PNSP pelo $\mathrm{MS}^{(75)}$.

O PNSP tem por objetivo geral contribuir para a qualificação do cuidado em saúde em todos os estabelecimentos de saúde do território nacional. De acordo com o Art. $3^{\circ}$, constituem-se objetivos específicos do PNSP ${ }^{(75)}$ :

I - promover e apoiar a implementação de iniciativas voltadas à segurança do paciente em diferentes áreas da atenção, organização e gestão de serviços de saúde, por meio da implantação da gestão de risco e de Núcleos de Segurança do Paciente nos estabelecimentos de saúde;

II - envolver os pacientes e familiares nas ações de segurança do paciente;

III - ampliar o acesso da sociedade às informações relativasà segurança do paciente;

IV - produzir, sistematizar e difundir conhecimentos sobre segurança do paciente; $\mathrm{e}$

$\mathrm{V}$ - fomentar a inclusão do tema segurança do paciente no ensino técnico e de graduação e pós-graduação na área da saúde.

Ainda de acordo com a Portaria, constituem-se estratégias de implementação do PNSP(75): 
I - elaboração e apoio à implementação de protocolos, guias e manuais de segurança do paciente;

II - promoção de processos de capacitação de gerentes, profissionais e equipes de saúde em segurança do paciente;

III - inclusão, nos processos de contratualização e avaliação de serviços, de metas, indicadores e padrões de conformidade relativosà segurança do paciente;

IV - implementação de campanha de comunicação social sobre segurança do paciente, voltada aos profissionais, gestores e usuários de saúde e sociedade;

V - implementação de sistemática de vigilância e monitoramento de incidentes na assistência à saúde, com garantia de retornoàs unidades notificantes;

VI - promoção da cultura de segurança com ênfase no aprendizado e aprimoramento organizacional, engajamento dos profissionais e dos pacientes na prevenção de incidentes, com ênfase em sistemas seguros, evitando-se os processos de responsabilização individual; e

VII - articulação, com o Ministério da Educação e com o Conselho Nacional de Educação, para inclusão do tema segurança do paciente nos currículos dos cursos de formação em saúde de nível técnico, superior e de pós-graduação.

O PNSP está sustentado por 4 eixos: 1) prática assistencial segura; 2) envolvimento do cidadão na sua segurança; 3) inclusão do tema no ensino; e 4) incremento de pesquisa sobre o tema ${ }^{(41)}$.

Com o intuito de estabelecer um foco nacional para criar liderança, pesquisa, ferramentas, recursos e protocolos sobre segurança foi instituído o Comitê de Implementação do Programa Nacional de Segurança do Paciente (CIPNSP) ${ }^{(75)}$.

A Portaria $n^{\circ} .941$, de 17 de maio de $2013^{(130)}$ altera e acresce dispositivo ao art. $8^{\circ}$ da Portaria №. 529/GM/MS, de $1^{\circ}$ de abril de 2013, que institui o PNSP(75), incluindo outras entidades para integrar o CIPNSP. Atualmente, o CIPNSP é composto por representantes, titulares e suplentes, dos órgãos e entidades ${ }^{(75,130)}$ : MS; ANVISA; Fiocruz; ANS; Conselho Nacional de Secretários de Saúde (CONASS); Conselho Nacional de Secretários Municipais de Saúde (CONASEMS); Conselho Federal de Medicina (CFM); Conselho Federal de Enfermagem (COFEN); Conselho Federal de Odontologia (CFO); Conselho Federal de Farmácia (CFF); OPAS/OMS; Instituições Superiores de Ensino e Pesquisa com notório saber no tema Segurança do Paciente; Conselho Nacional de Saúde e Confederação Nacional de Saúde. 
Diversas são as competências do CIPNSP, de acordo com a Portaria $n^{\circ}$. $529 / \mathrm{GM} / \mathrm{MS} / 2013^{(75):}$

I - propor e validar protocolos, guias e manuais voltados à segurança do paciente em diferentes áreas, tais como:

a) infecções relacionadas à assistência à saúde;

b) procedimentos cirúrgicos e de anestesiologia;

c) prescrição, transcrição, dispensação e administração de medicamentos, sangue e hemoderivados;

d) processos de identificação de pacientes;

e) comunicação no ambiente dos serviços de saúde;

f) prevenção de quedas;

g) úlceras por pressão;

h) transferência de pacientes entre pontos de cuidado; e

i) uso seguro de equipamentos e materiais;

II - aprovar o Documento de Referência do PNSP;

III - incentivar e difundir inovações técnicas e operacionais que visem à segurança do paciente;

IV - propor e validar projetos de capacitação em Segurança do Paciente;

V - analisar quadrimestralmente os dados do Sistema de Monitoramento incidentes no cuidado de saúde e propor ações de melhoria;

VI - recomendar estudos e pesquisas relacionados à segurança do paciente;

VII - avaliar periodicamente o desempenho do PNSP; e

VIII elaborar seu regimento interno e submetê-lo à aprovação do Ministro de Estado da Saúde.

\subsection{Ações de segurança do paciente em serviços de saúde}

Visando ao fortalecimento da regulação e do controle sanitário nos estabelecimentos de saúde no âmbito do PNSP, a ANVISA publicou a RDC ํ‥ 36, em 22 de julho de $2013^{(2)}$, que institui as ações de segurança do paciente em serviços de saúde.

Tanto a RDC no. 36/2012(2) quanto a Portaria no. 529/GM/MS/2013 $3^{(75)}$ instituem os Núcleos de Segurança do Paciente (NSP's) como agentes 
fomentadores e articuladores para a segurança do paciente dentro dos serviços de saúde públicos, privados, filantrópicos, civis ou militares, incluindo aqueles que exercem ações de ensino e pesquisa. Dessa forma, não apenas os hospitais, mas clínicas e serviços especializados de diagnóstico e tratamento devem possuir $N S P^{\prime} s^{(102)}$.

Os NSP's são instâncias que devem ser criadas nos serviços de saúde com as atribuições de elaborar, desenvolver e monitorar as ações previstas no PSP, apoiando a implementação de medidas de prevenção, controle e mitigação de incidentes nos serviços de saúde ${ }^{(2,102)}$.

Ressalta-se que o PSP deve estabelecer estratégias e ações de gestão de risco, conforme as atividades desenvolvidas pelo serviço de saúde para ${ }^{(2)}$ :

I - identificação, análise, avaliação, monitoramento e comunicação dos riscos no serviço de saúde, de forma sistemática;

II - integrar os diferentes processos de gestão de risco desenvolvidos nos serviços de saúde;

III - implementação de protocolos estabelecidos pelo Ministério da Saúde;

IV - identificação do paciente;

$\mathrm{V}$ - higiene das mãos;

VI - segurança cirúrgica;

VII - segurança na prescrição, uso e administração de medicamentos;

VIII-segurança na prescrição, uso e administração de sangue e hemocomponentes;

IX - segurança no uso de equipamentos e materiais;

$X$ - manter registro adequado do uso de órteses e próteses quando este procedimento for realizado;

$X I$ - prevenção de quedas dos pacientes;

XII - prevenção de úlceras por pressão;

XIII - prevenção e controle de eventos adversos em serviços de saúde, incluindo as infecções relacionadas à assistência à saúde;

XIV - segurança nas terapias nutricionais enteral e parenteral;

XV - comunicação efetiva entre profissionais do serviço de saúde e entre serviços de saúde; 
XVI - estimular a participação do paciente e dos familiares na assistência prestada;

XVII - promoção do ambiente seguro.

Ressalta-se que a norma técnica destaca no artigo $7^{\circ}$ diversas competências aos NSP's ${ }^{(2)}$ :

I - promover ações para a gestão de risco no serviço de saúde;

II - desenvolver ações para a integração e a articulação multiprofissional no serviço de saúde;

III - promover mecanismos para identificar e avaliar a existência de não conformidades nos processos e procedimentos realizados e na utilização de equipamentos, medicamentos e insumos propondo ações preventivas e corretivas;

IV - elaborar, implantar, divulgar e manter atualizado o Plano de Segurança do Paciente em Serviços de Saúde;

V - acompanhar as ações vinculadas ao Plano de Segurança do Paciente em Serviços de Saúde;

VI - implantar os Protocolos de Segurança do Paciente e realizar o monitoramento dos seus indicadores;

VII - estabelecer barreiras para a prevenção de incidentes nos serviços de saúde;

VIII - desenvolver, implantar e acompanhar programas de capacitação em segurança do paciente e qualidade em serviços de saúde;

IX - analisar e avaliar os dados sobre incidentes e eventos adversos decorrentes da prestação do serviço de saúde;

X - compartilhar e divulgar à direção e aos profissionais do serviço de saúde os resultados da análise e avaliação dos dados sobre incidentes e eventos adversos decorrentes da prestação do serviço de saúde;

XI - notificar ao Sistema Nacional de Vigilância Sanitária os eventos adversos decorrentes da prestação do serviço de saúde;

XII- manter sob sua guarda e disponibilizar à autoridade sanitária, quando requisitado, as notificações de eventos adversos;

XIII - acompanhar os alertas sanitários e outras comunicações de risco divulgadas pelas autoridades sanitárias.

Portanto, a segurança do paciente depende de um sistema capaz de identificar, investigar, analisar e corrigir inadequações ou não conformidades, a fim 
de minimizar ou eliminar riscos para pacientes. Ainda, os alertas sanitários e outras comunicações de risco divulgadas pelas autoridades sanitárias devem ser acompanhadas pelos serviços de saúde ${ }^{(2)}$, corroborando esta competência para a prevenção de incidentes nos serviços de saúde.

A notificação de EA ao SNVS pelos NSP's é obrigatória, de acordo, com a RDC $n^{\circ} .36 / 2013^{(2)}$. Os EA devem ser notificados ao SNVS utilizando-se o módulo de notificação de incidentes do NOTIVISA ${ }^{(102)}$.

Ainda em 2013, foi publicada a RDC $n^{\circ}$. 53, de 14 de novembro de $2013^{(131)}$, que alterou o artigo 12 da RDC $n$ ‥ 36/2013(2), prorrogando os prazos para a estruturação dos NSP's, elaboração do PSP e notificação mensal dos EA, incluindo os cirúrgicos, contados a partir da data da publicação da norma.

\subsection{Protocolos básicos para segurança do paciente}

Em 2013, o MS do Brasil publicou seis protocolos básicos de segurança do paciente $^{(81,132)}$ : a prática de higiene das mãos; a segurança na prescrição, uso e administração de medicamentos; a identificação dos pacientes; a prevenção de quedas e úlceras por pressão e a cirurgia segura.

O protocolo para cirurgia segura foi instituído pela Portaria $n^{\circ} .1 .377$ de 9 de julho ${ }^{(81)}$ na tentativa de melhorar o processo de segurança cirúrgica nos serviços de saúde do país. O protocolo em questão envolve, especialmente, a identificação do paciente, o consentimento informado e a demarcação do local da cirurgia, envolvendo a participação do paciente. Para auxiliar estas e outras checagens, a LVSC assegura a organização, o funcionamento dos equipamentos necessários para a realização da cirurgia e o procedimento de pausa antes e após a intervenção cirúrgica $^{(9,81)}$.

A vigilância, o monitoramento e a avaliação dos resultados é um componente essencial dos cuidados cirúrgicos. De acordo com o protocolo nacional para cirurgia segura $^{(81)}$, os seguintes indicadores devem ser monitorados pelos serviços de saúde:

- Percentual de pacientes que receberam antibioticoprofilaxia no momento adequado;

- Número de cirurgias em local errado;

- Número de cirurgias em paciente errado; 
- Número de procedimentos errados;

- Taxa de mortalidade cirúrgica intrahospitalar ajustada ao risco; e

- Taxa de adesão à LVSC.

O Quadro 1 mostra as principais legislações nacionais que apresentam interface com a segurança cirúrgica em serviços de saúde.

Quadro 1 - Principais legislações que apresentam interface com a segurança cirúrgica.

\begin{tabular}{|c|c|c|c|}
\hline LEGISLAÇŌES & TEMA & OBJETIVO & OBSERVAÇÃO \\
\hline $\begin{array}{l}\text { Portaria } \quad n=. \\
2.616 \text { de } 12 \text { de } \\
\text { maio de } 1998\end{array}$ & $\begin{array}{l}\text { Regulamenta as } \\
\text { ações de controle } \\
\text { de infecção } \\
\text { hospitalar no país. }\end{array}$ & $\begin{array}{l}\text { Reduzir a incidência e a } \\
\text { gravidade das infecções } \\
\text { dos hospitais. }\end{array}$ & $\begin{array}{l}\text { Revoga a Portaria } n^{\circ} \\
\text { 930, de } 27 \text { de agosto } \\
\text { de } 1992 .\end{array}$ \\
\hline $\begin{array}{l}\text { Resolução da } \\
\text { Diretoria } \\
\text { Colegiada } \\
\text { RDC no. } 50 \text { de } \\
21 \text { de fevereiro } \\
2002^{(116)}\end{array}$ & 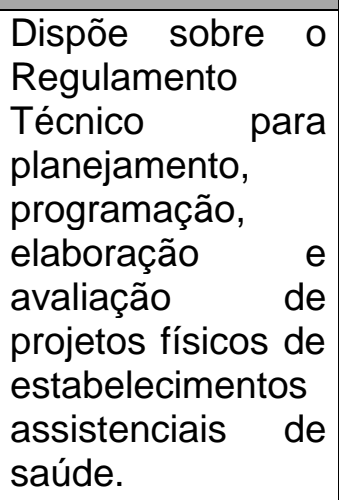 & $\begin{array}{l}\text { Regulamento Técnico } \\
\text { destinado ao } \\
\text { planejamento, } \\
\text { programação, elaboração, } \\
\text { avaliação e aprovação de } \\
\text { projetos físicos de } \\
\text { estabelecimentos } \\
\text { assistenciais de saúde, a } \\
\text { ser observado em todo } \\
\text { território nacional, na área } \\
\text { pública e privada. }\end{array}$ & \\
\hline $\begin{array}{l}\text { RE/Anvisa } \mathrm{n} \text {. } \\
2606 \text {, de } 11 \text { de } \\
\text { agosto } \\
2006^{(122)}\end{array}$ & $\begin{array}{lr}\text { Dispõe sobre } & \text { as } \\
\text { diretrizes } & \text { para } \\
\text { elaboração, } & \\
\text { validação } & \text { e } \\
\text { implantação } & \text { de } \\
\text { protocolos } & \text { de } \\
\text { reprocessamento } \\
\text { de } & \text { produtos } \\
\text { médicos e } & \text { dá } \\
\text { outras } & \\
\text { providências. }\end{array}$ & $\begin{array}{l}\text { Estabelecer os } \\
\text { parâmetros (protocolos) a } \\
\text { serem adotados pelos } \\
\text { estabelecimentos que } \\
\text { fazem o reprocessamento, } \\
\text { visando garantir a } \\
\text { segurança e a eficácia dos } \\
\text { produto }\end{array}$ & \\
\hline $\begin{array}{l}\text { RE/Anvisa } \mathrm{n} \text {. } \\
2605 \text {, de } 11 \text { de } \\
\text { agosto } \\
2006^{(121)}\end{array}$ & $\begin{array}{l}\text { Estabelece a lista } \\
\text { de produtos } \\
\text { médicos } \\
\text { enquadrados } \\
\text { como de uso } \\
\text { único proibidos de } \\
\text { ser reprocessados }\end{array}$ & $\begin{array}{l}\text { Estabelecer a lista de } \\
\text { produtos médicos cujo } \\
\text { reprocessamento não é } \\
\text { permitido. }\end{array}$ & $\begin{array}{l}\text { Revoga a RE no. } 515 \text {, } \\
\text { de } 15 \text { de fevereiro de } \\
2006 \text {, publicada em } 16 \\
\text { de fevereiro de } 2006\end{array}$ \\
\hline
\end{tabular}




\begin{tabular}{|c|c|c|c|}
\hline $\begin{array}{lr}\text { Resolução } & \text { da } \\
\text { Diretoria } \\
\text { Colegiada } \\
\text { RDC no. } \\
\text { de } 156 \text {, } 11 \text { de } \\
\text { agosto } \\
2006^{(120)}\end{array}$ & 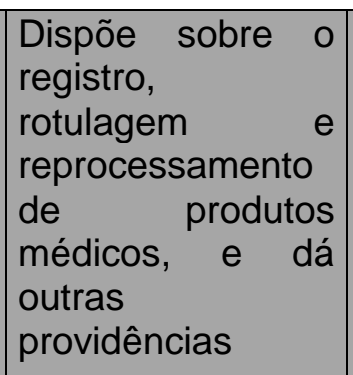 & \begin{tabular}{|lr} 
Estabelecer & rótulo, \\
registro & $e$ \\
reprocessamento & dos \\
produtos médicos. & \\
&
\end{tabular} & $\begin{array}{l}\text { Revoga a RDC } n^{\circ} 30, \\
\text { de } 15 \text { de fevereiro de } \\
2006 \text {. }\end{array}$ \\
\hline $\begin{array}{l}\text { Resolução da } \\
\text { Diretoria } \\
\text { Colegiada } \\
\text { RDC no } 199 \text { de } \\
26 \text { de outubro } \\
\text { de } 2006^{(127)}\end{array}$ & $\begin{array}{|lr|} & \\
\text { Institui } & \text { a } \\
\text { notificação } & \\
\text { simplificada } & \text { de } \\
\text { medicamentos } & \text { por } \\
\text { meio } & \text { eletrônico } \\
\text { disponível no } & \text { site } \\
\text { da ANVISA. } & \end{array}$ & $\begin{array}{lr}\text { Visa instituir a notificação } \\
\text { simplificada } & \text { de } \\
\text { medicamentos } & \text { que } \\
\text { possuem baixo risco de } \\
\text { causar agravos à saúde } \\
\text { quando } & \text { suas } \\
\text { características de uso e } \\
\text { qualidade } & \text { são } \\
\text { observadas. } & \end{array}$ & \\
\hline $\begin{array}{l}\text { Resolução da } \\
\text { Diretoria } \\
\text { Colegiada } \\
\text { RDC no. 8, de } \\
27 \text { de fevereiro } \\
\text { de } 2009^{(123)}\end{array}$ & $\begin{array}{|lr|} & \\
& \\
& \\
\text { Dispõe } & \text { sobre } \\
\text { medidas } & \text { para } \\
\text { redução } & \text { da } \\
\text { ocorrência } & \text { de } \\
\text { infecções } & \text { por } \\
\text { MCR em } & \text { serviços } \\
\text { de saúde. } & \end{array}$ & $\begin{array}{l}\text { Suspender a esterilização } \\
\text { química por imersão, } \\
\text { utilizando } \\
\text { esterilizantes agentes } \\
\text { para líquidos, } \\
\text { cirúrgico e produtos para } \\
\text { saúde utilizados nos } \\
\text { procedimentos cirúrgicos } \\
\text { e diagnósticos por } \\
\text { videoscopias de com } \\
\text { penetração de pele, } \\
\text { mucosas adjacentes, } \\
\text { tecidos sub-epiteliais e } \\
\text { sistema vascular, cirurgias } \\
\text { abdominais e pélvicas } \\
\text { convencionais, cirurgias } \\
\text { plásticas com o auxílio de } \\
\text { ópticas, mamoplastias e } \\
\text { procedimentos de } \\
\text { lipoaspiração. }\end{array}$ & \\
\hline $\begin{array}{l}\text { Resolução da } \\
\text { Diretoria } \\
\text { Colegiada } \\
\text { RDC n } \text { n }^{\circ} 42 \text { de } \\
25 \text { de outubro } \\
\text { de } 2010^{(73)}\end{array}$ & 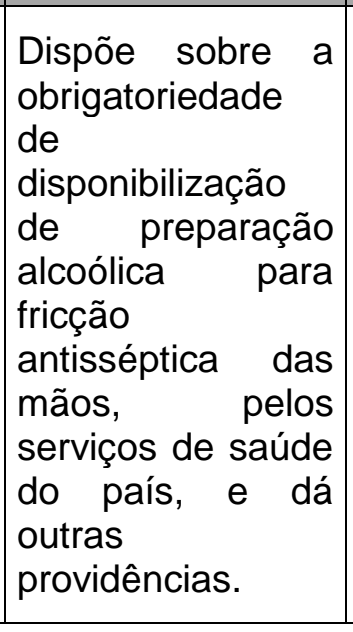 & $\begin{array}{l}\text { Instituir e promover a } \\
\text { higiene das mãos nos } \\
\text { serviços de saúde do país, } \\
\text { por meio de preparação } \\
\text { alcoólica para friçãa } \\
\text { antisséptica das mãos, de } \\
\text { acordo com as diretrizes } \\
\text { da OMS previstas na } \\
\text { AMSP, com o intuito de } \\
\text { prevenir e controlar as } \\
\text { infecções relacionadas à } \\
\text { assistência à saúde, } \\
\text { visando à segurança do } \\
\text { paciente e dos }\end{array}$ & \\
\hline
\end{tabular}




\begin{tabular}{|c|c|c|c|}
\hline & & profissionais de saúde. & \\
\hline $\begin{array}{ll}\text { Resolução } & \text { da } \\
\text { Diretoria } & \\
\text { Colegiada } & - \\
\text { RDC no. } 63 & \text { de } \\
25 & \text { de } \\
\text { novembro } & \text { de } \\
2011^{(76)} & \end{array}$ & $\begin{array}{l}\text { Dispõe sobre os } \\
\text { Requisitos } \\
\text { Boas Práticas de } \\
\text { Funcionamento } \\
\text { para os Serviços } \\
\text { de Saúde. }\end{array}$ & $\begin{array}{l}\text { Estabelecer padrões para } \\
\text { funcionamento dos } \\
\text { serviços de atenção à } \\
\text { saúde, fundamentados na } \\
\text { qualificação, na } \\
\text { humanização da atenção } \\
\text { e gestão, e na redução e } \\
\text { controle de riscos aos } \\
\text { usuários e meio ambiente. }\end{array}$ & \\
\hline $\begin{array}{l}\text { Resolução da } \\
\text { Diretoria } \\
\text { Colegiada } \\
\text { RDC no. } 15 \text {, de } \\
15 \text { de março } \\
\text { de } 2012^{(129)}\end{array}$ & $\begin{array}{lr}\text { Dispõe r sobre } \\
\text { requisitos de boas } \\
\text { práticas para } 0 \\
\text { processamento de } \\
\text { produtos r para } \\
\text { saúde e dá outras } \\
\text { providências. }\end{array}$ & $\begin{array}{l}\text { Estabelecer os requisitos } \\
\text { de boas práticas para o } \\
\text { funcionamento } \\
\text { serviços que realizam os } \\
\text { processamento } \\
\text { produtos para a saúde } \\
\text { visando à segurança do } \\
\text { paciente } \\
\text { profissionais envolvidos. }\end{array}$ & \\
\hline $\begin{array}{l}\text { Portaria } n=. \\
1.443 \text { de } 11 \text { de } \\
\text { outubro de } \\
2012^{(77)}\end{array}$ & 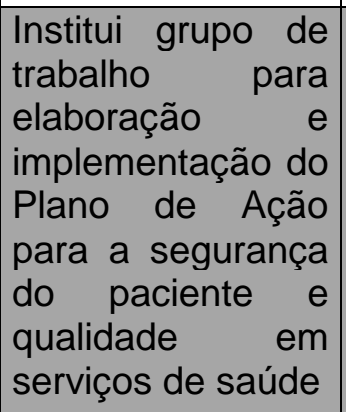 & 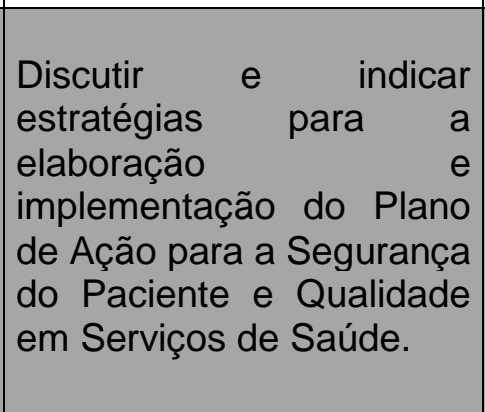 & \\
\hline $\begin{array}{l}\text { Portaria } n^{\circ} . \\
529 / G M / M S \text { de } \\
10 \text { de abril de } \\
2013^{(75)}\end{array}$ & $\begin{array}{l}\text { Institui o } \\
\text { Programa } \\
\text { Nacional de } \\
\text { Segurança do } \\
\text { Paciente (PNSP) }\end{array}$ & $\begin{array}{l}\text { Contribuir para a } \\
\text { qualificação do cuidado } \\
\text { em saúde em todos os } \\
\text { estabelecimentos de } \\
\text { saúde do território } \\
\text { nacional. }\end{array}$ & $\begin{array}{l}\text { A Portaria } \mathrm{n}^{\circ} .941 \text {, de } \\
17 \text { de maio de } 2013 \\
\text { altera e acresce } \\
\text { dispositivo ao art. } 8^{\circ} \text { da } \\
\text { Portaria } n^{\circ}= \\
529 / \mathrm{GM} / \mathrm{MS} \text {, de } 1^{\circ} \text { de } \\
\text { abril de } 2013 \text {, que } \\
\text { institui o PNSP. }\end{array}$ \\
\hline $\begin{array}{ll}\text { Portaria } & \text { no. } \\
1.377 \text { de } 9 & \text { de } \\
\text { julho } & \text { de } \\
2013^{(81)} & \end{array}$ & 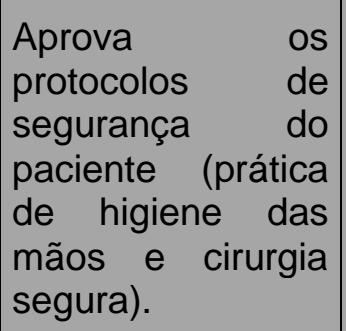 & $\begin{array}{l}\text { Instituir ações para } \\
\text { segurança do paciente em } \\
\text { serviços de saúde e a } \\
\text { melhoria da qualidade em } \\
\text { caráter nacional. }\end{array}$ & \\
\hline $\begin{array}{l}\text { Resolução da } \\
\text { Diretoria } \\
\text { Colegiada } \\
\text { RDC no. } 36 \text { de } \\
25 \text { de julho de }\end{array}$ & 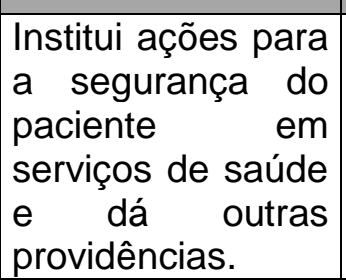 & $\begin{array}{l}\text { Instituir ações para a } \\
\text { promoção da segurança } \\
\text { do paciente e a melhoria } \\
\text { da qualidade nos serviços } \\
\text { de saúde. }\end{array}$ & $\begin{array}{l}\text { A RDC } n^{\circ} .53 \text {, de } 14 \\
\text { de novembro de } 2013 \text {, } \\
\text { alterou o artigo } 12 \text { da } \\
\text { RDC no. } 36 / 2013 \text {, } \\
\text { prorrogando os prazos } \\
\text { para a estruturação }\end{array}$ \\
\hline
\end{tabular}




\begin{tabular}{|c|c|c|c|}
\hline $2013^{(2)}$ & & & $\begin{array}{l}\text { dos NSPs, elaboração } \\
\text { do PSP e notificação } \\
\text { mensal dos EA. }\end{array}$ \\
\hline $\begin{array}{lr}\text { Portaria } & \text { no } \\
2.095 \text { de } 24 \text { de } \\
\text { setembro de } \\
2013^{(132)} \text {. }\end{array}$ & \begin{tabular}{|lr} 
Aprova & os \\
protocolos & de \\
segurança & do \\
paciente & \\
(segurança & na \\
prescrição, uso & e \\
administração & de \\
medicamentos; a \\
identificação dos \\
pacientes; r a \\
prevenção r de \\
quedas e úlceras \\
por pressão).
\end{tabular} & $\begin{array}{l}\text { Instituir ações para } \\
\text { segurança do paciente em } \\
\text { serviços de saúde e a } \\
\text { melhoria da qualidade em } \\
\text { caráter nacional. }\end{array}$ & \\
\hline $\begin{array}{l}\text { Resolução da } \\
\text { Diretoria } \\
\text { Colegiada } \\
\text { RDC n } \mathrm{n}^{\circ} .4 \text { de } \\
30 \text { de janeiro } \\
\text { de 2014 } 4^{(128)}\end{array}$ & $\begin{array}{lr}\text { Dispõe sobre os } \\
\text { requisitos técnicos } \\
\text { para } & \text { a } \\
\text { regularização de } \\
\text { produtos } & \text { de } \\
\text { higiene pessoal, } \\
\text { cosméticos r e } \\
\text { perfumes e dá } \\
\text { outras } & \\
\text { providências. }\end{array}$ & $\begin{array}{l}\text { Este Regulamento tem } \\
\text { como objetivo atualizar os } \\
\text { procedimentos } \\
\text { necessários para a } \\
\text { regularização de produtos } \\
\text { de higiene pessoal, } \\
\text { cosméticos e perfumes } \\
\text { por meio da simplificação } \\
\text { de processos que visa à } \\
\text { melhoria da qualidade da } \\
\text { informação e agilidade na } \\
\text { análise. }\end{array}$ & $\begin{array}{l}\text { Revoga as Resoluções } \\
\text { da Diretoria Colegiada } \\
\text { da Anvisa RDC no. } \\
211 \text {, de } 14 \text { de julho de } \\
2005 \text { e RDC n. } 343, \\
\text { de } 13 \text { de dezembro de } \\
2005 .\end{array}$ \\
\hline
\end{tabular}

\subsubsection{Ferramentas nacionais para a Segurança do Paciente Cirúrgico}

\subsection{Notificação}

Os serviços de saúde devem notificar os EA utilizando-se o módulo de notificação de incidentes do NOTIVISA ${ }^{(1,102)}$.

São considerados eventos graves relacionados aos procedimentos cirúrgicos e passíveis de notificação ao SNVS pelos NSP's ${ }^{(102)}$ : 1) cirurgia ou outro procedimento invasivo realizado no sítio errado; 2) cirurgia ou outro procedimento invasivo realizado no paciente errado; 3) realização de cirurgia ou outro procedimento invasivo errado em um paciente; 4) retenção não intencional de corpo 
estranho em um paciente após cirurgia ou outro procedimento invasivo e 5) óbito intra-operatório ou imediatamente pós-operatório / pós-procedimento em paciente ASA (American Society of Anesthesiologists) I.

No país, o sistema de informação para captação de EA relacionados ao processo de cuidado foi elaborado com base na Classificação Internacional para Segurança do Paciente, da AMSP, da OMS ${ }^{(41)}$. O preenchimento de cada parte do módulo de notificação é feito objetivamente pelos NSP's com informações sobre o evento detectado e investigado. O módulo se encontra dividido nas seguintes etapas $^{(102)}$ : 1) Tipo de incidente; 2) Consequências para o paciente; 3) Características do paciente; 4) Características do incidente; 5) Fatores contribuintes; 6) Consequências organizacionais; 7) Detecção; 8) Fatores atenuantes do dano; 9) Ações de melhoria e 10) Ações para reduzir o risco.

Apesar da notificação pelo serviço de saúde se realizar por ficha, isto é, por paciente, a identificação deste não é possível, sendo os dados resultantes do monitoramento analisados pelo consolidado de EA. A proposta do módulo de notificação é traçar o perfil de EA para nortear a tomada de decisão por parte dos gestores, sendo salutar ressaltar que não há intenção alguma em procurar culpados. O sistema de notificação ainda contempla a participação do cidadão e a lógica não punitiva também se estende a este perfil ${ }^{(1)}$.

\subsection{Materiais educativos}

As ferramentas da OMS para a segurança cirúrgica foram traduzidas para a língua portuguesa e adaptadas à realidade brasileira pela ANVISA e por um grupo de especialistas durante reunião realizada na sede da OPAS/OMS, em $2009^{(134)}$.

Em continuidade, a ANVISA, a SAS/MS e a OPAS/OMS disponibilizaram estes materiais educativos para a implantação do Programa Cirurgias Seguras Salvam Vidas nos serviços de saúde do Brasil, tais como, o manual Cirurgias Seguras Salvam Vidas ${ }^{(134)}$, o guia para a implantação da $\operatorname{LVSC}^{(63)}$, a $\operatorname{LVSC}^{(40,63,134)}$ e o cartaz Cirurgias Seguras Salvam Vidas ${ }^{(40)}$.

Ressalta-se que as publicações supraexpostas vêm apoiando a implantação da iniciativa Cirurgias Seguras Salvam Vidas nos serviços de saúde e provendo o 
conhecimento baseado em evidências e boas práticas, dando suporte ao processo de regulação do tema pelo SNVS.

Ainda em 2009, a ANVISA publicou o Manual de Critérios Nacionais de Infecções Relacionadas à Assistência à Saúde - Sítio Cirúrgico para sistematizar a vigilância da ISC e definir indicadores de resultado, processo e estrutura para a prevenção de infecção pós-operatória nos serviços de saúde do Brasil ${ }^{(135)}$.

Atualmente, as atividades de controle de infecção estão inseridas na proposta de segurança do paciente, uma vez que muitas IRAS são causadas por falhas na assistência, como a baixa adesão às medidas de prevenção baseadas em evidências, incluindo a ISC.

Posteriormente, foi publicado pela ANVISA, em 2010, o Manual de Indicadores Nacionais Epidemiológicos de Infecções Relacionadas à Assistência à Saúde, que institui os indicadores epidemiológicos para a vigilância das $\operatorname{IRAS}^{(136)}$. Segundo a publicação, a notificação dos indicadores de IRAS pelos estabelecimentos de saúde do território nacional, é feita por meio de Formulário de Notificação dos Indicadores Epidemiológicos de IRAS, elaborado a partir da ferramenta estruturante FormSUS - DATASUS ${ }^{(136)}$.

$\mathrm{Na}$ tentativa de prevenir danos e melhorar o cuidado cirúrgico prestado ao paciente, na etapa atual, a preparação da ANVISA para a cirurgia segura está voltada para a implementação dos instrumentos de segurança cirúrgica em salas operatórias do país, incluindo a aplicação da LVSC, a implantação dos critérios diagnósticos de ISC, pelo alcance da medida na identificação e o monitoramento dos EA, que abrangem também as IRAS ${ }^{(71)}$.

Para a capacitação de equipes cirúrgicas, os materiais audiovisuais, tais como vídeos e cartazes sobre implementação da LVSC também são bastante úteis. Recentemente, com a instituição do PNSP, os seguintes materiais educativos sobre a temática estão à disposição dos usuários: 1) cartaz do MS mostrando as metas principais do PNSP, destacando-se a meta - assegurar cirurgia em local de intervenção, procedimento e paciente corretos ${ }^{(137)}$; 2) vídeos sobre os protocolos básicos para a segurança do paciente desenvolvidos pelo Proqualis, incluindo 0 vídeo sobre cirurgia segura, centrado no uso da LVSC ${ }^{(138)}$. 


\subsubsection{Gestão de Risco}

A gestão de risco é a aplicação sistêmica e contínua de políticas, procedimentos, condutas e recursos na identificação, análise, avaliação, comunicação e controle de riscos e eventos adversos que afetam a segurança, a saúde humana, a integridade profissional, o meio ambiente e a imagem institucional $^{(2)}$.

Os objetivos da gestão de risco envolvem ${ }^{(139)}:$ 1) segurança da comunidade usuária; 2) redução de perdas; 3) preservação da organização; 4) atendimento à legislação vigente e 5) alinhamento aos padrões de qualidade para certificação da qualidade.

No contexto cirúrgico, os princípios da gestão de risco devem ser aplicados em todas as atividades, em especial, no que se refere ao consentimento esclarecido e informação do paciente acerca do processo de cuidados; ao preparo préoperatório, incluindo avaliação e comunicação das suas necessidades; à sua identificação e verificação do processo; à sua monitorização, durante todo o período peri-operatório; à sua movimentação, mobilização e posicionamento; aos procedimentos que garantam a continuidade dos cuidados; à verificação dos fatores ambientais; ao conhecimento, manutenção e utilização de equipamento e à técnica asséptica $^{(140,141)}$.

Alguns exemplos de ações para a minimização do risco envolvem a préqualificação de artigos e fornecedores, a manutenção preventiva e corretiva de equipamentos, as respostas às solicitações de consultas restritas, a ampliação de sinais, a emissão de pareceres ou informes técnicos de produtos sob vigilância sanitária e outros ${ }^{(102)}$.

Nos serviços de saúde, um dos princípios e diretrizes que devem ser adotados pelo NSP, conforme a RDC $n^{\circ} \cdot 36 / 2013^{(2)}$ é a articulação e a integração dos processos de gestão de risco. De acordo com o Art.7ํㅜ do regulamento técnico, uma das competências do NSP consiste na promoção de ações para a gestão de risco no serviço de saúde ${ }^{(2)}$.

O processo de gestão de risco consiste na aplicação sistemática de cinco etapas, pelo NSP(102): 1) Estabelecimento do Contexto; 2) Identificação do Risco; 3) Análise do Risco; 4) Avaliação do Risco; 5) Tratamento do Risco e 6) Comunicação do Risco. 
O estabelecimento do contexto envolve a identificação dos parâmetros externos e internos que devem ser levados em consideração na gestão de risco para definir o escopo e os critérios de risco para a política de gestão. Os parâmetros internos incluem a estrutura organizacional, os objetivos da instituição, os recursos disponíveis, a cultura organizacional, as relações contratuais, entre outros. Por sua vez, os parâmetros externos incluem o ambiente cultural, legal, político, econômico, tecnológico (nacional e internacional), percepção, valores externos e tendências que podem impactar nos objetivos internos, entre outros ${ }^{(102)}$.

Durante a etapa de identificação do risco faz-se necessário a identificação das fontes, sendo consideradas fontes usuais os relatórios, EA notificados, avaliação em processo de acreditação, indicadores, auditorias, resultados de pesquisa sobre qualidade e satisfação do usuário, reclamações dos usuários, avaliação de desempenho das equipes, informações em mídia, entre outros ${ }^{(102) .}$

A análise do risco inclui estimativa do risco baseada especialmente em dois parâmetros: frequência e gravidade do evento. Conhecer a magnitude do evento, a probabilidade de ocorrência e os efeitos das consequências tornam possíveis intervenções corretas para minimizar efeitos em cenários previamente identificados como vulneráveis ${ }^{(102)}$. Nesta etapa, a análise de causa raiz pode ser usada para identificar os fatores que contribuíram para o resultado de um EA ou near miss ${ }^{(96)}$.

A etapa de avaliação do risco reúne os dados de identificação e análise de risco para a tomada de decisão. Para determinar se a magnitude do risco é tolerável ou não, o NSP deve comparar os resultados da análise com os parâmetros estabelecidos na Etapa 1 para a classificação dos riscos ${ }^{(102)}$.

O tratamento do risco é feito após a identificação dos problemas prioritários e a realização da análise das causas, sendo que o NSP deve determinar ações para eliminar, reduzir, controlar ou prevenir os riscos, considerando a existência e a disponibilidade de medidas efetivas. Por outro lado, também pode decidir pelo não tratamento de determinado risco ${ }^{(102)}$.

A comunicação do risco é fundamental para sensibilizar os funcionários, socializar e implantar as ações em todas as unidades (ou todas as áreas) envolvidas. A divulgação das ações permite verificar se houve progresso na 
implantação das ações a partir de uma comparação com o diagnóstico da situação inicial $^{(102)}$.

\subsection{Segurança do procedimento cirúrgico}

\subsubsection{Epidemiologia do evento adverso cirúrgico}

De acordo com a OMS, a cirurgia tem sido um componente essencial do cuidado à saúde em todo o mundo há mais de um século(9).

Com a inversão na pirâmide demográfica, há alteração significativa no perfil de doenças e problemas de saúde pública ${ }^{(1)}$. Entra na agenda sanitária, com importante impacto, o cuidado e a assistência voltados para a incidência de doenças do envelhecimento, tais como, o diabetes, as doenças cardiovasculares, a obesidade, o câncer, dentre outras ${ }^{(142)}$. O tratamento de algumas delas invariavelmente leva ao tratamento cirúrgico e com isso à relação direta com o aumento dos riscos derivados desse tipo de assistência ${ }^{(27)}$, podendo ocasionar EA.

Assim, o grande número de procedimentos cirúrgicos anualmente realizados nos serviços de saúde pode favorecer a ocorrência de falhas e EA cirúrgicos, o que vem se tornando preocupação mundial de saúde pública ${ }^{(9)}$. Estima-se, a partir de dados de 56 países, que cerca de 234 milhões de cirurgias de maior porte sejam realizadas anualmente, o que representa, aproximadamente, uma cirurgia para cada 25 pessoas por ano ${ }^{(9,143)}$. As cirurgias de maior porte incluem qualquer procedimento realizado na sala operatória envolvendo incisão, excisão, manipulação ou sutura de tecido que geralmente requer anestesiologia geral ou regional, ou sedação profunda para controlar a dor ${ }^{(134,143)}$.

No Brasil, em 2010, foram realizados 4.056 .250 procedimentos cirúrgicos, representando um valor total de $\mathrm{R} \$ 4$ 4.987.999.594,72. Em 2011 foram feitos 4.123.794 procedimentos, totalizando $\mathrm{R} \$ 5.385 .823 .770,00^{(144)}$.

Estudos mostram que a letalidade de pacientes cirúrgicos em serviços de saúde localizados em países desenvolvidos varia entre $0,4 \%$ e $0,8 \%$ e trabalhos realizados em países em desenvolvimento estimam que a letalidade seja de 5 a $10 \%$ em pacientes submetidos às cirurgias de maior porte ${ }^{(9)}$. 
Apesar de o ato cirúrgico estar relacionado com riscos, cujas complicações cirúrgicas respondem a uma grande proporção dos óbitos e danos nos serviços de saúde, estes podem ser prevenidos ${ }^{(9)}$. A definição da responsabilidade ética, penal, civil e administrativa permite subdividir os EA em evitáveis e não evitáveis. Os EA não evitáveis são complicações que não podem ser prevenidas frente ao atual estado de conhecimento; por sua vez, os EA evitáveis são resultantes da má atenção em saúde e podem ser prevenidos com o atual estado de conhecimento ${ }^{(145)}$. Ressalta-se que os EA de maior interesse à saúde pública são os evitáveis, suscetíveis a intervenções dirigidas à sua prevenção(20).

A estimativa relacionada aos EA gira em torno de $3 \%-16 \%$ de todos os pacientes hospitalizados, e mais da metade desses eventos são reconhecidamente evitáveis. Assumindo uma taxa de EA perioperatórios de $3 \%$ e uma taxa de mortalidade de $0,5 \%$ no mundo, quase sete milhões de pacientes cirúrgicos podem sofrer complicações significativas a cada ano, um milhão dos quais morreria durante ou imediatamente após a cirurgia ${ }^{(9,134)}$.

Mais especificamente, cerca de $48 \%$ de todos EA ocorrem em blocos operatórios e estão relacionados com a cirurgia e/ou anestesiologia, afetando $2 \%$ de todas as internações hospitalares. Em 30 a $50 \%$ dos casos, tais eventos são reconhecidamente evitáveis ${ }^{(21,}{ }^{146)}$. Estes eventos apresentam tipologias e gravidades diversas, variando desde a simples perturbação do fluxo operatório, sem consequências para o paciente, até às mais graves complicações, com produção de danos irreversíveis ou mesmo a morte, abrangendo a atividade cirúrgica propriamente dita, a atividade anestésica e as complicações diretas de ambas ${ }^{(96)}$.

Portanto, além dos danos e sofrimento desnecessário, a ocorrência de EA nos serviços de saúde representa um problema financeiro. O custo financeiro dos EA, em termos de tratamento adicional e de prolongamento da hospitalização, é considerável e muito maior que os custos do litígio. Um dos achados mais constantes das revisões de prontuários é que, em média, um paciente que é vítima de EA permanece no hospital durante um período que varia de 6 a 8 dias, tornando os custos surpreendentemente altos ${ }^{(47)}$ e exigindo medidas de prevenção e controle destes eventos.

Diante do preocupante quadro mundial de insegurança, a melhoria dos processos de cuidado com foco na segurança passou a ser o principal componente da qualidade nos serviços de saúde. 
O movimento em prol da segurança do paciente avançou a partir da década de 80 e vários países desenvolveram estudos na tentativa de demonstrar a incidência dos EA. O método mais utilizado consiste na revisão retrospectiva de prontuários, sendo que a variabilidade dos resultados encontrados depende do objetivo do estudo, dos tipos de serviços selecionados para a realização do estudo e do tipo de população ${ }^{(54)}$.

Um estudo interdisciplinar realizado em hospitais no estado de New York encontrou-se uma taxa de incidência de EA de 3,7\%, sendo que 27,6\% estavam associados à negligência médica. Em relação à magnitude do dano, 70,5\% dos pacientes afetados desenvolveram incapacidades temporais, enquanto $2,6 \%$ apresentaram incapacidade permanente e $13,6 \%$ foram a óbito ${ }^{(14)}$.

Uma alta taxa de incidência de EA de 16,6\% foi encontrada no estudo realizado na Austrália em 1995, denominado Quality in Australian Health Care Study $(\mathrm{QAHCS})^{(147)}$. Taxas intermediárias de EA foram encontradas nos trabalhos realizados por Vincent et al., no período 1999-2000, em Londres, que mostraram taxa de incidência de EA de $10,8 \%{ }^{(148)}$, na pesquisa de Davis et al., realizada em 1995, na Nova Zelândia, com taxa de $12,9 \%{ }^{(149)}$ e no estudo realizado por Baker et al., no Canadá, em 2000, com taxa de 7,5\% ${ }^{(150)}$. A menor taxa de incidência de EA, 2,9\%, foi encontrada nos estudos efetuados em 1992 nos estados de Utah e Colorado, nos EUA ${ }^{(151)}$.

Os resultados de um estudo piloto realizado em três hospitais públicos da Região Administrativa de Lisboa, Portugal, mostraram taxa de incidência de EA de $11,1 \%$ e cerca de $50 \%$ dos EA foram considerados evitáveis ${ }^{(152)}$.

Diversos estudos mostram, ainda, a incidência de EA cirúrgicos. No trabalho realizado por Gawande et al., foi calculada a taxa de incidência de 1,9\% para o total de pacientes internados. Dentre os pacientes cirúrgicos e nos casos de parto, a taxa de incidência de EA cirúrgicos foi de 3,0\%, sendo $54 \%$ considerados evitáveis. Foi estimado que $5,6 \%$ dos EA cirúrgicos resultaram em óbito ${ }^{(16,20)}$.

A incidência acumulada de EA em um estudo de coorte prospectivo realizado na Colômbia foi reportada em 4,6\%, sendo as complicações técnicas intraoperatórias as mais frequentes $(27,6 \%)^{(18)}$.

Apesar da relevância dos EA cirúrgicos, pelo dano à saúde dos pacientes e pelos custos gerados pela assistência insegura, poucos estudos relacionados aos EA cirúrgicos têm sido realizados no Brasil. 
No estudo de avaliação de EA em hospitais brasileiros, a incidência de EA foi estimada em $7,6 \%$, sendo que $66,7 \%$ dos casos foram considerados evitáveis. A origem mais frequente de EA no estudo foi o procedimento cirúrgico, em $36,2 \%$ do total de casos. O Centro Cirúrgico foi considerado o segundo local de maior frequência de $E A$, onde ocorreram $34,7 \%$ dos casos $^{(153)}$.

Em um estudo de coorte retrospectivo realizado em hospitais do Rio de Janeiro, com o objetivo de avaliar a incidência de EA cirúrgicos utilizando-se análise descritiva de dados secundários do banco de dados gerado por programa computacional de EA, a incidência de pacientes com EA cirúrgicos foi 3,5\% (38 de 1.103 pacientes) e a proporção de pacientes submetidos à cirurgia entre os com EA cirúrgicos, 5,9\% (38 em 643). A proporção de pacientes com EA cirúrgicos evitáveis foi $65,8 \%$ (25 de 38 pacientes) e cerca de 1 em 5 resultaram em incapacidade permanente ou óbito ${ }^{(20)}$.

Cabe destacar que muitos EA - aproximadamente $70 \%$ na maioria dos estudos - não têm consequências importantes para o paciente, e os efeitos são mais econômicos (que resultam em gastos relacionados a tempo e recursos) do que clínicos. Outros, contudo, a exemplo da ISC grave, tem importantes consequências para os pacientes, tanto em termos de sofrimento desnecessário como no que se refere ao prolongamento do tempo de internação hospitalar ${ }^{(47)}$.

\subsubsection{Epidemiologia da Infecção do Sítio Cirúrgico}

O MS do Brasil, em consonância com outros órgãos oficiais internacionais, define a infecção hospitalar (mais recentemente denominada como IRAS) como "aquela adquirida após a admissão do paciente e que se manifesta durante a internação ou após a alta, quando puder ser relacionada com a internação ou procedimentos hospitalares ${ }^{(113),}$.

Atualmente, o problema das IRAS tem recebido maior atenção pública, especialmente aquelas causadas por micro-organismos resistentes. A cada ano 1,7 milhões de pacientes hospitalizados adquirem uma infecção, das quais 126.000 são causadas por estafilococos resistentes, e 99.000 são fatais ${ }^{(154)}$. Sabe-se, no entanto, que a maioria das IRAS pode ser evitável com o uso das melhores práticas atuais em serviços de saúde ${ }^{(55)}$. 
A ISC constitui o segundo mais frequente EA que ocorre nos pacientes hospitalizados $^{(14,155)}$. Ainda, este tipo de infecção persiste entre as quatro principais topografias de IRAS, além das infecções da corrente sanguínea, do trato urinário e da pneumonia.

A ISC decorre da complicação de uma cirurgia, comprometendo tecidos, órgãos ou cavidade manipulada, e podendo ser diagnosticada até 30 dias após realização do procedimento cirúrgico, ou até um ano no caso de implantes/próteses ${ }^{(65)}$. Ocorre geralmente entre $07^{\circ}$ ao $14^{\circ}$ dia de pós-alta hospitalar. Constitui um problema sério, de alto custo e tem um grande impacto sobre a mortalidade, sendo que $30 \%$ a $40 \%$ dos óbitos no período pós-operatório são causados por este tipo de infecção(156).

Recentemente, os CDC estabeleceram mudanças no período de observação pós-operatória de vários procedimentos cirúrgicos com diagnóstico de ISC incisional profunda e órgão/cavidade, recomendando vigilância por até 90 dias. Os procedimentos cirúrgicos envolvem: cirurgias de mama; cirurgias cardíacas; revascularização do miocárdio; craniotomia; cirurgias videolaparoscópicas (herniorrafia, colecistectomia, apendicectomia), artrodese de coluna, osteossíntese, prótese de joelho, prótese de quadril, implante de marcapasso definitivo, cirurgia de bypass vascular periférica e derivação ventrículo-peritoneal ${ }^{(157)}$.

Os pacientes que desenvolvem ISC têm duas vezes mais chance de ir a óbito, duas vezes mais chance de prolongamento do tempo de internação na UTI e cinco vezes mais chance de serem readmitidos após a alta. Ademais, a ISC leva a um aumento da duração da internação hospitalar de 4 a 7 dias $^{(9)}$.

Nos EUA, ocorrem pelo menos 780.000 ISC a cada ano ${ }^{(9)}$. Tais infecções resultaram em 3,7 milhões de dias hospitalares excedidos e em US\$1,6-3 bilhões em excesso de custos hospitalares por ano ${ }^{(156)}$.

As ISC contribuem para $16 \%$ de todas as IRAS ${ }^{(158,159)}$. No entanto, entre os pacientes cirúrgicos, a ISC é a que apresenta a maior incidência, representando $38 \%$ de todas as infecções nesta população ${ }^{(160)}$. Dois terços das ISC são incisionais e um terço confinado ao espaço orgânico ${ }^{(161)}$.

Um estudo realizado sobre 30.195 altas hospitalares em Nova lorque indicou que sobre o total dos EA detectados, 13,3\% foi considerada ISC (sendo que destas, $12,5 \%$ ocorreram devido à negligência), 12,9\% estava relacionada a complicações 
na técnica cirúrgica e 10,6\% foram consideradas como complicações pós-cirúrgicas $\operatorname{tardias}^{(155)}$.

Um estudo de prevalência realizado em 2006 em hospitais do Reino Unido mostrou que as ISC foram responsáveis por 14\% do total das IRAS e que, em média, $5 \%$ dos pacientes que se submeteram a cirurgias poderiam desenvolver ISC(162). Mesmo assim, acredita-se que esses dados possam estar subestimados, devido à falta de acompanhamento dessas infecções após a alta hospitalar do paciente ${ }^{(162,163)}$.

No Brasil, a ISC é considerada uma das principais IRAS, ocupando a terceira posição entre todas as infecções em serviços de saúde e compreendendo 14\% a $16 \%$ daquelas encontradas em pacientes hospitalizados. Estudo nacional realizado pelo MS no ano de 1999 encontrou a taxa de ISC de $11 \%$ do total de procedimentos cirúrgicos analisados ${ }^{(135)}$.

Foi demonstrado que a colonização (em particular, colonização das narinas por S. aureus), diabetes, tabagismo, uso de corticóides sistêmicos, obesidade (índice de massa corporal $\geq 30 \mathrm{~kg} / \mathrm{m} 2$ ), extremos de idade, estado nutricional debilitado, transfusão sanguínea pré-operatória e internação pré-operatória prolongada têm aumentado o risco de $\operatorname{ISC}^{(9,158,164)}$.

Com base em estudos que demonstraram a positividade de culturas do intraoperatório como um preditor de infecção, as cirurgias são classicamente categorizadas segundo o seu potencial de contaminação, com o objetivo de estimar a probabilidade da ocorrência de ISC, em $^{(113,118)}$ : 1) Cirurgias Limpas - aquelas realizadas em tecidos estéreis ou passíveis de descontaminação, na ausência de processo infeccioso ou inflamatório local ou falhas técnicas grosseiras. Cirurgias eletivas com cicatrização de primeira intenção e sem drenagem ou com drenagem fechada, que não abrem víscera oca ou mucosa; 2) Cirurgias Potencialmente Contaminadas - realizadas nos tratos respiratório, genital, gastrintestinal ou urinário em condições controladas e sem contaminação acidental; 3) Cirurgias Contaminadas - feridas abertas acidentalmente ou cirurgias com quebra importante de técnica asséptica ou grande contaminação do trato gastrintestinal. Cirurgias que entram no trato urinário com urina infecciosa ou trato biliar com bile infectada ou cirurgias onde é achado tecido inflamatório agudo não purulento e 4) Cirurgias Infectadas - lesões traumáticas antigas com tecido desvitalizado, corpo estranho, contaminação fecalóide, quando há perfuração inesperada de víscera. 
A principal fonte de micro-organismos é a inoculação direta da microbiota da pele, mucosas ou do sítio manipulado. Outras fontes envolvem a equipe cirúrgica, os materiais e equipamentos para saúde e o ambiente ${ }^{(118)}$.

Os micro-organismos isolados de infecções diferem, dependendo principalmente do tipo de procedimento cirúrgico. Em cirurgias limpas que não atingem os tratos gastrointestinal, ginecológico e as vias respiratórias, o $S$. aureus do ambiente exógeno ou da microbiota da pele do paciente é a causa habitual de infecção. Em outras categorias de procedimentos cirúrgicos, envolvendo as cirurgias potencialmente contaminadas, contaminadas e infectadas, a microbiota aeróbica e anaeróbica polimicrobiana que se assemelham muito à microflora endógena do órgão ressecado cirurgicamente são frequentemente os patógenos mais isolados ${ }^{(165)}$. Nos últimos anos nota-se a presença de micro-organismos multirresistentes como causadores de ISC $^{(118)}$.

Em março de 2009, a ANVISA publicou um documento intitulado "Critérios Nacionais de Infecções relacionadas à assistência à saúde" com o objetivo de sistematizar a vigilância das ISC, padronizando as definições para os procedimentos e estabelecendo critérios para o diagnóstico de ISC, favorecendo a harmonização do por todos os serviços de saúde do país ${ }^{(135)}$. De acordo com o referido documento nacional, o qual se encontra atualmente sob revisão, as ISC são classificadas em incisional superficial, profunda e de órgãos e cavidades. A ISC incisional superficial envolve apenas pele e tecido subcutâneo, ocorrendo até um mês após o procedimento. A infecção incisional profunda envolve tecidos moles profundos à incisão (como fáscia e/ou músculos) e ocorre nos primeiros 30 dias após a cirurgia ou até um ano, se houver colocação de prótese. A infecção órgão/cavidade envolve qualquer órgão ou cavidade que tenha sido aberta ou manipulada durante a cirurgia, ocorre nos primeiros 30 dias após a cirurgia ou até um ano, se houver colocação de prótese $^{(135)}$.

A infecção é uma complicação inerente ao ato cirúrgico e se faz necessário um grande esforço para mantê-la sob controle e em níveis aceitáveis, dentro dos padrões de uma determinada instituição, de tal modo que a análise de seus índices constitui, atualmente, em um parâmetro de controle de qualidade do serviço prestado por um hospital ${ }^{(166)}$.

As principais medidas preventivas para reduzir as ISC incluem ${ }^{(9)}$ : avaliação completa de todos os pacientes cirúrgicos no pré-operatório; redução da 
hospitalização pré-operatória; avaliação e tratamento de infecções metastáticas; redução de peso (para pacientes obesos); interrupção do uso de tabaco; controle da hiperglicemia; restauração das defesas do hospedeiro; diminuição da contaminação bacteriana endógena; uso de métodos apropriados para remoção de pelos; administração apropriada e oportuna de antimicrobianos profiláticos; confirmação de assepsia de instrumentais e antissepsia correta da pele; manutenção de técnica cirúrgica correta e de minimização do trauma tecidual; manutenção de normotermia durante a cirurgia; diminuição do tempo operatório e vigilância efetiva do sítio cirúrgico.

Para a identificação precisa das ISC é necessária a instituição de um programa ativo de vigilância epidemiológica nos serviços de saúde. A vigilância das ISC é a observação ativa, sistemática e contínua de sua ocorrência e de sua distribuição entre pacientes, hospitalizados ou não, e dos eventos e condições que afetam o risco de sua ocorrência, com vistas à execução oportuna das ações de prevenção e controle ${ }^{(113)}$. Cada serviço de saúde deve escolher os procedimentos para vigilância a partir dos critérios para o cálculo das taxas de incidência, envolvendo a frequência da realização na unidade, procedimentos limpos de grande porte ou complexidade, procedimentos limpos com uso de prótese e/ou outros procedimentos relevantes para a instituição ${ }^{(135)}$.

Para os pacientes internados e ambulatoriais, a observação direta do sítio cirúrgico pelo cirurgião, por um enfermeiro capacitado ou pela $\mathrm{CCIH}$ e a detecção indireta pela $\mathrm{CClH}$, relacionando os exames de laboratório à confirmação do caso com os cirurgiões consistem nas duas das estratégias mais comuns para a identificação de $\operatorname{ISC}^{(9,160)}$.

As ISC são frequentemente detectadas após a alta hospitalar do paciente. Os métodos de vigilância pós-alta incluem exame direto das feridas operatórias dos pacientes durante o retorno, revisão dos registros médicos e pesquisas por telefone ou correio eletrônico com os pacientes e cirurgiões ${ }^{(134)}$. O método escolhido deve estar em conformidade com as diversidades de cirurgias, recursos humanos e necessidades de informações nos serviços de saúde.

Como a permanência do paciente cirúrgico no hospital é frequentemente muito curta, a vigilância pós-alta tem se tornado cada vez mais importante para a obtenção de taxas precisas de $I S C^{(9)}$, uma vez que a alta precoce pode impedir a identificação das ISC que se manifestam nos primeiros dias do período pós- 
operatório. Estudos que restringem o seguimento do paciente cirúrgico durante o período de internação tendem a apresentar menores taxas de ISC, quando comparados àqueles que incluem o seguimento depois da alta, o que implica num adicional esforço para o sistema de vigilância hospitalar ${ }^{(167)}$.

De acordo com pesquisa publicada sobre vigilância em ISC, $82 \%$ destas infecções foram evidenciadas até o $7^{\circ}$ dia de pós-alta e $11 \%$ do $8^{\circ}$ ao $14^{\circ}$ dia de pós-alta, sendo que 100\% das infecções ocorreram durante o período de 30 dias de pós-alta hospitalar ${ }^{(168,169)}$.

Um estudo prospectivo e descritivo realizado em um hospital universitário, em agosto de 2001 a março de 2002, envolveu 357 pacientes submetidos à cirurgia do aparelho digestivo, sendo um dos objetivos do trabalho, determinar a incidência de ISC nesta especialidade, durante a internação e após a alta hospitalar. Foram notificadas 64 ISC, sendo 16 na internação e 48 pós-alta, mostrando incidência de $4,5 \%$ e $13,9 \%$, respectivamente. A taxa global da ISC foi de $18,0 \%$. O estudo concluiu que, caso a vigilância pós-alta não fosse realizada, a taxa global da ISC seria fortemente subnotificada ${ }^{(170)}$.

Bilimoria et al. ${ }^{(171)}$ realizaram um estudo envolvendo 330 pacientes atendidos em 181 hospitais participantes do Programa Nacional de Melhoria da Qualidade em Cirurgia do Colégio Americano de Cirurgiões, no período 2006 - 2007, cujo o objetivo era determinar a frequência das complicações pós-alta e óbitos bem como definir a continuidade ou não da posição do hospital frente aos resultados dos pacientes pósalta. As complicações pós-alta representaram 32,9\% de todas as complicações, sendo a mais frequente a ISC $(66,0 \%)$, seguida de embolia pulmonar $(42,2 \%)$, infecção do trato urinário $(39,4 \%)$ e trombose venosa profunda (34,5\%). Dos 5.827 óbitos no pós-operatório, 23,6\% ocorreram após a alta. De acordo com os autores, a vigilância pós-alta deve ser perseguida, pois programas de melhoria da qualidade que não consideram os resultados pós-alta podem oferecer informações incompletas para serviços de saúde, pagadoras, provedores e pacientes ${ }^{(171)}$.

Em um estudo realizado por Ferraz et al. ${ }^{(166)}$ foram avaliadas as infecções pós-cirúrgicas dentre 42.274 cirurgias realizadas no Serviço de Cirurgia Geral do Hospital das Clínicas da Universidade Federal de Pernambuco (UFPE), no período de janeiro de 1977 a dezembro de 1999. Os dados foram obtidos por meio de um sistema de busca ativa de infecção e de um sistema de vigilância epidemiológica de seguimento pós-operatório, no ambulatório de egressos. A taxa de infecção de ISC 
passou de índices em torno de 15-20\% para 7,7\% e a taxa de infecção de ISC em cirurgia limpa de 12,8 \% foi reduzida para 3,4\%. A redução destas taxas repercutiu na mortalidade, a qual foi reduzida de $2,8 \%$ para $0,9 \%$. As principais medidas de controle instituídas durante este período incluíram: diagnóstico preciso dos casos de infecção; ênfase na higiene corporal do paciente; suspensão de cirurgias eletivas em pacientes com infecção comunitária; redução da internação pré-operatória; tricotomia restrita ao local da incisão e realizada uma hora antes da cirurgia; antissepsia do campo operatório com PVPI degermante; curativo da ferida operatória mantido por apenas 24 horas; técnica cirúrgica apropriada e delicada e rigoroso controle da prescrição de antimicrobianos ${ }^{(166)}$.

\subsubsection{Epidemiologia do Erro Humano}

$\mathrm{Na}$ área da saúde, erro é definido como "uma falha em executar um plano de ação como pretendido ou como a aplicação de um plano incorreto". Os erros podem ocorrer por se fazer a coisa errada - erro de ação ou por falhar em fazer a coisa certa - erro de omissão, na fase de planejamento ou na de execução do cuidado ${ }^{(172)}$.

Nos serviços de saúde também pode ocorrer o incidente, cuja definição é "um evento ou circunstância que poderia ter resultado, ou resultou, em dano desnecessário ao paciente". Os incidentes classificam-se como ${ }^{(48,172)}$ : quase erro ou near miss - incidente que não atingiu o paciente (por exemplo: uma unidade de sangue é conectada ao paciente de forma errada, mas o erro é detectado antes do início da transfusão); incidente sem dano - evento que atingiu o paciente, mas não causou dano discernível (por exemplo: a unidade de sangue acabou sendo transfundida para o paciente, mas não houve reação); incidente com dano ou EA incidente que resulta em dano à saúde (por exemplo: é feita infusão da unidade errada de sangue no paciente e este vai a óbito por reação hemolítica).

A origem desses erros pode ser diferenciada em causas latentes ou sistêmicas e ativa ou individual, sendo que componentes de ambas as categorias estão tradicionalmente envolvidos quando o dano alcança o paciente. Essas causas abrangem decisões de gestão e podem permanecer não reconhecidas por um longo tempo. Os elementos latentes podem ser relacionados à estrutura ambiental ultrapassada, ausência de padrões clínicos e operacionais e baixa densidade de 
pessoal; elementos ativos podem envolver a atuação em um sistema complexo, dificuldades de comunicação, viés de confirmação, de erro de fixação e falha de memória. Essas causas têm um impacto direto no atendimento ao paciente e pode resultar em dano imediato aos pacientes ${ }^{(173)}$.

De acordo com o inciso II, Art. 4ํㅡㄹ da Portaria ํ․ 529/GM/MS/2013 ${ }^{(75)}$, dano é o comprometimento da estrutura ou função do corpo e/ou qualquer efeito dele oriundo, incluindo-se doenças, lesão, sofrimento, morte, incapacidade ou disfunção, podendo, assim, ser físico, social ou psicológico.

Duas abordagens podem ser utilizadas para visualizar o problema do erro humano: a abordagem tradicional e a abordagem sistêmica ${ }^{(174)}$. A abordagem tradicional dos erros tem sido a de culpar o profissional que oferece assistência direta ao paciente, ou seja, a abordagem está centrada na pessoa que prestou o cuidado ao paciente ${ }^{(10,174)}$. Por outro lado, a abordagem sistêmica tem como premissa básica a questão da falibilidade humana e que os erros podem ocorrer até mesmo nas melhores instituições ${ }^{(174)}$.

Segundo esta teoria, a segurança em ambientes complexos (por exemplo, na sala operatória) conta com várias defesas do sistema, envolvendo a estrutura organizacional, os protocolos, a capacitação dos profissionais e a qualidade dos equipamentos e das tecnologias. Quando as barreiras falham, um incidente pode acontecer. $\mathrm{Na}$ abordagem sistêmica, as condições em que os indivíduos trabalham são cuidadosamente investigadas, e esforços são investidos na construção de fortes defesas para evitar erros humanos ou diminuir seus efeitos ${ }^{(175)}$.

O movimento moderno de segurança do paciente substitui o jogo da "culpa e da vergonha" pela abordagem sistêmica, um reconhecimento de que a maioria dos erros é cometida por profissionais competentes, cuidadosos e atenciosos. Esse paradigma reconhece a condição humana, ou seja, que os humanos erram, e conclui que a segurança depende da criação de sistemas que antecipem erros e que os previnam ou os captem antes que eles causem danos ${ }^{(10)}$.

O Modelo do Queijo Suíço proposto por James Reason ${ }^{(174)}$ (Figura 1) pode ser uma alternativa para nortear as ações dos serviços de saúde. O modelo mostra a abordagem sistêmica de gerenciamento de erro. Foi elaborado a partir de inúmeras investigações sobre acidentes em áreas como aviação comercial e energia nuclear e enfatiza que, em organizações complexas, um erro em uma única "ponta" (a pessoa na cabine de controle na usina nuclear, ou o cirurgião que faz a incisão) 
raramente é suficiente para causar danos. Em vez disso, tais erros devem penetrar várias camadas incompletas de proteção (camadas do queijo suíço) para causar um resultado devastador ${ }^{(10,174)}$. Quando não há camadas (barreiras), os buracos do queijo se comunicam. Estes buracos abrem e fecham, aleatoriamente, e quando por acaso todos os buracos se alinham, há risco de atingir o paciente, causando-lhe $\operatorname{danos}^{(176)}$.

Figura 1. Modelo do queijo suíço proposto por Reason.

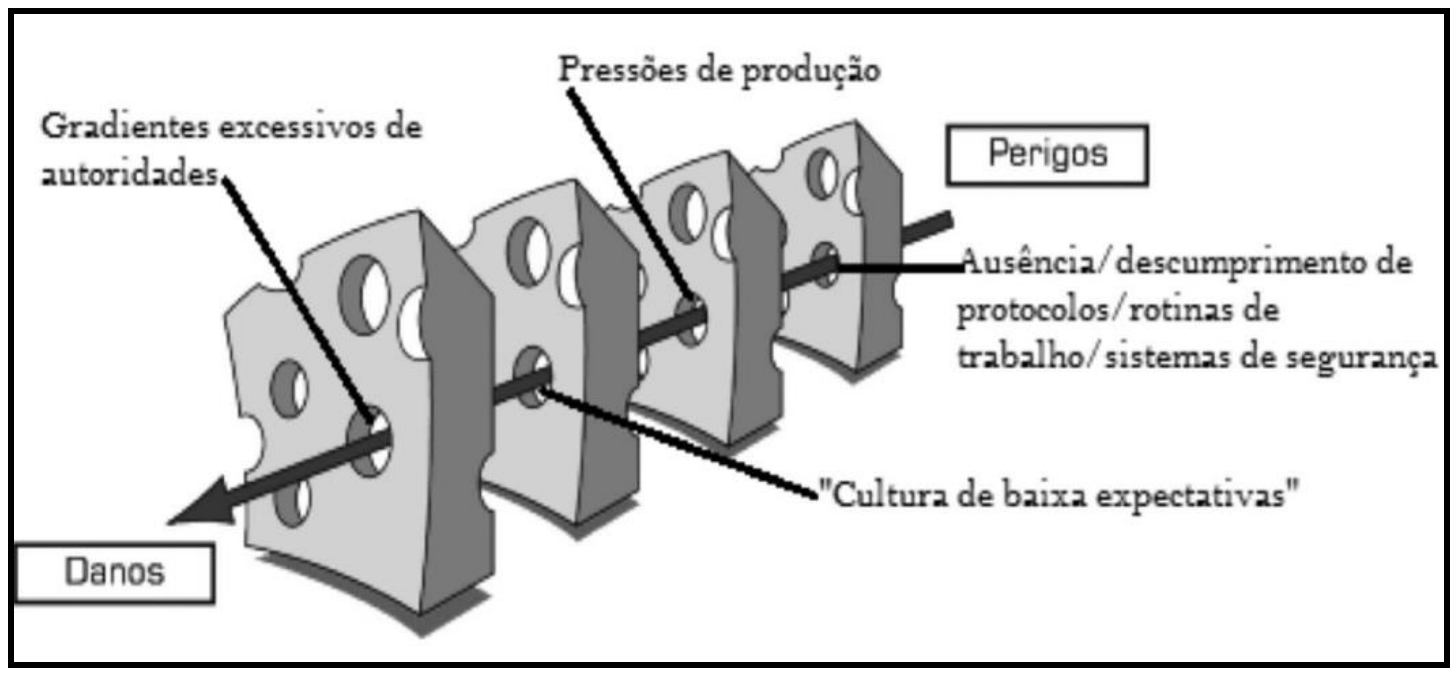

Fonte: Adaptado de: Wachter RM; 2013. p.22(10).

Para se criar sistemas mais seguros, diversas estratégias devem ser empregadas, incluindo simplificação, padronização, usar repetições, melhoria do trabalho em equipe e comunicação e aprendizado com os erros do passado(10).

\subsubsection{Fatores Humanos e Fatores de Equipe}

O termo "fatores humanos" está muito envolvido com a assistência à saúde e atualmente, está se tornando mais familiar, apesar de que há uma década a maioria das pessoas nunca tinha ouvido falar deste termo. Ainda, o termo foi derivado da aviação e surgiu a partir da necessidade de resolução de problemas relacionados ao erro, trabalho em equipe e comunicação ${ }^{(177)}$. 
Todos os sistemas humanos, e os mais complexos ainda mais, estão sujeitos a erros. É uma consequência da sua natureza, seja na saúde, nos negócios ou nos transportes. Não há uma causa única para um incidente, existem, sim, fatores humanos (atos eivados de erro), fatores sistêmicos ou organizacionais que propiciam as falhas humanas, e um conjunto de condições ambienciais latentes e de falhas que promovem a ocorrência do erro. Assim, $60 \%$ das falhas têm origem humana e só $30 \%$ são de sistemas, mas as falhas humanas são propiciadas por um defeituoso sistema ${ }^{(178)}$.

Os fatores humanos envolvem características humanas individuais que, ao interagir com elementos do ambiente, da organização, dos equipamentos para a saúde e da tarefa, influenciam os comportamentos de profissionais a respeito da segurança nos serviços de saúde. Diferentes componentes estão englobados nos fatores humanos, a saber ${ }^{(47,96)}$ : 1) indivíduo - inclui sua competência, capacidades técnicas, personalidade, atitude e percepção de risco; 2) organização - envolve o padrão de trabalho, a cultura no local de trabalho e a comunicação e a liderança, especialmente das equipes; 3) tarefa - inclui a natureza do trabalho, a carga de trabalho, o ambiente, o desenho de equipamentos e de procedimentos.

Por sua vez, os fatores de equipe envolvem os componentes: 1) liderança correta e gradientes adequados de hierarquia - a liderança deve ser colaborativa, sendo o líder um facilitador e não um ditador, e a hierarquia dominantemente aplanada, baseada em relações de projeto e colaboração de tarefas, mais do que em comandos formais; 2) boa comunicação - deve ser fácil e efetiva entre os membros e idealmente escrita e sempre com dupla confirmação; 3) distribuição de tarefas - deve haver prioridade de tarefas para que todos da equipe conheçam a sequência de trabalho; 4) supervisão adequada de juniores - envolve a monitorização do trabalho de cada membro da equipe, sem intuitos críticos, mas para não deixar passar falhas; 5) capacitação da equipe e para situações de crise engloba a aprendizagem conjunta e uso de checklists e guias e, se possível, com a utilização de cenários reais ou simuladores; 6) adoção de instruções (briefings) e de revisões (debriefings) - envolve a comunicação estruturada antes e depois de cada procedimento cirúrgico, especialmente no bloco operatório, para planejamento, análise e aperfeiçoamento da tarefa; 7) cultura ou ambiente local de antecipação e de segurança - envolve o relato não culpabilizado de erros e, sim, a aprendizagem contínua com a trajetória dos erros ${ }^{(96,146)}$. 
Os componentes fundamentais das habilidades não técnicas envolvem: 1) tomada de decisões - requer uma correta percepção de dados, o conhecimento e a capacidade de decisão partilhada; 2) consciência situacional - implica a capacidade de antecipar cenários e é dependente do treino em equipe e da cultura local; 3) comunicação - deve implicar bilateralidade, estruturação e segurança; 4) colaboração em equipe; 5) lidar com a fadiga; 6) gestão de condições de estresse e 5) liderança ${ }^{(96)}$.

Atualmente, a preocupação com a prática cirúrgica está voltada para as habilidades técnicas e aperfeiçoamento tecnológico, sendo que pouca atenção tem sido dada aos benefícios das habilidades não técnicas ${ }^{(179)}$.

Sabe-se, no entanto, que a maioria dos erros que podem ocorrer durante 0 procedimento cirúrgico pode ser atribuída às falhas nas habilidades não técnicas que a LVSC visa a melhorar, tais como a percepção da situação, a tomada de decisões, a comunicação entre a equipe cirúrgica e a liderança ${ }^{(179)}$.

Diante do exposto, a complexidade da maioria dos procedimentos cirúrgicos requer uma equipe cirúrgica bem integrada para evitar EA nos serviços de saúde ${ }^{(67)}$.

\subsubsection{A Sala Operatória}

A atividade na sala operatória é uma prática complexa, interdisciplinar, com forte dependência da atuação individual, exercida no seio de organizações complexas, onde os fatores de equipe e os fatores do sistema desempenham um papel fundamental, numa constante interação entre humanos, máquinas e equipamentos. A atividade envolve tarefas complexas, plenas de variação e de incerteza, exercida em condições ambienciais dominadas pela pressão e pelo estresse $^{(96)}$.

A moderna sala operatória consiste em um sistema complexo adaptativo o qual envolvem os agentes: 1) heterogêneos, com tomada de decisões interdependentes; 2) que interagem frequentemente uns com os outros; e 3) que desenvolvem uma característica chamada de emergência a qual surge quando o todo, na verdade, apresenta um melhor desempenho do que cada parte individual $^{(180)}$. Ou seja, é por meio da aprendizagem e da interdependência dos 
agentes heterogêneos que um maior e melhor sistema de funcionamento é criado. Segundo Gibbs $^{(181)}$, quem já trabalhou em uma sala operatória altamente funcionante ao longo do tempo pode entender como essa entidade pode evoluir e compreender quão raro e difícil pode ser este alcance. De fato, a sala operatória é a unidade dos hospitais onde os EA que afetam pacientes cirúrgicos ocorrem mais comumente ${ }^{(24)}$, entre $47,7 \%{ }^{(14)}$ e $50,3 \%{ }^{(147)}$. Pelo menos metade desses eventos pode ser prevenida ${ }^{(9)}$, por meio de retorno corretivo, recuperação de erros e melhoria das habilidades da equipe ${ }^{(25)}$. A sala operatória é também considerada como o local clássico de objetivos conflitantes entre as equipes cirúrgicas e os demais profissionais, bem como a instituição ${ }^{(25)}$.

O fato de que as pessoas têm de trabalhar em uma equipe que lida com casos difíceis, e o fato desta equipe ser formada por pessoas com forte personalidade e que trabalham em um espaço limitado, cria uma atmosfera especial no ambiente da sala operatória. Os cirurgiões, os anestesiologistas e a equipe de enfermagem dispõem de suas próprias experiências e responsabilidades profissionais. Por isso, eles têm as suas próprias opiniões sobre como lidar com um caso e como resolver um problema existente. Existem distinções na metodologia de formação, a estima social entre os especialistas é diferente e também há diferenças de personalidades entre as pessoas envolvidas. Existem também diferenças entre o pessoal (médicos contra enfermeiros) na percepção sobre o que é certo ou errado, ou bom ou mau. Todos estes fatores provavelmente podem gerar conflitos na sala operatória. Tais conflitos são chamados "conflitos de tarefa" (quem, o quê, quando e porquê). Além disso, os membros médicos da equipe frequentemente se esquecem de que outros profissionais (enfermeiros, técnicos, etc) também são membros da equipe e que devem desempenhar o seu próprio papel ${ }^{(25,182)}$.

Desta forma, este meio complexo oferece múltiplas oportunidades para a comunicação deficiente, motivações conflitantes e erros não decorrentes de incompetências técnicas, mas de habilidades interpessoais deficientes ${ }^{(25)}$.

A atmosfera em uma sala operatória pode ser facilmente preocupante, não apenas temporariamente, mas provavelmente também de forma mais permanente. Ela depende em grande medida do comportamento humano, da inter-relação e da forma como os membros da equipe se comunicam. Profissionais que desempenham papéis modelo e os controladores de comportamento da cultura local são fatores importantes. Assim, os líderes devem se comportar corretamente como um exemplo 
de boas maneiras. Comportamentos disruptivos afetam a dinâmica da equipe e a evolução do paciente ${ }^{(25,182)}$.

\subsubsection{Fatores Associados a Resultados Cirúrgicos Desfavoráveis}

A falta de acesso à assistência cirúrgica de qualidade continua sendo um problema significativo em grande parte do mundo, apesar de as intervenções cirúrgicas serem benéficas no que diz respeito a salvar vidas e evitar incapacidades. Em locais com escassez de recursos, os seguintes fatores contribuem para a falta de segurança cirúrgica em serviços de saúde: 1) infraestrutura e equipamentos inadequados; 2) os suprimentos e a qualidade de medicamentos não confiáveis; 3) as falhas na gestão das organizações e no controle das IRAS; 4) as capacitações e treinamentos de pessoal inapropriados; e 5) o subfinanciamento severo ${ }^{(63)}$.

Apesar da reconhecida ocorrência de progressos na assistência cirúrgica nos últimos séculos, as falhas de segurança durante o ato cirúrgico podem causar danos e injúrias consideráveis ao paciente, comprometendo sua saúde, prolongando a estadia hospitalar e podendo levar à morte nos serviços de saúde ${ }^{(7,183)}$. Assim sendo, os erros ocorridos durante a prestação de cuidados cirúrgicos assumem uma particular relevância nos serviços de saúde.

A comunicação entre os membros da equipe cirúrgica é extremamente importante para melhorar a segurança do paciente ${ }^{(184)}$. A maioria dos erros que ocorrem em unidades dos serviços de saúde, especialmente nas salas operatórias, pode ser atribuível à comunicação deficiente e à falta de trabalho em equipe ${ }^{(33)}$. Em um estudo realizado por Gawande et al. ${ }^{(22)}$, a comunicação foi considerada como fator contribuinte em $43 \%$ dos erros cometidos em procedimentos cirúrgicos .

A determinação do resultado cirúrgico ainda depende da complexidade da tarefa a ser realizada no paciente (dificuldade técnica, idade, co-morbidade, tipo de doença, estádio de avanço, fatores técnicos, anatômicos ou outros fatores de dificuldade) e do desempenho individual, da equipe e da instituição. Esta última envolve fatores técnicos humanos, fatores de equipe e fatores da organização ou sistema (equipamentos, protocolos, cultura local de segurança, volume de casos, experiência, entre outros). Depende ainda das condições locais de trabalho (recursos, staff, urgência) e finalmente, depende ainda de um fator de pura variação 
aleatória - 0 acaso. $O$ efeito acaso é gerado a partir das relações interdependentes do fenômeno biológico, da interação com as pessoas e os sistemas. Todas estas determinantes atuam no bloco operatório e produzem um maior ou menor grau de ocorrência de eventos, conforme o nível ou ambiente local da cultura de segurança $^{(96)}$.

A realização de um procedimento cirúrgico constitui, de forma inevitável, em uma atividade relevantemente estressante. Os níveis excessivos de estresse intraoperatório pode comprometer tanto as habilidades técnicas ${ }^{(185,186)}$ quanto as não técnicas ${ }^{(187)}$.

Estudos relatam que o papel do cirurgião (cirurgião principal ou assistente) consiste em um potencial agente estressante, sendo que os fatores técnicos estressantes incluem a complexidade do procedimento, a presença de sangramento, e os problemas relacionados com os equipamentos ${ }^{(188)}$. Por sua vez, os fatores não técnicos estressantes incluem, distrações, pressão de tempo, estar de plantão, presença de visitantes na sala operatória, e transmissão ao vivo da cirurgia(185188).

Segundo Gawande et al. ${ }^{(22)}$, diversos fatores organizacionais e humanos contribuem para resultados cirúrgicos desfavoráveis, a saber: inexperiência do cirurgião; pequeno volume de cirurgias; excessiva carga de trabalho; fadiga; tecnologia desfavorável; insuficiente supervisão de estagiários/residentes; sistemas hospitalares inadequados; comunicação deficiente entre profissionais da equipe; turno e falhas administrativas.

Outros fatores associados com o aumento do risco de erros cirúrgicos envolvem a prestação de cuidados durante a cirurgia de emergência, mudança não planejada durante $o$ ato operatório e índice de massa corporal ${ }^{(189)}$.

Diversos problemas que aumentam a probabilidade de ocorrência de EA nos serviços de saúde e que extrapolam o procedimento cirúrgico em si são os cuidados prestados de forma inadequada nas fases pré, peri e pós operatória nos serviços de saúde ${ }^{(9)}$. Neste contexto, a LVSC é aplicável não apenas para evitar a omissão acidental de etapas críticas do procedimento cirúrgico, mas também para melhorar a comunicação na sala operatória ${ }^{(28,190)}$. 
Um fator importante relacionado à cirurgia insegura consiste no uso inapropriado de antibioticoprofilaxia. Os antimicrobianos frequentemente não são administrados no tempo correto para permitir um nível tecidual adequado no período operatório $^{(191)}$, ou seja, até 60 minutos antes da incisão cirúrgica ${ }^{(9)}$, exceto para vancomicina e fluoroquinolonas, cujos tempos apropriados para administração é até 120 minutos antes da incisão cirúrgica ${ }^{(192)}$.

As complicações cirúrgicas importantes variam entre $3 \%$ e $17 \%{ }^{(9)}$ e incluem paciente, local e procedimento errados, problemas com o equipamento de anestesiologia, a falta de disponibilidade de equipamentos necessários, perda de sangue inesperada e produtos para a saúde (por exemplo, compressas) deixados no interior dos pacientes ${ }^{(67)}$.

Os três principais incidentes de segurança evitáveis em pacientes cirúrgicos e que ocorrem dentro da sala operatória são: 1) cirurgias no local errado; 2) retenção de artigos cirúrgicos; e 3) incêndios cirúrgicos. Nos EUA, a incidência de todos três eventos afeta quase 5.000 pacientes por ano (aproximadamente 2.000 eventos de cirurgia errada, 2.000 de retenção de objetos estranhos e 500 incêndios cirúrgicos) ${ }^{(181)}$.

Um relatório disponibilizado pelo Departamento de Saúde do Estado de Minnesota dos EUA, envolvendo as notificações de instituições de saúde do período de 2007 a 2008, mostrou a ocorrência de 77 EAs cirúrgicos, dos quais: 21 (realizados no local errado do corpo); 2 (feitos no paciente errado); 16 (procedimentos errados realizados); 37 (retenção de objetos estranhos) e 01 (óbito do paciente) ${ }^{(193)}$.

Estes resultados apontam que as habilidades técnicas são necessárias, mas insuficientes para manter o alto nível de desempenho ao longo do tempo. Para o alcance e a manutenção de elevado desempenho cirúrgico, a atenção precisa também estar revestida de habilidades não técnicas, tais como, o trabalho em equipe, a liderança, a percepção da situação, a tomada de decisão, a gestão (gerenciamento) da atividade e a comunicação ${ }^{(194)}$.

Diversas intervenções para a segurança do paciente cirúrgico foram estabelecidas pelo NQF ${ }^{(195)}$, tais como: 1) criar uma cultura de segurança no cuidado à saúde; pedir a cada paciente ou seu representante legal para recontar o que foi informado durante a aplicação do consentimento informado; 2) implementar um 
protocolo padronizado para prevenir a ocorrência de procedimento no local errado ou no paciente errado; 3) avaliar cada paciente para o risco de ISC tendo em vista o planejamento do procedimento cirúrgico; e 4) implementar profilaxia cirúrgica apropriada com antimicrobiano.

\subsubsection{Lista de Verificação de Segurança}

As listas de verificações ou checklists são comumente empregadas como dispositivos ou ferramentas de avaliação mnemônica, usadas como um sistema de lembretes para ajudar a padronizar procedimentos normais, anormais ou complexos, relembrando, tarefas ou comportamentos tipicamente omitidos durante períodos de estresse ou de crise ${ }^{(196,197)}$. O benefício de se utilizar listas mnemônicas reside no fato de elas proporcionarem uma estrutura organizacional para a recuperação rápida de informações críticas e das melhores práticas atuais ${ }^{(197)}$.

Assim, as listas de verificações consistem em auxiliares cognitivos que funcionam como anotações mentais e protocolos padronizados ${ }^{(198)}$. Devido à sistematização de ações e processo de checagem de etapas, as listas de verificações são fundamentais para a concretização de tarefas de complexidade e repetição reconhecidas, auxiliando na execução correta das atividades.

A LVSC é uma ferramenta simples, eficiente, objetiva e de fácil uso que auxilia na redução de EA evitáveis, reforçando as habilidades das equipes cirúrgicas e salvando vidas. O instrumento minimiza os lapsos mentais, pois funciona como lembrete de etapas essenciais a serem seguidas no ato cirúrgico e pode reduzir erros e falhas devido a várias razões ${ }^{(67)}$ : 1) assegurando que todas as tarefas críticas sejam realizadas; 2) incentivando uma abordagem não hierárquica de trabalho em equipe; 3) melhorando a comunicação; 4) detectando incidentes que não atingiram o paciente; 5) prevenindo potenciais complicações e 6) dispondo de tecnologias para o gerenciamento de complicações previstas e imprevistas.

O desenvolvimento de listas de verificações requer uma abordagem sistemática e abrangente, especialmente quando implementadas em campos de alta intensidade de cuidados como a medicina ${ }^{(197)}$. Sabe-se que a medicina moderna tornou-se extremamente complexa, especializada e interdisciplinar, oferecendo 
esperança e curas fantásticas, mas também inadvertidamente introduzindo riscos potencialmente devastadores ${ }^{(199)}$.

$\mathrm{Na}$ área da saúde, a função mais importante de uma lista de verificação é garantir a correta execução de um determinado procedimento ou cuidado e constitui a primeira etapa da realização do procedimento padrão ${ }^{(175)}$. Listas de verificações bem desenhadas padronizam o quê, quando, como e por quem as intervenções são feitas e pode reduzir os erros em situações de rotina e de emergência ${ }^{(199)}$. Assim, essas simples conferências podem impedir o início de uma série de complicações para o paciente ${ }^{(142)}$.

As listas de verificações têm sido comumente usadas no setor da aeronáutica para a redução de falhas, facilitando o cumprimento de todas as etapas de um determinado processo e promovendo a segurança ${ }^{(200)}$. Embora tenham sido amplamente utilizadas neste setor, a utilização de listas e protocolos na área da saúde tem sido recente.

Um exemplo de aplicação de protocolo com experiência exitosa envolveu a inserção de CVC com a finalidade de reduzir as IRAS e constituiu uma das primeiras listas de verificação amplamente divulgada aos serviços e profissionais de saúde. Em uma intervenção realizada em Michigan, nos EUA, junto a 103 UTI's, que incluiu a adoção do protocolo de inserção CVC, foi observada a redução em $66 \%$ na densidade de incidência de infecção da corrente sanguínea associada a CVC ao final de 18 meses de intervenção ${ }^{(201)}$.

Vale notar que a criação de medidas padronizadas básicas nos serviços cirúrgicos constituem passos importantes para a segurança do paciente em serviços de saúde. Quando aplicadas nas salas operatórias dos serviços de saúde, as LVSC podem melhorar os resultados cirúrgicos e reduzir mortes e complicações. $O$ mecanismo para esta promoção da segurança cirúrgica envolve a atenuação dos riscos específicos de uma sequência de atividades de rotina na sala operatória, incluindo a avaliação pré-operatória, a intervenção cirúrgica e a preparação correta dos cuidados pós-operatórios. Assim, a implementação do sistema de checagem pode identificar as possíveis lacunas e confirmar a adesão aos padrões comprovados de cuidados na prática cirúrgica ${ }^{(9)}$.

A LVSC pode aumentar o conhecimento existente, que geralmente pode ser encoberto por fadiga ou grande número de ações necessárias para a realização de atividades. A combinação de cansaço e estresse, uma situação comum na sala 
operatória, tem sido associada com declínio no desempenho cognitivo, o que representa uma contribuição substancial para o mecanismo de erro ${ }^{(188,198,202)}$.

Stahl et al. ${ }^{(203)}$ mostrou que itens "perdidos" durante a passagem de plantão em unidades de trauma e terapia intensiva cirúrgica foram reduzidos de $20 \%$ para $3,6 \%$, por meio do uso de uma lista de verificação direcionada para o cuidado pósoperatório, numa passagem de plantão estruturada.

Semel et al. ${ }^{(204)}$ utilizou um estudo de modelagem econômica para estimar que a adoção de uma LVSC reduziria significativamente os custos para os hospitais ${ }^{(204)}$.

A utilização da LVSC, medida sanitária de baixo custo, e de simples execução, permite a melhora da segurança cirúrgica ${ }^{(9)}$. A simples checagem de processos de assistência associados a cada fase da operação com o uso da LVSC, envolvendo a participação ativa da equipe cirúrgica, pode ser traduzida em significativa redução de complicações cirúrgicas e óbitos, conforme demonstrado em diversos estudos mundiais ${ }^{(28,39,205-207)}$.

Pelo fato da LVSC consistir em uma ferramenta simples, é provável que muitos dos seus efeitos sejam indiretos ${ }^{(208)}$. De Vries et al. ${ }^{(209)}$ mostraram em um estudo que as complicações pós-operatórias foram reduzidas com a implementação de uma lista de verificação nas salas operatórias, embora tais resultados técnicos apresentem maior relação com o cirurgião do que com outros membros da equipe cirúrgica. Os atores sugerem que o ocorrido pode ser devido aos importantes efeitos indiretos do uso lista de verificação, proporcionando benefícios. Por exemplo, um cirurgião pode operar em um ambiente menos estressante e com menores oportunidades para distrações, além da melhoria da comunicação da equipe ${ }^{(208)}$.

A implementação da LVSC nos serviços de saúde implica em um trabalho de equipe integrado, com maior participação e conscientização do sentido de responsabilidade da equipe cirúrgica. Diversos estudos mostram, ainda, que a LVSC pode modificar as atitudes pessoais dos profissionais que atuam nas salas operatórias $^{(33-35)}$. Um instrumento muito utilizado para a mensuração das atitudes de segurança é o Safety Attitudes Questionnaire (SAQ) - Short Form $2006^{(35)}$, o qual foi desenvolvido por pesquisadores da Universidade do Texas. A ferramenta é composta por seis domínios: clima de trabalho em equipe, satisfação no trabalho, percepção da gerência da unidade e do hospital, clima de segurança, condições de 
trabalho e percepção do estresse ${ }^{(35,36)}$ e vem sendo adaptada para uso em difentes unidades dos serviços de saúde, a exemplo da unidade de Centro Cirúrgico ${ }^{(33)}$.

Ademais, o uso da LVSC nas salas operatórias pode melhorar a comunicação entre a equipe cirúrgica e aprimorar a cultura de segurança do paciente no serviço de saúde ${ }^{(33,210,211)}$.

\subsubsection{Lista de Verificação de Segurança Cirúrgica da Organização Mundial da Saúde}

A LVSC para a otimização de práticas cirúrgicas foi disponibilizada pela OMS e a viabilidade de sua implantação tem sido descrita em estudos envolvendo serviços de saúde de vários países e em diversos contextos econômicos ${ }^{(9)}$.

Este instrumento compreende a lista de checagem cirúrgica mais citada e debatida na área da saúde, desde sua publicação, em 2008, o que pode ter contribuído para o aumento do interesse por LVSC em diversas partes do mundo ${ }^{(212)}$. A ferramenta foi traduzida pelo menos para seis idiomas. Em março de 2012, cerca de 4.000 serviços de saúde e instituições governamentais no mundo manifestaram interesse e apoio no uso da LVSC da OMS e 1.790 destes serviços reportaram que já aplicavam este instrumento em pelo menos uma das salas operatórias $^{(213)}$.

Em 2009, uma lista atualizada foi publicada pela OMS, incluindo 19 itens de segurança destinados a reduzir as complicações cirúrgicas. A LVSC da OMS (Figura 2) consiste em um instrumento de uma única página, resumindo 19 pontos críticos globalmente aplicáveis a todas as cirurgias ${ }^{(28)}$ e foi desenvolvido por um comitê internacional composto por mais de 200 especialistas, entidades representativas e especialistas dos setores da aviação. O comitê procedeu à revisão de práticas baseadas em evidências, que identificaram as causas mais comuns de danos ao paciente no período perioperatório. Sendo assim, o principal objetivo da LVSC é auxiliar as equipes cirúrgicas a seguir procedimentos de segurança em etapas

críticas do processo, checando itens necessários para a prevenção de EA em pacientes cirúrgicos ${ }^{(9)}$. 
Figura 2. Lista de Verificação de Segurança Cirúrgica (LVSC) da OMS.

\section{(2)}

\section{Lista de Verificação de Segurança Cirúrgica}

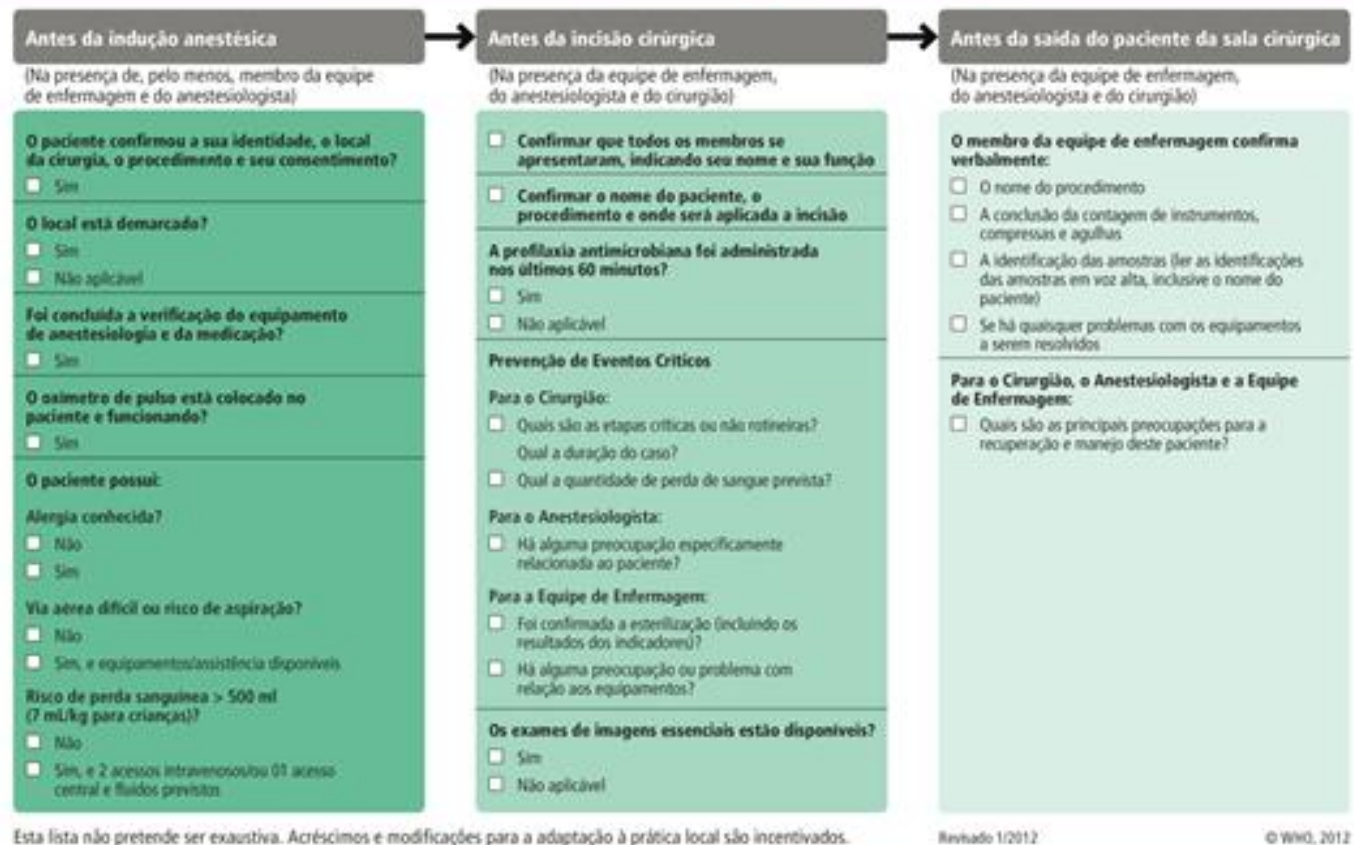

Fonte: WHO; $2009^{(9)}$; BRASIL; $2013^{(49)}$.

A LVSC da OMS foi testada em um estudo piloto, multicêntrico, realizado em oito hospitais (Amã, Jordânia; Nova Deli, Índia; Seattle, EUA; Ifakara, Tanzânia; Manila, Filipinas; Toronto, Canadá; Londres, Inglaterra; Auckland, Nova Zelândia), por Haynes et al. ${ }^{(28)}$, envolvendo 7.688 pacientes divididos em dois grupos (3.733 pacientes antes da aplicação da LVSC e 3.955 pacientes após a aplicação deste instrumento) de 8 hospitais localizados em países desenvolvidos e em desenvolvimento, no período de outubro de 2007 a setembro de 2008. O estudo evidenciou que o uso da LVSC da OMS reduziu $65 \%$ das complicações cirúrgicas (de $11 \%$ para $7 \% ; p<0,001$ ) e a letalidade pós-cirúrgica apresentou queda de $47 \%$ (de $1,5 \%$ a $0,8 \% ; p=0,003$ ). A redução significativa de complicações pósoperatórias foi encontrada predominantemente em estabelecimentos de saúde com 
menores recursos ${ }^{(28)}$. Conforme relatado pelos autores, estes hospitais apresentavam variabilidade no número de leitos (de 371 a 1800), na quantidade de salas operatórias (de 3 a 39) e no nível de recursos econômicos do país. Em relação aos procedimentos de segurança cirúrgica, antes da implementação da LVSC da OMS também apresentavam diferenças quanto ao uso rotineiro da monitorização intra-operatória com oxímetro de pulso (apenas seis de oito hospitais), confirmação oral da identidade de pacientes e demarcação do sítio cirúrgico nas salas operatórias (presente em dois dos oito hospitais) e administração rotineira de antibióticos profiláticos na sala operatória (cinco de oito hospitais). Ainda, nenhum dos oito locais dispunha de um protocolo para acesso intravenoso para casos de perda sanguínea elevada ou briefings pré ou pós-operatórios.

O estudo de Haynes et al. ${ }^{(28)}$ não conseguiu identificar os mecanismos responsáveis pela redução de complicações e de mortalidade - o que é mais provável que seja multifatorial - envolvendo mudanças no comportamento individual e da equipe e melhoria da comunicação ${ }^{(214)}$. Haynes et al. ${ }^{(28)}$ reconheceram as seguintes razões para o encontro das melhorias decorrentes da realização do estudo: 1) a LVSC propriamente dita; 2) o efeito Hawthorne (ou seja, as taxas reduziram porque as equipes cirúrgicas sabiam o que estava sendo mensurado); 3) a simples existência de uma pausa formal ou instrução pré-operatória, um componente necessário da LVSC; 4) o aumento da absorção de tecnologias de segurança, a exemplo da administração de antibióticos profiláticos nas salas operatórias ao invés de realização deste procedimento em enfermarias. Esta mudança podia ser considerada um subproduto da introdução da LVSC, ou seja, o hospital administrou mais antibióticos que estavam disponíveis na sala operatória devido ao item de checagem de antibiótico presente na LVSC ${ }^{(28)}$.

No entanto, o estudo de Haynes et al. ${ }^{(28)}$ despertou grande interesse e uma nova exigência de segurança nos procedimentos cirúrgicos realizados nos serviços de saúde no século $X X I^{(142)}$.

Considerando a busca pela segurança do paciente, a LVSC da OMS identifica três etapas do procedimento cirúrgico, sendo cada uma delas correspondente a um período específico no fluxo de trabalho rotineiro na sala operatória ${ }^{(9)}$ : 1) antes da indução anestésica (Entrada - Sign in); 2) antes da incisão cirúrgica (Pausa cirúrgica - Time out); e 3) antes da saída do paciente da sala cirúrgica (Saída - Sign out). Em cada fase, o coordenador da LVSC deve confirmar com o cirurgião e demais 
membros da equipe cirúrgica se as tarefas foram completadas antes de seguir adiante $^{(9,134)}$. Tais instruções (briefings) objetivam verificar ações específicas que permeiam as etapas do procedimento cirúrgico, trocando informações necessárias para a execução de uma tarefa conjunta, resultando na melhoria da cooperação, da motivação, do trabalho transdisciplinar e dos resultados das equipes cirúrgicas.

A LVSC da OMS abrange pontos importantes na prevenção da ISC e dos EA relacionados à assistência à saúde bem como do controle da resistência microbiana, tais como ${ }^{(134)}: 1$ ) identificação - do paciente, do sítio cirúrgico e do procedimento a ser realizado; 2) confirmação - etapa na qual a profilaxia antimicrobiana, quando indicada, deve ser realizada até 60 minutos antes da incisão cirúrgica e também é verificada a validade do processamento dos instrumentais cirúrgicos; e 3) registro etapa fundamental para também avaliar a qualidade do procedimento cirúrgico.

Ao final da conclusão das três etapas supracitadas, a LVSC pode ser anexada ao prontuário do paciente ou utilizada em auditorias e análises de controle de qualidade do serviço de saúde ${ }^{(9)}$.

Com o intuito de reforçar a segurança do paciente no bloco operatório, a OMS delineou os objetivos essenciais para a segurança cirúrgica ${ }^{(9,63)}$, os quais estão indicados no Quadro 2. 
Quadro 2. Dez objetivos essenciais da OMS para a segurança cirúrgica.

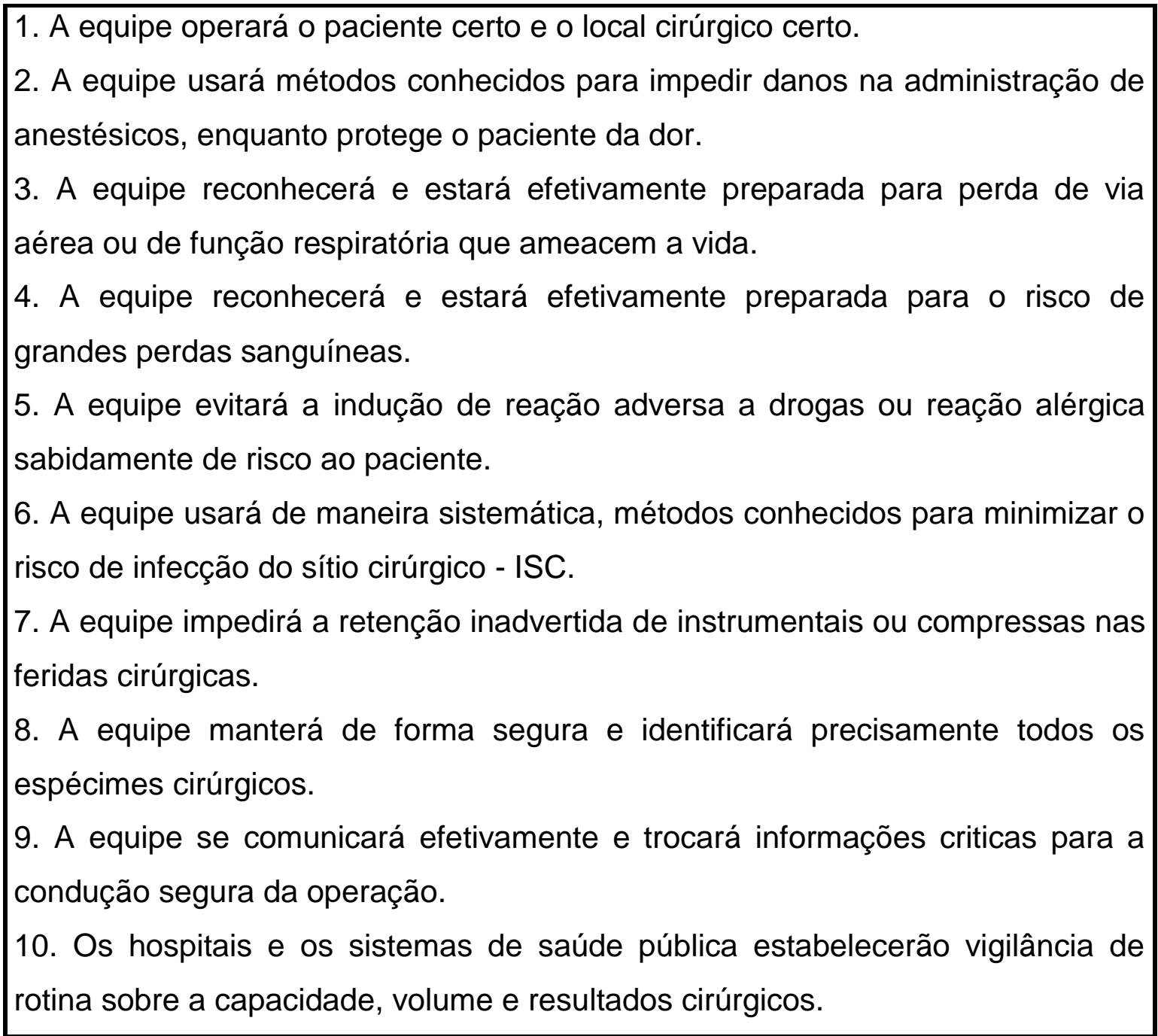

Fonte: WHO; $2009^{(9)}$; BRASIL; $2013^{(49)}$.

A seguir serão descritos, detalhadamente, os 10 objetivos essenciais da OMS para a cirurgia segura.

\subsection{Objetivo 1: a equipe operará o paciente certo e o local cirúrgico certo}

As falhas no processo de identificação do paciente estão entre as causas mais comuns de EA, tais como na administração de medicamentos, de sangue e hemoderivados, nos exames diagnósticos e nos procedimentos cirúrgicos ${ }^{(9)}$. 
Embora a cirurgia em local errado ou paciente errado seja rara, mesmo um caso isolado pode resultar em dano considerável ao paciente. Estudos mostram que ocorrem cerca de 1.500 a 2.500 cirurgias no lado errado, anualmente, nos EUA ${ }^{(9,}$ 215).

Uma análise de eventos sentinelas relatados pela Joint Commission, entre 1995 e 2006, apontou que 13\% dos EA relatados ocorrem devido à realização de cirurgias em sítios errados ${ }^{(134)}$. A literatura apoia a suposição que a cirurgia em local errado seja mais comum em certas especialidades, particularmente em cirurgia ortopédica $^{(9)}$.

Os procedimentos cirúrgicos em locais ou membros errados são reconhecidos como erros preveníveis oriundos de falhas na comunicação. Além de se configurarem no segundo desafio global da OMS, também ocupam posição dentre as metas internacionais de segurança, integrando a meta 4 - Assegurar cirurgias com local de intervenção, procedimento e paciente corretos ${ }^{(216)}$.

Diante da problemática, para alcançar o primeiro objetivo da LVSC, a OMS recomenda que antes da indução anestésica, um membro da equipe confirme verbalmente (com o próprio paciente ou membro da família) se o paciente está corretamente identificado e se apresenta bracelete de identificação ou outro método apropriado de identificação física. A identidade deve ser confirmada não apenas pelo nome, mas também por uma segundo identificador (por exemplo, data de nascimento e registro no hospital) ${ }^{(9)}$.

Adicionalmente, um membro da equipe cirúrgica deve verificar: 1) consentimento informado para o procedimento, a confirmação do sítio e o procedimento; 2) demarcação do local da cirurgia em casos envolvendo lateralidade ou múltiplas estruturas ou níveis, tais como dedo da mão ou pé, lesão cutânea ou vértebra $^{(9,217)}$. Tanto o anestesiologista quanto o profissional de enfermagem deve checar o local, para confirmar que foi demarcado pelo cirurgião que realizará a operação, e confirmar a demarcação com a informação nos registros do paciente. A demarcação deve estar claramente visível e feita com marcador estável para que não saia durante a preparação do sítio cirúrgico. O tipo de marca pode ser determinado localmente ${ }^{(9)}$.

A identificação precisa do paciente e da demarcação do sítio cirúrgico, o envolvimento do paciente no planejamento pré-operatório, a confirmação do consentimento informado, a melhor comunicação entre os membros da equipe, a 
melhora do trabalho e o seguimento dos protocolos podem reduzir falhas na sala operatória $^{(9)}$.

\subsection{Objetivo 2: a equipe usará métodos conhecidos para impedir danos na administração de anestésicos, enquanto protege o paciente da dor}

$\mathrm{Na}$ década de 1970 verificava-se que um paciente ia a óbito a cada 5.000 procedimentos anestésicos, associados a erros com equipamentos. No ano 2.000, com a melhoria da tecnologia e a adoção de um checklist anestésico, a proporção de pacientes classificados segundo critérios da Sociedade Americana de Anestesiologia, como ASA I e ASA II, é de 1 paciente para 250.000 procedimentos anestésicos $^{(9)}$. Contudo, na África Subsaariana, tal relação atual é de um óbito para 150 anestesiologias $^{(9,218)}$.

A ASA estratifica os pacientes segundo o critério de classificação do estado físico em: ASA I - nenhum distúrbio orgânico, fisiológico ou bioquímico salvo a patologia cirúrgica; ASA II - alterações orgânicas leves ou moderadas; ASA III alterações orgânicas intensas; ASA IV - alterações orgânicas graves; risco de morte alto; ASA V - paciente em estado crítico, com baixa probabilidade de sobreviver 24 horas sem a intervenção cirúrgica e ASA VI - paciente em morte cerebral, cujos órgãos serão removidos para transplante ${ }^{(9)}$.

No contexto da anestesiologia, para alcançar o objetivo 2 da segurança cirúrgica, é altamente recomendado a presença contínua de um anestesiologista qualificado e vigilante no Centro Cirúrgico ${ }^{(219)}$.

Oxigênio suplementar deve ser fornecido a todos os pacientes submetidos à anestesiologia geral. A oxigenação tecidual e perfusão devem ser continuamente monitorizadas usando um oxímetro de pulso com alarme variável, alto o suficiente para ser ouvido por toda equipe da sala operatória ${ }^{(134)}$. Em um trabalho de Cooper et al. ${ }^{(220)}$, os relatos de incidentes identificaram falha no suprimento de oxigênio para os pacientes como a causa principal de óbito durante a anestesiologia.

A oximetria de pulso consiste em um método não invasivo de monitorização da saturação arterial de oxigênio, importante para a prática anestésica. Um estudo envolvendo 1.256 EA relacionados à anestesia geral, na Austrália, mostrou que o uso de oxímetro de pulso teria evitado $82 \%$ destes eventos ${ }^{(221)}$. 
Um método de mensuração da temperatura corporal deve estar disponível e usado em intervalos regulares quando indicado, como nos casos de anestesiologia prolongada e em cirurgias abdominais ${ }^{(135)}$.

\subsection{Objetivo 3: a equipe reconhecerá e estará efetivamente preparada para perda de via aérea ou de função respiratória que ameacem a vida}

O reconhecimento pré-operatório de uma via aérea difícil permite preparação e planejamento apropriados. Quando o anestesiologista suspeitar de uma via aérea difícil, métodos alternativos de anestesiologia devem ser considerados, incluindo anestesiologia regional ou intubação com o paciente consciente sob anestesia local $^{(9)}$.

Falhas na avaliação das vias aéreas e na previsão de problemas são amplamente aceitas como os fatores mais importantes nos fracassos relacionados à ventilação e à oxigenação. As vias aéreas de todos os pacientes devem ser minuciosamente avaliadas antes da anestesiologia e os resultados da avaliação devidamente registrados ${ }^{(222,223)}$.

\subsection{Objetivo 4: a equipe reconhecerá e estará efetivamente preparada para o risco de grandes perdas sanguíneas}

A perda de sangue, principalmente, quando vinculada à instabilidade hemodinâmica, está associada a piores resultados cirúrgicos. O controle da hemorragia e a atenuação de seus efeitos clínicos por meio da reposição apropriada com fluidos são componentes importantes do cuidado transoperatório ${ }^{(224)}$. A reposição com volume inclui a infusão de soluções cristaloides e a transfusão de hemoderivados ou de outros expansores de volume ${ }^{(9)}$. 


\subsection{Objetivo 5: a equipe evitará a indução de reação adversa a drogas ou reação alérgica sabidamente de risco ao paciente}

Em anestesiologia, causas comuns de incidentes envolvem a substituição inadvertida de uma seringa preenchida com um medicamento por outro, troca de seringas e ampolas, além de doses excessivas de medicamentos ${ }^{(134)}$.

Grande parte dos erros de medicamentos envolve a administração intravenosa em bolo, a infusão ou a administração de gases ou vapores, mas qualquer via de administração pode estar envolvida. A maioria se encaixa dentro das seguintes categorias ${ }^{(9)}:$ 1) omissão - não se administrou o medicamento desejado; 2) repetição - administrou-se uma dose extra, involuntariamente, do medicamento desejado; 3) substituição - administrou-se o medicamento errado; 4) dose ou infusão incorreta; 5) via incorreta - administrou-se o medicamento pela via errada; e 6) paciente incorreto - administrou-se o medicamento no paciente errado.

Pesquisadores afirmam que vários fatores podem predispor à ocorrência dos erros de medicação, como excesso de trabalho, falta de atenção durante os processos de prescrever, dispensar e de administrar os medicamentos, falhas na comunicação entre as equipes e entre setores, falta de informação sobre o paciente, dificuldade de acesso às informações sobre os medicamentos, além de fatores ambientais e individuais ${ }^{(225,226)}$.

As reações adversas a medicamentos incluem as reações alérgicas, os efeitos colaterais (por exemplo, resposta asmática severa a antiinflamatórios nãoesteroidais em pacientes suscetíveis), os efeitos originados de super ou subdosagem e os danos atribuíveis à omissão de administração de medicamentos importantes ou o uso inoportuno de antimicrobianos para prevenir infecções. As causas comuns de anafilaxia incluem neurobloqueadores, látex, antibióticos, coloides, hipnóticos e opioides. Reações cruzadas com o uso de medicamentos também podem ocorrer. A realização de uma anamnese completa sobre uso de medicamentos, incluindo informação sobre alergias e outras reações de hipersensibilidade devem ser obtidas antes da administração de qualquer medicamento $^{(9)}$. 


\subsection{Objetivo 6: a equipe usará de maneira sistemática, métodos conhecidos para minimizar o risco de infecção do sítio cirúrgico}

As medidas para reduzir as taxas de ISC nos serviços de saúde incluem o banho antisséptico, a tricotomia com tricotomizador (até 2 horas antes da cirurgia), o preparo da pele e a antissepsia cirúrgica das mãos e antebraços ${ }^{(9)}$. Ainda, a equipe cirúrgica deve cobrir os cabelos apropriadamente, usar capotes estéreis e calçar luvas de procedimento cirúrgico, estéreis, durante a cirurgia ${ }^{(9)}$.

Outros fatores como o ambiente da sala operatória, a esterilização de instrumentais, o uso de campos estéreis e a profilaxia antimicrobiana podem reduzir significativamente as taxas de $\operatorname{ISC}^{(9)}$. Estudos demonstram que a administração de antimicrobiano até 60 minutos antes da incisão cirúrgica pode reduzir em $50 \%$ as ISC $^{(191,227)}$.

A eficácia da esterilização de cada artigo processado, independentemente do método utilizado, deverá ser testada por meio de monitoramento com indicadores biológicos químicos, bem como integradores.

Os indicadores biológicos são sistemas quem contêm esporos de dois tipos: Bacillus subtilis (esterilização a óxido de etileno) e $B$. stearothermophilos (esterilização a vapor). Quanto aos indicadores químicos devem ser usados de maneira rotineira para monitorar o desempenho do equipamento e da esterilização, sendo caracterizados por tinta termocrômica que muda de cor quando exposta ao agente esterilizante ${ }^{(9)}$.

Outros princípios importantes para a obtenção do objetivo 6 da cirurgia segura envolvem a duração da operação e a técnica cirúrgica asséptica ${ }^{(9)}$.

\subsection{Objetivo 7: a equipe impedirá a retenção inadvertida de instrumentais ou compressas nas feridas cirúrgicas}

Os materiais retidos ao final de uma cirurgia tende a resultar em sequelas, incluindo infecção, reoperação para remoção, perfuração intestinal, fístula ou obstrução e até mesmo óbito. Os fatores de risco para a retenção de corpos estranhos no paciente envolvem a cirurgia de emergência e o alto índice de massa corpórea $^{(189)}$. 
A contagem manual de todos os instrumentais e compressas no começo e na conclusão da cirurgia é uma prática padronizada pela enfermagem. Medidas como a incorporação de material radiopaco às compressas possibilitam achar as que ficaram retidas por meio de radiografias transoperatórias, caso haja algum erro de contagem. O cirurgião deve realizar uma exploração metódica antes do fechamento da ferida em qualquer cavidade anatômica ${ }^{(9)}$.

\subsection{Objetivo 8: a equipe manterá seguro e identificará precisamente todos os espécimes cirúrgicos}

Para se atingir o objetivo 8 da segurança cirúrgica, todo espécime cirúrgico retirado do paciente deve ser identificado por pelo menos dois identificadores (como exemplo, nome e registro). Um estudo de Makary et al. ${ }^{(228)}$ mostrou que os erros de identificação ou etiquetagem de espécimes cirúrgicas ocorreram em 3,7 de 1.000 espécimes. Os principais erros neste estudo envolveram a ausência de identificação ou etiquetagem correta, a omissão de detalhes a respeito do local de onde o tecido se originou e a ausência do nome do paciente.

Para evitar tais erros a OMS propõe que o profissional da equipe de enfermagem revise os detalhes da amostra com o cirurgião com leitura em voz alta do nome do paciente, nome do espécime, local de origem e identificação ${ }^{(134)}$.

\subsection{Objetivo 9: a equipe se comunicará efetivamente e trocará informações críticas para a condução segura da operação}

Há evidência crescente de que as falhas na comunicação entre os membros da equipe são causas comuns de erros e EA. Em um estudo realizado por Sexton et al. ${ }^{(229)}$, dois terços dos enfermeiros e médicos citaram a melhoria na comunicação dentro da equipe como o elemento mais importante no aperfeiçoamento da segurança e da eficiência na sala operatória.

A Joint Comission reportou que a falta de comunicação entre os profissionais contribuiu para quase $70 \%$ dos EA ocorridos em 2005, nos EUA ${ }^{(230,231)}$. 
Segundo a OMS, além da comunicação eficiente da equipe, as informações registradas pelo cirurgião devem incluir a descrição minuciosa do procedimento e as intercorrências do tempo operatório. A informação do anestesiologista deve incluir, no mínimo, parâmetros dos sinais vitais transoperatórios. O registro completo da cirurgia deve incluir os nomes de todos os membros da equipe envolvidos ${ }^{(134)}$.

\subsection{Objetivo 10: os hospitais e os sistemas de saúde pública estabelecerão vigilância de rotina sobre a capacidade, volume e resultados cirúrgicos}

Um dos objetivos centrais do Programa Cirurgias Seguras Salvam Vidas da OMS é definir um conjunto de indicadores para as cirurgias que incorporem indicadores de estrutura e resultado e que monitorem os indicadores de processo, tais como o uso da LVSC e a implementação de protocolos padronizados nos serviços de saúde ${ }^{(63)}$.

No contexto, para a vigilância cirúrgica nos serviços de saúde devem ser coletados sistematicamente os seguintes indicadores: a taxa de mortalidade no dia da cirurgia; a taxa de mortalidade pós-operatória em pacientes internados e a taxa de ISC. Indicadores cirúrgicos demográficos adicionais envolvem o número de salas cirúrgicas, o número de procedimentos cirúrgicos realizados e o número de cirurgiões e anestesiologistas na instituição ${ }^{(9)}$.

Os indicadores para monitoramento dos EA relativos aos pacientes submetidos a procedimentos cirúrgicos envolvem: cirurgias em sítio errado; complicações anestésicas; corpo estranho deixado no corpo do paciente durante o procedimento; deiscência de ferida operatória; desordem fisiológica e metabólica pós-operatória; embolia pulmonar ou trombose venosa profunda no pós-operatório; falência respiratória pós-operatória; hemorragia ou hematoma pós-operatório; ISC; óbitos de pacientes cirúrgicos com graves complicações tratáveis; pacientes com EA devido a procedimentos cirúrgicos; sepsis pós-operatória e indicadores relacionados a eventos obstétricos ${ }^{(9,232)}$. 


\subsubsection{Outros estudos envolvendo a aplicação da Lista de Verificação de Segurança}

O efeito na redução de EA por meio do uso da LVSC vem sendo estudado excessivamente nos últimos anos.

No estudo de Yuan et al. ${ }^{(233)}$, a LVSC da OMS foi aplicada em dois hospitais na República da Libéria com recursos limitados, no período de 2008 a 2009. Na fase pré-intervenção, os dados foram coletados prospectivamente de processos cirúrgicos e dos resultados de 232 pacientes submetidos à cirurgia. Na fase pósintervenção (após a introdução da LVSC), os dados foram coletados de 249 pacientes cirúrgicos. A LVSC foi associada com melhoria significativa $(p<0,05)$, em termos gerais de processos e resultados cirúrgicos. No hospital 1, a LVSC foi significativamente associada a uma melhor adesão à medida composta de processos cirúrgicos, mas não foi associada a melhores resultados cirúrgicos. Por outro lado, no hospital 2, a LVSC foi significativamente associada a melhores resultados cirúrgicos, mas não foi associada a uma melhor adesão à medida composta de processos cirúrgicos. Os autores sugerem que o mecanismo de melhoria da LVSC pode ser influenciado pelas diferenças no nível hospitalar, envolvendo a disponibilidade de recursos necessários para concluir os processos recomendados, a variação no funcionamento da equipe e 0 contexto organizacional $^{(233)}$.

Weiser et al. ${ }^{(29)}$ reportaram que a LVSC pode funcionar de forma eficaz mesmo em cirurgias de urgência. $O$ estudo prospectivo foi realizado antes e após a introdução da LVSC da OMS e envolveu 1.750 pacientes $\geq 16$ anos submetidos à cirurgia de urgência, não cardíaca, em um grupo diversificado de 8 hospitais localizados em diferentes países. Foi definida, como cirurgia de urgência, aquela na qual a operação teria que ser realizada até 24 horas após admissão. No período préintervenção (antes da aplicação da LVSC), foram acompanhados 842 pacientes e após a introdução da LVSC, 908 pacientes. Foi observada redução de $67 \%$ nas complicações cirúrgicas $(18,4 \%$ pré e $11,7 \%$ pós - $p=0,0001)$ e redução de $2,3 \%$ nas mortes ( 3,7 pré e $1,4 \%$ pós - $p=0,0067)$. $A$ adesão às medidas de segurança melhorou de $18,6 \%$ para $50,7 \%(p<0,0001)$. 
Em uma pesquisa qualitativa com o objetivo de identificar as práticas de segurança do paciente no Centro Cirúrgico, incluindo a opinião de enfermeiros sobre a LVSC, os resultados da análise de conteúdo das entrevistas mostraram que para grande parte dos entrevistados, a "opinião foi favorável", ou seja, a LVSC foi considerada um instrumento útil para a redução dos riscos, importante para a reflexão, averiguação, rotinização e sistematização da execução de procedimentos essenciais para a segurança do paciente na sala operatória, e eficaz na sua promoção. Entretanto, alguns participantes emitiram "opinião parcialmente favorável", alegando que a LVSC pode ser redutora, não contemplando aspectos que consideram necessários de melhoria para maior adesão ao instrumento, tais como a falta de responsabilização dos integrantes da equipe cirúrgica, a não definição do coordenador da LVSC, a falta de apoio por alguns cirurgiões, o não envolvimento de todas as pessoas no projeto de implementação do instrumento e a implantação da LVSC por imposição, e não por motivação da equipe cirúrgica ${ }^{(141)}$.

Em 2015, Melekie \& Getahun ${ }^{(234)}$ realizaram um estudo observacional prospectivo em um hospital universitário da Etiópia com o objetivo de avaliar o cumprimento da LVSC da OMS adaptada, localmente, em 282 pacientes submetidos a cirurgias eletivas e de emergência no período de janeiro a março de 2013. A LVSC foi utilizada em $39,7 \%$ (112/282) dos casos, sendo a maioria em procedimentos cirúrgicos de emergência. As etapas antes da indução anestésica, antes da incisão cirúrgica e antes da saída do paciente da sala operatória não foram realizadas em 30,5\% (273/896), 35,4\% (436/1.232) e 45,7\% (307/672), respectivamente. As principais razões relatadas para o não uso do instrumento foram falta de capacitação $(45,1 \%)$ e de cooperação entre os membros da equipe cirúrgica $(21,6 \%)$.

Várias autoridades proeminentes no campo da segurança do paciente têm proposto o uso de LVSC na tentativa de prevenir erros relacionados à cirurgia. Estes instrumentos vem sendo desenvolvidos cuidadosamente por especialistas da área, e têm evoluído ao longo do tempo para capturar apenas as considerações essenciais $^{(67)}$.

Em janeiro de 2009, a NPSA tornou obrigatória a utilização da versão adaptada da LVSC da OMS, sendo implantada em 100\% dos hospitais da Inglaterra e do País de Gales. Um estudo piloto em dois hospitais britânicos foi realizado pouco antes destes alertas e demonstrou que a aplicação da lista não foi um processo simples. Os autores não observaram o mesmo declínio nas complicações 
cirúrgicas e óbitos, como no estudo da $\mathrm{OMS}^{(28)}$. No entanto, mencionaram melhorias em práticas de segurança, como administração de antibióticos profiláticos no tempo correto e aprimoramento da comunicação entre a equipe cirúrgica $^{(39)}$.

Recentemente, no Canadá, uma LVSC contendo 26 itens de segurança foi adaptada pelo Instituto de Segurança do Paciente Canadense (Canadian Patient Safety Institute). A divulgação pública dos seus níveis de adesão é obrigatória, pelo MS do Canadá, desde julho de 2010 ${ }^{(235)}$. Dados de 2011 revelam a adesão ao preenchimento da lista em torno de $99,0 \%$ nos hospitais de Ontário ${ }^{(236)}$.

No estudo de 1.440 procedimentos cirúrgicos realizado por Fourcade et al. ${ }^{(237)}$, em 2010, foram incluídos 18 centros que estavam aplicando a LVSC obrigatória pela Autoridade Nacional Francesa para a Saúde (French National Authority for Health). A análise incluiu 1.440 procedimentos cirúrgicos, sendo 80 registros aleatórios de cada centro. No geral, 1.299 checklists foram incluídos e 28.578 itens da lista foram analisados. A taxa de adesão média ao checklist foi de $90,2 \%$ e a taxa de preenchimento, 61\%. As principais barreiras para a implementação da lista nas instituições, identificadas por meio de entrevistas e questionários com equipe cirúrgica, foram: a duplicação de itens existentes no checklist (16/18 centros); má comunicação entre o cirurgião e o anestesiologista (10/18); o tempo gasto para preenchimento da LVSC e nenhum benefício percebido; falta de compreensão e tempo de checagem de itens (9/18); ambiguidade (8/18); riscos não identificados na lista (7/18); confirmação oral de itens desnecessária e dificuldade de identificação do coordenador da lista durante cirurgia de emergência ou procedimento cirúrgico rápido $(6 / 18)^{(237)}$.

Um estudo realizado na Finlândia, envolvendo 150 pacientes (83 antes e 67 após a implementação da LVSC da OMS adaptada), objetivou avaliar o impacto da aplicação da lista sobre as questões relacionadas com a segurança na sala operatória e em EA pós-operatórios em neurocirurgia. A partir de questionários estruturados entregues à equipe cirúrgica na sala operatória, os autores avaliaram as respostas dos entrevistados por meio de análise retrospectiva de prontuários eletrônicos, comparando-se o tempo de internação, EA relatados e reinternações nas duas fases do trabalho. $O$ estudo reportou que a comunicação entre o cirurgião e o anestesiologista foi reforçada, e as questões relacionadas com a segurança foram melhoradas quando a lista foi utilizada. As readmissões não planejadas de 
pacientes reduziram de $25 \%$ para $10 \%(p=0,02)$ bem como as taxas de ISC (de $19 \%$ para $8 \% ; p=0,04)$ após a implementação da $\operatorname{LVSC}^{(238)}$.

Bashford et al. ${ }^{(239)}$ aplicaram a LVSC da OMS, adaptada localmente, em uma unidade de cirurgia plástica reconstrutiva de um hospital na Etiópia, no período 2011-1012. A intervenção envolveu os elementos: consulta, liderança local, introdução formal da LVSC com capacitação, e monitoramento da adesão com auditoria e retorno. A adesão à LVSC após um mês de implantação foi de $83 \%$ (38/46 casos com anestesiologias geral) com 6 listas preenchidas de forma incompleta no Sign Out (16\%). Em oito meses de implantação a LVSC foi aplicada em 289 cirurgias com anestesiologia geral, sendo 65\% a taxa de adesão ao instrumento. O Sign Out foi reportado como a etapa mais difícil de preenchimento e incompleta em $25 \%$ dos casos.

Em Portugal, no ano 2010, a Direção Geral da Saúde emitiu a circular normativa $n \cong .16 / 2010$, que determinou a implementação obrigatória do programa Cirurgia Segura Salva Vidas, estabelecido pela OMS, em todos os serviços cirúrgicos do país ${ }^{(240)}$.

Alguns estudos relatam que a implementação da LVSC não mostrou melhoras nos resultados dos pacientes, a exemplo do trabalho realizado por Sewell et al. ${ }^{(241)}$, na Inglaterra, no qual a LVSC da OMS foi aplicada em cirurgias da especialidade de ortopedia. No estudo não houve redução significativa nas taxas de complicações (de 8,5\% no período pré-intervenção para 7,6\%, no período pós-intervenção) e nem nas de mortalidade (1,9\% no período pré-intervenção e 1,6\% no período pósintervenção). No entanto, as equipes cirúrgicas relataram melhoria da comunicação na sala operatória ${ }^{(241)}$.

Em 2014, Urbach et al. ${ }^{(242)}$ realizaram um estudo em Ontário, Canadá, envolvendo 101 hospitais, 3 meses antes e depois da implementação de uma LVSC, envolvendo 109.341 e 106.370 procedimentos realizados, respectivamente. Contrastando com alguns estudos realizados, a implementação da LVSC em Ontário, no Canadá não foi associada com reduções estatisticamente significativas nas taxas de mortalidade e de complicações cirúrgicas.

No Brasil, em um estudo desenvolvido por Cunha et al. ${ }^{(243)}$, a LVSC foi capaz de evitar 3 falhas onde, por incorreção nos dados ou formulários de agendamento, as cirurgias foram marcadas para o órgão contralateral e puderam ser corrigidas antes que causassem danos aos pacientes. 
Em um trabalho realizado por Freitas et al. ${ }^{(244)}$ com o objetivo de avaliar a adesão à LVSC, dados respectivos de 375 cirurgias (212 ginecológicas e 163 urológicas) foram avaliados em 2 hospitais localizados em Natal, Rio Grande do Norte (RN). A LVSC esteve presente em 60,8\% das cirurgias (IC 95\%: 55,3\% 65,2\%), estando completamente preenchida em 3,5\% (IC 95\%: 1,1\% - 6,0\%). A existência da LVSC se relacionou com as cirurgias ginecológicas e à maior duração da cirurgia, enquanto a melhor qualidade no preenchimento foi relacionada às cirurgias urológicas. De acordo com os autores, estas diferenças sugerem a influência das distintas estratégias de implantação da LVSC utilizadas em cada hospital participante.

Outros trabalhos descritos no Brasil sobre LVSC descrevem a elaboração e a validação de instrumentos, baseados no proposto pela $\mathrm{OMS}^{(9)}$, para implementação em diversas especialidades cirúrgicas.

No estudo conduzido por Anger et al. ${ }^{(245)}$ em um hospital em São Paulo (SP), no ano 2011, foi feita a descrição de uma LVSC para ser utilizada na última etapa da consulta pré-operatória de cirurgias plásticas estéticas, composto de 29 perguntas, com respostas do tipo sim e não, quatro espaços para inserção de dados e uma questão para classificação do nível de risco em trombose venosa profunda. Os quesitos foram divididos em três tabelas relativas a três áreas: anestesiologia, aspectos psicológicos e riscos clínicos. As respostas foram enquadradas em quatro cores, que identificam o nível de risco e sugerem o grau de atenção requisitada ${ }^{(245)}$. De acordo com os autores, a classificação das respostas por cores, relacionando-as com níveis de risco, objetiva chamar a atenção do cirurgião na avaliação final individual de cada paciente.

Uma LVSC foi adaptada com o objetivo de asseverar práticas seguras durante implementação em cirurgia cardíaca pediátrica em um hospital localizado em São José do Rio Preto (SP), conforme trabalho descrito por Croti et al ${ }^{(246)}$, em 2011. O instrumento é dividido em quatro partes: antes da indução anestésica, antes da incisão da pele, após o término da operação e na passagem do caso operado à equipe da UTI. Um vídeo autoexplicativo foi disponibilizado para auxiliar a implantação da LVSC e ajudar a evitar falhas no atendimento à criança durante o pré, intra e pós-operatório imediato ${ }^{(246)}$.

Apesar dos benefícios comprovados da LVSC, a integração da LVSC à prática clínica na área da saúde ainda não se faz de forma tão rápida e ampla como 
em outros campos. Com o estabelecimento do PNSP e outros regulamentos recentemente vigentes no país, avanços e melhorias na adoção e implementação da LVSC nos serviços de saúde podem ser observadas em um futuro próximo.

\subsubsection{Principais desafios para a aplicação da Lista de Verificação de Segurança Cirúrgica nos serviços de saúde}

De acordo com a OMS, a LVSC se mostrou bastante eficiente, de baixo custo e não intrusiva. Estima-se que aproximadamente 15 a 25 bilhões de dólares poderiam ser economizados se a LVSC da OMS fosse implementada nas salas operatórias dos serviços de saúde dos EUA ${ }^{(204)}$.

Embora a aplicação da LVSC possa parecer extremamente simples, seu desenvolvimento e uso consistem em uma questão bastante complexa na prática dos serviços de saúde ${ }^{(212)}$, sendo necessários esforços intensivos para a incorporação do instrumento como um procedimento padrão em serviços de saúde. O motivo se deve a várias razões, envolvendo fatores sociais, culturais e operacionais. Alguns médicos, por exemplo, percebem a padronização como uma limitação para seus julgamentos clínicos ${ }^{(38,198,247)}$.

Por outro lado, pesquisas recentes sugerem que os enfermeiros têm muitas vezes mais atitudes positivas em relação à LVSC quando comparados com os médicos, anestesiologistas e cirurgiões ${ }^{(211,248,249)}$.

A LVSC para uso em sala operatória vem sendo bem difundida em serviços de saúde, mas, recentemente, surgiram questionamentos a respeito de sua facilidade de introdução em padrões de fluxo de trabalho e seu verdadeiro impacto na segurança ${ }^{(39,211,212)}$. Muitos profissionais de saúde consideram a LVSC como redundante e alegam desperdício de tempo em sua aplicação, desconsiderando seu papel crítico na otimização da segurança dos pacientes cirúrgicos ${ }^{(250)}$.

Apesar da existência de estudos mostrando que 90\% dos médicos gostariam que a LVSC da OMS fosse aplicada se tivessem que se submeterem a um procedimento cirúrgico, estes profissionais ainda abrigam algumas reservas a respeito da $\operatorname{LVSC}{ }^{(251,252)}$. Uma objeção comum é que alguns dos itens previstos na LVSC já são verificados na rotina do serviço, mesmo quando este instrumento não é 
usado. Entretanto, muitas informações não são comunicadas de forma sistemática e a verificação repetida faz aumentar a segurança do procedimento cirúrgico ${ }^{(252)}$.

O tempo previsto de checagem das três etapas da LVSC (Sign in, Time out e Sign out) na sala operatória leva apenas 2-3 minutos, entretanto, o tempo necessário para a checagem dos itens de segurança constitui um dos motivos para a falta de adesão à $\operatorname{LVSC}^{(39,247)}$.

Outras barreiras que podem impedir a adoção da LVSC na sala operatória ou causar preenchimento incompleto do instrumento envolvem: desconhecimento, embaraço, hierarquia, logística, duplicações de processos existentes, falta de comunicação e modificação da LVSC ${ }^{(39,247)}$.

Apesar dos esforços dos profissionais de saúde voltados para as conformidades com a segurança e metas de melhoria para a redução de EA, diversos estudos mostraram que a adesão da equipe cirúrgica aos itens presentes na LVSC ainda não é satisfatória.

Garnerin et al. ${ }^{(253)}$ mostraram que a auditoria proveniente de 1.000 interações entre o paciente e o anestesiologista ou o enfermeiro levou a acentuada melhoria na conformidade dos critérios de qualidade, incluindo a taxa de adesão à identificação correta do paciente $(9,7 \%$ to $38,1 \%)$. Entretanto, a adesão ao cumprimento de checagem do sítio cirúrgico foi considerada baixa (32,2\% para $52,0 \%)$. De acordo com os autores, o impacto da intervenção foi limitado por problemas de comunicação entre pacientes e profissionais, acrescido da falta de colaboração com os serviços cirúrgicos.

Kasatpibal et al. ${ }^{(254)}$ conduziram um estudo descritivo envolvendo 4.340 pacientes submetidos a procedimento cirúrgico em 9 unidades da Tailândia, no período de março a agosto de 2009. A adesão a alguns itens da LVSC foi considerada extremamente baixa, como na demarcação do sítio cirúrgico (19.4\%) e checagem de imagens essenciais $(64,4 \%)$. Os autores reportaram que os resultados obtidos podem refletir os diferentes padrões de trabalho e normas culturais entre as unidades.

Um estudo transversal analítico realizado de janeiro de 2009 a março de 2011, objetivando avaliar o grau de cumprimento das equipes cirúrgicas à LVSC e seu efeito sobre os resultados dos pacientes em 2 hospitais de ensino no Teerã, Irã, envolveu 100 pacientes submetidos a cirurgias eletivas, subdivididos em dois grupos ( $A$ - com adesão e B - sem adesão). As taxas de complicação foram 14 e 18 por 100 
pacientes nos grupos A e B, respectivamente. Os resultados mostraram que antes da indução anestésica, a demarcação do sítio cirúrgico não foi realizada na maioria dos pacientes (76\%). Na etapa de identificação, houve $100 \%$ de adesão à confirmação da esterilidade dos artigos e a menor adesão foi relatada com a checagem de problema a ser resolvido com equipamento, durante a etapa de registro pela equipe de enfermagem ${ }^{(255)}$.

No estudo de van Klei et al. ${ }^{(256)}$, a LVSC foi totalmente concluída pelos membros da equipe cirúrgica apenas em 39\% dos casos (4.353 de 11.151 pacientes). O trabalho evidenciou que a média de itens concluídos foi 16 (73\% de 22 itens).

De acordo com a pesquisa qualitativa de Rebelo ${ }^{(141)}$, realizada em 2013, com o objetivo de identificar as práticas de segurança do paciente no Centro Cirúrgico, os cuidados que as equipes cirúrgicas não prestam de forma sistemática envolvem a verificação do consentimento informado, a checagem dos indicadores de esterilização e a contagem de instrumentais, compressas e agulhas. No estudo de Maziero $^{(257)}$, na totalidade das cirurgias observadas em que a lista de verificação foi aplicada, porém, os itens mais negligenciados foram a apresentação dos membros da equipe, a realização da pausa cirúrgica ao início da cirurgia e a contagem de compressas, gazes e agulhas.

A aplicação inapropriada da LVSC pode promover uma perigosa e falsa sensação de segurança e, assim, converter o efeito positivo da lista de verificação em seu oposto. O benefício mensurável da LVSC depende da melhoria em paralelo da cultura de segurança e da comunicação, mas isto não pode acontecer se os itens da lista são simplesmente checados ${ }^{(252)}$.

Logo, a lista também ajuda a romper as barreiras hierárquicas que afetam a comunicação, permitindo a transferência de informações de forma mais frequente ${ }^{(252)}$. A realização de instrução (briefing) com o auxílio de listas de verificação ajuda a manter uma cultura local de trabalho aberto, em que a formação é melhorada por meio da troca de informações, diálogo, e oportunidade de expressar a sua própria opinião ${ }^{(252)}$

Os itens da lista devem ser lidos em voz alta em sua totalidade e a lista não deve ser aplicada confiando-se apenas na memória. Um grave problema em particular surge quando o briefing não é levado a sério pelos funcionários em 
posições de liderança, que, em seguida, deixam de servir de modelo para ajudar os outros a melhorar suas práticas de comunicação ${ }^{(252)}$.

Com a crescente evidência de sua eficácia, a LVSC vem recebendo, gradativamente, uma maior aceitação pela equipe cirúrgica e muitos hospitais em todo o mundo já adotaram as LVSC na prática diária da sala operatória ${ }^{(250)}$.

Cabe ressaltar que sem uma cultura de segurança organizacional e boa comunicação entre a equipe cirúrgica, a aplicação da LVSC nos serviços de saúde pode acontecer por mera formalidade, de maneira superficial, produzindo apenas uma ilusão de segurança ${ }^{(215)}$.

\subsubsection{Lista de Verificação de Segurança Cirúrgica x Efeitos Adversos}

Não foram encontrados na literatura estudos mostrando quaisquer efeitos adversos resultantes da aplicação da LVSC na sala operatória ${ }^{(67)}$.

Em 2011, Sewell et al. ${ }^{(241)}$ mostrou um aumento da taxa de infecção do trato respiratório após a implementação da LVSC da OMS (de 2,1\% para 2,5\%). Porém, não ficou claro no estudo se este aumento foi causado pela aplicação da LVSC. Os autores também reportaram redução nas taxas de ISC (4,4\% para $3,5 \%)$ e de mortalidade (1,9\% para 1,6\%) com o uso da $\operatorname{LVSC}^{(67,241)}$.

Kearns et al. ${ }^{(258)}$ relatou em um estudo que 3 meses após a implementação da LVSC da OMS, 30\% dos entrevistados acreditavam que a aplicação do instrumento era inconveniente em casos de emergência. Porém, este percentual encontrado foi menor do que aquele evidenciado antes da implementação de LVSC, quando os funcionários foram perguntados hipoteticamente se acreditavam que o instrumento seria inconveniente em casos de emergência (53\% responderam afirmativamente) $)^{(67,258,259)}$.

Existem algumas preocupações sobre alguns pontos da LVSC que merecem destaque. Alguns profissionais de saúde podem ter uma atitude cética em relação à mudança na rotina, acreditando que a aplicação da LVSC pode causar um aumento significativo na carga de trabalho. Portanto, importante ressaltar que a LVSC apenas formaliza as tarefas que devem ser executadas e não aumentam a carga de trabalho ${ }^{(254)}$. 
Do ponto de vista médico-legal, a aplicação da lista não altera a divisão do trabalho ou a distribuição de responsabilidade na sala operatória. A pessoa que assina a lista de verificação confirma, assim, apenas o que foi implementado, não que o conteúdo esteja necessariamente correto. É verdade, no entanto, que a documentação de aplicação correta pode ser relevante em casos de negligência, onde inexecução de um briefing pode ser interpretado como negligência ${ }^{(252)}$.

\subsubsection{Fatores contribuintes para a implementação exitosa da Lista de Verificação de Segurança Cirúrgica nos serviços de saúde}

Para que o processo de implantação local da LVSC seja altamente efetivo são necessários determinados componentes, a saber: liderança ativa; ampla discussão da temática; boa comunicação multidisciplinar; capacitação da equipe; retorno dos resultados e realização de auditorias regulares ${ }^{(39,247,250)}$.

Conley et al. ${ }^{(250)}$ relataram, em um trabalho qualitativo, que o estabelecimento de um líder persuasivo, engajado, e flexível é necessário para a implementação exitosa da LVSC. Por sua vez, a implementação apropriada da LVSC pode promover a melhoria da comunicação interdisciplinar, ajudando a prevenir conflitos na sala operatória. Ainda, instruções escritas devem estar disponíveis à equipe cirúrgica ${ }^{(252)}$, a exemplo do protocolo para cirurgia segura.

A disponibilização de uma LVSC informatizada bem como a definição prévia de condutores ou coordenadores do instrumento podem facilitar o cumprimento da lista, devido à provável escassez de tempo e ao excessivo número de folhas e formulários que já são preenchidos nas salas operatórias ${ }^{(39,260)}$.

Com o propósito de apoiar localmente o processo de implementação da LVSC, cada serviço cirúrgico pode avaliar o efeito da lista pelo monitoramento das taxas de complicações e óbitos antes e após a sua adoção ${ }^{(9)}$. A avaliação pode ser feita por meio de ${ }^{(234)}: 1$ ) auditoria prospectiva de casos cirúrgicos para identificar as oportunidades nas quais o uso da LVSC poderia prevenir erros e danos; 2) revisão retrospectiva de casos cirúrgicos nos quais as consequências poderiam ter sido alteradas pelo uso da LVSC e 3) coleta prospectiva de "bons casos" durante a etapa inicial da implementação da LVSC, comprovando a utilidade do instrumento. 
O ideal é que a LVSC se torne parte de um plano de segurança perioperatório abrangente, podendo incorporar outras listas de verificação já em uso no serviço de saúde ${ }^{(252)}$.

Desta forma, o sucesso na implementação da LVSC requer, pois, a sua adaptação às rotinas e expectativas de cada local, o que só será possível com o empenho dos dirigentes, assumindo que a segurança do paciente é uma prioridade e que a utilização da lista contribui para torná-la realidade ${ }^{(239)}$.

Um requisito essencial para a implementação exitosa da LVSC é a harmonização do conhecimento e da aceitação da LVSC entre os membros da equipe cirúrgica. Tomados em conjunto, os efeitos da utilização da LVSC sobre os resultados dos pacientes têm sido amplamente reconhecidos e considerados determinantes relevantes para a implementação bem-sucedida ${ }^{(260)}$.

\subsection{Participação dos pacientes e familiares nos cuidados cirúrgicos}

As ações que têm por objetivo envolver os pacientes no seu próprio cuidado são de importância fundamental, sendo que iniciativas de sensibilização do paciente para participação em sua assistência têm sido adotadas por diversas agências e demais instituições internacionais responsáveis pelo desenvolvimento da segurança dos pacientes ${ }^{(9,261)}$. Quando os pacientes e familiares são envolvidos em sua própria segurança, são capazes de participar de estratégias direcionadas para a prevenção de falhas e danos, potencializando sua segurança nos serviços de saúde.

Assim, o envolvimento do paciente como indutor dos cuidados em saúde está sendo cada vez mais reconhecido e abordado na prática clínica e em investigação, e sua participação constitui um peso importante na introdução de novas medidas de segurança nestes serviços ${ }^{(262)}$.

Em um estudo realizado por Russ et al. ${ }^{(262)}$ em 2 hospitais no Reino Unido, foi aplicado um questionário a 141 pacientes com o objetivo de avaliar suas percepções em relação à LVSC. A maioria dos pacientes $(78 \%)$ concordou que gostariam que a LVSC fosse utilizada no caso de realização de cirurgia, em comparação com um número muito pequeno de pacientes $(4,3 \%)$ que não estavam a favor de seu uso. Em linha com esta percepção positiva da LVSC, os pacientes concordaram em grande parte $(74 \%)$ que se sentiriam mais seguros se a LVSC fosse utilizada, $69 \%$ 
dos entrevistados afirmaram que a LVSC melhora a comunicação entre a equipe cirúrgica na sala operatória, e 67\% concordaram que o instrumento seria capaz de reduzir o número de erros durante a cirurgia. Os autores destacaram a necessidade de melhoria na educação pública e dos pacientes para se tornarem mais ativamente envolvidos em prol da melhoria da segurança e atenção à saúde.

As medidas de mitigação de EA só serão efetivas se a sociedade estiver consciente da dimensão dos eventos aos quais está exposta. Para estimular a participação do paciente e de seus familiares no processo do cuidado é muito importante a disponibilização de documentos apropriados que sejam capazes de instrumentalizá-los ${ }^{(1)}$.

A JCAHO também vem reforçando que os pacientes ou seus familiares devem participar ativamente na verificação da segurança cirúrgica, e publicou folhetos informativos direcionados aos pacientes que reforçam o papel importante destes na prevenção de cirurgias em local errado ${ }^{(263)}$.

No Brasil, a ANVISA disponibilizou, em 2012, os materiais educativos previstos no Projeto intitulado "Pacientes pela Segurança dos Pacientes", tais como folder, cartazes, hotsite e vídeos, visando à melhoria da comunicação com os usuários dos serviços de saúde (261). Os materiais foram lançados em 18 de dezembro de 2012, durante reunião do GT Segurança do Paciente e Qualidade em Serviços de Saúde ${ }^{(1)}$.

O folheto informativo da ANVISA sobre o tema orienta o paciente a fazer determinadas perguntas consideradas como estratégicas durante o processo de assistência à saúde, promovendo a boa comunicação com o profissional de saúde. O paciente deve ser informado, por exemplo, sobre os riscos envolvidos em um processo cirúrgico e os cuidados a se tomar antes da cirurgia (como é a cirurgia e o preparo pré-operatório, qual o tempo de duração, quais os resultados esperados, como irá se sentir após a cirurgia e quais são as possíveis complicações cirúrgicas). Ainda, o paciente deve ter certeza que ele e o cirurgião estão de acordo com a cirurgia que será realizada e deve informar ao cirurgião, ao anestesiologista, ao farmacêutico e ao enfermeiro, casos de alergia a medicamentos e reação adversa à anestesiologias $^{(264)}$. 
Todo paciente cirúrgico espera que a equipe cirúrgica aplique todo o seu saber e conhecimento para evitar erros que podem ter graves consequências à sua saúde. Isto pode resultar não só na satisfação de cirurgiões e de pacientes, mas também de toda a sociedade, que aprecia diminuição de gastos desnecessários em função da redução das complicações associadas aos procedimentos cirúrgicos ${ }^{(265)}$. 


\subsection{GERAL}

Analisar o processo de aplicação da LVSC nas salas operatórias de hospitais no DF, no período 2012 a 2014, utilizando-se o intrumento da OMS para a segurança cirúrgica em serviços de saúde.

\subsection{ESPECÍFICOS}

- Avaliar os resultados da implementação da LVSC nas salas operatórias.

- Conhecer as atitudes e opiniões sobre segurança cirúrgica das equipes cirúrgicas antes e após a aplicação da LVSC.

- Depreender os níveis de percepção das equipes cirúrgicas sobre os elementos da atenção anestésico-cirúrgica e a segurança do paciente. 


\subsection{TIPO DE ESTUDO}

Para avaliar aspectos sanitários referentes à segurança do paciente cirúrgico, previstos no Projeto Cirurgias Seguras Salvam Vidas, da ANVISA, envolvendo o planejamento e a sistematização da cirurgia, agregado ao uso da LVSC da OMS (Anexo A), foi desenvolvido um estudo nas salas operatórias de hospitais públicos do DF, na busca de estratégias de minimização de riscos a serem adotadas por outros estabelecimentos de saúde do país.

O presente estudo, devidamente autorizado pela Agência (Anexo B), foi realizado no período 2012 a 2014 e envolveu três etapas: realização de estudo piloto com aplicação da LVSC da OMS (Etapa 1); avaliação das atitudes e opiniões das equipes sobre segurança cirúrgica (Etapa 2) e análise da atenção anestésicocirúrgica e segurança do paciente, a partir da percepção de equipes cirúrgicas (Etapa 3).

$\mathrm{Na}$ primeira etapa realizou-se um estudo transversal, prospectivo, com avaliação Pré (Período I) e Pós-intervenção (Período II) da LVSC, no qual foram analisados 19 itens de segurança nos passos: antes da indução anestésica, antes da incisão cirúrgica e antes da saída do paciente da sala operatória. Ainda nesta etapa, foram analisados itens referentes ao controle pré-operatório, incluindo aqueles relacionados às medidas de prevenção de ISC.

Concomitantemente à realização da avaliação Pré e Pós-intervenção da LVSC, foi desenvolvido, na Etapa 2, um estudo transversal, com a aplicação do instrumento baseado no Safety Attitudes Questionnaire-Operating Room (SAQ$\mathrm{OR})^{(33)}$ com o objetivo de avaliar as atitudes e opiniões sobre segurança cirúrgica dos profissionais dos Centros Cirúrgicos.

$\mathrm{Na}$ última etapa (Etapa 3), procurou-se analisar em um estudo, a atenção anestésico-cirúrgica e a segurança do paciente, a partir da percepção de equipes cirúrgicas. Para isso, foi realizado um estudo quantitativo, descritivo, com delineamento transversal, aplicando-se instrumento de autoavaliação a profissionais das equipes cirúrgicas.

A Figura 3 mostra a linha do tempo do estudo e a implementação da LVSC nos hospitais avaliados. 


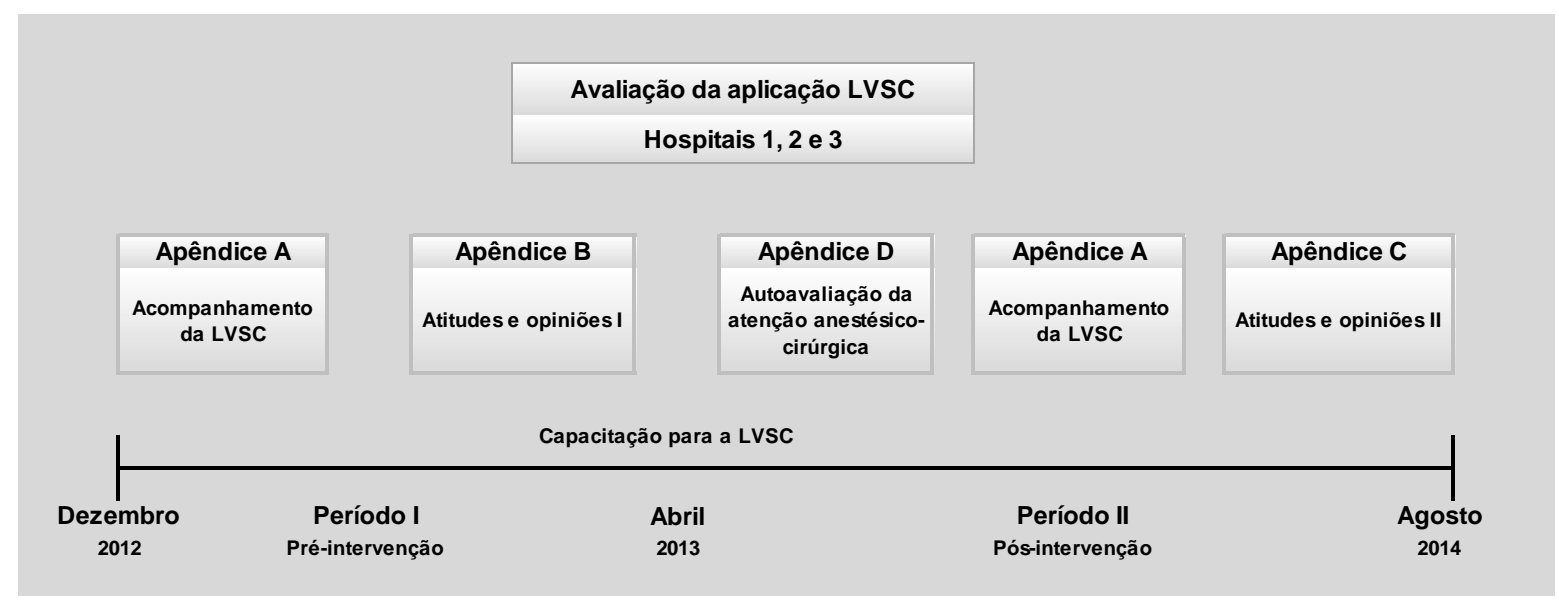

Figura 3. Linha do tempo do estudo e implementação da LVSC nos hospitais avaliados.

\subsection{LOCAL DO ESTUDO}

O estudo foi realizado nos Centros Cirúrgicos de três hospitais públicos da Secretaria de Estado de Saúde do DF (Hospital 1, Hospital 2 e Hospital 3), que integram o SUS, no período de dezembro de 2012 a agosto de 2014.

A escolha dos hospitais para o estudo obedeceu aos seguintes critérios: ser público (SUS); pertencer à Rede Sentinela da ANVISA; e possuir $\geq$ uma sala operatória.

O Hospital 1 é de ensino, atende casos de alta complexidade e dispõe de 748 leitos. A unidade conta com 16 salas operatórias e realizam 7.267 cirurgias/ano, incluindo: Proctologia, Urologia, Ortopedia, Cirurgia Cardiovascular, Cirurgia Plástica, Ginecologia, além das neurológicas, de câncer, traumas e transplantes de órgãos. O Hospital 2 é considerado um hospital geral de média e alta complexidade, com 299 leitos, e é de ensino. Conta com dez salas operatórias com registro de 2905 cirurgias/ano, dentre elas, Cirurgia Geral, Cabeça e Pescoço, Proctologia, Urologia, Ortopedia, Cirurgia Vascular, Cirurgia Plástica e Ginecologia. O Hospital 3 dispõe de 226 leitos, é de ensino, apresenta cinco salas operatórias, nas quais são 
realizadas anualmente, 3695 cirurgias nas especialidades de Cirurgia Geral, Proctologia, Urologia, Ortopedia, entre outras.

\subsection{AMOSTRA}

\subsubsection{ETAPA 1}

O estudo concernente à Etapa 1, com a implementação da LVSC da OMS nas salas operatórias, envolveu 1.141 pacientes no Período Pré-intervenção e 1.052 no Pós-intervenção, totalizando 2.193 pacientes.

\subsubsection{Critérios de inclusão}

Foram incluídos todos os serviços de saúde do DF participantes do Projeto Cirurgias Seguras Salvam Vidas, no período da pesquisa.

A análise do processo de aplicação da LVSC envolveu os dados relacionados aos casos de procedimentos cirúrgicos eletivos realizados em pacientes com 18 anos de idade ou mais, em um dos hospitais, durante o período do estudo.

\subsubsection{Critérios de exclusão}

Foram excluídos da amostra, os procedimentos cirúrgicos eletivos realizados em pacientes com menos de 18 anos de idade submetidos a cirurgias ambulatoriais, pediátricas, cardíacas com circulação extracorpórea e com implantes e próteses, nas unidades de estudo, no período da pesquisa.

\subsubsection{Coleta de dados e intervenção}

O período pré-intervenção ou Período I, por meio de observação direta, deuse de dezembro/2012 a março/2013, no qual as seguintes variáveis foram coletadas, utilizando-se o Apêndice A (Acompanhamento da LVSC): dados demográficos, permanência hospitalar, classificação e duração da cirurgia, tipo de anestesiologia, 
tricotomia - momento e equipamento, antissepsia cirúrgica das mãos, paramentação cirúrgica, drenagem cirúrgica e complicações pós-operatórias.

Foram consideradas complicações pós-operatórias: parada cardíaca necessitando de reanimação cardiopulmonar; intubação não planejada; uso do respirador por 48 horas ou mais; pneumonia; deiscência da ferida operatória; sepse; retorno não planejado à sala operatória; ISC; retenção urinária e óbito ${ }^{(9,28)}$. A revisão dos casos com complicações e óbitos foi realizada por médico cirurgião e profissionais experientes em controle de infecção.

A intervenção consistiu de duas fases: 1) capacitação das equipes cirúrgicas dos três hospitais para uso da LVSC, por especialistas em cirurgia e vigilância sanitária, com carga horária de 18 horas e materiais técnicos da $\mathrm{OMS}^{(9)}, \operatorname{ANVISA}^{(134 \text {, }}$ ${ }^{135)}$ e MS do $\operatorname{Brasil}^{(63,134)}$; 2) implementação da $\operatorname{LVSC}^{(9)}$.

A seguir, prosseguiu-se no levantamento do Período II (pós-intervenção) onde se aplicou a LVSC entre abril/2013 a agosto/2014.

O instrumento de coleta de dados nas duas etapas foi aplicado por pesquisadores, capacitados pelo pesquisador principal nos instrumentos de coleta, incluindo a LVSC, e sem vínculo empregatício com os hospitais participantes. Os critérios para avaliação de currículos, entrevistas e seleção dos pesquisadores envolveram: possuir curso superior de Enfermagem, comprovar experiência em Centro Cirúrgico e dispor de 8 horas diárias durante os dias úteis da semana para as atividades de coleta.

No período pós-intervenção (Período II) foram coletados os mesmos dados do período I, acrescido dos dados da LVSC (Anexo A).

A coleta de dados relativos a complicações e reinternações por motivos relacionados às cirurgias foi realizada até 30 dias após a cirurgia. Na vigilância da ISC utilizaram-se informações das Comissões de Controle de Infecção Hospitalar (CCIH); revisão de prontuários, de egressos e exames microbiológicos; avaliação da ferida operatória e informações do paciente via telefone. Para identificação de ISC, foram utilizados os critérios diagnósticos definidos pela ANVISA ${ }^{(135)}$.

O tamanho da amostra foi calculado para detectar uma redução de $20 \%$ na probabilidade de ocorrer uma complicação no grupo tratamento (pós-intervenção), comparado com o grupo controle (pré-intervenção) - assumindo um nível de significância estatística de 0,05 (valor de alfa) e $80 \%$ de probabilidade de estar 
corretamente rejeitando a hipótese de que não há diferença entre as proporções de complicações pós-cirúrgicas entre os grupos.

\subsubsection{ETAPA 2}

No estudo da Etapa 2, envolvendo a avaliação das atitudes e opiniões sobre segurança cirúrgica, a população foi constituída por 504 profissionais de saúde com atuação nos três Centros Cirúrgicos (cirurgião, anestesiologista, instrumentador, enfermeiro, técnico e auxiliar de enfermagem, residentes e estudantes de Medicina e Enfermagem, além de chefes dos serviços médicos e enfermagem) dos hospitais investigados.

\subsubsection{Critérios de inclusão}

Foram incluídos os profissionais das equipes dos Centros Cirúrgicos, inclusive chefe de serviço médico ou de enfermagem, estudante da Graduação ou PósGraduação que estivessem por, no mínimo, duas semanas no Centro Cirúrgico ou escalado para o trabalho no período da coleta de dados.

\subsubsection{Critérios de exclusão}

Os critérios de exclusão envolveram os profissionais que não estivessem atuando, no mínimo, por duas semanas no Centro Cirúrgico e que estavam ausentes por férias, licenças ou outros afastamentos durante a coleta de dados.

\subsubsection{Coleta de dados}

Os profissionais foram abordados nos locais de trabalho e quando disponíveis para participação no estudo.

Os dados foram coletados por meio do instrumento "Avaliação de Atitudes e Opiniões sobre Segurança Cirúrgica em Serviços de Saúde" I (Apêndice B), com base no SAQ-OR modificado ${ }^{(36)}$, incluindo as dimensões percepção de segurança do 
paciente, comunicação e trabalho em equipe, bem como acrescidas questões sobre a LVSC ${ }^{(33)}$.

Após realização do pré-teste, o instrumento intitulado "Avaliação de Atitudes e Opiniões sobre Segurança Cirúrgica em Serviços de Saúde I" (Apêndice B) foi aplicado duas semanas após a finalização do instrumento "Acompanhamento da LVSC" (Apêndice A), no Período I, e antes do início do Período II. O questionário "Avaliação de Atitudes e Opiniões sobre Segurança Cirúrgica em Serviços de Saúde II" (Apêndice C), com questões acrescidas sobre a LVSC, foi aplicado duas semanas após a finalização do Apêndice A e antes do término do Período II.

\subsubsection{ETAPA 3}

No período do estudo, a população foi constituída por 149 profissionais dos Centros Cirúrgicos dos três Centros Cirúrgicos, entre cirurgiões, anestesiologistas, instrumentadores, enfermeiros, técnicos e auxiliares de enfermagem, residentes de cirurgia e anestesiologia, além de chefes dos serviços médicos e de enfermagem. Os profissionais foram abordados nos locais de trabalho em momentos que estavam disponíveis para participação no estudo, respondendo ao instrumento de autoavaliação.

\subsubsection{Critérios de inclusão}

Foram incluídos os profissionais das equipes dos Centros Cirúrgicos, inclusive chefe de serviço médico ou de enfermagem, estudante da Graduação ou PósGraduação.

\subsubsection{Critérios de exclusão}

Os critérios de exclusão envolveram os profissionais que estavam ausentes por férias, licenças ou outros afastamentos durante a coleta de dados. 


\subsubsection{Coleta de dados}

A coleta de dados foi realizada durante a implantação da LVSC da OMS, prevista no Projeto Cirurgias Seguras Salvam Vidas da ANVISA (2012-2014).

A participação deu-se por meio do preenchimento de instrumento estruturado e autoaplicável intitulado Autoavaliação da atenção cirúrgica e anestésica em serviços de saúde (Apêndice D), no período de maio e junho de 2013. O instrumento foi desenvolvido utilizando-se os critérios de referência da literatura e da legislação sanitária federal brasileira(116), que orienta para a existência de infraestrutura e padrões mínimos necessários ao funcionamento dos Centros Cirúrgicos, além de elementos envolvendo as equipes tradicionalmente envolvidas nos procedimentos cirúrgicos e segurança do paciente ${ }^{(76)}$. Também foi utilizado para elaboração do instrumento de coleta, o Roteiro de Autoinspeção e Inspeção da Secretaria Municipal de Saúde e Defesa Civil do Rio de Janeiro ${ }^{(37)}$.

O instrumento de autoavaliação foi constituído por 27 questões objetivas, agrupadas de acordo com os critérios de estrutura física e operacional, além de questões específicas sobre a realização de ações voltadas para a segurança do paciente. Para cada questão, o respondente deveria marcar uma única alternativa.

Os participantes não receberam o questionário com antecedência e não foi dado tempo para preparar suas respostas. O objetivo era obter respostas espontâneas dos participantes, garantindo simultaneamente 0 anonimato e a confidencialidade.

\subsection{ANÁLISE ESTATÍSTICA}

Para os estudos constantes nas Etapas 1, 2 e 3, as respostas foram transcritas para o formulário online SurveyMonkey, sendo cada inserção revisada pelo pesquisador. Na formação do banco de dados utilizou-se o software Statistical Package for the Social Sciences (SPSS), versão 16.0.

No estudo referente à Etapa 1, para o planejamento amostral foi utilizado o teste exato de Fisher para comparar as proporções das amostras por grupo, identificando diferenças entre perfis. Foram calculadas proporções dos itens da LVSC (Pré e a Pós-intervenção) e entre hospitais, considerando o total de 
observações. Na comparação entre as fases pré e pós-intervenção foram utilizados os testes não paramétrico de Kruskal-Wallis, considerando o nível de significância de 5,0\% e Mann-Whitney. Para a identificação dos principais itens com problema de adesão à LVSC, utilizou-se o gráfico de Pareto.

No estudo da Etapa 2, o p-valor foi calculado com base no teste MannWhitney para a diferença na distribuição dos Períodos I e II.

Para a análise estatística do estudo referente à Etapa 3, foi utilizado o teste Qui-quadrado para verificar diferença na distribuição das variáveis categóricas.

\subsection{ASPECTOS ÉTICOS DA PESQUISA}

O projeto de pesquisa foi protocolado e aprovado junto ao Comitê de Ética em Pesquisa (CEP) da Faculdade de Ciências da Saúde, da Universidade de Brasília (Unb), tendo obtido parecer favorável em 12 de janeiro de 2012, conforme Anexo C. As instituições de saúde onde o estudo foi realizado receberam Termo de Consentimento Livre e Esclarecido (TCLE) informando sobre a pesquisa, o sigilo dos dados, bem como, a livre escolha em participar. O TCLE utilizado está indicado no Apêndice $\mathrm{E}$. 
5. RESULTADOS E DISCUSSÃO 
O estudo permitiu compreender os resultados da análise do processo de aplicação da LVSC em hospitais no DF, no período 2012 a 2014, utilizando-se o intrumento da OMS para a segurança cirúrgica em salas operatórias dos serviços de saúde.

Os resultados são apresentados seguindo a sequência das três etapas do estudo: resultados da avaliação da aplicação da LVSC da OMS (Etapa 1); resultados da avaliação das atitudes e opiniões de segurança das equipes cirúrgicas (Etapa 2) e resultados da análise da atenção anestésico-cirúrgica e segurança do paciente, a partir da percepção de equipes cirúrgicas (Etapa 3).

5.1 RESULTADOS DA ETAPA 1 - AVALIAÇÃO DA APLICAÇÃO DA LISTA DE VERIFICAÇÃO DE SEGURANÇA CIRÚRGICA DA ORGANIZAÇÃO MUNDIAL DA SAÚDE EM HOSPITAIS PÚBLICOS DO DISTRITO FEDERAL, BRASIL

Artigo submetido ao Journal of Infection and Public Health. 2015 (Anexo D).

\section{Avaliação da aplicação da lista de verificação de segurança cirúrgica da OMS em hospitais públicos do Distrito Federal, Brasil}

WHO Safety Surgical Checklist implementation evaluation in public hospitals in the Brazilian Federal District

\section{Summary}

The World Health Organization (WHO) created the WHO Surgical Safety Checklist to prevent adverse events in operating rooms. The aim of this study was to analyze the results of the WHO checklist implementation in three operating rooms of public hospitals in the Brazilian Federal District. A prospective cross-sectional study was carried out with pre (Period I) and post (Period II) checklist intervention evaluations. In the Period I, 1,141 patients were studied, and 1,052 in Period II, totaling 2,193 patients. Period I took place from December 2012 to March 2013 and Period II occurred from April 2013 to August 2014. Regarding preoperatory items, most surgeries were classified as clean-contaminated in both phases and team attire improved from $19.2 \%$ to $71.0 \%$ in Period II. As for checklist adherence in Period II, it was noted that "Patient identification" significantly improved in the stage "Before induction of anesthesia". "Allergy verification", "Airway obstruction verification", and "Risk of blood loss assessment" had low adherence in all three hospitals. The items in the stage "Before surgical incision" showed greater than $90.0 \%$ adherence, except for "Anticipated 
critical events: Anesthesia team review" (86.7\%) and "Essential imaging display" (80.0\%). In the stage "Before patient leaves operating room" low "Instrument counts" and "Equipment problems" were noted. Complications and deaths were low in both periods. Despite the findings of checklist item compliance variation in the surveyed hospitals, the WHO checklist implementation as an intervention tool showed good adherence to the majority of items from the list. Nevertheless, motivation to use the instrument by the surgical team with the intent of improving surgical patient safety continues to be crucial.

Keywords: Surgical checklist, Adverse events, Patient safety, Surgical team, Infection control.

\section{Introduction}

Errors and surgical adverse events (AEs) require the development of effective preventive measures that promote patient safety. Data from 56 countries show that 234 million major surgeries are performed every year [1], resulting in seven million postoperative complications (50.0\% of which could be avoided) and one million deaths $[1,2]$. In developed countries, complications in major surgical practice range from $3.0 \%$ to $16.0 \%$, with a mortality rate from $0.4 \%$ to $0.8 \%$, compared to $5.0 \%$ to $10.0 \%$ in developing countries [2].

In the United States, one AE is estimated in 50,000 to 100,000 surgical procedures, which represents 1,500-2,500 incidents/year [2-4]. Also in the US, in 126 cases of AEs, more than $70.0 \%$ of the cases were wrong-site surgery, $13.0 \%$ wrong patient, and $11.0 \%$ involved the wrong procedure [2]. In Brazil, few studies assess the magnitude of surgical AEs. Mendes et al. [5] reported 5.9\% of AEs in three public hospitals in Rio de Janeiro, of which $65.8 \%$ were preventable.

Given the scale of the problem of surgical AEs, the WHO created the Surgical Safety Checklist, with possible adaptation to local services [2]. Results from the use of the WHO checklist, including Haynes et al's. [6] multicenter study conducted with 7,688 patients, showed a reduction of major complications from $11.0 \%$ to $7.0 \%$, a $36.0 \%$ drop ( $p<0.001$ ), and a decrease of $47.0 \%$ in mortality, from $1.0 \%$ to $0.8 \%(p=0.03)$. Askarian, Kouchak \& Palenik [7] observed a reduction in AEs from $22.9 \%$ to $10.0 \%$ in a teaching hospital in Iran. In 2014 in Norway, from the 2,212 surgical procedures that did not use the checklist and the 2,263 cases that adopted that tool, a reduction 
in complications was reported, from $19.9 \%$ to $11.5 \%(p<0.001)$, and in deaths, from $1.9 \%$ to $0.2 \%(p=0.020)$ in one of the two hospitals studied [8].

In Brazil an observational and cross-sectional study carried out in 2012 in two hospitals in the state of Rio Grande do Norte by Freitas et al. [9] reviewed the implementation of the WHO checklist in 375 surgeries, finding that $61.0 \%$ used the checklist, but only $4.0 \%$ of them were filled out completely. According to the authors, adherence to the tool needs to be improved in order to raise awareness among surgeons about the importance of its use.

Since 2009 Ferraz [10] has been stressing the need to enhance surgical safety. In 2013 the Brazilian Ministry of Health $(\mathrm{MoH})$ created the National Patient Safety Program reinforcing the importance of surgical safety $[11,12]$.

A pilot study on the implementation of the WHO checklist was developed in public hospitals in the Federal District in order to map out strategies to be adopted by other health facilities in the country. This study aims to analyze the results of the implementation of the checklist in three public hospitals in the Brazilian Federal District.

\section{Material and Methods}

\section{Study Design}

This is a prospective cross-sectional study with pre- and post-intervention evaluation of the WHO checklist. Inclusion criteria were: elective surgeries and patients 18 years old or older. Outpatient, pediatric and cardiac surgeries (due to the seriousness of the patient's condition and/or the stress of the team/patient, especially in surgeries with cardiopulmonary bypass), surgical emergency, and surgeries with implants and prostheses (due to the need for lengthy post-operative follow up, which would make data collection related to the occurrence of infection more difficult) were excluded. The same inclusion and exclusion criteria were applied to the pre- and postintervention phases.

\section{Settings}

The study was conducted in three public hospitals in the Brazilian Federal District from December 2012 to August 2014 (Table 1). 
Table 1 Features of public hospitals participating in the study - Federal District, 2015.

\begin{tabular}{|c|c|c|c|}
\hline Features & Hospital 1 & Hospital 2 & Hospital 3 \\
\hline District & Federal District & Federal District & Federal District \\
\hline Type & Public & Public & Public \\
\hline$N^{0}$. of beds & 748 & 299 & 226 \\
\hline $\begin{array}{l}N^{0} \text {. of surgical } \\
\text { beds }^{a}\end{array}$ & 482 & 68 & 72 \\
\hline $\begin{array}{l}\mathrm{N}^{0} \text {. of operating } \\
\text { rooms }\end{array}$ & 16 & 10 & 5 \\
\hline $\begin{array}{l}N^{0} \text {. of surgeries per } \\
\text { year }\end{array}$ & 7,267 & 2,905 & 3,695 \\
\hline
\end{tabular}

\section{Data collection and Intervention}

The pre-intervention phase (Period I), through direct observation by the researcher took place from December 2012 to March 2013, when the following data were collected: demographics, hospital stay data, classification and duration of surgery, type of anesthesia, trichotomy - time and equipment, surgical hand antisepsis, surgical attire, surgical drainage, surgical specialties and postoperative complications. Complications were considered to be: cardiac arrest requiring cardiopulmonary resuscitation, unplanned intubation, use of ventilator for 48 hours or more, pneumonia, wound dehiscence, sepsis, unplanned return to the operating room (OR), surgical site infection (SSI), urinary retention, and death [2, 6, 13].

The intervention consisted of two phases: 1) surgical team training (surgeons, anesthetists, nursing team) in the three hospitals to improve checklist use, which was conducted by experts in surgery and health surveillance with a workload of 18 hours and technical materials provided by the WHO [2] and 2) WHO checklist implementation. Afterwards, the Period II survey (post-intervention) was conducted, when the checklist was applied by a trained researcher who participated directly with the surgical teams, from April 2013 to August 2014 and the same data from Period I were collected in addition to the checklist data (Table 2). Counted on the participation of all of the professionals (surgeons, anesthetists, nursing team, Hospital Infection 
Control Committee - HICC, quality risk management) in the checklist training. Despite the fact that the training was not mandatory, heads of services signed an agreement to train staff and implement the checklist in their institutions In both phases the data collection instrument was applied by trained researchers (nurses) without any employment relationship with the participating hospitals.

Data collection for complications and readmissions due to surgery-related problems was gathered up to 30 days after the surgery. For the SSI surveillance, information from the HICC, review of discharged patient records and of microbiological tests, wound assessment, and patient information via phone was used. SSI identification was performed by diagnostic criteria defined by ANVISA [13], based on CDC's guideline (14). The review of the cases with complications and deaths had the full support of surgeons with experience in infection control.

The sample size was calculated to detect a $20.0 \%$ reduction in the probability of a complication in the treatment group (post-intervention) compared with the control group (pre-intervention) - assuming a 0.05 level of statistical significance (alpha value) and $80.0 \%$ probability of correctly rejecting the hypothesis that there is no difference between the proportions of post-surgical complications between the groups. 
Table 2 Constant variables in the Surgical Safety Checklist ${ }^{\mathrm{a}}$.

\section{Checklist}

\section{Before induction of anesthesia (Sign in)}

Item 1 - Patient identification

Item 2 - Surgical site demarcation

Item 3 - Pulse oximeter placement

Item 4 - Pulse oximeter functioning

Item 5 - Allergy verification

Item 6 - Airway obstruction verification

Item 7 - Risk of blood loss assessment

\section{Before skin incision (Time out)}

Item 8 - Surgical team member introduction

Item 9 - Surgical team verbally confirms patient data

Item 10 - Anticipated critical events: Surgeon review

Item 11 - Anticipated critical events: Anesthesia team review

Item 12 - Anticipated critical events: Nursing team review

Item 13 - Antibiotic prophylaxis

Item 14 - Essential imaging display

\section{Before patient leaves operating room (Sign out)}

Item 15 - Name of the procedure is recorded

Item 16 - Instrument count

Item 17 - Specimen labeling

Item 18 - Equipment problems

Item 19 - Patient recovery and patient management review

${ }^{a}$ Based on the WHO Surgical Safety Checklist [2].

\section{Data analysis}

Fisher's exact test was used for sample design in order to compare the sample proportions per group, thus identifying differences between profiles.

The software SPSS version 11.5 for Windows was used for analysis. Proportions of checklist items were calculated (pre- and post-intervention) and between hospitals, taking into consideration the total number of observations. Nonparametric KruskalWallis and Mann-Whitney tests were used to compare the pre- and post-intervention phases, with a significance level of $5.0 \%$. A Pareto chart was used to identify those items in the checklist with low adherence. 


\section{Ethical considerations}

The study was approved by the Ethics Committee of the University of Brasilia (UnB), Opinion $\mathrm{N}^{0}$. 185/12.

\section{Results}

The characteristics of the 2,193 patients are shown in Table 3, with 1,141 patients in Period I (pre-intervention) and 1,052 in Period II (post-intervention). The average age of patients in the pre- and post-intervention phases was 47.2 years and 49.4 years, respectively. Most patients were female in both phases, 64.9\% and $62.0 \%$, respectively.

Most surgeries were classified as clean-contaminated in both phases, $56.9 \%$ and $49.8 \%$, respectively. General anesthesia was predominant in both phases, $46.8 \%$ and $49.7 \%$, respectively. The average stay was less than 15 days for $82.8 \%$ of the patients in Period I and $88.0 \%$ in Period II, with a significant reduction of stay after intervention for those with more than 15 days of hospitalization (Table 3). 
Table 3 Patient and surgical procedure characteristics according to checklist intervention phase (Period I - Pre and Period II Post), in hospitals in the Federal District. Brazil, 2012 - 2014.

\begin{tabular}{|c|c|c|c|c|c|c|c|c|c|c|c|c|c|c|c|c|}
\hline \multirow{3}{*}{$\begin{array}{l}\text { Patient and surgical } \\
\text { procedure } \\
\text { characteristics }\end{array}$} & \multicolumn{4}{|c|}{ Hospital 1} & \multicolumn{4}{|c|}{ Hospital 2} & \multicolumn{4}{|c|}{ Hospital 3} & \multicolumn{4}{|c|}{ Total } \\
\hline & \multicolumn{2}{|c|}{ Period I } & \multicolumn{2}{|c|}{ Period II } & \multicolumn{2}{|c|}{ Period I } & \multicolumn{2}{|c|}{ Period II } & \multicolumn{2}{|c|}{ Period I } & \multicolumn{2}{|c|}{ Period II } & \multicolumn{2}{|c|}{ Period I } & \multicolumn{2}{|c|}{ Period II } \\
\hline & No. & $\%$ & No. & $\%$ & No. & $\%$ & No. & $\%$ & No. & $\%$ & No. & $\%$ & No. & $\%$ & No. & $\%$ \\
\hline $\begin{array}{l}\text { Number of surgeries } \\
\text { Sex }\end{array}$ & 516 & 100.0 & 526 & 100.0 & 348 & 100.0 & 229 & 100.0 & 277 & 100.0 & 297 & 100.0 & 1141 & 100.0 & 1052 & 100.0 \\
\hline e & & 44.9 & 206 & 40.6 & 91 & 27.8 & 55 & 27.4 & 53 & 23.7 & 119 & 40.9 & 369 & & 380 & 38.0 \\
\hline & & 55.1 & 302 & 59.4 & 236 & 72.2 & 146 & 72.6 & 171 & & 172 & 59.1 & & & 620 & \\
\hline & & 100.0 & 508 & 100.0 & 327 & 100.0 & 201 & 100.0 & 224 & 100.0 & 291 & 100.0 & 1052 & 100.0 & 1000 & 100.0 \\
\hline & \multicolumn{4}{|c|}{0.162} & \multicolumn{4}{|c|}{0.908} & \multicolumn{4}{|c|}{$<0.001$} & \multicolumn{4}{|c|}{0.169} \\
\hline \multicolumn{17}{|l|}{ Age group } \\
\hline & 62 & 12.5 & 31 & 6.3 & 31 & & 27 & 13.4 & 27 & 12.2 & 29 & 10.2 & 120 & 11.6 & 87 & 8.9 \\
\hline & & 13. & 80 & 16.1 & 92 & & 46 & 22 & 50 & & & 20.7 & & & 185 & \\
\hline & & 17.0 & 103 & 20.8 & 87 & 27 & 50 & 24.9 & 55 & & 71 & 24.9 & 22 & 8 & 224 & 22.8 \\
\hline & & 18.0 & 107 & 21.6 & 68 & & 45 & 22 & 32 & 14 & 49 & 17.2 & 18 & 18 & 201 & 20.5 \\
\hline & & 38.6 & 175 & 35. & 40 & & 3 & 16 & 58 & 26 & & 27.0 & & 27 & 285 & 29 \\
\hline & & 100.0 & 496 & 100.0 & 318 & 100.0 & 201 & 100 & 222 & 100.0 & 285 & 100.0 & 10 & 100.0 & 982 & 100.0 \\
\hline$p$-value ${ }^{a}$ & \multicolumn{4}{|c|}{0.744} & \multicolumn{4}{|c|}{0.482} & \multicolumn{4}{|c|}{0.395} & \multicolumn{4}{|c|}{0.072} \\
\hline \multicolumn{17}{|l|}{ Surgery classification } \\
\hline & & & 228 & 44.9 & 40 & & & 15 & 104 & & 166 & 57.2 & & & 424 & 42.5 \\
\hline & 0 & 44.0 & 238 & 46.9 & 264 & 80.5 & 153 & 76 & 116 & 51 & 106 & 36.6 & 600 & 56.9 & 497 & 49.8 \\
\hline & 3 & 7.6 & 31 & 6.1 & 24 & 7.3 & 16 & 8. & 4 & & 15 & 5.2 & & & 62 & 6.2 \\
\hline & 2 & 5.0 & 11 & 2.2 & 0 & - & 1 & 0. & 2 & & 3 & & & & 15 & 1.5 \\
\hline Total & 500 & 100.0 & 508 & 100.0 & 328 & 100.0 & 200 & 100.0 & 226 & 100.0 & 290 & 100.0 & 1054 & 100.0 & 998 & 100.0 \\
\hline$p$-value ${ }^{a}$ & \multicolumn{4}{|c|}{0.147} & \multicolumn{4}{|c|}{0.291} & \multicolumn{4}{|c|}{$<0.001$} & \multicolumn{4}{|c|}{0.007} \\
\hline
\end{tabular}




\section{Surgery duration}

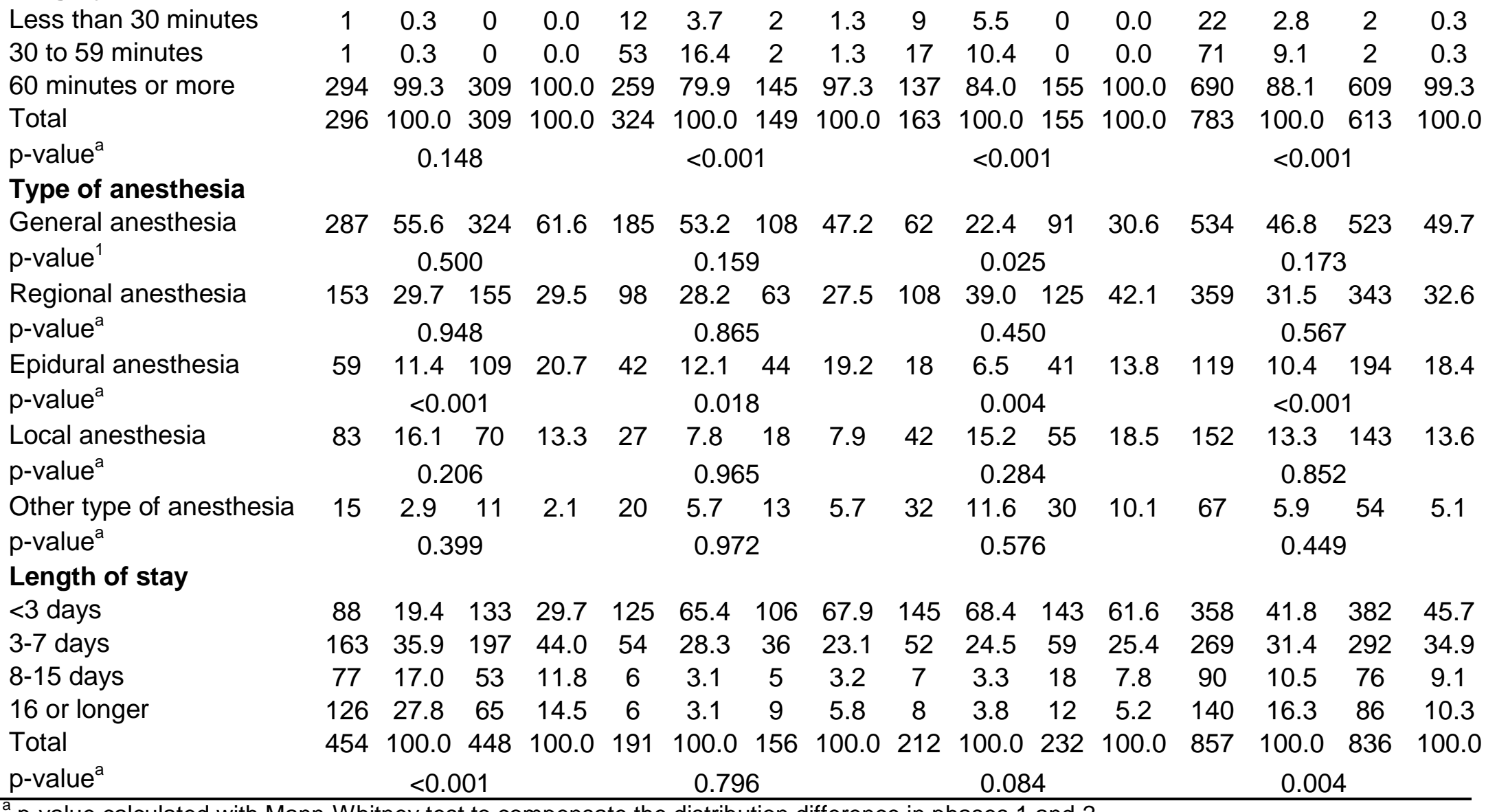

${ }^{a} p$-value calculated with Mann-Whitney test to compensate the distribution difference in phases 1 and 2.

- No observation. 
Table 4 shows four important measures for the prevention of SSI that were evaluated: hair removal using razor blades in about $20 \%$ of the surgeries and performed over 2 hours before the surgery in $70 \%$ of the cases in both phases, except in Hospital 2; surgical hand antisepsis performed by all surgeons, which improved in all three hospitals (10.2\%); surgical attire, which improved from $19.2 \%$ to $71.0 \%$, with special attention to Hospital 3, which presented 100\% "incomplete" (when any one of the items that should be used during the surgical procedure such as sterile aprons, sterile gloves, masks, shoe covers, caps, or goggles was not used) in Period I and improved to 69.8\% "complete" in Period II. The most common surgical specialties in both periods were general ( $n=877)$, urology $(n=301)$, mastology $(n=278)$ and gynecology $(n=223)$ (Table 4), with the median length of stay 2.0, 6.0, 2.0 and 3.0 days, respectively. 
Table 4 Pre-operatory control item assessment and specialties according to checklist intervention period (Period I - Pre and Period II - Post) by hospital in the Federal District. Brazil, 2012 - 2014.

\begin{tabular}{|c|c|c|c|c|c|c|c|c|c|c|c|c|c|c|c|c|}
\hline \multirow{3}{*}{$\begin{array}{l}\text { Infection prevention procedures } \\
\text { and specialties }\end{array}$} & \multicolumn{4}{|c|}{ Hospital 1} & \multicolumn{4}{|c|}{ Hospital 2} & \multicolumn{4}{|c|}{ Hospital 3} & \multicolumn{4}{|c|}{ Total } \\
\hline & \multicolumn{2}{|c|}{ Period I } & \multicolumn{2}{|c|}{ Period II } & \multicolumn{2}{|c|}{ Period I } & \multicolumn{2}{|c|}{ Period II } & \multicolumn{2}{|c|}{ Period I } & \multicolumn{2}{|c|}{ Period II } & \multicolumn{2}{|c|}{ Period I } & \multicolumn{2}{|c|}{ Period II } \\
\hline & No. & $\%$ & No. & $\%$ & No. & $\%$ & No. & $\%$ & No. & $\%$ & No. & $\%$ & No. & $\%$ & No. & $\%$ \\
\hline Number of surgeries & 516 & 100.0 & 526 & 100.0 & 348 & 100.0 & 229 & 100.0 & 277 & 100.0 & 297 & 100.0 & 1141 & 100.0 & 1052 & 100.0 \\
\hline \multicolumn{17}{|c|}{ P } \\
\hline With clipper & 1 & 0.2 & 0 & - & 4 & 1.2 & 0 & - & 0 & - & 4 & 1.4 & 5 & 0.5 & 4 & 0.4 \\
\hline With razor blade & 118 & 23.5 & 119 & 23.3 & 49 & 14.8 & 35 & 17.3 & 80 & 35.4 & 40 & 13.7 & 247 & 23.3 & 194 & 19.3 \\
\hline No removal & 58 & 11.5 & 14 & 2.7 & 2 & 0.6 & 0 & 0.0 & 42 & 18.6 & 9 & 3.1 & 102 & 9.6 & 23 & 2.3 \\
\hline Not applicable & 326 & 64.8 & 377 & 73.9 & 276 & 83.4 & 167 & 82.7 & 104 & 46.0 & 238 & 81.8 & 706 & 66.6 & 782 & 78.0 \\
\hline Total & 503 & 100.0 & 510 & 100.0 & 331 & 100.0 & 202 & 100.0 & 226 & 100.0 & 291 & 100.0 & 1060 & 100.0 & 1003 & 100.0 \\
\hline$p$-value ${ }^{a}$ & \multicolumn{4}{|c|}{0.015} & \multicolumn{4}{|c|}{0.857} & \multicolumn{4}{|c|}{$<0.001$} & \multicolumn{4}{|c|}{$<0.001$} \\
\hline \multicolumn{17}{|l|}{ Trichotomy interval } \\
\hline $\begin{array}{l}2 \text { hours or more before the surgical } \\
\text { procedure }\end{array}$ & 116 & 98.3 & 118 & 99.2 & 3 & 5.8 & 7 & 20.0 & 55 & 68.8 & 25 & 56.8 & 174 & 69.6 & 150 & 75.8 \\
\hline $\begin{array}{l}\text { Less than } 2 \text { hours before the } \\
\text { surgical procedure }\end{array}$ & 2 & 1.7 & 1 & 0.8 & 49 & 94.2 & 28 & 80.0 & 25 & 31.3 & 19 & 43.2 & 76 & 30.4 & 48 & 24.2 \\
\hline Total & 118 & 100.0 & 119 & 100.0 & 52 & 100.0 & 35 & 100.0 & 80 & 100.0 & 44 & 100.0 & 250 & 100.0 & 198 & 100.0 \\
\hline$p$-value ${ }^{a}$ & \multicolumn{4}{|c|}{0.557} & \multicolumn{4}{|c|}{0.042} & \multicolumn{4}{|c|}{0.186} & \multicolumn{4}{|c|}{0.148} \\
\hline
\end{tabular}




\section{Surgical hand antisepsis}

Not performed

$\begin{array}{cccccccccccccccc}0 & - & 0 & - & 1 & 0.3 & 0 & - & 1 & 0.4 & 0 & - & 2 & 0.2 & 0 & - \\ 5 & 1.0 & 0 & - & 33 & 10.1 & 3 & 1.5 & 78 & 34.5 & 18 & 6.2 & 116 & 11.0 & 21 & 2.1 \\ 496 & 99.0 & 510 & 100.0 & 293 & 89.6 & 195 & 98.5 & 147 & 65.0 & 273 & 93.8 & 936 & 88.8 & 978 & 97.9 \\ 118 & 100.0 & 119 & 100.0 & 52 & 100.0 & 35 & 100.0 & 80 & 100.0 & 44 & 100.0 & 250 & 100.0 & 198 & 100.0 \\ & 0.024 & & & <0.001 & & & <0.001 & & & <0.001 & \end{array}$

\section{Team attire}

Complete for only part of the professionals

Complete for all professionals

Incomplete

Total

p-value ${ }^{a}$

\begin{tabular}{cccccccccccccccc}
190 & 37.8 & 17 & 3.3 & 301 & 91.2 & 174 & 87.4 & 0 & - & 2 & 0.7 & 491 & 46.4 & 193 & 19.3 \\
180 & 35.9 & 481 & 94.5 & 23 & 7.0 & 25 & 12.6 & 0 & - & 203 & 69.8 & 203 & 19.2 & 709 & 71.0 \\
132 & 26.3 & 11 & 2.2 & 6 & 1.8 & 0 & 0.0 & 226 & 100.0 & 86 & 29.6 & 364 & 34.4 & 97 & 9.7 \\
501 & 100.0 & 510 & 100.0 & 327 & 100.0 & 198 & 100.0 & 226 & 100.0 & 291 & 100.0 & 1054 & 100.0 & 999 & 100.0 \\
& 0.001 & \multicolumn{1}{c}{0.193} & & & $<0.001$ & & & 0.056 &
\end{tabular}

\section{Surgical drainage}

With closed system

Not performed

Not applicable

Other (specify)

Total

$p$-value ${ }^{a}$

$\begin{array}{cccccccccccccccc}490 & 97.8 & 506 & 99.6 & 74 & 22.4 & 49 & 25.7 & 115 & 50.9 & 98 & 34.3 & 679 & 64.2 & 653 & 66.3 \\ 8 & 1.6 & 0 & - & 0 & - & 2 & 1.0 & 25 & 11.1 & 4 & 1.4 & 33 & 3.1 & 6 & 0.6 \\ 3 & 0.6 & 2 & 0.4 & 249 & 75.5 & 135 & 70.7 & 34 & 15.0 & 169 & 59.1 & 286 & 27.1 & 306 & 31.1 \\ 0 & - & 0 & - & 7 & 2.1 & 5 & 2.6 & 52 & 23.0 & 15 & 5.2 & 59 & 5.6 & 20 & 2.0 \\ 502 & 100.0 & 509 & 100.0 & 330 & 100.0 & 199 & 100.0 & 226 & 100.0 & 291 & 100.0 & 1058 & 100.0 & 999 & 100.0 \\ & 0.011 & & & 0.375 & & & 0.030 & & & 0.260 & \end{array}$




\section{Specialties}

Head and Neck

General

Gynecology

Mastology

Nephrology

Ophthalmology

Otorhinolaringology

Plastic

Pulmonology

Proctology

Thoracic

Urology

Vascular

Total

$\begin{array}{cccccccccccccccl}50 & 9.7 & 59 & 11.3 & 21 & 6.2 & 15 & 6.6 & 1 & 0.4 & 0 & 0.0 & 72 & 6.4 & 74 & 7.1 \\ 138 & 26.8 & 198 & 38.0 & 132 & 39.1 & 108 & 47.2 & 136 & 49.3 & 165 & 55.6 & 406 & 36.0 & 471 & 45.0 \\ 16 & 3.1 & 26 & 5.0 & 62 & 18.3 & 42 & 18.3 & 48 & 17.4 & 29 & 9.8 & 126 & 11.2 & 97 & 9.3 \\ 88 & 17.1 & 86 & 16.6 & 29 & 8.6 & 24 & 10.5 & 29 & 10.5 & 22 & 7.4 & 146 & 12.9 & 132 & 12.6 \\ 2 & 0.4 & 10 & 1.9 & 0 & 0.0 & 0 & 0.0 & 0 & 0.0 & 0 & 0.0 & 2 & 0.2 & 10 & 1.0 \\ 0 & 0.0 & 0 & 0.0 & 1 & 0.3 & 0 & 0.0 & 0 & 0.0 & 0 & 0.0 & 1 & 0.1 & 0 & 0.0 \\ 16 & 3.1 & 13 & 2.4 & 19 & 5.6 & 8 & 3.5 & 0 & 0.0 & 0 & 0.0 & 35 & 3.1 & 21 & 2.0 \\ 12 & 2.3 & 6 & 1.2 & 16 & 4.7 & 3 & 1.3 & 9 & 3.3 & 23 & 7.7 & 37 & 3.3 & 32 & 3.1 \\ 27 & 5.3 & 0 & 0.0 & 8 & 2.4 & 0 & 0.0 & 0 & 0.0 & 0 & 0.0 & 35 & 3.1 & 0 & 0.0 \\ 22 & 4.3 & 17 & 3.3 & 10 & 3.0 & 6 & 2.6 & 11 & 4.0 & 4 & 1.3 & 43 & 3.8 & 27 & 2.6 \\ 17 & 3.3 & 6 & 1.2 & 5 & 1.5 & 0 & 0.0 & 0 & 0.0 & 0 & 0.0 & 22 & 2.0 & 6 & 0.6 \\ 105 & 20.4 & 97 & 18.6 & 35 & 10.4 & 22 & 9.6 & 20 & 7.2 & 22 & 7.4 & 160 & 14.2 & 141 & 13.5 \\ 21 & 4.1 & 3 & 0.6 & 0 & 0.0 & 1 & 0.4 & 22 & 8.0 & 32 & 10.8 & 43 & 3.8 & 36 & 3.4 \\ 514 & 100.0 & 521 & 100.0 & 338 & 100.0 & 229 & 100.0 & 276 & 100.0 & 297 & 100.0 & 1128 & 100.0 & 1047 & 100.0\end{array}$

p-value $^{a}$ $<0.001$ $<0.001$

0.048 0.005

${ }^{\mathrm{a} p} \mathrm{p}$-value calculated with Mann-Whitney test to compensate the distribution difference in Periods I and II.

- No observation 
Table 5 displays adherence to checklist data for Period II (post-intervention) after the completion of each item. In the first stage "Before induction of anesthesia", it was noted that Item 1 (Patient identification) improved significantly in the three hospitals; the same cannot be said about Item 2 (Surgical site confirmation), with average adherence rates lower than $25 \%$. As for Item 3 "Pulse oximeter placement" and Item 4 "Pulse oximeter functioning", adherence was higher than 95\%. Item 5 (Allergy verification), and Item 6 (Airway obstruction verification) and Item 7 (Risk of blood loss assessment) had low adherence in all the three hospitals.

All items in the stage "Before surgical incision" showed adherence higher than $90 \%$, except for Item 11 (Anticipated critical events: Anesthesia team review) and Item 14 (Essential imaging display) with average adherence rates of $86.7 \%$ and $80.0 \%$, respectively.

In the stage "Before patient leaves OR", the low adherence to "Instrument count" (Item 16) in Hospital 2 and "Equipment problems" (Item 18) in Hospitals 2 and 3 is worth mentioning.

Table 5 Safety items marked on the checklist for Period II in hospitals in the Federal District. Brazil, 2012 - 2014.

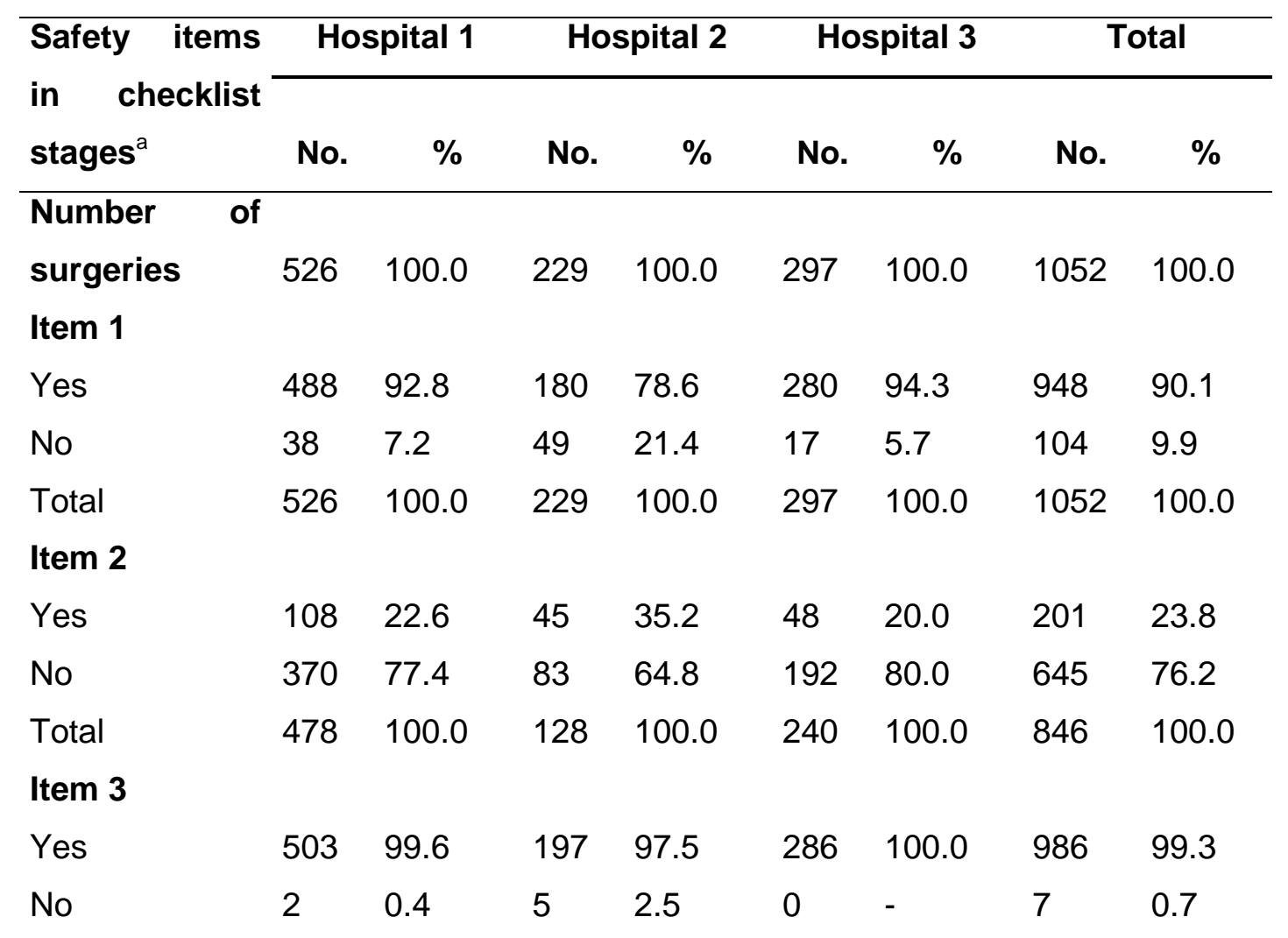




\begin{tabular}{|c|c|c|c|c|c|c|c|c|}
\hline $\begin{array}{l}\text { Total } \\
\text { Item } 4\end{array}$ & 505 & 100.0 & 202 & 100.0 & 286 & 100.0 & 993 & 100.0 \\
\hline Yes & 504 & 99.2 & 196 & 97.5 & 286 & 100.0 & 986 & 99.1 \\
\hline No & 4 & 0.8 & 5 & 2.5 & 0 & & 9 & 0.9 \\
\hline $\begin{array}{l}\text { Total } \\
\text { Item } 5\end{array}$ & 508 & 100.0 & 201 & 100.0 & 286 & 100.0 & 995 & 100.0 \\
\hline Yes & 67 & 13.2 & 29 & 14.5 & 49 & 17.1 & 145 & 14.6 \\
\hline No & 441 & 86.8 & 171 & 85.5 & 238 & 82.9 & 850 & 85.4 \\
\hline $\begin{array}{l}\text { Total } \\
\text { Item } 6\end{array}$ & 508 & 100.0 & 200 & 100.0 & 287 & 100.0 & 995 & 100.0 \\
\hline Yes & 32 & 6.3 & 22 & 11.3 & 45 & 15.6 & 99 & 10.0 \\
\hline No & 474 & 93.7 & 173 & 88.7 & 244 & 84.4 & 891 & 90.0 \\
\hline $\begin{array}{l}\text { Total } \\
\text { Item } 7\end{array}$ & 506 & 100.0 & 195 & 100.0 & 289 & 100.0 & 990 & 100.0 \\
\hline Yes & 58 & 11.4 & 70 & 34.8 & 22 & 7.6 & 150 & 15.0 \\
\hline No & 451 & 88.6 & 131 & 65.2 & 267 & 92.4 & 849 & 85.0 \\
\hline $\begin{array}{l}\text { Total } \\
\text { Item } 8\end{array}$ & 509 & 100.0 & 201 & 100.0 & 289 & 100.0 & 999 & 100.0 \\
\hline Yes & 479 & 94.5 & 184 & 91.1 & 255 & 88.2 & 918 & 92.0 \\
\hline No & 28 & 5.5 & 18 & 8.9 & 34 & 11.8 & 80 & 8.0 \\
\hline $\begin{array}{l}\text { Total } \\
\text { Item } 9\end{array}$ & 507 & 100.0 & 202 & 100.0 & 289 & 100.0 & 998 & 100.0 \\
\hline Yes & 503 & 99.4 & 188 & 93.1 & 282 & 97.9 & 973 & 97.7 \\
\hline No & 3 & 0.6 & 14 & 6.9 & 6 & 2.1 & 23 & 2.3 \\
\hline $\begin{array}{l}\text { Total } \\
\text { Item 10 }\end{array}$ & 506 & 100.0 & 202 & 100.0 & 288 & 100.0 & 996 & 100.0 \\
\hline Yes & 503 & 99.6 & 182 & 91.5 & 245 & 84.8 & 930 & 93.7 \\
\hline No & 2 & 0.4 & 17 & 8.5 & 44 & 15.2 & 63 & 6.3 \\
\hline $\begin{array}{l}\text { Total } \\
\text { Item } 11\end{array}$ & 505 & 100.0 & 199 & 100.0 & 289 & 100.0 & 993 & 100.0 \\
\hline Yes & 501 & 99.4 & 117 & 59.4 & 242 & 83.7 & 862 & 86.7 \\
\hline No & 3 & 0.6 & 80 & 40.6 & 47 & 16.3 & 132 & 13.3 \\
\hline $\begin{array}{l}\text { Total } \\
\text { Item } 12\end{array}$ & 504 & 100.0 & 197 & 100.0 & 289 & 100.0 & 994 & 100.0 \\
\hline Yes & 503 & 99.8 & 201 & 100.0 & 287 & 99.3 & 991 & 99.7 \\
\hline No & 1 & 0.2 & 0 & - & 2 & 0.7 & 3 & 0.3 \\
\hline
\end{tabular}




\begin{tabular}{|c|c|c|c|c|c|c|c|c|}
\hline $\begin{array}{l}\text { Total } \\
\text { Item } 1\end{array}$ & 504 & 100.0 & 201 & 100.0 & 289 & 100.0 & 994 & 100.0 \\
\hline Yes & 505 & 99.8 & 172 & 98.9 & 223 & 96.5 & 900 & 98.8 \\
\hline No & 1 & 0.2 & 2 & 1.1 & 8 & 3.5 & 11 & 1.2 \\
\hline $\begin{array}{l}\text { Total } \\
\text { Item } 1\end{array}$ & 506 & 100.0 & 174 & 100.0 & 231 & 100.0 & 911 & 100.0 \\
\hline Yes & 491 & 97.0 & 149 & 74.1 & 156 & 54.2 & 796 & 80.0 \\
\hline No & 15 & 3.0 & 52 & 25.9 & 132 & 45.8 & 199 & 20.0 \\
\hline Total & 506 & 100.0 & 201 & 100.0 & 288 & 100.0 & 995 & 100.0 \\
\hline \multicolumn{9}{|c|}{ Item 15} \\
\hline Yes & 501 & 99.4 & 3 & 1.6 & 248 & 85.2 & 752 & 76.1 \\
\hline No & 3 & 0.6 & 190 & 98.4 & 43 & 14.8 & 236 & 23.9 \\
\hline Total & 504 & 100.0 & 193 & 100.0 & 291 & 100.0 & 988 & 100.0 \\
\hline \multicolumn{9}{|c|}{ Item 16} \\
\hline Yes & 500 & 98.4 & 4 & 2.0 & 197 & 67.7 & 701 & 70.2 \\
\hline No & 8 & 1.6 & 195 & 98.0 & 94 & 32.3 & 297 & 29.8 \\
\hline Total & 508 & 100.0 & 199 & 100.0 & 291 & 100.0 & 998 & 100.0 \\
\hline \multicolumn{9}{|c|}{ Item 17} \\
\hline Yes & 450 & 100.0 & 139 & 97.9 & 163 & 96.4 & 752 & 98.8 \\
\hline No & 0 & - & 3 & 2.1 & 6 & 3.6 & 9 & 1.2 \\
\hline Total & 450 & 100.0 & 142 & 100.0 & 169 & 100.0 & 761 & 100.0 \\
\hline \multicolumn{9}{|c|}{ Item 18} \\
\hline Yes & 470 & 92.9 & 26 & 13.8 & 9 & 3.1 & 505 & 51.4 \\
\hline No & 36 & 7.1 & 163 & 86.2 & 279 & 96.9 & 478 & 48.6 \\
\hline Total & 506 & 100.0 & 189 & 100.0 & 288 & 100.0 & 983 & 100.0 \\
\hline \multicolumn{9}{|c|}{ Item 19} \\
\hline Yes & 506 & 100.0 & 4 & 2.0 & 277 & 95.8 & 787 & 79.2 \\
\hline No & 0 & 0.0 & 195 & 98.0 & 12 & 4.2 & 207 & 20.8 \\
\hline Total & 506 & 100.0 & 199 & 100.0 & 289 & 100.0 & 994 & 100.0 \\
\hline
\end{tabular}

${ }^{a}$ Indicated in Table 2.

Taking the three hospitals into consideration, $70 \%$ of the adherence problems referred to Items 2, 5, 6, and 7 as shown by the Pareto charts in Figure 1 (1a, 1b, 1c, and $1 \mathrm{~d})$.

The frequency of surgical complications was low in both phases, with SSI $(2.0 \%)$ in the pre-intervention phase, unplanned return to the OR (1.4\%), and wound 
dehiscence $(1.1 \%)$ standing out. Other complications (cardiac arrest, unplanned intubation, use of ventilator for 48 hours or more, pneumonia, sepsis, urinary retention, and death) accounted for $1.0 \%$. In the post-intervention phase, none of the complications mentioned above reached $1.0 \%$ of the cases, without statistically significant change in the distribution of the percentage of complications in both phases.

1a) Total:

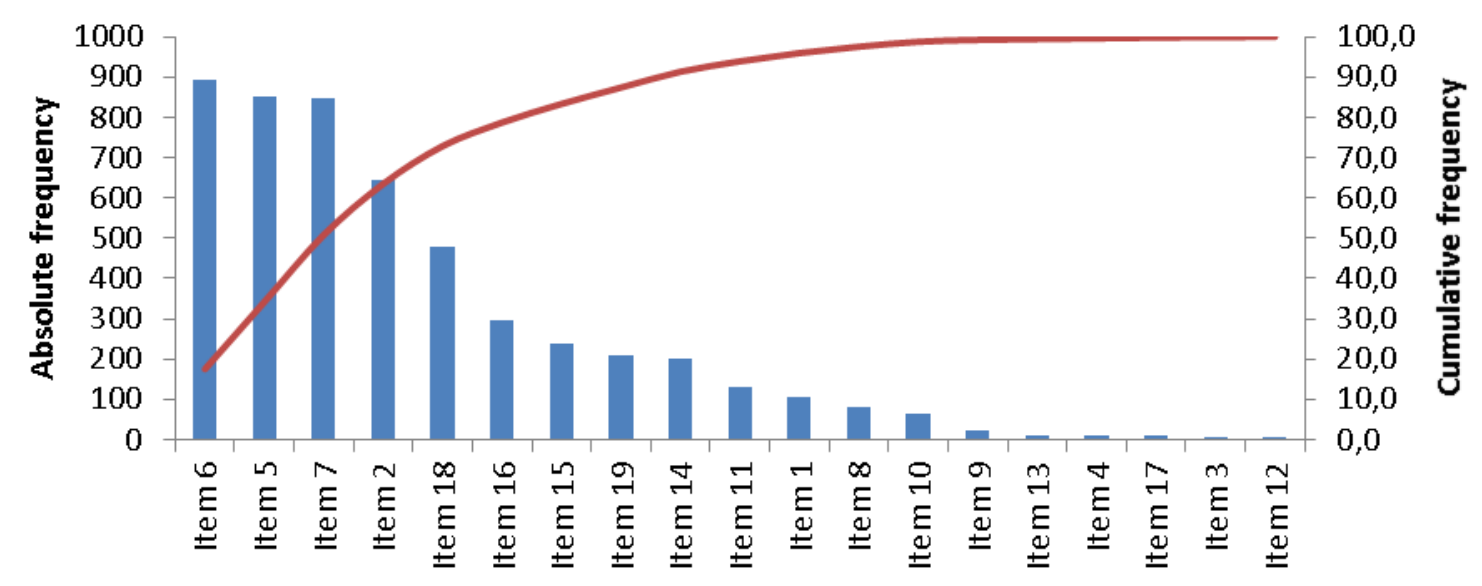

1b) Hospital 1:

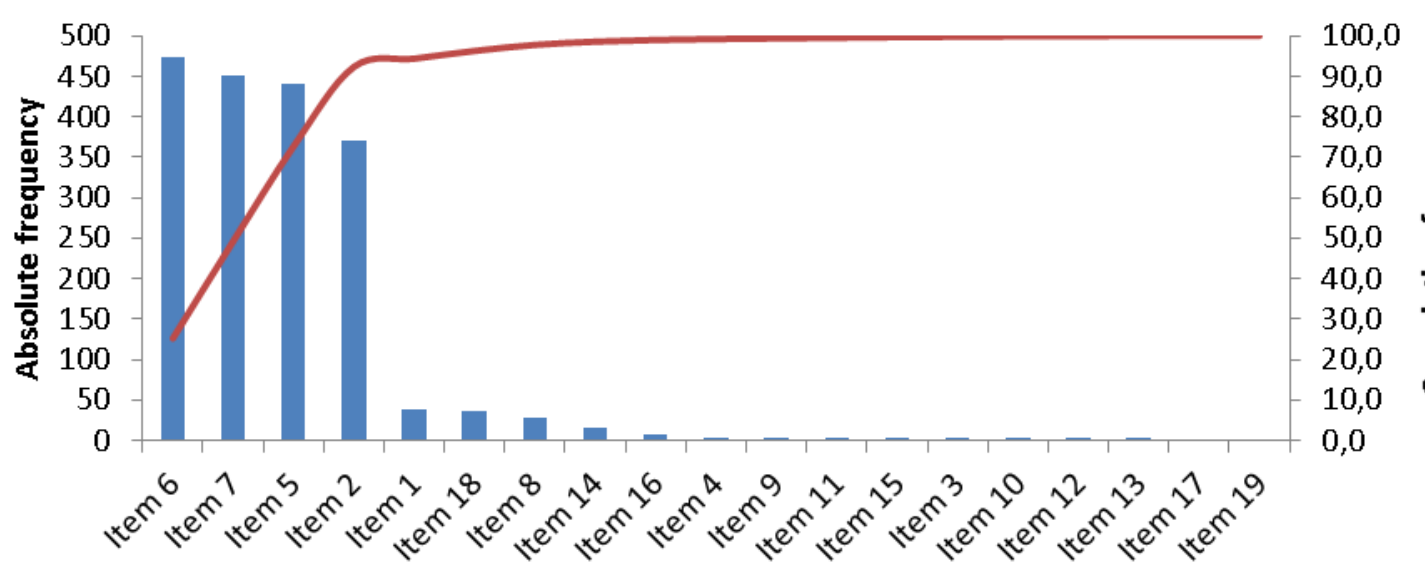


1c) Hospital 2:

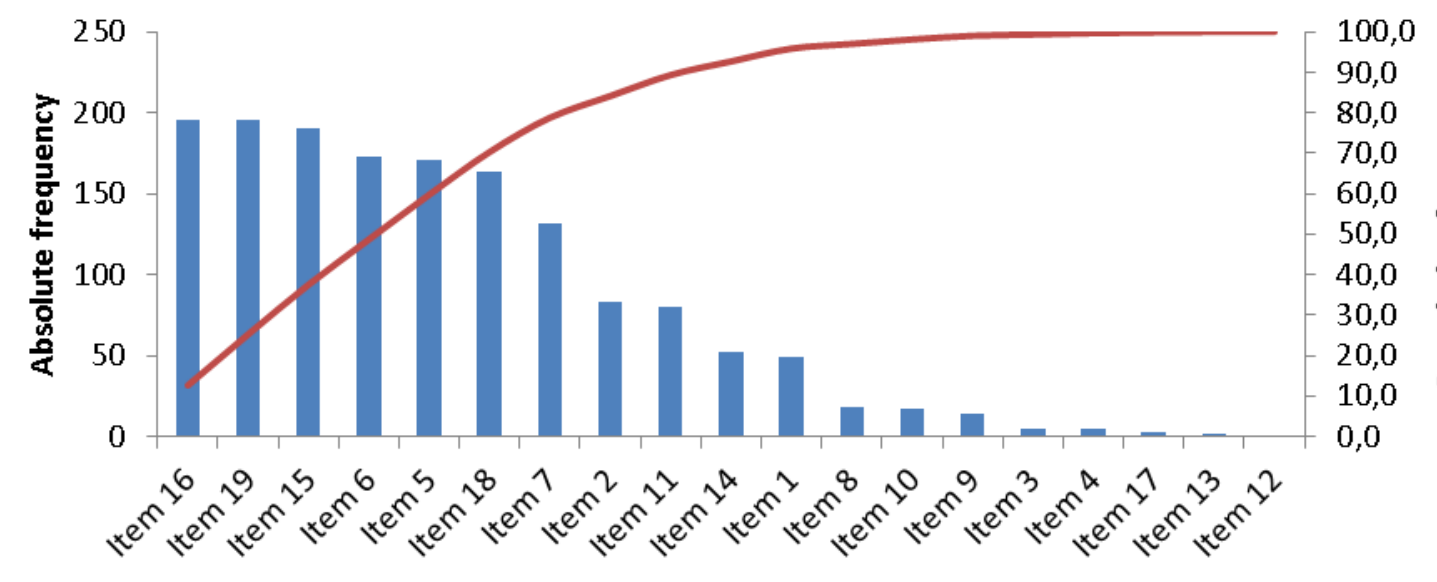

100,0

80,0

70,0

60,0

50,0

30,0

20,0

10,0

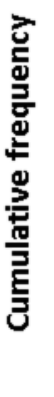

1d) Hospital 3:

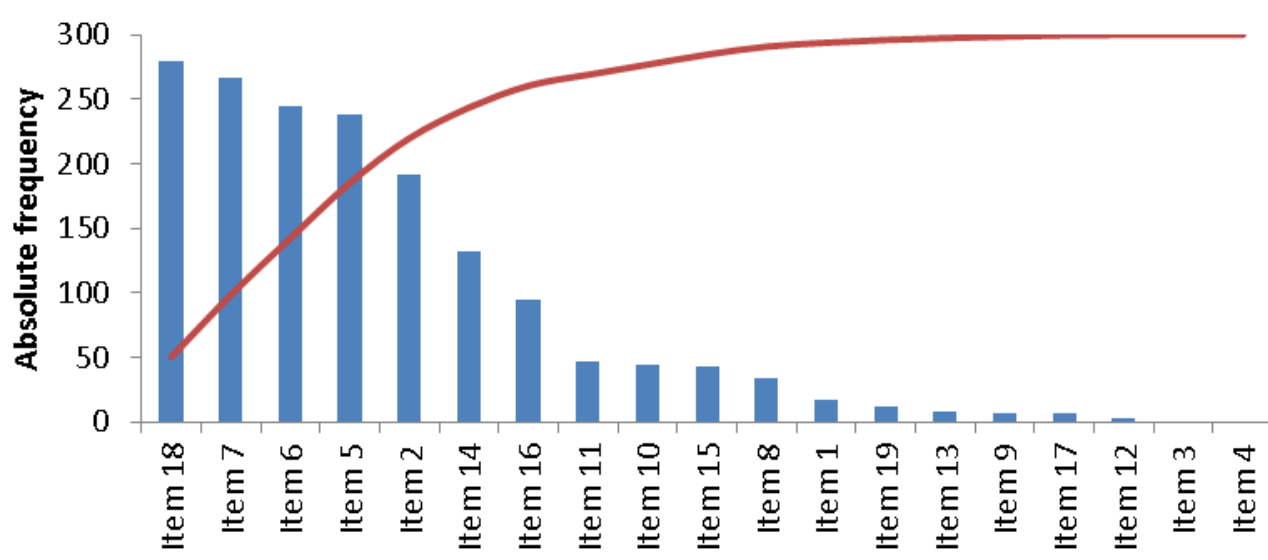

100,0

80,0

60,0

40,0

20,0

0,0

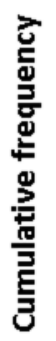

Figure 1 Pareto chart for the least frequently adhered to items in relation to the total and per hospital in the Federal District. Brazil, 2012 - 2014. 


\section{Discussion}

Considering the low adherence to items in different stages of the WHO Surgical Safety Checklist reported by other authors [15, 16], good levels of compliance for most of the checklist items were reported in this study after the implementation of the checklist, showing a positive initiative for patient safety.

In the first stage of the checklist, "Before induction of anesthesia", the $90 \%$ adherence to Item 1 (Patient identification) represents quality improvement and is in accordance with the findings of other authors. Biffl et al. [17] studied adherence to the Surgical Safety Checklist items in 10 hospitals in Colorado (USA) in 850 surgeries (elective, urgent, and emergency), and found that compliance with the items in this stage was better, especially Item 1, with $95.0 \%$ to $99.0 \%$ adherence. Considerable levels of verification for Item 1 (94.3\%) were also observed in Freitas et al's. [9] study. It should be noted that during the present study, one of the hospitals adopted wristbands for patient identification, which may have influenced the improvement of this result.

On the other hand, poor adherence to "Surgical site demarcation" (Item 2) in this study can be attributed to the exclusion of orthopedic surgeries with implant/prosthesis in which the demarcation of the surgical site is essential. In addition, the instrument needed to perform the surgical site demarcation was not available during part of the study. Similar to the present study, Kasatpibal et al. [18], evaluating 4,340 patients who underwent surgical procedures in Thailand, showed reduced compliance with surgical site demarcation (19.4\%). Khorshidifar, Kadkhodaee \& Zamen [19] reported a $24 \%$ adherence in two hospitals in Tehran. Seiden \& Barach [6] analyzed multiple databases in search of AEs with the wrong patient, wrong site, wrong side, and wrong procedure surgeries, identifying 5,940 records in which demarcation before the surgery was made in only $24.0 \%$ of the patients. In a pediatric hospital in Argentina, surgical site demarcation was done in $56.0 \%$ of the cases [20]. Adherence to surgical site checking was also considered low in the work of Garnerin et al. [21] (32.2\% to 52.0\%).

Hospitals already systematically used signal processing methods for pulse oximetry, resulting in adherence superior to $99 \%$ to Items 3 and 4 . "Risk of blood loss assessment" (Item 7) was observed in only $15 \%$ of the cases in this study. This finding shows that the surgical teams need to give more importance to this item.

Regarding the stage "Before skin incision", there was satisfactory compliance with safety items (Items 8-13), including antibiotic prophylaxis been given within the last 60 minutes. The initial part of this stage is important to facilitate communication between professionals [2]. Adequate levels of confirmation were seen in Item 8 (Surgical team member introduction) during the time out stage was observed. The high level of confirmation of this item in our study may have been supported by the use of tables hanging on the OR walls indicating, among other things, the names of 
the surgical team members. The low adherence (54.2\%) to Item 14 (Essential imaging display) in Hospital 2 is similar to that found by Freitas et al. [9]; i.e., $54.0 \%$ in all of the surgeries assessed in the study, and by Kasatpibal et al. [18], with $64.4 \%$.

In general, adherence to the items that pertain to the last stage, "Before patient leaves the OR" was inferior to the adherence in the first two stages, ranging from $51.4 \%$ on Item 18 (Equipment problems) to $98.8 \%$ in Item 17 (Specimen labeling). The high occurrence of issues related to insufficient equipment problem checks (Item 18) at this stage draws our attention. The checklist coordinator should ensure that equipment problems that have occurred during surgery are identified, reported, and documented by the team [2]. In Khorshidifar, Kadkhodaee \& Zamen's study [19], the lowest adherence to the checklist items was related to equipment problem checking. In our study, despite the existence of difficulties observed in the substitution as well as in the maintenance of hospital equipment, the need for a better understanding of the importance of this item for the safety of the surgical teams is essential.

Low adherence to Item 16 (Instrument count) involving swab, sponge, and needle counts was observed in Hospital 2. In procedures in which the count was performed, in $80.0 \%(n=16)$ of the cases, it was finalized and checked when the patient was no longer in the OR, contrary to what is recommended by the checklist [2]. These findings show that the need for the surgical teams to be made aware of the importance about checking this item on the checklist is fundamental. Hospital 2 showed a great weakness in Item 19 (Patient recovery and patient management review), which brought the average of the three hospitals down. Nugent et al. [22] in Ireland revealed that Item 19 was one of the most omitted from the list $(38.0 \%)$ and, for those authors, it was probably affected by reduced interdisciplinary communication, similar to what occurred in the Brazilian Federal District. It is known that the surgeon, anesthesiologist, and nurse must review the postoperative recovery plan, focusing particularly on anesthetic or surgical issues that may interfere with patient recovery [2]. In the checklist run through in this study it was noted that some members of the surgical teams did not respond to or confirm these items orally when asked. This can be due to the rotation of residents/interns; however, for the new residents/interns, the checklist training was conducted by faculty members. Studies are needed to investigate ways to improve and sustain surgical team member compliance with the checklist, which would increase its acceptance, especially in teaching hospitals in developing countries.

In the context of this study, hair removal was routinely performed in hospitals with a statistically significant reduction between the periods investigated. However, most of the procedures used razor blades and not electric clippers, as recommended by the WHO [2] and CDC [14]. This may have occurred due to a lack of clippers in the hospitals studied. Another non-compliance was the two-hour or longer gap between hair removal and surgery $[2,14]$, which may have occurred as a result of a lack of attention to or the failure to follow SSI prevention protocols by the surgical teams. "Complete" team attire (aprons, gloves, masks, shoe covers, caps, and goggles or 
protective masks) by all professionals on duty improved from $19.2 \%$ to $71.0 \%$. Surgeon hand antisepsis presented improvement between the two periods and was carried out by most professionals. The results of the evaluations of team attire and surgical hand antisepsis may reflect that such procedures are already routine practice in those facilities surveyed. The prevalence of clean-contained surgeries during Periods I and II can be explained by the high frequency of gynecological and digestive tract surgeries in this study. Surgical drainage was used in most of the cases [14], with a closed system in both periods.

A significant reduction in hospital stay after intervention reflects the importance of raising awareness of surgical teams to improve the quality of surgical care.

In this study, there was no significant reduction in the rates of surgical complications or deaths. Similarly, other studies, such as Sewell et al. [23] in England and Urbach et al. [24] in Canada, have shown no drop in surgical complications or mortality. Although Bergs et al. [25], in a meta-analysis to assess the association between efficacy and adherence to the WHO Checklist, have concluded that there is evidence of the reduction of both events; however, this cannot be considered as definitive, due to a lack of more substantial studies. In the present study, the fact that some of the hospitals have no systematic monitoring of post-discharge surgical patients as recommended by CDC $[14,26]$ may have contributed to the underreporting of SSI. It is understood that routine post-discharge SSI follow-up by the HICC, audits, and ongoing training can optimize infection prevention and control as well as improve adherence to and use of the checklist by surgical teams.

A limitation of this study can be the possible biases inherent to the prospective design (pre- and post-intervention), the selection bias that excluded emergency surgeries, and surgeries with implants and prosthetics, especially orthopedic procedures and plastic surgeries with prostheses due to the inability to follow up for one year after the surgery, and more complex surgeries, such as cardiac surgeries with cardiopulmonary bypass. Differences in compliances observed in some of the safety checklist items in the hospitals in this study may have occurred due to the hospital type, the diversity of specialties, and to the characteristics of surgical teams and patients. The delay in data collection during Period II due to the World Cup which was held in Brazil (dropouts and cancellations of surgeries), a change in the researcher, and the need for training, in addition to some refusals to apply the checklist (surgeon/patient). The fact that the professionals were aware they were being observed, which might have contributed to behavior changes, also known as the Hawthorne effect [27]. Also, during the research, Brazilian laws were established on patient safety [11,12], probably with better assimilation and conformity of certain safety items by surgical teams. 


\section{Conclusions}

Despite the findings of checklist item compliance variation in the surveyed hospitals, the implementation of the WHO checklist as an intervention tool in this study showed good compliance for most items. However, despite the presence of researchers in the ORs as checklist coordinators during the procedure, some security items were neglected, and should be reinforced with frequent supervision during the checklist training programs.

Managerial attention should be given to the items with greater adherence problems in each facility. In order to improve adherence to the WHO checklist in the health services that were evaluated, the following actions are suggested: managers need to guarantee necessary supplies for the application of the checklist in hospitals; monitoring the supervision of the performance of all of the members of the surgical teams in regards to the checklist and including periodic feedback; permanent training and obligation in regards to checklist implementation, especially for those items that have shown lower levels of adherence; updating local requirements and motivation to use the instrument by the surgical teams with the intent to improve surgical patient safety.

In addition, qualitative studies should be conducted to improve understanding of the reasons for the variable adherence to the checklist items.

Our findings may help guide the decision-making process of managers and health officials in the implementation of the Surgical Safety Checklist in surgical centers in Brazil. Moreover, they can support decision-making for recommendations and regulations by ANVISA on surgical safety.

\section{Acknowledgments}

The authors thank ANVISA for technical collaboration in this study. 


\section{References}

[1] Weiser TG, Regenbogen SE, Thompson KD, Haynes AB, Lipsitz SR, Berry WR, et al. An estimation of the global volume of surgery: a modelling strategy based on available data. Lancet 2008; 372:139-44.

[2] World Health Organization. WHO guidelines for safe surgery. Geneva: WHO; 2009.

[3] Kwaan MR, Studdert DM, Zinner MJ, Gawande AA. Incidence, patterns, and prevention of wrong-site surgery. Arch Surg 2006;14:353-7.

[4] Seiden SC, Barach P. Wrong side/wrong site, wrong-procedure, and wrongpatient adverse events: Are they preventable? Arch Surg 2006;141:931-39.

[5] Mendes W, Martins M, Rozenfeld S, Travassos C. The assessment of adverse events in hospitals in Brazil. Int J Qual Health Care 2009; 2:279-84.

[6] Haynes AB, Weiser TG, Berry WR, Lipsitz SR, Breizat AH, Dellinger EP, et al. A surgical safety checklist to reduce morbidity and mortality in a global population. $\mathrm{N}$ Engl J Med 2009;360:491-9.

[7] Askarian M, Kouchak F, Palenik CJ. Effect of Surgical Safety Checklists on Postoperative Morbidity and Mortality Rates, Shiraz, Faghihy Hospital, a 1-Year Study. Q Manage Health Care 2011; 20:293-7.

[8] Haugen AS, Søfteland E, Almeland SK, Sevdalis N, Vonen B, Eide GE, et al. Effect of the World Health Organization Checklist on Patient Outcomes: A Stepped Wedge Cluster Randomized Controlled Trial. Ann Surg 2015;261:821-8.

[9] Freitas MR, Antunes AG, Lopes BN, Fernandes FdaC, Monte L de C, Gama ZA. Assessment of adherence to the WHO surgical safety checklist in urological and gynecological surgeries at two teaching hospitals in Natal, Rio Grande do Norte State, Brazil. Cad. Saúde Pública 2014; 30:137-148.

[10] Ferraz EM. A XXI century exigence. Rev Col Bras Cir 2009;36:281-82.

[11] Brasil. Ministério da Saúde. Portaria No. 529 de $1^{\circ}$ de abril de 2013. Institui o Programa Nacional de Segurança do Paciente (PNSP). Diário Oficial da União 2013, abr 23.

[12] Brasil. Agência Nacional de Vigilância Sanitária. Resolução da Diretoria Colegiada - RDC No. 36 de 25 de julho de 2013. Institui ações para a segurança do paciente em serviços de saúde e dá outras providências. Diário Oficial da União 2013;26 jul. 
[13] Agência Nacional de Vigilância Sanitária. Manual de Critérios Nacionais de Infecções Relacionadas à Assistência à Saúde - Sítio Cirúrgico [Accessed 2015 mar 10].

Available

from:

http://portal.anvisa.gov.br/wps/wcm/connect/35b4530049bef5c89d01bf6dcbd9c63c/C rit\%C3\%A9rios+S\%C3\%ADtio+Cir\%C3\%BArgico.pdf?MOD=AJPERES .

[14] Mangram AJ, Horan TC, Pearson ML, Silver LC, Jarvis WR. Guideline for Prevention of Surgical Site Infection, 1999. Centers for Disease Control and Prevention (CDC). Hospital Infection Control Practices Advisory Committee. Am J Infect Control 1999;27:97-132; quiz 3-4; discussion 96.

[15] Pickering SP, Robertson ER, Griffin D, Hadi M, Morgan LJ, Catchpole KC, et al. Compliance and use of the World Health Organization checklist in UK operating theatres. Br J Surg 2013; 100:1664-70.

[16] Rydenfält C, Johansson G, Odenrick P, Åkerman K, Larsson PA. Compliance with the WHO surgical safety checklist: deviations and possible improvements. Int $\mathrm{J}$ Qual Health Care 2013; 25:182-7.

[17] Biffl WL, Gallagher AW, Pieracci FM, Berumen C. Suboptimal compliance with surgical safety checklists in Colorado: A prospective observational study reveals differences between surgical specialties. Patient Saf Surg 2015;9:5. doi: 10.1186/s13037-014-0056-z. eCollection 2015.

[18] Kasatpibal N, Senaratana W, Chitreecheur J, Chotirosniramit N, Pakvipas P, Junthasopeepun P. Implementation of the World Health Organization surgical safety checklist at a university hospital in Thailand. Surg Infect (Larchmt) 2012;13:50-6.

[19] Khorshidifar A, Kadkhodaee H, Zamen Z. Degree of Observance of the WHO Surgical Safety Checklist. Trauma Mon. 2012 Autumn;17:315-18.

[20] Dackiewicz N, Viteritti L, Marciano B, Bailez M, Merino P, Bortolato D, et al. Lista de verificación de seguridad de la cirugía: logros y dificultades de su implementación em hospital pediátrico. Arch Argent Pediatr 2012;110:503-8.

[21] Garnerin P, Arès M, Huchet A, Clergue F. Verifying patient identity and site of surgery: improving compliance with protocol by audit and feedback. Qual Saf Health Care 2008;17:454-8.

[22] Nugent E, Hseino H, Ryan K, Traynor O, Neary P, Keane FB. The surgical safety checklist survey: a national perspective on patient safety. Ir J Med Sci 2013;182:1716.

[23] Sewell M, Adebibe M, Jayakumar P, Jowett C, Kong K, Vemulapalli K, et al. Use of the WHO surgical safety checklist in trauma and orthopaedic patients. Int Orthop 2011;35:897-901. 
[24] Urbach DR, Govindarajan A, Saskin R, Wilton AS, Baxter NN. Introduction of surgical safety checklists in Ontario, Canada. N Engl J Med 2014;370:1029-1038.

[25] Bergs J, Hellings J, Cleemput I, Zurel1 Ö, De Troyer V, Van Hiel M, et al. Systematic review and meta-analysis of the effect of the World Health Organization surgical safety checklist on postoperative complications. Br J Surg 2014;101:150-8.

[26] Centers for Disease Control and Prevention. Surgical Site Infection (SSI) Event [Accessed 2015 may 15]. Available from: http://www.cdc.gov/nhsn/PDFs/pscManual/9pscSSIcurrent.pdf?agree=yes\&next=Acc ept

[27] Mayo E. The Human Problems of an Industrial Civilization: Early Sociology of Management and Organizations. New York: Taylor \& Francis Group; 2003. 


\subsection{RESULTADOS DA ETAPA 2 - AVALIAÇÃO DAS ATITUDES DE SEGURANÇA E OPINIÕES DAS EQUIPES SOBRE SEGURANÇA CIRÚRGICA EM HOSPITAIS PÚBLICOS DO DISTRITO FEDERAL, BRASIL}

Artigo submetido à BMC Research Notes. 2015 (Anexo E).

\section{Avaliação das atitudes de segurança e opiniões das equipes sobre segurança cirúrgica em hospitais públicos do Distrito Federal, Brasil}

\section{Clinician's attitudes and opinions towards surgical safety in public hospitals in the Brazilian Federal District}

Background: According to the World Health Organization, the WHO Surgical Safety Checklist can prevent complications, improve communication and contribute to postsurgical safety culture; hence, there is a need to investigate the attitudes and opinions of surgical teams regarding safety utilizing the WHO instrument. The aim of this study was to assess the attitudes and opinions towards surgical safety among operating room professionals in three public hospitals in the Brazilian Federal District. Methods: A cross-sectional study was conducted with the use of a research instrument based on the Safety Attitudes Questionnaire-Operating Room, sent out during the pre- and post-intervention surveys of the WHO Surgical Safety Checklist (Period I and Period II) between 2012 and 2014. Results: About 500 professionals, mostly nurse technicians, responded to the questionnaire in both periods. Regarding the perception of safety and agreement about the collaboration of the operating team, a significant statistical improvement of the nursing staff and anesthesiologists was observed in the operating room after the checklist was implemented. After utilizing the checklist before each surgical procedure, concerns about patient safety and compliance with standards as well as rules and hand-washing practices in the operating room statistically improved after the post-intervention, especially by the nursing staff. The checklist was considered easy and quick to use by most respondents. They also believed that the checklist inclusion improved communication, reflecting significant differences. At least $90.0 \%$ of respondents from each team agreed that the checklist helps prevent errors in the operating room. Conclusions: The study results showed progress in relation to the attitudes and opinions regarding surgical safety from operating teams in relation to the checklist response in the surveyed units. However, difficulties in its implementation are experienced, especially in relation to checklist use acceptance by the surgeons. New studies 
are needed to verify the sustainability of the surgical teams' changes in attitudes in the hospitals studied.

Keywords: Patient safety. Adverse events. Surgery. WHO surgical safety checklist. Attitudes. Operating Room. Health services. Health Surveillance.

\section{Background}

Safety errors can cause damage and injuries to surgical patients, compromising their health during surgery, and can even lead to death $[1,2]$. In the United States, 9,000 sentinel events or never events were reported between 1990 and 2010, including: foreign objects left in a patient after a surgical procedure, wrong patient and wrong procedure, resulting in $6.0 \%$ deaths, $32.9 \%$ permanent and temporary (59.2\%) sequelae at a cost of 1.3 billion dollars [3, 4$]$.

The World Health Organization (WHO) Safe Surgery Saves Lives program addresses the prevention of adverse events (AEs), which includes surgical site infection (SSI) prevention, safe surgical teams, safe anesthesia and surgical services [5]. This initiative, besides the administrative and managerial aspects of health care, prioritizes safety attitudes of surgical teams, given the complexities of the operating room (OR). Furthermore, patient safety culture indicates communication as its main tool, as established by the WHO Surgical Safety Checklist, which can be applied not only to prevent surgical complications, but also to improve dialogue in the OR $[6,7]$.

Given the sensitive nature of surgical care, surgical procedures require integration, communication and multidisciplinary team work among surgeons, anesthesiologists and nursing staff. Therefore, the WHO recommends the use of a surgical safety checklist to improve patient safety [5]. Haugen et al. [8] noted that the attitudes and behaviors of surgical teams reflect the development of safety procedures in the OR. The question to be asked is the following: to what extent do the surgical teams' attitudes regarding safety contribute to the improvement or to the reduction of safety in the OR?

Studies relating team work to cohesion of the surgical team and to safety culture reveal a reduction in patient morbidity and mortality [6, 7, 9]. Also, assessments of attitudes and opinions of surgical teams about quality care and patient safety in the OR identified communication gaps between professionals [6, 10- 
14], which provide opportunities for changes in surgical procedures, excluding the empowerment of surgeons over the other members of the team and reducing gender conflict, which should improve levels of responsibility for complying with items on the list.

Conducting a survey on safety attitudes and morbidity and mortality reduction with the Safety Attitudes Questionnaire - Operating Room (SAQ-OR) [15], Haynes et al. [6] found, in the pre-intervention period, a mean safety attitude score of 3.91 ( $p=$ $0.0381)$ and, in the post-intervention period ( $n=257), 4.01$ in 5 ( $p=0.0127)$, which corresponds to high levels of good attitudes in the OR. In Brazil, researchers have been using the SAQ-OR [16]. Da Correggio, Amante \& Barbosa [17] found a SAQ score below 75 points in operating rooms, revealing that workers do not perceive a climate of safety for performing their work.

An initiative of the Brazilian Health Surveillance Agency (ANVISA) involved, at first, the implementation of the WHO Surgical Safety Checklist in public teaching hospitals in the Brazilian Federal District (DF) as a pilot project to promote strategies for the expansion of this initiative to other health services in the country. This study aims to evaluate the attitudes and opinions regarding surgical safety among operating room professionals in these hospitals before and after implementation of the checklist.

\section{Methods}

\section{Research Design}

A cross-sectional study was performed in surgical centers in three public hospitals in the Federal District Department of Health, in the Central-West region of Brazil, between 2012 and 2014.

The hospitals for the study were chosen based on the following criteria: be public; belong to ANVISA's Sentinel Network (Rede Sentinela); and have one or more ORs. Hospital 1 is a district teaching hospital with a high level of care and has 748 beds. The health unit has 16 ORs and performs 7,267 surgeries/year in the following areas: proctology, urology, orthopedics, vascular surgery, plastic surgery, gynecology, in addition to neurological surgery, cancer, trauma, and organ transplants. Hospital 2 is a federal teaching unit, regarded as a general hospital, which cares for medium to high-risk patients and 299 beds. It has ten ORs and performs 2,905 surgeries/year in the following areas: general surgery, head and neck 
surgery, proctology, urology, orthopedics, vascular surgery, plastic surgery and gynecology. Hospital 3 is a district teaching unit with 226 beds. It has five ORs and performs 3,695 surgeries/year in general surgery, proctology, urology, orthopedics, among others.

\section{Participants}

The study population consisted of 504 health professionals working in three surgical centers (surgeons, anesthesiologists, surgical technologists, nurses, nursing technicians and nursing assistants, resident physicians, medical and nursing students, as well as heads of medical and nursing services) from the hospitals surveyed. Professionals from the surgery team included the chief physician or chief nurse, undergraduate or graduate students who would be scheduled to work for at least two weeks in the operating room or during the data collection period. Exclusion criteria included professionals who were absent due to vacations or other absences during the data collection. Professionals were interviewed in their workplaces when they were available for participation in the study. The interviews were conducted by trained professional nurses.

\section{Data collection}

Data were collected through an Attitude and Opinion Assessment Tool about Surgical Safety in Health Services, based on the SAQ-OR modified questionnaire, including items regarding patient safety perception, communication and teamwork, as well as some questions about checklist implementation [6]. It is important to highlight that in 2011 a content validation study for Brazilian public hospitals under a crosscultural perspective (SAQ-Short Form) showed moderate to strong correlation in each domain for all of the variables, except for the item "stress recognition" [18].

The instrument was concurrently applied while a prospective cross-sectional study was conducted with pre- and post-intervention (Period I - Pre-intervention and Period II - Post-intervention) of the WHO Surgical Safety Checklist, based on ANVISA's project Safe Surgery Saves Lives. All of the respondents are aware of the surgical safety checklist and had been previously trained on its use. After the conclusion of the pre-test stage, the questionnaire was applied two weeks before the beginning of Period I and two weeks after the end of Period II. 


\section{Data analysis}

The $p$-value was calculated using the Mann-Whitney test for the differences in the distribution of Periods I and II. Patients used an online survey builder (SurveyMonkey) to enter their data, which was revised by the researcher. The database was set up with SPSS software, version 16.0 for Windows.

\section{Ethical consideration}

The research project was approved by the Ethics Committee of the University of Brasilia (UnB), Report No. 185/12.

\section{Results}

Out of 504 participants from surgical teams and heads of services, 272 were interviewed before intervention (Period I) and 232 post-intervention (Period II). The gender distribution was predominantly female in both periods, with no statistical difference, except for Hospital 1 (Table 1).

The average age of respondents in the pre-intervention period was 37.2 years and 38.4 years in the post-intervention period, without statistical significance. In relation to hospitals, most of them showed no significant difference between the mean ages and the periods, except for Hospital 1, where, for Period I, the mean was 38.2 years and for Period II, 40.5 years (Table 1 ). The interquartile range was from 15.8 to 16.0 , considering the $1^{\text {st }}$ and $2^{\text {nd }}$ quartiles.

Work experience among interviewed healthcare professionals did not differ statistically between the two periods; the average for Period I was 12.4 years and for Period II, 11.5 years. In relation to the hospitals, only Hospital 2 showed significant difference in mean work experience between the two periods. In Hospital 3, participants had an average of 35 years of experience in healthcare, with no statistical difference between the periods.

In general, regarding work experience, there was no difference between the average years of experience in the current unit for the assessed periods. The average for Period I was seven years and for Period II, six years. The comparison between hospitals in the same period did not show significant difference regarding work experience $(p=0.395)$, except for Hospital 2, where professionals interviewed in Period I had 8.7 years of experience and 5.4 years for Period II. 
Most respondents from Period I were nursing technicians (20.6\%), followed by surgeons $(16.9 \%)$, anesthesiologists $(12.9 \%)$ and surgery resident physicians (12.5\%). In Period II, the nursing technician category was predominant (28.9\%), followed by surgery resident physicians (17.2\%). There was no significant statistical difference in the occupation distribution of respondents considering both periods, in almost all hospitals except for Hospital 2 (Table 1). 
Table 1 Socio-demographic characteristics of surgery teams according to period of intervention using the Surgical Safety Checklist.

\begin{tabular}{|c|c|c|c|c|c|c|c|c|c|c|c|c|c|c|c|c|}
\hline \multirow{3}{*}{$\begin{array}{l}\text { Socio-demographic } \\
\text { characteristics }\end{array}$} & \multicolumn{4}{|c|}{ Hospital 1} & \multicolumn{4}{|c|}{ Hospital 2} & \multicolumn{4}{|c|}{ Hospital 3} & \multicolumn{4}{|c|}{ Total } \\
\hline & \multicolumn{2}{|c|}{ Period I } & \multicolumn{2}{|c|}{ Period II } & \multicolumn{2}{|c|}{ Period I } & \multicolumn{2}{|c|}{ Period II } & \multicolumn{2}{|c|}{ Period I } & \multicolumn{2}{|c|}{ Period II } & \multicolumn{2}{|c|}{ Period I } & \multicolumn{2}{|c|}{ Period II } \\
\hline & $\mathbf{n}$ & $\%$ & $\mathbf{n}$ & $\%$ & $n$ & $\%$ & $\mathbf{n}$ & $\%$ & $n$ & $\%$ & $\mathbf{n}$ & $\%$ & $\mathbf{n}$ & $\%$ & $n$ & $\%$ \\
\hline \multicolumn{17}{|l|}{$\operatorname{Sex}^{\mathrm{a}}$} \\
\hline Male & 38 & 36.2 & 36 & 36.7 & 42 & 56.8 & 35 & 50.7 & 41 & 52.6 & 20 & 47.6 & 121 & 47.1 & 91 & 43.5 \\
\hline Female & 67 & 63.8 & 62 & 63.3 & 32 & 43.2 & 34 & 49.3 & 37 & 47.4 & 22 & 52.4 & 136 & 52.9 & 118 & 56.5 \\
\hline Total & 105 & 100.0 & 98 & 100.0 & 74 & 100.0 & 69 & 100.0 & 78 & 100.0 & 42 & 100.0 & 257 & 100.0 & 209 & 100.0 \\
\hline$p$-value & \multicolumn{4}{|c|}{0.936} & \multicolumn{4}{|c|}{0.471} & \multicolumn{4}{|c|}{0.607} & \multicolumn{4}{|c|}{0.446} \\
\hline \multicolumn{17}{|l|}{$\mathrm{Age}^{\mathrm{b}}$} \\
\hline Mean & \multicolumn{2}{|c|}{38.2} & \multicolumn{2}{|c|}{40.5} & & 37.6 & \multicolumn{2}{|c|}{36.7} & & 35.5 & \multicolumn{2}{|r|}{34.8} & \multicolumn{4}{|c|}{38.4} \\
\hline Median & \multicolumn{2}{|c|}{35.0} & \multicolumn{2}{|c|}{38.0} & & 35.0 & \multicolumn{2}{|c|}{31.0} & & 32.0 & \multicolumn{2}{|c|}{32.0} & \multicolumn{4}{|c|}{36.0} \\
\hline Standard deviation & \multicolumn{2}{|c|}{9.8} & \multicolumn{2}{|c|}{9.7} & & 10.9 & \multicolumn{2}{|c|}{12.1} & & 10.4 & & 9.0 & & 0.3 & & 0.5 \\
\hline Minimum & & 4.0 & & 26.0 & & 22.0 & & 22.0 & & 22.0 & & 25.0 & & 2.0 & & 2.0 \\
\hline Maximum & & 7.0 & & 79.0 & & 63.0 & & 67.0 & & 65.0 & & 57.0 & & 7.0 & & 9.0 \\
\hline IQR (Q3 - Q1) & & 4.0 & & 14.0 & & 18.0 & & 19.5 & & 15.0 & & 13.5 & & 5.8 & & 6.0 \\
\hline Total & & 04.0 & & 13.0 & & 55.0 & & 61.0 & & 77.0 & & 41.0 & & 36.0 & & 15.0 \\
\hline$p$-value & & 0.0 & 35 & & & & 361 & & & & 372 & & & 0.2 & 23 & \\
\hline
\end{tabular}




\section{Occupation}

Anesthesiologist

Nurse Assistant

Surgeon

Nurse

Instrument nurse

Other (specify)

Resident anesthesiologist

Resident surgeon

Resident nurse

$\begin{array}{lllllllllll}7 & 6.7 & 6 & 5.3 & 14 & 15.7 & 10 & 13.2 & 14 & 17.9 & 5\end{array}$

$\begin{array}{lllllllllll}14 & 13.3 & 16 & 14.0 & 6 & 6.7 & 4 & 5.3 & 3 & 3.8 & 4\end{array}$

$\begin{array}{lllllllllll}7 & 6.7 & 8 & 7.0 & 27 & 30.3 & 8 & 10.5 & 12 & 15.4 & 5\end{array}$

$\begin{array}{lllllllllll}9 & 8.6 & 8 & 7.0 & 2 & 2.2 & 1 & 1.3 & 1 & 1.3 & 1\end{array}$

$\begin{array}{lllllllllll}11 & 10.5 & 10 & 8.8 & 6 & 6.7 & 3 & 3.9 & 4 & 5.1 & 1\end{array}$

$\begin{array}{lllll}4 & 3.8 & 1 & 0.9 & 9\end{array}$

$\begin{array}{llllll}10.1 & 11 & 14.5 & 15 & 19.2 & 5\end{array}$

$\begin{array}{lllllllllll}7 & 6.7 & 11 & 9.6 & 3 & 3.4 & 0 & 0.0 & 6 & 7.7 & 7\end{array}$

$\begin{array}{lllllllllll}14 & 13.3 & 14 & 12.3 & 9 & 10.1 & 19 & 25.0 & 11 & 14.1 & 7\end{array}$

$\begin{array}{ccccc}11.9 & 35 & 12.9 & 21 & 9.1 \\ 9.5 & 23 & 8.5 & 24 & 10.3 \\ 11.9 & 46 & 16.9 & 21 & 9.1 \\ 2.4 & 12 & 4.4 & 10 & 4.3 \\ 2.4 & 21 & 7.7 & 14 & 6.0 \\ 11.9 & 28 & 10.3 & 17 & 7.3 \\ 16.7 & 16 & 5.9 & 18 & 7.8 \\ 16.7 & 34 & 12.5 & 40 & 17.2 \\ 0.0 & 1 & 0.4 & 0 & 0.0 \\ 16.7 & 56 & 20.6 & 67 & 28.9 \\ & & 0.055 & \end{array}$

p-value

0.888

0.007

0.631

0.055

Without response (7.5\% of the respondents).

${ }^{\mathrm{b}}$ Without response $(10.5 \%$ of the respondents). 
In relation to safety perception in the OR (Table 2), there was an improvement of favorable responses from nursing staff and anesthesiologists $(p=0.001$ and $\mathrm{p}=0.046$, respectively) after checklist intervention. Regarding the need for verifications before surgery, only the nursing staff showed a significant statistical increase in the post-intervention period $(p<0.001)$. As for the anesthesiologist and surgeon teams, there was no significant change after intervention. The assessment regarding patient safety concerns in the OR improved significantly among the nursing team $(p<0.001)$. Regarding the agreement on teamwork implementation (question 5 ), there was a significant increase in the proportion of favorable responses in the postintervention period among nursing staff and anesthesiologists $(p<0.001$ and $p=0.038$, respectively). In relation to the frequency professionals ignore rules or surgical safety standards and hand hygiene (items 6-8), there was a high percentage of those who never ignored the post-intervention rules among the nursing team, which is a statistically significant response $(p<0.001)$. 
Table 2 Surgical team safety attitudes on surgical safety checklist according to intervention period.

\begin{tabular}{|c|c|c|c|c|c|c|c|c|c|c|}
\hline \multirow{2}{*}{ Questions } & \multirow{2}{*}{ Response } & & \multicolumn{2}{|c|}{ Total } & \multicolumn{2}{|c|}{ Nursing Team } & \multicolumn{2}{|c|}{ Anesthesia Team } & \multicolumn{2}{|c|}{ Surgeon Team } \\
\hline & & & Period I & Period II & Period I & Period II & Period I & Period II & Period I & Period II \\
\hline 1. & Yes & n (\%) & $193(72.8 \%)$ & $189(84.4 \%)$ & $\begin{array}{c}80 \\
(73.4 \%)\end{array}$ & $\begin{array}{c}100 \\
(90.1 \%)\end{array}$ & $\begin{array}{c}32 \\
(62.7 \%)\end{array}$ & $\begin{array}{c}32 \\
(82.1 \%)\end{array}$ & $\begin{array}{c}58 \\
(74.4 \%)\end{array}$ & $\begin{array}{c}46 \\
(79.3 \%)\end{array}$ \\
\hline \multirow[t]{2}{*}{2.} & Essential & n (\%) & $195(72.0 \%)$ & $190(81.9 \%)$ & $\begin{array}{c}76 \\
(67.9 \%)\end{array}$ & $\begin{array}{c}103 \\
(89.6 \%)\end{array}$ & $\begin{array}{c}46 \\
(90.2 \%)\end{array}$ & $\begin{array}{c}34 \\
(87.2 \%)\end{array}$ & $\begin{array}{c}54 \\
(67.5 \%)\end{array}$ & $\begin{array}{c}41 \\
(67.2 \%)\end{array}$ \\
\hline & & $p$-value & \multicolumn{2}{|c|}{0.009} & \multicolumn{2}{|c|}{$<0.001$} & \multicolumn{2}{|c|}{0.654} & \multicolumn{2}{|c|}{0.971} \\
\hline 3. & & $p$-value & \multicolumn{2}{|c|}{$<0.001$} & \multicolumn{2}{|c|}{$<0.001$} & \multicolumn{2}{|c|}{0.592} & \multicolumn{2}{|c|}{0.626} \\
\hline \multirow[t]{2}{*}{4.} & Very easy & n (\%) & $32(12.1 \%)$ & $60(26.3 \%)$ & $\begin{array}{c}13 \\
(12.1 \%)\end{array}$ & 35 (32.7\%) & $\begin{array}{c}10 \\
(20.0 \%)\end{array}$ & $9(25.7 \%)$ & $7(8.8 \%)$ & $\begin{array}{c}15 \\
(32.6 \%)\end{array}$ \\
\hline & & $p$-value & \multicolumn{2}{|c|}{$<0.001$} & \multicolumn{2}{|c|}{0.001} & \multicolumn{2}{|c|}{0.679} & \multicolumn{2}{|c|}{0.009} \\
\hline \multirow[t]{2}{*}{5} & Yes & n (\%) & $175(66.3 \%)$ & $191(83.0 \%)$ & $\begin{array}{c}74 \\
(67.9 \%)\end{array}$ & $\begin{array}{c}101 \\
(88.6 \%)\end{array}$ & $\begin{array}{c}28 \\
(54.9 \%)\end{array}$ & $\begin{array}{c}29 \\
(76.3 \%)\end{array}$ & $\begin{array}{c}54 \\
(70.1 \%)\end{array}$ & $\begin{array}{c}46 \\
(75.4 \%)\end{array}$ \\
\hline & & $p$-value & \multicolumn{2}{|c|}{$<0.001$} & \multicolumn{2}{|c|}{$<0.001$} & \multicolumn{2}{|c|}{0.038} & \multicolumn{2}{|c|}{0.492} \\
\hline
\end{tabular}




\begin{tabular}{|c|c|c|c|c|c|c|c|c|c|}
\hline \multirow[t]{2}{*}{7.} & \multirow[t]{2}{*}{ Never } & n (\%) & $5(1.9 \%)$ & $118(52.0 \%)$ & $1(0.9 \%) \quad 78(69.6 \%)$ & $2(3.9 \%)$ & $\begin{array}{c}17 \\
(44.7 \%)\end{array}$ & $1(1.3 \%)$ & $\begin{array}{c}22 \\
(36.7 \%)\end{array}$ \\
\hline & & $p$-value & \multicolumn{2}{|c|}{$<0.001$} & $<0.001$ & \multicolumn{2}{|c|}{$<0.001$} & \multicolumn{2}{|c|}{$<0.001$} \\
\hline \multirow[t]{2}{*}{8.} & Never & n (\%) & $11(4.1 \%)$ & 119 (52.7\%) & 79 (70.5\%) & $4(8.2 \%)$ & $\begin{array}{c}17 \\
(47.2 \%)\end{array}$ & $1(1.3 \%)$ & $\begin{array}{c}22 \\
(36.1 \%)\end{array}$ \\
\hline & & $\mathrm{p}$-value & \multicolumn{2}{|c|}{$<0.001$} & $<0.001$ & \multicolumn{2}{|c|}{$<0.001$} & \multicolumn{2}{|c|}{$<0.001$} \\
\hline
\end{tabular}


The majority of respondents thought that the checklist was easy to use. However, a significant difference was noted in the proportions of professionals $(p=0.008)$. The checklist was considered by most respondents quick to use, with a significant difference $(p=0.012)$. The question of the use of the checklist in case the respondents were to undergo surgery themselves showed no significant difference in the proportional distribution in relation to the groups (Table 3).

Most groups believed that checklist implementation improved communication: $92.7 \%$ of the nursing team, $87.9 \%$ of the anesthesiologists and $75.6 \%$ of the surgeons, with significant proportional differences $(p<0.001)$. At least $90.0 \%$ of respondents from each team agree that the checklist helps reduce OR errors, with statistical difference between the teams. Moreover, although most respondents also agree that the checklist helps to develop surgical safety culture in the unit, there are significant differences among teams, with $96.4 \%$ in the nursing team, $93.9 \%$ of anesthesiologists and $78.7 \%$ of surgeons (Table 3 ). 
Table 3 Surgical team opinions towards the Surgical Safety Checklist implementation in participating hospitals.

\begin{tabular}{|c|c|c|c|c|c|c|c|c|c|}
\hline \multirow{2}{*}{ Questions } & \multicolumn{2}{|c|}{ Total } & \multicolumn{2}{|c|}{ Nursing Team } & \multicolumn{2}{|c|}{ Anesthesia Team } & \multicolumn{2}{|c|}{ Surgeon Team } & \multirow{2}{*}{$p$-value } \\
\hline & $\mathrm{n}$ & $\%$ & $\mathrm{n}$ & $\%$ & $\mathrm{n}$ & $\%$ & $\mathrm{n}$ & $\%$ & \\
\hline \multicolumn{10}{|l|}{$1^{a}$} \\
\hline Hard to use/fill out & 12 & 5.5 & 5 & 4.5 & 0 & 0.0 & 7 & 13.0 & \multirow{3}{*}{0.008} \\
\hline Easy to use/fill out & 207 & 94.5 & 106 & 95.5 & 39 & 100.0 & 47 & 87.0 & \\
\hline $\begin{array}{l}\text { Total } \\
2^{\mathbf{b}}\end{array}$ & 219 & 100.0 & 111 & 100.0 & 39 & 100.0 & 54 & 100.0 & \\
\hline \multirow{2}{*}{$\begin{array}{l}\text { Brief and quick } \\
\text { Extensive and time } \\
\text { consuming }\end{array}$} & 206 & 92.0 & 105 & 92.9 & 39 & 100.0 & 49 & 86.0 & \multirow{3}{*}{0.012} \\
\hline & 18 & 8.0 & 8 & 7.1 & 0 & 0.0 & 8 & 14.0 & \\
\hline $\begin{array}{l}\text { Total } \\
3^{\mathbf{c}}\end{array}$ & 224 & 100.0 & 113 & 100.0 & 39 & 100.0 & 57 & 100.0 & \\
\hline Yes & 228 & 98.3 & 113 & 98.3 & 39 & 100.0 & 59 & 96.7 & \multirow{3}{*}{0.739} \\
\hline No & 4 & 1.7 & 2 & 1.7 & 0 & 0.0 & 2 & 3.3 & \\
\hline $\begin{array}{l}\text { Total } \\
4^{d}\end{array}$ & 232 & 100.0 & 115 & 100.0 & 39 & 100.0 & 61 & 100.0 & \\
\hline Yes & 172 & 87.8 & 102 & 92.7 & 29 & 87.9 & 31 & 75.6 & \multirow[b]{2}{*}{$<0.001$} \\
\hline $\begin{array}{l}\text { No } \\
\text { Total } \\
\mathbf{5}^{\mathrm{e}}\end{array}$ & $\begin{array}{c}24 \\
196\end{array}$ & $\begin{array}{c}12.2 \\
100.0\end{array}$ & $\begin{array}{c}8 \\
110\end{array}$ & $\begin{array}{c}7.3 \\
100.0\end{array}$ & $\begin{array}{c}4 \\
33\end{array}$ & $\begin{array}{c}12.1 \\
100.0\end{array}$ & $\begin{array}{l}10 \\
41\end{array}$ & $\begin{array}{c}24.4 \\
100.0\end{array}$ & \\
\hline Yes & 217 & 96.9 & 113 & 99.1 & 39 & 100.0 & 51 & 89.5 & \\
\hline $\begin{array}{l}\text { No } \\
\text { Total }\end{array}$ & $\begin{array}{c}7 \\
224\end{array}$ & $\begin{array}{c}3.1 \\
100.0\end{array}$ & $\begin{array}{c}1 \\
114\end{array}$ & $\begin{array}{c}0.9 \\
100.0\end{array}$ & $\begin{array}{c}0 \\
39\end{array}$ & $\begin{array}{c}0.0 \\
100.0\end{array}$ & $\begin{array}{c}6 \\
57\end{array}$ & $\begin{array}{c}10.5 \\
100.0\end{array}$ & $<0.001$ \\
\hline
\end{tabular}


$6^{f}$

\begin{tabular}{lccccccccc} 
Yes & 185 & 91.1 & 106 & 96.4 & 31 & 93.9 & 37 & 78.7 & $<0.001$ \\
No & 18 & 8.9 & 4 & 3.6 & 2 & 6.1 & 10 & 21.3 & $<0$ \\
Total & 203 & 100.0 & 110 & 100.0 & 33 & 100.0 & 47 & 100.0 & \\
\hline
\end{tabular}

$1^{\mathrm{a}}$ In relation to the checklist usability would you consider it: $2^{\mathrm{b}}$ In relation to checklist completion, do you consider it to be a tool? $3^{\mathrm{c}}$ If you were submitted to surgery, would you like the checklist to be used? $4^{\mathrm{d}}$ Was communication improved by using the checklist? $5^{\mathrm{e}}$ Does the checklist help avoid errors in the OR? $6^{\dagger}$ Has the checklist contributed to developing a surgery safety culture in the OR? 


\section{Discussion}

The use of the WHO surgical safety checklist has been mandatory in several countries [14, 19, 20], and in Brazil, several national laws [21-25] and other sanitation regulations [26, 27] were published for the safety of surgical care in health services. The implementation of the checklist in these health units implies an integrated team effort, with greater participation and surgical team situation awareness. In addition, several studies show that the WHO surgical safety checklist can modify personal attitudes of professionals working in ORs [11, 28, 29] and is seen as a tool that improves patient safety [30].

In this study, the members of the participating surgical teams (surgeons, anesthesiologists and nursing staff) had an average of 12 years of experience in the healthcare area and six years in the current surgical unit, which can be translated into appropriate and useful knowledge for the evaluation of attitudes towards surgical safety in the OR.

The survey revealed that, regarding checklist application, most of the nursing staff $(92.9 \%)$ and $100.0 \%$ of anesthesiologists indicated that the checklist is a brief and quick tool, while, in contrast, $14.0 \%$ of surgeons considered it as extensive and time consuming. Recent research suggests that nurses have more positive attitudes towards filling out the checklist compared to surgeons [4, 31, 32]. It is important to recall that the nursing profession is predominantly occupied by females in Brazil and therefore this result could have been influenced by gender. It is noteworthy to mention that some health professionals may have skeptical attitudes towards checklist implementation and/or in relation to changes in their routines since they associate it with a significant expansion in their workloads. However, the checklist only formalizes the tasks to be performed without adding tasks to services [33]. Besides, the filling time is singular and takes from two to three minutes [34].

Regarding communication between surgical team members, according to most respondents (87.8\%), with an emphasis on the nursing teams $(92.7 \%)$ and anesthesiologists (87.9\%), the use of the checklist improved communication. Similar results were reported in other studies [35]; i.e., checklist use helped improve communication within the team [9, 35-38] or between multi-professional teams [39]. It is important to mention that miscommunication between team members is a common cause of adverse events (AEs) or sentinel events (never events), such as surgeries 
performed on the wrong body part. The US Joint Commission reports showed that out of 843 EAs registered, almost $70.0 \%$ of the cases were related to communication problems [39]. In Brazil, about 8,000 incidents were reported by Patient Safety Centers (NSP) to the National Health Surveillance System (SNVS) in 2014, which included 216 never events: five cases of retained foreign objects in a patient after a surgical procedure and one related to intraoperative death or immediate postoperative death in an ASA Class 1 patient [40]. A study with 3,231 orthopedic surgeons during the $44^{\text {th }}$ Brazilian Congress of Orthopedics and Traumatology, in 2012, designed to investigate awareness and knowledge about the WHO Surgical Safety Checklist among Brazilian orthopedic surgeons, showed that $40.8 \%$ of the 502 respondents reported having experienced wrong-site or wrong-patient surgery and $25.6 \%$ of them reported "miscommunication" as a cause for the error [41].

In this study, when asked if the checklist would help prevent errors in the OR, 217 surgical team members $(96.9 \%)$ responded affirmatively, highlighting the nursing teams $(99.1 \%)$ and anesthesiologists (100.0\%). Similar to the studies conducted by Haynes et al. [6], about $80.0 \%$ of the respondents stated that the checklist prevented the occurrence of errors. In other words, surgical team awareness about the potential of this tool to prevent damage to patients in the OR environment is evident. In a descriptive study carried out in three hospitals in Guatemala in 2011 [9], one year after local implementation of the checklist, when professionals were asked if errors committed in the OR could have been avoided by making use of the checklist, $42.5 \%$ (17) of the resident surgery physicians, 63.2\% (28) of the resident anesthesiologists, $100.0 \%$ (6) of the anesthesiologists and $35.7 \%$ (20) of the nursing team gave an affirmative answer. In turn, most of the errors that take place during surgeries can also be attributed to failures related to non-technical skills that the checklist aims to improve, such as situational awareness, the decision-making process, communication between the surgical team and team leader during the performance of tasks [42].

Most respondents in this study $(91.1 \%)$ calling attention to the nursing teams (106) and anesthesiologists (31), stated that the checklist has helped to develop a surgical safety culture in the OR, which may suggest sustained advances in the current regulations in force in Brazil, confirming changing attitudes towards safety in health services. It should be noted that ANVISA RDC Resolution No. 36/2013 [21] defines safety culture as "a set of values, attitudes, skills and behaviors that 
determine the commitment to health and safety management, replacing guilt and punishment with the opportunity to learn from failures and improve health care". In a cross-sectional study conducted during the $97^{\text {th }}$ Annual Congress of the Swiss Society of Surgery in 2010, where the opinions of 138 surgeons and anesthesiologists towards the checklist were surveyed, the majority of respondents (75.4\%) agreed that the checklist helps develop a safety culture in the OR [35], which is also corroborated by the WHO [5]. Research reports that briefing sessions supported by a checklist help maintain an open culture of professional development in the workplace, where training is improved through the exchange of information, communication and opportunity to express one's opinion [43]; i.e., it serves as an anchor for surgical safety culture in the OR.

In this study, it was also found that $98.3 \%$ of participants expressed that they would like the checklist to be used should they themselves be subject to surgery, suggesting that the tool had good acceptance by most participant surgical teams. This finding was similar to the one reported by Haynes et al. [6] in their study, in which $93.0 \%$ of the participants responded positively to that question. In 2015, a study to assess the perceptions of 1,852 members of surgical teams towards several dimensions of surgical safety with the use of a checklist (35 items) in 38 hospitals in South Carolina (USA), showed that almost all members of the teams $(1,237 / 1,852)$ indicated a preference for using this tool if they themselves would be submitted to a surgical procedure [44]. It can be concluded, thus, that the checklist reinforces organizational safety culture and improves communication among the surgical team, and that it is not about mere operational formality or the implementation of a superficial instrument. It replaces, indeed, the illusion of safety with a guiding tool for positive results for the patient in the OR [44].

Regarding participants' attitudes (sense of safety in relation to the hospital), although a significant improvement of favorable response in Period II can be noted among all professionals, including nursing teams and anesthesiologists, such an improvement was not observed among surgeons. Singer et al. [44] found that $15.0 \%$ of all surgical team members and up to $57.0 \%$ in other hospitals indicated that they would not feel safe as a patient in their own ORs. According to the authors, the successful implementation of the checklist should lead to improved surgical safety culture and attitudes in the OR and, as a consequence, lead practitioners to experience greater perceived safety in the care provided. Hence, surgical team 
members could feel safe as patients in the units where they work [45], similar to the results found in this study.

The need for checks before the surgical procedure and patient safety concerns showed significant improvement only among the nursing team (questions 2 and 3, respectively). Studies with similar responses to this sample, as in Haynes et al. [6], found strong agreement among surgical team members in the postintervention period in relation to checklist implementation, considering the same variables in hospitals in the Brazilian Federal District.

Limitations of this study are: the number of participating hospitals, the specific populations in each health service who responded to the instrument, the characteristics of surgical teams, a variety of hospital environments, as well as the several different cases admitted to the OR during the study. Thus, the results may not be applicable to all units. On the one hand, there is the possibility of biases inherent to the prospective design (pre- and post-intervention), because members of surgical teams were aware that the checklist was being implemented and assessed, which may have influenced the provision of answers demonstrating the success of its implementation. On the other hand, the implementation of the checklist itself, together with the training conducted in the hospitals surveyed may have improved communication and therefore led to a better understanding of teamwork and safety culture in these services. Additionally, various laws on patient safety were established in Brazil during the research, including the establishment of the National Program of Patient Safety - PNSP [22] and ANVISA's regulation on the issue [21], as well as the Protocol for Safe Surgery [25], which may have led to better assimilation and or understanding of the importance of surgical safety by the participating teams.

\section{Conclusions}

In general, the study results indicate progress in the attitudes and opinions of surgical safety teams towards the checklist in the assessed units, contributing to further improvement of safety in the OR. However, given the difficulties found in the implementation of the checklist, especially as it relates to the acceptance of the referred instrument by surgeons, it is urgent that health planners draw up new strategies to deal with the problem, in an attempt to make surgeons understand that this is a work procedure, without a hierarchy in which some professionals are dominant over others, with the empowerment of all team members and where care is 
centered on the patient. That is, it is essential that teams override purely technological aspects and make advances in interpersonal relations and communication, with the participation and responsibility of all members in order to increase surgical patient safety.

Furthermore, research on safety culture measurement is suggested, including qualitative studies on the subject in order to clarify these difficulties, as well as costeffectiveness analyses of the checklist in surgical centers in the country. The assessment of patient safety perceptions and behaviors of members of surgical teams allows one to identify the most vulnerable areas so that managers and leaders can promptly intervene in order to solve problems in the OR. Ultimately, methodological strategies for motivational training grounded in appropriate communication with a transversal axis can institute team empowerment, with a focus on a work process that is centered on the patient and that favors attitudes regarding safety. Finally, new studies are necessary in order to verify the sustainability of the surgical teams' changes in attitudes towards safety in the hospitals studied.

\section{References}

1. Needleman J, Buerhaus P, Pankratz S, Leibson CL, Stevens SR, Harris M. Nurse staffing and inpatient hospital mortality. N Eng J Med. 2011;364:1037-45.

2. deVries EM, Ramrattan RM, Smorenburg SM, Gouma DJ, Boermeester MA. The incidence and nature of in-hospital adverse events: a systematic review. Qual Saf Health Care. 2008;17:216-23.

3. Mehtsun WT, Ibrahim AM, Diener-West M, Pronovost PJ, Makary MA. Surgical never events in the United States. Surgery. 2013;153:465-72.

4. O'Connor P, Reddin C, O'Sullivan M, O'Duffy F, Keogh I. Surgical checklists: the human factor. Patient Saf Surg. 2013;7:14.

5. World Health Organization. WHO guidelines for safe surgery. Geneva: WHO; 2009.

6. Haynes AB, Weiser TG, Berry WR, Lipsitz SR, Breizat AH, Dellinger EP, et al. Changes in safety attitude and relationship to decreased postoperative morbidity and mortality following implementation of a checklist-based surgical safety intervention. BMJ Qual Saf. 2011;20:102-07.

7. Kawano T, Taniwaki M, Ogata K, Sakamoto M, Yokoyama M. Improvement of teamwork and safety climate following implementation of the WHO surgical safety checklist at a university hospital in Japan. J Anesth. 2014;28:467-70. 
8. Haugen AS, Murugesh S, Haaverstad R, Eide GE, Søfteland E. A survey of surgical team members' perceptions of near misses and attitudes towards Time Out protocols. BMC Surg. 2013;13:46.

9. Delgado Hurtado JJ, Jiménez X, Peñalonzo MA, Villatoro $C$, de Izquierdo S, Cifuentes M. Acceptance of the WHO Surgical Safety Checklist among surgical personnel in hospitals in Guatemala city. BMC Health Serv Res. 2012;12:169.

10. Papaconstantinou HT, Jo C, Reznik SI, Smythe WR, Wehbe-Janek H. Implementation of a surgical safety checklist: impact on surgical team perspectives. Ochsner J 2013;13:299-309.

11. Makary MA, Sexton JB, Freischlag JA, Holzmueller CG, Millman EA, Rowen L, et al. Operating room teamwork among physicians and nurses: teamwork in the eye of the beholder. J Am Coll Surg. 2006; 202:746-52.

12. Makary MA, Mukherjee A, Sexton JB, Syin D, Goodrich E, Hartmann E, et al. Operating room briefings and wrong-site surgery. J Am Coll Surg. 2007;204:236-43.

13. Carney BT, West P, Neily J, Mills PD, Bagian JP. Differences in nurse and surgeon perceptions of teamwork: implications for use of a briefing checklist in the OR. AORN J. 2010;91:722-9.

14. Fourcade A, Blache JL, Grenier C, Bourgain J, Minvielle E. Barriers to staff adoption of a surgical safety checklist. BMJ Qual Saf. 2012;21:191-197.

15. Sexton JB, Helmreich RL, Neilands TB, Rowan K, Vella K, Boyden J, et al. The Safety Attitudes Questionnaire: psychometric properties, benchmarking data, and emerging research. BMC Health Serv Res. 2006; 6:44.

16. Rigobello MCG, Carvalho REFL, Cassiani SHB, Galon T, Capucho HC, Deus NN de. Clima de segurança do paciente: percepção dos profissionais de enfermagem. Acta paul. enferm. 2012;25:728-735.

17. Da Corregio TC, Amante LN, Barbosa SFF. Avaliação da cultura de segurança do paciente em Centro Cirúrgico. Rev. SOBECC; 2014;19: 67-73.

18. Carvalho REFL de, Cassiani SHB. Cross-cultural adaptation of the Safety Attitudes Questionnaire - Short Form 2006 for Brazil. Rev. Latino-Am. Enfermagem. 2012; 20: 575-82.

19. Hayes C. Surgical safety checklist: improved patient safety through effective teamwork. Healthc Q. 2012;15 Spec No:57-62.

20. Ministry of Health and Long-Term Care. Patient Safety Indicator Reporting: Ontario Totals. 2011. http://www.health.gov.on.ca/en/public/programs/patient_safety/ 
21. Brasil. Agência Nacional de Vigilância Sanitária. Resolução da Diretoria Colegiada - RDC no 36 de 25 de julho de 2013 que institui ações para a segurança do paciente em serviços de saúde e dá outras providências. Diário Oficial da União 2013;26 jul.

22. Brasil. Ministério da Saúde. Portaria no 529 de 10 de abril de 2013. Institui o Programa Nacional de Segurança do Paciente (PNSP). Diário Oficial da União; 23 abr 2013.

23. Brasil. Agência Nacional de Vigilância Sanitária. Resolução da Diretoria Colegiada - RDC no 63 de 26 de novembro de 2011. Dispõe sobre os requisitos de Boas Práticas de funcionamento para os serviços de saúde. Diário Oficial da União; 28 nov2011.

24. Brasil. Ministério da Saúde. Portaria no 2616, de 12 de maio de 1998. Expede, na forma dos anexos I, II, III, IV e V, diretrizes e normas para a prevenção e o controle das infecções hospitalares. Diário Oficial da União 1998; 13 mai.

25. Brasil. Ministério da Saúde. Portaria no 1.377 de 9 de julho de 2013. Aprova os Protocolos de Segurança do Paciente. Diário Oficial da União 2013;10 jul.

26. Agência Nacional de Vigilância Sanitária. Manual de Critérios Nacionais de Infecções Relacionadas à Assistência à Saúde - Sítio Cirúrgico. ANVISA.2009. http://portal.anvisa.gov.br/wps/wcm/connect/35b4530049bef5c89d01bf6dcbd9c63c/C rit\%C3\%A9rios+-+S\%C3\%ADtio+Cir\%C3\%BArgico.pdf?MOD=AJPERES.Accessed 10 Apr 2015.

27. Agência Nacional de Vigilância Sanitária. Assistência Segura: uma reflexão teórica aplicada à prática. Série Segurança do Paciente e Qualidade em Serviços de Saúde. Brasília:ANVISA; 2013.

28. Sexton JB, Makary MA, Tersigni AR, Pryor D, Hendrich A, Thomas EJ, et al. Teamwork in the operating room: frontline perspectives among hospitals and operating room personnel. Anesthesiology.2006; 105:877-84.

29. Lingard L, Regehr G, Orser B, Reznick R, Baker GR, Doran D, et al. Evaluation of a preoperative checklist and team briefing among surgeons, nurses, and anesthesiologists to reduce failures in communication. Arch Surg. 2008;143:12-17; discussion 8.

30. Cullati S, Le Du S, Raë AC, Micallef M, Khabiri E, Ourahmoune A, et al. Is the Surgical Safety Checklist successfully conducted? An observational study of social interactions in the operating rooms of a tertiary hospital.BMJ QualSaf. 2013;22:63946. 
31. Makary MA, Holzmueller CG, Thompson D, Rowen L, Heitmiller ES, Maley WR, et al. Operating room briefings: working on the same page. Jt Comm J Qual Patient Saf. 2006;32:351-5.

32. Takala RSK, Pauniaho SL, Kotkansalo A, Helmio P, Blomgren K, Helminen M, et al. A pilot study of the implementation of WHO Surgical Checklist in Finland: improvements in activities and communication. ActaAnaesthesiol Scand. 2011; 55:1206-14.

33. Khorshidifar A, Kadkhodaee H, Zamen Z. Degree of Observance of the WHO Surgical Safety Checklist. Trauma Mon. 2012;17:315-18.

34. Vats A, Vincent CA, Nagpal K, Davies RW, Darzi A, Moorthy K. Practical challenges of introducing WHO surgical checklist: UK pilot experience. BMJ. 2010; doi: http://dx.doi.org/10.1136/bmj.b5433 .

35. Cullati S, Licker MJ, Francis P, Degiorgi A, Bezzola P, Courvoisier DS, et al. Implementation of the surgical safety checklist in Switzerland and perceptions of its benefits: cross-sectional survey. PLoS One. 2014;doi: 10.1371/journal.pone.010915.

36. Abdel-Galil K. The WHO Surgical Safety Checklist: are we measuring up? $\mathrm{Br} \mathrm{J}$ Oral Maxillofac Surg. 2010;48:397-98.

37. Kearns RJ, Uppal V, Bonner J, Robertson J, Daniel M, McGrady EM. The introduction of a surgical safety checklist in a tertiary referral obstetric centre. BMJ Qual Saf. 2011;20:818-22.

38. McDowell DS, McComb SA. Safety Checklist Briefings: A Systematic Review of the Literature. AORN J. 2014; doi: 10.1016/j.aorn.2013.11.015.

39. The Joint Commission. Advancing effective communication, cultural competence, and patient- and family-centered care: a roadmap for hospitals. Oakbrook Terrace, IL: The Joint Commission; 2010.

40. Boletim Informativo Segurança do Paciente e Qualidade em Serviços de Saúde [Internet]. Incidentes Relacionados à Assistência à Saúde - 2014 [Brasília (DF)]: Agência Nacional de Vigilância Sanitária; Ano IV, n. 9 Jun, 2015. No prelo.

41. Filho GRM, da Silva LFN, Ferracini AM, Bähr GL. Protocolo de Cirurgia Segura da OMS: O grau de conhecimento dos ortopedistas brasileiros. Rev bras ortop. 2013;48:554-562.

42. Weinbroum AA, Ekstein P, Ezri T. Efficiency of the operating room suite. Am J Surg. 2003;185:244-50.

43. Fudickar A, Hörle K, Wiltfang J, Bein B. The effect of the WHO Surgical Safety Checklist on complication rate and communication. Dtsch Arztebl Int. 2012;109:695701. 
44. Singer SJ, Jiang W, Huang LC, Gibbons L, Kiang MV, Edmondson L, et al. Surgical team member assessment of the safety of surgery practice in 38 South Carolina hospitals. Med Care Res Rev. 2015; 72:298-323.

45. Seiden SC, Barach P. Wrong-side/wrong-site, wrong-procedure, and wrongpatient adverse events: Are they preventable? Arch Surg. 2006;141:931-39. 


\subsection{RESULTADOS DA ETAPA 3 - ANÁLISE DA ATENÇÃO ANESTÉSICO- CIRÚRGICA E SEGURANÇA DO PACIENTE A PARTIR DA PERCEPÇÃO DAS EQUIPES CIRÚRGICAS EM HOSPITAIS PÚBLICOS DO DISTRITO FEDERAL, BRASIL}

Artigo submetido à Revista do Colégio Brasileiro de Cirurgiões. 2015 (Anexo F).

\section{Análise da atenção anestésico-cirúrgica e segurança do paciente a partir da percepção das equipes cirúrgicas em hospitais públicos do Distrito Federal, Brasil}

\section{Analysis of the anesthetic-surgical care and patient safety from the perception of surgical teams in public hospitals in the Federal District, Brazil}

\section{RESUMO}

Objetivo: analisar a atenção anestésico-cirúrgica e a segurança do paciente, a partir da percepção de equipes cirúrgicas em hospitais públicos do Distrito Federal. Método: estudo quantitativo, descritivo, com delineamento transversal, aplicando-se instrumento de autoavaliação a 149 profissionais das equipes cirúrgicas, no período de maio a junho de 2013. Na formação do banco de dados utilizou-se o software SPSS, versão 16.0. O teste Qui-quadrado foi utilizado para verificar se havia diferença na distribuição das variáveis categóricas nos hospitais. Resultados: a maioria dos participantes era formada por técnico de enfermagem $(31,3 \%)$, seguida de cirurgião $(19,7 \%)$ e residentes de cirurgia $(12,9 \%)$. Verificaram-se fragilidades na estrutura física, como ausência de controle de temperatura e de pressão positiva na maioria das salas operatórias. A permanência do circulante, cirurgião e anestesiologista na sala operatória durante o período da cirurgia foi confirmada pela maioria dos respondentes, com os respectivos percentuais 82,6\% ( $p<0,001), 86,6 \%$ $(p=0,026)$ e 87,2 ( $p=0,019)$. Observou-se, ainda: a inexistência de duplo mecanismo de identificação do paciente pela maioria dos profissionais (64,6\%); que o monitoramento do tempo médio de atraso no início da cirurgia e do tempo médio na Recuperação Anestésica apresentou $80,9 \% \quad(p=0,235)$ e $67,4 \% \quad(p<0,001)$ de respostas negativas; que 0 acompanhamento da taxa de reinternação cirúrgica não é realizado em todos os hospitais $(82,2 \%)$ e que a vigilância pós-alta dos pacientes cirúrgicos, em $72,2 \%$ não são realizadas. 
Conclusão: o estudo apontou fragilidades na estrutura físico-operacional dos Centros Cirúrgicos e nos itens de segurança do paciente, sinalizando para o descumprimento de regulamentos sanitários pelos hospitais.

Descritores: Autoavaliação. Segurança do Paciente. Salas Cirúrgicas. Serviços de Saúde. Vigilância Sanitária.

\section{INTRODUÇÃO}

O Programa Nacional de Segurança do Paciente (PNSP), publicado em 2013, e as regulamentações sobre segurança do paciente em serviços de saúde vêm sendo disseminadas no Brasil ${ }^{1,2}$ com o propósito de orientar e melhorar a qualidade do cuidado cirúrgico ${ }^{3}$, cabendo às VISAS o desafio de apoiar o processo de implantação dos princípios e diretrizes previstas no $\mathrm{PNSP}^{1,2}$.

No remodelamento desse sistema, a implementação e o desenvolvimento contínuo de uma cultura construtiva para o gerenciamento dos riscos são fundamentais ${ }^{4}$, especialmente nos Centros Cirúrgicos dos serviços de saúde.

Em ambientes cirúrgicos, as complicações cirúrgicas variam entre $3 \%$ a $17 \%{ }^{5,6}$ envolvendo paciente, sítio cirúrgico e procedimento errados, problema com o equipamento de anestesiologia, falta de equipamentos, perda de sangue inesperada e falhas no manuseio de artigos, a exemplo de compressas retidas no interior dos pacientes $^{7}$.

A origem desses erros pode ser diferenciada em causas latentes ou sistêmicas e ativa ou individual, sendo que componentes de ambas as categorias estão tradicionalmente envolvidos quando o dano alcança o paciente. Essas causas abrangem decisões de gestão e podem permanecer não reconhecidas por um longo tempo. Os elementos latentes podem ser relacionados à estrutura ambiental ultrapassada, ausência de padrões clínicos e operacionais e baixa densidade de pessoal; elementos ativos podem envolver a atuação em um sistema complexo, dificuldades de comunicação, viés de confirmação, de erro de fixação, falha de memória ${ }^{4}$. Essas causas têm um impacto direto no atendimento ao paciente e pode resultar em dano imediato aos pacientes ${ }^{4}$.

O Brasil possui um importante arcabouço jurídico-sanitário, cuja correta implementação é capaz de interferir positivamente para evitar a ocorrência de danos ao paciente cirúrgico ${ }^{8-12}$. 
Uma série de estudos tem lidado com os conteúdos e diferentes tipos de elementos que interferem na implantação da cultura da segurança do paciente, mas poucos apontam as perspectivas das equipes cirúrgicas quanto ao seu ambiente de trabalho, os padrões estabelecidos e a interação com os demais profissionais dentro das salas operatórias.

O objetivo deste estudo foi depreender os níveis de percepção das equipes cirúrgicas de hospitais públicos do Distrito Federal (DF), Brasil, sobre os elementos da atenção anestésico-cirúrgica e a segurança do paciente.

\section{MÉTODOS}

Foram incluídos no estudo os profissionais integrantes das equipes cirúrgicas de hospitais públicos participantes da Rede Sentinela da Agência Nacional de Vigilância Sanitária (ANVISA). O Hospital 1 é distrital, de ensino, atende casos de alta complexidade, de grande porte, e dispõe de 748 leitos. A unidade conta com 16 salas operatórias e realizam 7.267 cirurgias/ano, incluindo Proctologia, Urologia, Ortopedia, Cirurgia Vascular, Cirurgia Plástica, Ginecologia, além das neurológicas, de câncer, traumas e transplantes de órgãos. O segundo Hospital (Hospital 2) é federal, de ensino, considerado um hospital geral de média e alta complexidade, de médio porte, com 299 leitos. Possui com dez salas operatórias com registro de 2905 cirurgias/ano, dentre elas, Cirurgia Geral, Cabeça e Pescoço, Proctologia, Urologia, Ortopedia, Cirurgia Vascular, Cirurgia Plástica e Ginecologia. O último Hospital ou hospital 3 é distrital, de ensino, dispõe de 226 leitos, apresenta cinco salas operatórias, nas quais são realizadas anualmente, 3695 cirurgias nas especialidades de Cirurgia Geral, Proctologia, Urologia, Ortopedia, entre outras.

\section{População}

No período do estudo, a população foi constituída por 147 profissionais dos Centros Cirúrgicos dos três serviços, entre cirurgiões, anestesiologistas, instrumentadores, enfermeiros, técnicos e auxiliares de enfermagem, residentes de cirurgia e anestesiologia, além de chefes dos serviços médicos e de enfermagem.

Os profissionais foram abordados nos locais de trabalho em momentos que estavam disponíveis para participação no estudo, respondendo ao instrumento de autoavaliação. 


\section{Desenho do estudo}

Trata-se de um estudo descritivo e quantitativo obtido a partir da aplicação de instrumento de avaliação junto aos profissionais de saúde atuantes em Centros Cirúrgicos, de três hospitais situados no DF.

A participação deu-se por meio do preenchimento de instrumento estruturado e autoaplicável, no período de maio e junho de 2013. A coleta de dados foi realizada durante a implantação da Lista de Verificação da Segurança Cirúrgica (LVSC) da Organização Mundial de Saúde (OMS), prevista no Projeto Cirurgias Seguras Salvam Vidas da ANVISA (2012-2014).

Os participantes não receberam o questionário com antecedência e não foi dado tempo para preparar suas respostas. O objetivo era obter respostas espontâneas dos participantes, garantindo simultaneamente 0 anonimato e a confidencialidade.

O instrumento de coleta foi desenvolvido utilizando-se os critérios de referência da literatura e da legislação sanitária federal brasileira ${ }^{13}$, que orienta para a existência de infraestrutura e padrões mínimos necessários ao funcionamento dos Centros Cirúrgicos, além de elementos envolvendo as equipes tradicionalmente envolvidas nos procedimentos cirúrgicos. Também foi utilizado para elaboração do instrumento, o Roteiro de Autoinspeção e Inspeção da Secretaria Municipal de Saúde e Defesa Civil do Rio de Janeiro ${ }^{14}$.

\section{Métodos de mensuração}

O instrumento de autoavaliação foi constituído por 27 questões objetivas, agrupadas de acordo com os critérios de estrutura física e operacional, além de questões específicas sobre a realização de ações voltadas para a segurança do paciente. Para cada questão, o respondente deveria marcar uma única alternativa.

As respostas foram transcritas para o formulário online SurveyMonkey, sendo cada inserção revisada pelo pesquisador. Na formação do banco de dados utilizouse o software SPSS, versão 16.0.

Para análise estatística, foi utilizado o teste Qui-quadrado para verificar diferença na distribuição das variáveis categóricas. 


\section{Aspectos Éticos}

O projeto de pesquisa foi aprovado no Comitê de Ética em Pesquisa (CEP) da Universidade de Brasília (Unb), Parecer №. 185/12.

\section{RESULTADOS}

O instrumento de autoavaliação foi respondido por 149 profissionais das equipes cirúrgicas, dos três hospitais situados no DF.

A Tabela 1 revela que a maioria dos participantes era técnico de enfermagem $(31,3 \%)$ seguida de cirurgião $(19,7 \%)$ e residentes de cirurgia (12,9\%). Verifica-se que essas categorias profissionais representaram $63,9 \%$ do universo de participantes do estudo.

Tabela 1 Distribuição dos participantes do estudo por categoria profissional e por hospital. Distrito Federal, Brasil. 2013.

\begin{tabular}{|c|c|c|c|c|c|c|c|c|}
\hline \multirow{2}{*}{$\begin{array}{l}\text { Profissão do } \\
\text { respondente, por } \\
\text { hospital }\end{array}$} & \multicolumn{2}{|c|}{ Hospital 1} & \multicolumn{2}{|c|}{ Hospital 2} & \multicolumn{2}{|c|}{ Hospital 3} & \multicolumn{2}{|c|}{ Total } \\
\hline & no. & $\%$ & no. & $\%$ & $\mathrm{n} \times$. & $\%$ & $\mathrm{n} \times$. & $\%$ \\
\hline Anestesiologista & 0 & 0,0 & 6 & 10,7 & 4 & 7,8 & 10 & 6,8 \\
\hline Auxiliar de Enfermagem & 8 & 20,0 & 3 & 5,4 & 3 & 5,9 & 14 & 9,5 \\
\hline Cirurgião & 1 & 2,5 & 11 & 19,6 & 17 & 33,3 & 29 & 19,7 \\
\hline Enfermeiro & 2 & 5,0 & 2 & 3,6 & 2 & 3,9 & 6 & 4,1 \\
\hline Instrumentador & 4 & 10,0 & 1 & 1,8 & 0 & 0,0 & 5 & 3,4 \\
\hline Outro & 1 & 2,5 & 8 & 14,3 & 0 & 0,0 & 9 & 6,1 \\
\hline $\begin{array}{l}\text { Residente de } \\
\text { anestesiologia }\end{array}$ & 0 & 0,0 & 9 & 16,1 & 0 & 0,0 & 9 & 6,1 \\
\hline Residente de cirurgia & 3 & 7,5 & 7 & 12,5 & 9 & 17,6 & 19 & 12,9 \\
\hline Técnico de Enfermagem & 21 & 52,5 & 9 & 16,1 & 16 & 31,4 & 46 & 31,3 \\
\hline Total & 40 & 100,0 & 56 & 100,0 & 51 & 100,0 & 147 & 100,0 \\
\hline
\end{tabular}


$\mathrm{Na}$ análise da percepção dos participantes em relação aos aspectos de infraestrutura que influenciam a segurança do paciente (Tabela 2), verificou-se: evidência da existência de pelo menos um lavabo cirúrgico para cada 02 salas operatórias (item 1) e a disponibilidade de antisséptico líquido para antissepsia cirúrgica das mãos (item 3); ausência de controle individual de temperatura, filtros de ar específicos e pressão positiva na maioria das salas operatórias dos hospitais (item 4); que existe norma de restrição de circulação de pessoas na sala operatória (item 5 ), nos quais $57,7 \%$ dos entrevistados responderam positivamente, apesar de metade das respostas $(50,0 \%)$ serem negativas no Hospital 2; que o mecanismo autônomo de manutenção de portas fechadas na sala operatória apresentou $65,8 \%$ de respostas negativas na totalidade dos hospitais, exceto no Hospital 1, com 83,3\% de respostas favoráveis (item 6); que referente às normas de limpeza e desinfecção do Centro Cirúrgico (item 7), observou-se $70, \%$ de respostas favoráveis na totalidade dos hospitais, embora no Hospital 3, 39,0\% desconhecem estes procedimentos (item 7$)$, com diferença significativa, respectivamente $(p<0,001)$; e que quanto à existência de lavabos cirúrgicos com torneiras de acionamento com o cotovelo, pé, joelho ou célula fotoelétrica para realização da antissepsia cirúrgica das mãos (item 2), a maioria respondeu afirmativamente $(92,6 \%)(p=0,168)$. 
Tabela 2 Percepção da equipe relativa à estrutura física e operacional mínima para a segurança do paciente na atenção anestésico-cirúrgica nos hospitais do Distrito Federal, Brasil. 2013.

\begin{tabular}{|c|c|c|c|c|c|c|c|c|c|}
\hline \multirow{2}{*}{ Estrutura Funcional $^{\mathrm{a}}$} & \multicolumn{2}{|c|}{ Hospital 1} & \multicolumn{2}{|c|}{$\begin{array}{c}\text { Hospital } \\
2\end{array}$} & \multicolumn{2}{|c|}{ Hospital 3} & \multicolumn{2}{|c|}{ Total } & \multirow{2}{*}{ p-valor } \\
\hline & no & $\%$ & $\mathrm{n}^{\circ}=$ & $\%$ & no & $\%$ & $\mathrm{n}^{\circ}$ & $\%$ & \\
\hline
\end{tabular}

\section{Item 1}

$\begin{array}{lccccccccl}\text { Não } & 1 & 2,4 & 3 & 5,4 & 20 & 40,8 & 24 & 16,4 & \\ \text { Sim } & 40 & 97,6 & 53 & 94,6 & 29 & 59,2 & 122 & 83,6 & <0,001 \\ \text { Total } & 41 & 100,0 & 56 & 100,0 & 49 & 100,0 & 146 & 100,0 & \end{array}$

\section{Item 2}

$\begin{array}{lccccccccl}\text { Não } & 2 & 4,8 & 7 & 12,7 & 2 & 3,9 & 11 & 7,4 & \\ \text { Sim } & 40 & 95,2 & 48 & 87,3 & 49 & 96,1 & 137 & 92,6 & 0,168 \\ \text { Total } & 42 & 100,0 & 55 & 100,0 & 51 & 100,0 & 148 & 100,0 & \end{array}$

Item 3

\begin{tabular}{|c|c|c|c|c|c|c|c|c|c|}
\hline Não & 15 & 35,7 & 9 & 16,1 & 2 & 4,0 & 26 & 17,6 & \\
\hline Sim & 27 & 64,3 & 47 & 83,9 & 48 & 96,0 & 122 & 82,4 & $<0,001$ \\
\hline Total & 42 & 100,0 & 56 & 100,0 & 50 & 100,0 & 148 & 100,0 & \\
\hline \multicolumn{10}{|c|}{ Item 4} \\
\hline Não & 42 & 100,0 & 38 & 69,1 & 47 & 94,0 & 127 & 86,4 & \multirow{3}{*}{$<0,001$} \\
\hline Sim & 0 & 0,0 & 17 & 30,9 & 3 & 6,0 & 20 & 13,6 & \\
\hline Total & 42 & 100,0 & 55 & 100,0 & 50 & 100,0 & 147 & 100,0 & \\
\hline \multicolumn{10}{|c|}{ Item 5} \\
\hline Não & 34 & 81,0 & 28 & 50,0 & 1 & 2,0 & 63 & 42,3 & \multirow{3}{*}{$<0,001$} \\
\hline Sim & 8 & 19,0 & 28 & 50,0 & 50 & 98,0 & 86 & 57,7 & \\
\hline Total & 42 & 100,0 & 56 & 100,0 & 51 & 100,0 & 149 & 100,0 & \\
\hline \multicolumn{10}{|c|}{ Item 6} \\
\hline Não & 7 & 16,7 & 44 & 80,0 & 45 & 91,8 & 96 & 65,8 & \multirow{3}{*}{$<0,001$} \\
\hline Sim & 35 & 83,3 & 11 & 20,0 & 4 & 8,2 & 50 & 34,2 & \\
\hline Total & 42 & 100,0 & 55 & 100,0 & 49 & 100,0 & 146 & 100,0 & \\
\hline \multicolumn{10}{|c|}{ Item 7} \\
\hline Não & 7 & 17,1 & 13 & 24,1 & 19 & 54,3 & 39 & 30,0 & \multirow{3}{*}{0,001} \\
\hline Sim & 34 & 82,9 & 41 & 75,9 & 16 & 45,7 & 91 & 70,0 & \\
\hline Total & 41 & 100,0 & 54 & 100,0 & 35 & 100,0 & 130 & 100,0 & \\
\hline
\end{tabular}

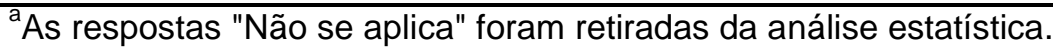

Item 1. Existência de pelo menos 01 lavabo cirúrgico para cada 02 salas operatórias. Item 2. Existência de lavabos cirúrgicos com torneiras de acionamento com o cotovelo, pé, joelho ou célula fotoelétrica para realização da antissepsia cirúrgica das mãos. Item 3 . Disponibilização de antisséptico líquido para antissepsia cirúrgica das mãos. Item 4. Sala operatória com controle individual de temperatura, filtros de ar específicos e pressão positiva. Item 5 . Norma de restrição da circulação de pessoas na sala operatória. Item 6. Mecanismo autônomo de manutenção de portas fechadas na sala operatória. Item 7. Documentação de procedimentos de limpeza e desinfecção no Centro Cirúrgico. 
Para as questões referentes à permanência do circulante (item 10), cirurgião (item 11) e anestesiologista (item 12) na sala operatória durante todo período da cirurgia, a maioria das equipes respondeu positivamente, sendo o percentual de respostas favoráveis e estatisticamente significativa, $82,6 \% \quad(p<0,001), 86,6 \%$ $(p=0,026)$ e 87,2 ( $p=0,019)$, respectivamente. A permanência do enfermeiro na unidade durante todo período de funcionamento do Centro Cirúrgico e na Unidade de Recuperação Pós-anestésica (itens 9 e 10, respectivamente) foi percebida pela maioria dos participantes, em $64,4 \%$ e $61,1 \%$ respectivamente, com resultado significativo $(p<0,001)$ (Tabela 3$)$. 
cirúrgicos por anestesiologista (item 15), seja na enfermaria seja no próprio Centro Cirúrgico, não é uma rotina para $57,4 \%$ dos entrevistados, enquanto o atendimento pós-anestésico é percebido por apenas 58,6\%; e que o registro de possíveis alergias a medicamentos pelo paciente, não é percebido como rotina para $19,3 \%$ dos entrevistados (item 17).

O Hospital 3 apresentou maior disparidade entre as respostas e no conjunto das respostas, a maioria $(86,1 \%)$ dos entrevistados reconhece a existência de orientações para administração segura de medicamentos (item 18) e para a administração segura de sangue e hemocomponentes nos serviços hospitalares (item 19), sobretudo no Hospital 3, onde as respostas apontam para uma assimilação mais homogênea da prática entre as diferentes categorias profissionais do Centro Cirúrgico. Por outro lado, os profissionais do Hospital 2 apontou a maior disparidade na percepção de segurança para a administração de sangue e hemocomponentes. Comportamento semelhante pode ser observado frente à importância dos cuidados com os materiais esterilizados (item 20), particularmente quanto à sua manutenção na embalagem de processamento, fechada e datada até o momento da utilização por 95,9\% dos entrevistados, alcançando $98 \%$ entre os profissionais do Hospital 3.

Quanto ao item 21, referente ao registro do monitoramento de indicadores de infecção do sítio cirúrgico (ISC), este surgiu com um elemento pouco representativo para a segurança do paciente, sobretudo para os participantes do Hospital 3, que responderam afirmativamente, 58,5\%. Por outro lado, os profissionais do Hospital 1 (82,9\%) parecem considerar este monitoramento importante.

As ações de prevenção (75,6\%) de eventos adversos relacionados à assistência à saúde no Centro Cirúrgico (item 22) e o registro das falhas $(90,2 \%)$ parecem ter sido mais bem assimiladas pelos profissionais que atuam no Hospital 1 (item 23).

O monitoramento do tempo de atraso para o início da cirurgia e o tempo de Recuperação Anestésica (itens 24 e 25) apresentaram 80,9\% (p=0,235) e 67,4\% $(p<0,001)$ de respostas negativas, indicando ser esta uma questão de qualidade pouco relevante para a maioria dos entrevistados, principalmente para aqueles atuantes no Hospital 3. Os profissionais do Hospital 2 são mais atentos a esses indicadores, quando comparados com os participantes dos demais serviços. 
O acompanhamento da taxa de reinternação cirúrgica $(82,2 \%)$ e a vigilância pós-alta $(72,2 \%)$ não é realizado em todos os hospitais participantes sendo estes indicadores praticamente inexistentes na rotina os entrevistados do Hospital 3 (95\%) e Hospital 1 (95,1\%), respectivamente (itens 26 e 27 ).

Tabela 4 Percepção da existência de barreiras frente às metas nacionais para a segurança do paciente na atenção anestésico-cirúrgica, por hospital do Distrito Federal, Brasil. 2013.

\begin{tabular}{|c|c|c|c|c|c|c|c|c|c|}
\hline \multirow{2}{*}{$\begin{array}{l}\text { Segurança do } \\
\text { Paciente }^{\mathrm{a}}\end{array}$} & \multicolumn{2}{|c|}{ Hospital 1} & \multicolumn{2}{|c|}{ Hospital 2} & \multicolumn{2}{|c|}{ Hospital 3} & \multicolumn{2}{|c|}{ Total } & \multirow{2}{*}{ p-valor } \\
\hline & no. & $\%$ & no. & $\%$ & $\mathrm{n}$ ‥ & $\%$ & no. & $\%$ & \\
\hline
\end{tabular}

\section{Item 13}

$\begin{array}{lccccccccc}\text { Não } & 1 & 2,4 & 6 & 10,9 & 21 & 43,8 & 28 & 19,3 & \\ \text { Sim } & 41 & 97,6 & 49 & 89,1 & 27 & 56,3 & 117 & 80,7 & <0,001 \\ \text { Total } & 42 & 100,0 & 55 & 100,0 & 48 & 100,0 & 145 & 100,0 & \end{array}$

Item 14

Não

$\begin{array}{llllllll}40 & 95,2 & 14 & 25,5 & 41 & 82,0 & 95 & 64,6\end{array}$

$\operatorname{Sim}$

$2 \quad 4,8 \quad 41 \quad 74,5 \quad 9 \quad 18,0 \quad 52 \quad 35,4 \quad<0,001$

Total

$42 \quad 100,0 \quad 55 \quad 100,0 \quad 50 \quad 100,0 \quad 147 \quad 100,0$

\section{Item 15}

Não

$\begin{array}{llllllll}31 & 75,6 & 1 & 1,8 & 28 & 63,6 & 60 & 42,6\end{array}$

$\operatorname{Sim}$

$\begin{array}{lllllllll}10 & 24,4 & 55 & 98,2 & 16 & 36,4 & 81 & 57,4 & <0,001\end{array}$

Total

$\begin{array}{llllllll}41 & 100,0 & 56 & 100,0 & 44 & 100,0 & 141 & 100,0\end{array}$

Item 16

$\begin{array}{lccccccccc}\text { Não } & 7 & 16,7 & 23 & 41,8 & 28 & 65,1 & 58 & 41,4 & \\ \text { Sim } & 35 & 83,3 & 32 & 58,2 & 15 & 34,9 & 82 & 58,6 & <0,001 \\ \text { Total } & 42 & 100,0 & 55 & 100,0 & 43 & 100,0 & 140 & 100,0 & \end{array}$

Item 17

Não

$\begin{array}{llllllll}1 & 2,4 & 6 & 10,9 & 21 & 43,8 & 28 & 19,3\end{array}$

$\operatorname{Sim}$

$\begin{array}{lllllllll}41 & 97,6 & 49 & 89,1 & 27 & 56,3 & 117 & 80,7 & <0,001\end{array}$

Total

$42 \quad 100,0 \quad 55 \quad 100,0 \quad 48 \quad 100,0 \quad 145 \quad 100,0$

Item 18

Não

Sim

$\begin{array}{ccccccccc}8 & 19,5 & 9 & 16,4 & 3 & 6,3 & 20 & 13,9 & 0,159 \\ 33 & 80,5 & 46 & 83,6 & 45 & 93,8 & 124 & 86,1 & \end{array}$


Total

$\begin{array}{llllllll}41 & 100,0 & 55 & 100,0 & 48 & 100,0 & 144 & 100,0\end{array}$

Item 19

Não

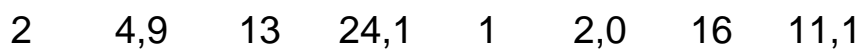

Sim

$\begin{array}{lllllllll}39 & 95,1 & 41 & 75,9 & 48 & 98,0 & 128 & 88,9 & 0,001\end{array}$

Total

$\begin{array}{llllllll}41 & 100,0 & 54 & 100,0 & 49 & 100,0 & 144 & 100,0\end{array}$

Item 20

Não

$\begin{array}{llllllll}2 & 4,8 & 3 & 5,5 & 1 & 2,0 & 6 & 4,1\end{array}$

Sim

$\begin{array}{lllllllll}40 & 95,2 & 52 & 94,5 & 49 & 98,0 & 141 & 95,9 & 0,650\end{array}$

Total

$42 \quad 100,0 \quad 55 \quad 100,0 \quad 50 \quad 100,0 \quad 147 \quad 100,0$

Item 21

Não

$\begin{array}{llllllll}7 & 17,1 & 20 & 36,4 & 29 & 74,4 & 56 & 41,5\end{array}$

Sim

$\begin{array}{lllllllll}34 & 82,9 & 35 & 63,6 & 10 & 25,6 & 79 & 58,5 & <0,001\end{array}$

Total

$\begin{array}{llllllll}41 & 100,0 & 55 & 100,0 & 39 & 100,0 & 135 & 100,0\end{array}$

Item 22.

Não

$\begin{array}{llllllll}10 & 24,4 & 19 & 35,8 & 18 & 38,3 & 47 & 33,3\end{array}$

Sim

$\begin{array}{lllllllll}31 & 75,6 & 34 & 64,2 & 29 & 61,7 & 94 & 66,7 & 0,344\end{array}$

Total

$\begin{array}{llllllll}41 & 100,0 & 53 & 100,0 & 47 & 100,0 & 141 & 100,0\end{array}$

Item 23

Não

$\begin{array}{llllllll}4 & 9,8 & 11 & 21,2 & 9 & 19,1 & 24 & 17,1\end{array}$

Sim

$\begin{array}{lllllllll}37 & 90,2 & 41 & 78,8 & 38 & 80,9 & 116 & 82,9 & 0,320\end{array}$

Total

$\begin{array}{llllllll}41 & 100,0 & 52 & 100,0 & 47 & 100,0 & 140 & 100,0\end{array}$

Item 24

Não

$\begin{array}{llllllll}35 & 83,3 & 40 & 74,1 & 35 & 87,5 & 110 & 80,9\end{array}$

Sim

$\begin{array}{lllllllll}7 & 16,7 & 14 & 25,9 & 5 & 12,5 & 26 & 19,1 & 0,235\end{array}$

Total

$42 \quad 100,0 \quad 54 \quad 100,0 \quad 40 \quad 100,0 \quad 136 \quad 100,0$

Item 25

Não

$\begin{array}{llllllll}36 & 85,7 & 20 & 37,7 & 35 & 87,5 & 91 & 67,4\end{array}$

Sim

$\begin{array}{lllllllll}6 & 14,3 & 33 & 62,3 & 5 & 12,5 & 44 & 32,6 & <0,001\end{array}$

Total

$\begin{array}{llllllll}42 & 100,0 & 53 & 100,0 & 40 & 100,0 & 135 & 100,0\end{array}$

Item 26

Não

$\begin{array}{llllllll}36 & 87,8 & 32 & 66,7 & 38 & 95,0 & 106 & 82,2\end{array}$

Sim

$\begin{array}{lllllllll}5 & 12,2 & 16 & 33,3 & 2 & 5,0 & 23 & 17,8 & 0,001\end{array}$

Total

$\begin{array}{llllllll}41 & 100,0 & 48 & 100,0 & 40 & 100,0 & 129 & 100,0\end{array}$ 


\section{Item 27}

$\begin{array}{lccccccccl}\text { Não } & 39 & 95,1 & 25 & 50,0 & 19 & 79,2 & 83 & 72,2 & \\ \text { Sim } & 2 & 4,9 & 25 & 50,0 & 5 & 20,8 & 32 & 27,8 & <0,001 \\ \text { Total } & 41 & 100,0 & 50 & 100,0 & 24 & 100,0 & 115 & 100,0 & \end{array}$

${ }^{\mathrm{a}}$ As respostas "Não se aplica" foram retiradas da análise estatística.

Item 13- Orientações para estimular a participação do paciente na assistência prestada. Item 14Existência de pelo menos 02 mecanismos de identificação do paciente. Item 15- Atendimento préanestésico aos pacientes cirúrgicos por anestesiologistas na enfermaria ou no Centro Cirúrgico. Item 16- Atendimento pós-anestésico aos pacientes cirúrgicos por anestesiologistas na enfermaria ou Recuperação Pós-anestésica. Item 17- Registro de questionamento aos pacientes de possíveis alergias a medicamentos. Item 18- Orientações para administração segura de medicamentos. Item 19- Orientações para administração segura de sangue e hemocomponentes. Item 20- Cuidados com materiais esterilizados que são mantidos na embalagem do processo, fechada e datados até o momento da utilização. Item 21- Registro do monitoramento de indicadores de infecção do sítio cirúrgico. Item 22- Ações de prevenção de eventos adversos associados aos cuidados à saúde no Centro Cirúrgico. Item 23- Registro de eventos adversos associados aos cuidados à saúde. Item 24Monitoramento do tempo médio de atraso no início da cirurgia. Item 25- Monitoramento do tempo médio na Recuperação Anestésica. Item 26- Acompanhamento da taxa de reinternação cirúrgica. Item 27- Vigilância pós-alta de pacientes cirúrgicos.

\section{DISCUSSÃO}

Sabe-se que sobre os serviços de saúde incidem multiplicidade de riscos, de origens e naturezas diversas. Uma vez identificados os elementos relevantes para a segurança do paciente a partir de rotinas e condições de trabalho, uma gama de mecanismos e instrumentos de regulação à disposição no ordenamento jurídicosanitário podem ser utilizados, como legislação, educação e orientação sanitária, inspeção da prestação de serviços, sistema de informação, monitoramento de EA relacionados à assistência à saúde e participação popular, entre outros ${ }^{15}$.

Neste estudo foi possível apontar as rotinas e as condições de trabalho das equipes cirúrgicas sobre atenção anestésico-cirúrgica e segurança do paciente, determinantes sobre as causas e fatores latentes e ativos das organizações hospitalares.

Foram reveladas inadequações no ambiente dos Centros Cirúrgicos avaliados, tais como ausência de controle individual de temperatura, filtros de ar específicos e pressão positiva da sala operatória, conforme exigido pela RDC $\mathrm{n}$ ㅇ. $50 / 2002^{13}$. Cada sala operatória deve ter controle individual de temperatura e é recomendável a adoção de filtros de ar específicos de alta eficiência (High Efficiency Particulate Air - HEPA), que têm eficiência mínima de $99,97 \%$ e retenção de partículas de até $0,3 \mu \mathrm{m}$. Para prevenir a entrada de ar potencialmente contaminado 
de áreas adjacentes, também é importante a pressão positiva dentro das salas operatórias $^{16}$.

O estudo aponta para a ausência de mecanismos autônomos de fechamento de portas nas salas operatórias e de normas de restrição de pessoas no ambiente. Sabe-se que o excesso de pessoas nas salas operatórias e a abertura de portas durante o procedimento cirúrgico pode prejudicar o fluxo de ar climatizado e, consequentemente, a renovação de ar limpo no ambiente, comprometendo a qualidade do ar ambiente ${ }^{16}$.

A dimensão relacionada às práticas e rotinas dos profissionais participantes do estudo, no que se refere à estrutura física dos hospitais, sugere a existência de irregularidades estruturais importantes, sobretudo no Hospital 2, enquanto nos Hospitais 1 e 3 a identificação dos problemas foi hegemônica.

Os resultados evidenciaram que a maioria dos hospitais do estudo (64,2\%) não realiza a devida identificação dos pacientes (pelo menos 02 mecanismos de identificação), o que pode predispor à ocorrência de erros. Um estudo realizado em hospital universitário em Porto Alegre com o objetivo de avaliar o uso da pulseira de identificação em pacientes hospitalizados, utilizando um formulário estruturado, mostrou que $83,9 \%$ dos pacientes encontravam-se com a pulseira corretamente identificada, 11,9\% possuíam a pulseira de identificação com erros e 4,2\% dos pacientes estavam sem a pulseira ${ }^{17}$. Em uma pesquisa feita em um hospital de ensino do estado de SP, na qual foi feita a investigação em um dia escolhido casualmente para verificar a identificação de pacientes internados em uma instituição hospitalar, observou-se que $23,8 \%$ dos pacientes possuíam pulseira de identificação colocada, na maioria dos pacientes, no dia anterior à cirurgia e não no momento da internação ${ }^{18}$. De acordo com os autores, os resultados evidenciaram a pouca importância dada à identificação do paciente por parte da instituição.

Desta forma, é notável em todos os hospitais, sobretudo no Hospital 1, a urgência da implantação dos mecanismos de dupla identificação do paciente, asseverando que o cuidado seja prestado à pessoa para a qual se destina, a fim de ajudar a reduzir a ocorrência de incidentes relacionados à assistência à saúde, com base no Protocolo Nacional para a Identificação dos pacientes ${ }^{10,19}$.

Segundo os participantes, os monitoramentos do tempo médio de atraso no início da cirurgia, do tempo médio na Recuperação Pós-anestésica, e o acompanhamento da taxa de reinternação cirúrgica não são realizados 
adequadamente $(80 \%, 67,4 \%$ e $82,2 \%$, respectivamente, da totalidade dos hospitais). Sabe-se que o movimento cirúrgico é considerado uma variável que interfere nos indicadores de qualidade e da produtividade dos serviços de saúde, incluindo taxa de ocupação, tempo de permanência, recuperação anestésica, intervalo de tempo entre cirurgias, taxa de atraso e de suspensão de cirurgia ${ }^{20,21}$.

Os resultados apontados pelos profissionais mostram que a vigilância pós-alta não é uma rotina na maioria hospitais (72,2\%), apontando para a possível subnotificação dos registros de infecção de sítio cirúrgico de pacientes operados nos serviços participantes. Muitas instituições realizam a vigilância do paciente cirúrgico apenas durante o período de internação e, consequentemente, a ocorrência de ISC nesses serviços pode ser considerada baixa, uma vez que a infecção pode se manifestar depois de o paciente haver recebido alta, levando à subnotificação dos casos de $\mathrm{ISC}^{20,22}$.

Sob a dimensão das rotinas e práticas adotadas para instituir barreiras aos erros, os profissionais atuantes no Hospital 1 demonstraram possuir conhecimento mais homogêneo para as ações, registros e monitoramento dos indicadores de qualidade e segurança, enquanto o Hospital 2 apresentou a grande assimetria de percepção entre os profissionais, exceto para as questões relativas à dupla identificação do paciente, administração segura de medicamentos, sangue e hemocomponentes e atendimento pré-anestésico, evidenciando aspectos latentes da instituição e apontando para a necessidade premente de ações de gestão bem direcionadas para aumentar a segurança do paciente.

Os processos autoavaliativos em serviços de saúde permitem uma análise preliminar das condições higiênico sanitárias, além de auxiliar os dirigentes e os profissionais de saúde a tornar sua conduta mais apropriada. Devem ser constituídos não apenas para a identificação de problemas de segurança do paciente nas unidades avaliadas, mas também para servir como base para melhorias locais, estabelecendo prioridades para 0 planejamento $\mathrm{e}$ operacionalização de estratégias de ação, com iniciativas concretas para a superação dos problemas identificados.

Os resultados desta pesquisa mostram que a autoavaliação realizada pelos participantes pode ser complementada por outros instrumentos que informem diferentes aspectos da cultura institucional para a segurança e a qualidade, além daqueles que o respondente pode perceber. 
Além disso, os instrumentos sanitários utilizados nas unidades de serviços de saúde devem oferecer subsídios para a análise e evidência concreta de como os processos são realizados, de sua qualidade de assistência e de sua necessidade para a promoção das práticas de segurança. Para isso, as vigilâncias sanitárias podem disponibilizar instrumentos para facilitar a avaliação da estrutura, processo e resultado do hospital. Tais instrumentos podem nortear a reorganização das práticas dentro dos hospitais, concorrendo para o processo de melhorias contínuas nesses serviços ${ }^{14,23}$.

Os resultados deste estudo devem ser considerados à luz de algumas limitações, como o caráter voluntário de aplicabilidade do instrumento de coleta de dados. Outra consiste na restrição do próprio instrumento, limitando-se às respostas ao juízo de valor de cada respondente no momento da participação, resultando em uma avaliação mais positiva de suas ações, em relação ao existente no serviço de saúde, ou ao contrário. $E$, ainda, os resultados obtidos são limitados à amostra investigada, não permitindo generalizações a toda população de profissionais que atuam no Centro Cirúrgico dos hospitais avaliados ou de outros serviços.

No decorrer da pesquisa novas legislações sobre segurança do paciente foram estabelecidas no país, incluindo o PNSP, protocolos de Segurança do Paciente e a regulação e regulamentação por parte da ANVISA sobre o tema da segurança do paciente em serviços de saúde $2,9,10,19$. Essas condições podem ter provocado vieses de avaliação das reais condições sanitárias dos hospitais pelas equipes participantes.

\section{CONCLUSÃO}

Os resultados obtidos neste estudo apontaram fragilidades na atenção anestésico-cirúrgica, especialmente no que se refere à estrutura física e organizacional para a segurança do paciente, sinalizando aos gestores dos hospitais avaliados a assimetria de informações entre profissionais do mesmo serviço e o possível descumprimento de normas sanitárias direcionadas ao Centro Cirúrgico. Isto pode nortear a tomada de decisões por parte de gestores e líderes para aumentar a segurança do paciente, orientando para o funcionamento de qualidade dos Centros Cirúrgicos, além de favorecer a programação de intervenções locais, visando à melhoria da segurança e da cultura de segurança do paciente nos serviços de saúde avaliados. 
As pesquisas utilizando-se de instrumentos sanitários, a exemplo de roteiro de inspeção de vigilância sanitária, são sugeridas e podem melhor avaliar as reais condições da atenção anestésico-cirúrgica e segurança do paciente nas unidades participantes, identificando as incongruências administrativas, estruturais, organizacionais e assistenciais, além da possibilidade de expor orientações ao seu funcionamento.

\section{REFERÊNCIAS}

1. Brasil. Ministério da Saúde. Documento de referência para o Programa Nacional de Segurança do Paciente. Ministério da Saúde; Fundação Oswaldo Cruz; Agência Nacional de Vigilância Sanitária. Brasília: Ministério da Saúde; 2013. p. 40.

2. Brasil. Ministério da Saúde. Portaria $n^{\circ} .529$ de $1^{\circ}$ de abril de 2013. Institui o Programa Nacional de Segurança do Paciente (PNSP). Diário Oficial da União; 23 abr 2013.

3. Institute of Medicine. Crossing the Quality Chasm. A New Health System for the 21st Century. Washington:National Academy Press; 2001.

4. Waeschle RM, Bauer M, Schmidt CE. Errors in medicine: Causes, impact and improvement measures to improve patient safety. Anaesthesist. 2015;64(9):689-704.

5. World Health Organization. WHO guidelines for safe surgery. Geneva: WHO; 2009.

6. Kable AK GR, Spigelman AD. Adverse events in surgical patients in Australia.Int $\mathrm{J}$ Qual Health Care. 2002;14(4):269-76.

7. Treadwell JR LS. Preoperative checklists and anesthesia checklists. In: Shekelle PG WR, Pronovost PJ, Schoelles K, McDonald KM, Dy SM et al, editor. Making health care safer II: an updated critical analysis of the evidence for patient safety practices Comparative Effectiveness Review No 211: Agency for Healthcare Research and Quality; 2013.

8. Brasil. Agência Nacional de Vigilância Sanitária. Resolução da Diretoria Colegiada - RDC n. 63 de 25 de novembro de 2011. Dispõe sobre os requisitos de Boas Práticas de funcionamento para os serviços de saúde. Diário Oficial da União; 28 nov2011. 
9. Brasil. Agência Nacional de Vigilância Sanitária. Resolução da Diretoria Colegiada - RDC n. 36 de 25 de julho de 2013 que institui ações para a segurança do paciente em serviços de saúde e dá outras providências. Diário Oficial da União 2013;26 jul. 10. Brasil. Ministério da Saúde. Portaria n 1.377 de 9 de julho de 2013. Aprova os Protocolos de Segurança do Paciente. Diário Oficial da União 2013;10 jul.

11. Bello AC, Carvalho AA, Sousa FC, Santana HT, Siqueira HN, Ferreira KA, et al. Ações da Anvisa/MS para a Segurança do Paciente e Qualidade em Serviços de Saúde. In: Agência Nacional de Vigilância Sanitária. Assistência Segura: uma reflexão teórica aplicada à prática. Série Segurança do Paciente e Qualidade em Serviços de Saúde. Brasília: ANVISA; 2013.

12. Santana HT, Siqueira HN, Costa MMM, Oliveira DCAN, Gomes SM, Sousa FC, et al. A segurança do paciente cirúrgico na perspectiva da vigilância sanitária - uma reflexão teórica. Vig Sanit Debate 2014, 2(2):34-42.

13. Brasil. Agência Nacional de Vigilância Sanitária. Resolução da Diretoria Colegiada (RDC) nํ. 50, de 21 de fevereiro de 2002. Dispõe sobre o Regulamento Técnico para planejamento, programação, elaboração e avaliação de projetos físicos de estabelecimentos assistenciais de saúde. Diário Oficial da União, 20 mar 2002; seção 1.

14. Secretaria Municipal de Saúde e Defesa Civil. Rio de Janeiro. Roteiro de Autoinspeção e Inspeção; acessado em 15 jan 2015. Disponível em: http://www2.rio.rj.gov.br/vigilanciasanitaria/index.cfm.

15. Brasil. Ministério da Saúde. Secretaria de Gestão do Trabalho e da Educação na Saúde. Departamento de Gestão da Educação na Saúde. Direito sanitário e saúde pública / Ministério da Saúde, Secretaria de Gestão do Trabalho e da Educação na Saúde, Departamento de Gestão da Educação na Saúde; Márcio lorio Aranha (Org.) - Brasília: Ministério da Saúde; 2003.

16. Sociedade Brasileira de Enfermeiros de Centro Cirúrgico, Recuperação Anestésica e Centro de Material e Esterilização. 2ª ed. São Paulo: SOBECC; 2013.

17. Hoffmeister LV, Moura GMSS. Uso de pulseiras de identificação em pacientes internados em um hospital universitário. Rev. Latino-Am. Enfermagem [Internet]. 2015 [acesso em: 20 Ago 2015]; 23(1):36-43. Disponível em: http://www.scielo.br/scielo.php?script=sci_arttext\&pid=S010411692015000100036\&l $\mathrm{ng}=\mathrm{pt}$ 
18. Miasso Al, Cassiani SHB. Erros na administração de medicamentos: divulgação de conhecimentos e identificação do paciente como aspectos relevantes. Rev Esc Enferm USP. 2000;34(1):16-25.

19. Brasil. Ministério da Saúde. Portaria n 2.095 de 24 de setembro de 2013. Aprova os Protocolos de Segurança do Paciente. Diário Oficial da União 2013; 25 set.

20. Perroca MG, Jericó MC, Facundin SD. Monitorando o cancelamento de procedimentos cirúrgicos: indicador de desempenho organizacional. Rev Esc Enferm USP 2007; 41(1):113-9.

21. Gatto MAF, Jouclas VMG. Otimizando o uso da SO. Rev SOBECC. 1998;3(1):23-8.

22. Batista TF, Rodrigues MCS. Vigilância de infecção de sítio cirúrgico pós-alta hospitalar em hospital de ensino do Distrito Federal, Brasil: estudo descritivo retrospectivo no período 2005-2010. Epidemiol. Serv. Saúde [Internet]. 2012 [acesso em: $\quad 30 \quad$ Ago 2015];21(2):253-64. Disponível em: http://scielo.iec.pa.gov.br/scielo.php?script=sci_arttext\&pid=\$1679497420120002000 08\&lng=pt.

23. Bahia. Portaria Estadual no. 1083 de 15 de maio de 2001. Estabelece os Padrões de Qualidade da Assistência para Autoavaliação Hospitalar com Foco no Controle de Infecção Hospitalar. $3^{\text {a }}$ Edição. Anexos revisados e ampliados. Acessado em 10 jan $2015 . \quad$ Disponível em:

http://www.suvisa.ba.gov.br/sites/default/files/galeria/texto/2014/12/18/Anexos\%20da \%20Portaria\%201083\%20Revisada\%20e\%20ampliada\%20vers\%C3\%A30\%20preli minar\%2017\%2012\%202014.pdf. 
6. CONCLUSÕES 
O estudo permitiu compreender alguns aspectos sanitários importantes referentes à segurança do paciente cirúrgico nos Centros Cirúrgicos avaliados, indicando pistas que podem corroborar para a minimização de riscos nestes serviços.

Embora percebido bons níveis de conformidade à maioria dos itens da LVSC, verifica-se que a implementação da lista nas salas operatórias como intervenção neste estudo mostrou achados de variação do cumprimento destes itens, tais como: 1) Antes da indução anestésica - "colocação do oxímetro de pulso" e "funcionamento do oxímetro" (adesão superior a 95,0\%); "verificação de alergias", "avaliação de dificuldade aérea" e "avaliação de perda sanguínea" (14, 6\%, 10,0 \% e 15,0\%, respectivamente); 2) Antes da incisão cirúrgica - adesão superior a $90,0 \%$, exceto "eventos críticos previstos pelo anestesista" (86,7\%) e "disponibilização de exames de imagem" $(80,0 \%)$ e 3 ) Antes do paciente sair da sala operatória", houve baixa verificação de problemas com equipamentos $(51,4 \%)$.

Destarte, alguns itens de segurança foram negligenciados pelas equipes cirúrgicas durante a implementação da LVSC nas salas operatórias. Este encontro pode inferir que o processo de implementação da LVSC não é feito de maneira sistemática em todos os hospitais avaliados, devendo ser foco de futuras intervenções. Todavia, esforços e maior atenção, por parte dos gestores locais, devem ser concentrados nos itens com maiores problemas de adesão em cada uma das instituições.

Em relação às atitudes de segurança, percebeu-se que as equipes de enfermagem e de anestesiologia exibiram mais atitudes positivas em relação à LVSC do que cirurgiões, notadamente em relação à sensação de segurança e integração da equipe de trabalho. Assim, apesar das melhorias observadas, ainda foram apreendidas dificuldades de implementação da LVSC nas unidades avaliadas, especialmente no que se refere à aceitação do instrumento por todos os membros das equipes cirúrgicas. A maioria dos respondentes acredita que a comunicação entre a equipe cirúrgica foi melhorada com a utilização da LVSC, que este instrumento ajuda a evitar erros na sala operatória e, ainda, que tem contribuído para desenvolver uma cultura de segurança cirúrgica na instituição.

Ademais, os resultados permitem reconhecer fragilidades na estrutura físicooperacional dos Centros Cirúrgicos e nos itens de segurança do paciente nas unidades avaliadas, sinalizando para o possível descumprimento de determinados 
regulamentos sanitários, tais como: ausência de controle de temperatura e pressão positiva na maioria das salas operatórias; a maioria não reconhece o duplo mecanismo de identificação do paciente, do monitoramento do tempo de atraso da cirurgia e tempo na Recuperação Anestésica; a taxa de reinternação não é monitorada (82,2\%) e a vigilância pós-alta, em 72,2\% não é realizada.

Ressalta-se que o uso da LVSC constitui apenas em uma das muitas estratégias que podem ser empregadas a fim de melhorar a qualidade e instituir uma cultura de segurança nos blocos cirúrgicos dos serviços de saúde. Assim, outras estratégias devem ser adotadas pelos serviços de saúde avaliados, a exemplo do desenvolvimento de um plano de segurança que inclua mecanismos para a cirurgia segura, acompanhamento sistemático dos incidentes bem como a investigação em profundidade dos incidentes ocorridos, apoiado pelo gerenciamento de risco e pela segurança do paciente.

As limitações do estudo podem ter ocorrido em virtude do número e tipo de hospital, da diversidade de ambientes hospitalares e especialidades atendidas nas salas operatórias, as quais foram diversas e em contextos diferentes, das populações específicas em cada serviço de saúde, das características das equipes cirúrgicas e dos pacientes. Assim, os resultados podem não ser generalizáveis a todas as instituições. Também, no decorrer do presente estudo, foram estabelecidas legislações nacionais sobre segurança do paciente, além do Protocolo para Cirurgia Segura do MS, provavelmente, com melhor assimilação e conformidade de determinados itens de segurança pelas equipes cirúrgicas.

Espera-se que os resultados obtidos com a condução deste estudo possibilite subsidiar o processo de tomada de decisão pelos gestores e autoridades de saúde na utilização da LVSC nos Centros Cirúrgicos dos serviços de saúde. Ainda, esperase que os achados desse estudo possa apoiar a tomada de decisão para recomendações e regulamentações pela ANVISA sobre segurança cirúrgica, sustentando a promoção de ações que visem à melhoria da segurança do procedimento cirúrgico.

Novos estudos devem ser realizados neste campo na tentativa de alcançar a melhoria do cuidado prestado ao paciente cirúrgico, tais como: 1) estudos qualitativos para melhor compreensão das razões para a adesão variável aos itens da LVSC: como se dá a sustentação da adesão dos membros da equipe cirúrgica à LVSC; qual o envolvimento e a aceitação dos gestores; e a percepção e a aceitação 
dos profissionais na implantação da LVSC nos serviços; 2) análise de custo benefício do uso da LVSC; 3) investigações que utilizem instrumentos sanitários, como o roteiro de inspeção de VISA, que podem melhor avaliar as reais condições da atenção anestésico-cirúrgica e segurança do paciente, identificando as incongruências administrativas, estruturais, organizacionais e assistenciais, além da possibilidade de expor orientações ao seu bom funcionamento; e 4) pesquisas sobre a mensuração da cultura de segurança nas unidades participantes que podem melhor avaliar as percepções e comportamentos dos membros das equipes cirúrgicas relacionados à segurança, permitindo identificar áreas mais problemáticas para que gestores e líderes possam programar intervenções locais.

Apesar de os avanços observados quanto aos aspectos pertinentes à segurança do paciente com a condução do estudo, ainda são necessárias outras medidas em busca da qualidade e da segurança dos cuidados cirúrgicos, as quais são recomendadas, a seguir:

- Concentração de esforços nos itens com maiores problemas de adesão da LVSC em cada uma das instituições com o intuito de melhorar a adesão e a utilização da LVSC pela equipe cirúrgica;

- Sensibilização da alta direção e das equipes cirúrgicas para o uso da LVSC de forma estruturada com o intuito de prevenir erros cirúrgicos, por melhor trabalho em equipe, e aprimorar a percepção da necessidade de cuidados cirúrgicos confiáveis e de responsabilidades compartilhadas;

- Motivação para o uso da LVSC pelas equipes cirúrgicas, visando à melhoria da segurança do paciente cirúrgico;

- Monitoramento da supervisão do desempenho de todos os integrantes das equipes cirúrgicas para o uso da LVSC, com devolutivas periódicas, individualizadas e não punitivas da adesão ao instrumento;

- Estímulo à melhoria da comunicação com vistas a favorecer o trabalho em equipe na sala operatória e redução do risco de erros cirúrgicos;

- Atualização e seguimento de normas e protocolos locais de segurança do paciente; 
- Tomada de decisões por parte de gestores e líderes para aumentar a segurança do paciente, orientando para o funcionamento de qualidade dos Centros Cirúrgicos;

- Desenvolvimento de programas de capacitação para o cuidado do paciente cirúrgico, com treinamento obrigatório para o uso da LVSC, especialmente direcionado aos itens com maior dificuldade de adesão;

- Planejamento e realização de intervenções locais, visando à melhoria da segurança e da cultura de segurança do paciente nos serviços de saúde;

- Realização de auditorias e rigoroso acompanhamento pós-alta das ISC nos hospitais investigados, visando otimizar as medidas de prevenção e controle de infecções pela $\mathrm{CClH}$;

- Elaboração, implantação e execução de planos de segurança do paciente, com destaque para as ações de segurança do procedimento cirúrgico;

- Melhoria do cumprimento das regulamentações sanitárias vigentes para a minimização de riscos em serviços de saúde, especialmente nos blocos cirúrgicos;

- Investimentos em pesquisa sobre qualidade e segurança do paciente cirúrgico, aumentando o conhecimento, e dando apoio à tomada de decisões. 
1. Santana HT, Siqueira HN, Costa MMM, Oliveira DCAN, Gomes SM, Sousa FC, et al. A segurança do paciente cirúrgico na perspectiva da vigilância sanitária - uma reflexão teórica. Vig Sanit Debate 2014; 2(2):34-42.

2. Brasil. Agência Nacional de Vigilância Sanitária. Resolução da Diretoria Colegiada - RDC no. 36 de 25 de julho de 2013 que institui ações para a segurança do paciente em serviços de saúde e dá outras providências. Diário Oficial da União 2013;26 jul.

3. Kohn L, Corrigan J, Donaldson MS. To err is human: building a safer health system.Committee on Quality of Health Care in America. Institute of Medicine. Washington, DC: National Academy Press; 2000.

4. Brasil. Agência Nacional de Vigilância Sanitária. Investigação de Eventos Adversos em Serviços de Saúde. Série Segurança do Paciente e Qualidade em Serviços de Saúde. Brasília: ANVISA; 2013.

5. Thungjaroenkul P, Cummings GG, Embleton A. The impact of nursing staffing on hospital costs and patient length of stay: a systematic review. Nurs Econ 2007;25(5):255-65.

6. Curran CR, Totten MK. Governing for improved quality and patient safety. Nurs Econ $2011 ; 29(1): 38-41$.

7. Needleman J, Buerhaus P, Pankratz S, Leibson CL, Stevens SR, Harris M. Nurse staffing and inpatient hospital mortality. NEJM. 2011;364(11):1037-45.

8. Fragata J. Segurança dos Doentes:uma abordagem prática. Lisboa: Lidel; 2011. 312 p.

9. World Health Organization. WHO guidelines for safe surgery.Geneva: WHO; 2009. 
10. Wachter RM. Compreendendo a segurança do paciente. Porto Alegre: Artmed; 2010. 320p.

11. Baker T. Reconsidering the Harvard Medical Practice Study conclusions about the validity of medical malpractice claims. J Law Med Ethics 2005;33:501-14.

12. Thomas EJ, Studdert DM, Burstin HR, Orav EJ, Zeena T, Williams EJ, et al. Incidence and types of adverse events and negligent care in Utah and Colorado. Med Care 2000;38:261-71.

13. Quality Interagency Coordination Task Force. Doing What Counts for Patient Safety. Washington, DC: Quality Interagency Task Force; Feb 2000.

14. Brennan TA, Leape LL, Laird NM, Hebert L, Localio R, Lawthers A, et al. Incidence of adverse events and negligence in hospitalize patients. Results of the Harvard Medical Practice Study I. New Engl J Med1991;324:370-6.

15. Wilson RM, Runciman WB, Gibberd RW, Harrison BT, Newby L, Hamilton JD, et al. The quality in Australian health care study. Med J Aust 1995 Nov 6; 163:458-471.

16. Gawande AA, Thomas EJ, Zinner MJ, Brennan TA. The incidence and nature of surgical adverse events in Colorado and Utah in 1992. Surgery 1999 Jul; 126(1):66-75.

17. Kable AK, Gibberd RW, Spigelman AD. Adverse events in surgical patients in Australia. Int J Qual Health Care 2002 Aug 14;(4):269-76.

18. Gaitán-Duarte H, Eslava-Schmalbach J, Rodriguez-Malagon N, ForeroSupelano V, Santofimio-Sierra D, Altahona H. Incidencia y evitabilidade de eventos adversos en pacientes hospitalizados en tres instituciones hospitalarias en Colombia, 2006. Rev Salud Pública 2008 May;10(2):215-226. 
19. Mendes W, Martins M, Rozenfeld S, Travassos C. The assessment of adverse events in Brazilian hospitals. Int J Qual Health Care 2009; 21(4):279-284.

20. Moura MLO. Avaliação de eventos adversos cirúrgicos em hospitais do Rio de Janeiro [Dissertação]. [Rio de Janeiro]: Escola Nacional de Saúde Pública Sergio Arouca; 2010.106p.

21. Leape LL, Brennan TA, Laird N, Lawthers AG, Localio AR, Barnes BA, et al. Incidence of adverse events and negligence in hospitalized patients: results of the Harvard Medical Practice Study I. N Engl J Med 1991 Feb 7;324(6):370-6.

22. Gawande AA, Zinner MJ, Studdert DM, Brennan TA. Analysis of errors reported by surgeons at three teaching hospitals. Surgery 2003 Jun; 133(6):614-21.

23. Rogers SO, Gawande AA, Kwaan M, Puopolo AL, Yoon C, Brennan TA, et al. Analysis of surgical errors in closed malpractice claims at 4 liability insurers. Surgery 2006;140(1):25-33.

24. Leape L. Error in medicine. JAMA 1994 dec 21; 272(23):1851-57.

25. D'Addessi A, Bongiovanni L, Volpe A, Pinto F, Bassi P. Human factors in surgery: from Three Mile Island to the operating room. Urol Int 2009; 83:249257.

26. World Health Organization. World Alliance for Patient Safety forward programme 2005. Geneva: World Health Organization; 2004.

27. Donaldson L, Fletcher M. The WHO World Alliance for Patient Safety: towards the years of living less dangerously. Med J Aust 2006:184(10 Suppl);S69-72. 
28. Haynes AB, Weiser TG, Berry WR, Lipsitz SR, Breizat AH, Dellinger EP, et al. Safe surgery saves lives study group. A surgical safety checklist to reduce morbidity and mortality in a global population. N Engl J Med 2009;360(5):491 99.

29. Weiser TG, Haynes AB, Dziekan G, Berry WR, Lipsitz SR, Gawande AA. Effect of A 19-Item Surgical safety checklist during urgent operations in a global patient population. Ann Surg 2010;251:976-80.

30. Bliss LA, Ross-Richardson CB, Sanzari LJ, Shapiro DS, Lukianoff AE, Bernstein BA, et al. Thirty-day outcomes support implementation of a surgical safety checklist. J Am Coll Surg 2012;215(6):766-76.

31. Kwok AC, Funk LM, Baltaga R, Lipsitz SR, Merry AF, Dziekan G, et al. Implementation of the World Health Organization surgical safety checklist, including introduction of pulse oximetry, in a resource-limited setting. Ann Surg 2013;257(4):633-9.

32. Neily J, Mills PD, Young-Xu Y, Carney BT, West P, Berger DH, et al. Association between implementation of a medical team training program and surgical mortality. JAMA. 2010 Oct 20; 304(15):1693-700.

33. Haynes AB, Weiser TG, Berry WR, Lipsitz SR, Breizat AH, Dellinger EP, et al. Changes in safety attitude and relationship to decreased postoperative morbidity and mortality following implementation of a checklist-based surgical safety intervention. BMJ Qual Saf 2011;20:102-07.

34. Makary MA, Sexton JB, Freischlag JA, Holzmueller CG, Millman EA, Rowen L, et al. Operating room teamwork among physicians and nurses: teamwork in the eye of the beholder. J Am Coll Surg 2006 May; 202(5):746-52.

35. Sexton JB, Makary MA, Tersigni AR, Pryor D, Hendrich A, Thomas EJ, et al. Teamwork in the operating room: frontline perspectives among hospitals and operating room personnel. Anesthesiology 2006 Nov; 105(5):877-84. 
36. Sexton JB, Helmreich RL, Neilands TB, Rowan K, Vella K, Boyden J, et al. The Safety Attitudes Questionnaire: psychometric properties, benchmarking data, and emerging research. BMC Health Serv Res. 2006;6:44.

37. Secretaria Municipal de Saúde e Defesa Civil. Rio de Janeiro. Roteiro de Autoinspeção e Inspeção [acesso em 15 jan 2015]. Disponível em: http://www2.rio.rj.gov.br/vigilanciasanitaria/index.cfm.

38. Bosk CL, Dixon-Woods M, Goeschel CA, Pronovost PJ. Reality check for checklists. Lancet 2009;374(9688):444-5.

39. Vats A VC, Nagpal K, Davies RW, Darzi A, Moorthy K. Practical challenges of introducing WHO surgical checklist: UK pilot experience. BMJ 2010; 340:b5433.

40. Bello AC, Carvalho AA, Sousa FC, Santana HT, Siqueira HN, Ferreira KA, et al. Ações da Anvisa/MS para a Segurança do Paciente e Qualidade em Serviços de Saúde. In: Agência Nacional de Vigilância Sanitária. Assistência Segura: uma reflexão teórica aplicada à prática. Série Segurança do Paciente e Qualidade em Serviços de Saúde. Brasília: ANVISA; 2013.

41. Brasil. Ministério da Saúde. Documento de referência para o Programa Nacional de Segurança do Paciente. Ministério da Saúde; Fundação Oswaldo Cruz; Agência Nacional de Vigilância Sanitária. Brasília: Ministério da Saúde; 2013. p. 40.

42. Padilha MICS, Rolim MJ. Florence Nightingale e as irmãs de caridade: revisitando a história. Rev Bras Enferm [Internet]. 2005 Dec [acesso em 03 nov 2015];58(6):723-726. Disponível em: http://www.scielo.br/scielo.php?script=sci_arttext\&pid=S0034$71672005000600018 \&$ Ing $=$ en. 
43. Fee E, Garofalo ME. Florence Nightingale and the Crimean War. Am J Public Health 2010;100:1591.

44. Semmelweis I. The etiology, concept and prophylaxis of childbed fever [excerpts]. In: Buck C, Llopis A, Najera E, Terris M, editors. The challenge of epidemiology-issues and selected readings. Washington: PAHO Scientific Publication; 1988. p. 46-59.

45. Fernandes AT, Filho NR. As bases do Hospital Contemporâneo: a Enfermagem, os Caçadores de Micróbios e o Controle de Infecção. In: Fernandes AT, Fernandes MOV, Ribeiro Filho N, Graziano KU, Cavalcante NJF, Lacerda RA. Infecção hospitalar e suas interfaces na área da saúde. São Paulo: Atheneu; 2000. p. 56-74.

46. Sousa FC, Rodrigues IP, Santana HT. Perspectiva Histórica. In: Segurança do Paciente em Serviços de Saúde - Higienização das Mãos. Brasília: ANVISA; 2009.

47. Vincent C. Segurança do Paciente: orientações para evitar eventos adversos. São Caetano do Sul, SP: Yendis; 2009.

48. Travassos C, Caldas B. A qualidade do cuidado e a segurança do paciente: histórico e conceitos. In: Assistência Segura: Uma Reflexão Teórica Aplicada à Prática. Série Segurança do Paciente e Qualidade em Serviços de Saúde. Brasília: ANVISA; 2013.

49. Brasil. Agência Nacional de Vigilância Sanitária. Assistência Segura: uma reflexão teórica aplicada à prática. Série Segurança do Paciente e Qualidade em Serviços de Saúde. Brasília:ANVISA; 2013. 
50. Ribeiro MJF, Madureira MC. Qualidade nos Serviços de Saúde. In: Zucchi P, Ferraz MB, coordenadores. Guia de economia e gestão em saúde. Séries guias de Medicina ambulatorial e hospitalar. Barueri, SP: Manole; 2010. p. 434.

51. Mellin-Olsen J, Staender S, Whitaker DK, Smith AF. The Helsinki Declaration on Patient Safety in Anaesthesiology. Eur J Anaesthesiol 2010;27(7):592-7.

52. Cordero IE, Sainz HC, Santos MSP, Rojas OS. Anestesia y seguridad del paciente. Un llamado urgente. Rev cuba anestesiol reanim [Internet]. 2013 Jun [citado 2015 Nov 03];12(2): 151-157. Disponible en: http://scielo.sld.cu/scielo.php?script=sci_arttext\&pid=S1726$67182013000200006 \& \operatorname{lng}=\mathrm{es}$.

53. Cyril C. The role and education of doctors in the delivery of health care. Lancet 1999;353(9159):1178-81.

54. Varela JS, Suárez JR, coordenadores. Marco General de la Seguridad del paciente. Folleto del Curso de Evaluación y Mejora de la Calidad de Atención y la Seguidad del Paciente. México: Comision Nacional de Arbitraje Medido. Centro Colaborador de la OPS/OMS; 2011.

55. Leape LL. Scope of problem and history of patient safety. Obstet Gynecol Clin North Am 2008 Mar; 35(1):1-10.

56. Barach P, Small SD. How the NHS can improve safety and learning. By learning free lessons from near misses. Br Med J 2000; 320:1683-1684.

57. Department of Health. Report of an Expert Group on Learning from Adverse Events in the NHS. An organisation with a memory. London: Stationery Office; 2000. Available from: www.doh.gov.uk/orgmemreport/index.htm 
58. NHS England Patient Safety Domain. An introduction to the NHS England Patient Safety Alerting System. England: NHS; 2014. Available from: https://www.england.nhs.uk/wp-content/uploads/2014/01/npsas-guide.pdf

59. Department of Health. Annual Report and Accounts 2011/12. London: The Stationery Office; 2012.

60. World Health Organization. World Alliance for Patient Safety. Forward Programme 2006-2007. Geneva: WHO Press; 2006. 56p.

61. World Health Organization (WHO). World Alliance for Patient Safety. Forward Programme - 2008-2009. [acesso em 10 set 2013]. Disponível em: http://www.who.int/patientsafety/information_centre/documents/en/.

62. Allegranzi B, Storr J, Dziekan G, Leotsakos A, Donaldson L, Pittet D. The First Global Patient Safety Challenge "Clean Care is Safer Care": from launch to current progress and achievements. J Hosp Infect. 2007 Jun;65 Suppl 2:11523.

63. Organização Mundial de Saúde. Segundo desafio global para a segurança do paciente. Cirurgias seguras salvam vidas (Guia de Implementação para cirurgia segura da OMS). Organização Mundial da Saúde. Ministério da Saúde. Agência Nacional de Vigilância Sanitária. Rio de Janeiro: Organização Pan-Americana da Saúde; 2010.

64. Wachter RM, Pronovost PJ. The 100,000 Lives Campaign: A scientific and policy review. Jt Comm J Qual Patient Saf 2006;32(11):621-7.

65. Centers for Disease Control and Prevention (CDC). Patient safety component manual. Identifying healthcare-associated infections (HAls). [cited 2015 jan 14].

Available from: http://www.cdc.gov/nhsn/pdfs/pscmanual/pcsmanual_current.pdf . 
66. Surgical Care Improvement Project (SCIP). Project Information; 2014. [cited 2015 jan 21]. Available from: http://www.jointcommission.org/surgical_care_improvement_project/.

67. Treadwell JR, Lucas S. Preoperative checklists and anesthesia checklists. In: Shekelle PG et al. Making Health Care Safer II: An Updated Critical Analysis of the Evidence for Patient Safety Practices. Comparative Effectiveness Review No. 211. Agency for Healthcare Research and Quality. March 2013. [cited 2015 mar 05]. Available from: www.ahrq.gov/research/findings/evidencebasedreports/ptsafetyuptp.html .

68. Montserrat-Capella D, Cho M, Lima RS. A Segurança do Paciente e a Qualidade em Serviços de Saúde no Contexto da América Latina e Caribe. In: Assistência Segura: Uma Reflexão Teórica Aplicada à Prática. Série Segurança do Paciente e Qualidade em Serviços de Saúde. Brasília: ANVISA; 2013.

69. Pan American Health Organization. World Health Organization. 27th Pan American Sanitary Conference. CSP27R10. 59th Session of the Regional Committee. 1-5 October 2007. [Internet].Washington D.C. [cited 2015 feb 10]. Disponível em http://www1.paho.org/spanish/gov/csp/csp27.r10-s.pdf.

70. Pan American Health Organization. World Health Organization. 27th Pan American Sanitary Conference. CSP27R16. 59th Session of the Regional Committee. 17 July 2007. [Internet].Washington D.C. [acesso em 10 jan 2015]. Disponível em: http://www1.paho.org/spanish/gov/csp/csp27-16-s.pdf .

71. Brasil. Agência Nacional de Vigilância Sanitária. Boletim Informativo Segurança do Paciente e Qualidade em Serviços de Saúde. Brasília jan-jul2011; 1(3).

72. Mercosur. Acta ํ‥ 02/07. XXIII Reunión de Ministros de Salud del Mercosur. Montevideo; 2007. 
73. Brasil. Agência Nacional de Vigilância Sanitária. Resolução da Diretoria Colegiada - RDC n‥ 42, de 25 de outubro de 2010. Dispõe sobre a obrigatoriedade de disponibilização de preparação alcoólica para fricção antisséptica das mãos, pelos serviços de saúde do país e dá outras providências. Diário Oficial da União 2010; 26 out.

74. Ministerio de Sanidad, Política Social y Igualdad. Estudio IBEAS Prevalencia De Eventos Adversos En Hospitales de Latinoamérica. Informes, estudios e investigaciones España 2009; [168p]. Disponible en: URL: http://www.msc.es/organizacion/sns/planCalida dSNS/docs/INFORME_IBEAS.pdf .

75. Brasil. Ministério da Saúde. Portaria $n^{\circ} .529$ de $1^{\circ}$ de abril de 2013. Institui o Programa Nacional de Segurança do Paciente (PNSP). Diário Oficial da União 2013; 23 abr.

76. Brasil. Agência Nacional de Vigilância Sanitária. Resolução da Diretoria Colegiada - RDC n. 63, de 25 de Novembro de 2011. Requisitos de Boas Práticas de Funcionamento para os Serviços de Saúde. Diário Oficial da União 2011; 28 nov.

77. Brasil. Portaria $n^{\circ}$. 1.443 de 11 de outubro de 2012. Institui grupo de trabalho para elaboração e implementação do Plano de Ação para a segurança do paciente e qualidade em serviços de saúde. Diário Oficial da União 2013;15 out.

78. World Health Organization (WHO). World Alliance for Patient Safety: Clean care is safer care - global patient safety challenge. [Internet] Geneva: WHO; 2005-2006. [Acesso em 25 nov 2014]. Disponível em: http://www.who. int/patientsafety/events/05/GPSC_Launch_ENGLISH_FINAL.pdf

79. Brasil. Portaria $n \div$. 523, de 4 de abril de 2012. Dispõe sobre Acréscimos à Composição da Rede Sentinela. Diário Oficial da União 2012; 5 abr. Seção 1. 
80. Brasil. Portaria no. 1.660, de 22 de julho de 2009. Institui o Sistema de Notificação e Investigação em Vigilância Sanitária - VIGIPÓS, no âmbito do Sistema Nacional de Vigilância Sanitária, como parte integrante do Sistema Único de Saúde - SUS. Diário Oficial da União 2009; 24 jul.

81. Brasil. Ministério da Saúde. Portaria o․ 1.377 de 9 de julho de 2013. Aprova os Protocolos de Segurança do Paciente. Diário Oficial da União 2013;10 jul.

82. Centro Colaborador para a Qualidade do Cuidado e Segurança do Paciente (Proqualis). Fiocruz. Acesso em 20 ago 2015. Disponível em: http://proqualis.net/.

83. Hotsite Segurança do Paciente. Agência Nacional de Vigilância Sanitária [Internet]. Acesso em 20 ago 2015. Disponível em: http://www20.anvisa.gov.br/segurancadopaciente/ .

84. Brasil. Agência Nacional de Vigilância Sanitária [homepage na internet]. Plano Integrado para o fortalecimento do Sistema Nacional de Vigilância Sanitária nos processos de gestão da segurança do paciente em serviços de saúde Monitoramento e Investigação de Eventos Adversos e Avaliação de Práticas de Segurança do Paciente [acesso em 10 ag 2015]. Disponível em http://www20.anvisa.gov.br/segurancadopaciente/index.php/publicacoes.

85. Donabedian A. The definition of quality and approaches to its assessment. In: A. Donabedian, Explorations in quality assessment and monitoring. volume I. Ann Arbor, Michigan: Health Administration Press; 1980.

86. Silva LMV, Formigli VLA. Health evaluation: problems and perspectives. Cad Saude Publica 1994;10(1):80-91. 
87. Donabedian A. The role of outcomes in quality assessment and assurance. QRB Qual Rev Bull. 1992;18(11):356-60.

88. Donabedian A. An Introduction to Quality Assurance in Health Care. New York: Oxford University Press; 2003.

89. Feldman LB. O enfermeiro analista de risco institucional. Brasília: Rev bras enferm 2004;57(6):742-5.

90. Institute of Medicine. Crossing the Quality Chasm. A New Health System for the 21st Century. Washington:National Academy Press; 2001.

91. Donabedian A. Quality assurance. Structure, process and outcome. Nurs Stand 1992;7(11 Suppl QA):4-5.

92. Duarte IG, Ferreira DP. Uso de indicadores na gestão de um centro cirúrgico. RAS. 2006 Abr-Jun; 8(31):63-70.

93. Donabedian A. The seven pillars of quality. Arch Pathol Lab Med. 1990;114(11):1115-8.

94. Wennberg JE. Tracking Medicine: a researcher's quest to understand health care. New York: Oxford University Press; 2010.

95. Malik AM, Schiesari LMC. Qualidade na gestão local de serviços e ações de saúde. São Paulo: Peirópolis; 1998.

96. Fragata J. Segurança dos doentes - uma abordagem prática. Lisboa: Lidel; 2011. p. 312 p. 
97. Shcolnik W. Erros laboratoriais e segurança dos pacientes: revisão sistemática Rio de Janeiro: Fundação Oswaldo Cruz; 2012.

98. Brasil. Ministério da Saúde. Programa de Avaliação do Desempenho do Sistema de Saúde (Proadess). [acesso em 10 maio 2012]. Disponível em: http://www.proadess.icict.fiocruz.br/index.php?pag=princ.

99. Brasil. Agência Nacional de Saúde Suplementar (ANS). Resolução Normativa (RN) $n^{\circ}$ 275, de $1^{\circ}$ de novembro de 2011. Dispõe sobre a instituição do Programa de Monitoramento da Qualidade dos Prestadores de Serviços na Saúde Suplementar. Diário Oficial da União, 2011; 03 de nov.

100. Agência Nacional de Saúde Suplementar (ANS). Programa de Qualificação de Prestadores de Serviços de Saúde. Acesso em 10 maio 2014. Disponível em: http://www.ans.gov.br/prestadores/qualiss-programa-de-qualificacao-deprestadores-de-servicos-de-saude .

101. Brasil. Lei ํo. 8.080 , de 19 de setembro de 1990. Dispõe sobre a organização para promoção, proteção e recuperação da saúde, a organização e o funcionamento dos serviços correspondentes, e dá outras providências. Diário Oficial da União 1990; 20 set.

102. Brasil. Agência Nacional de Vigilância Sanitária. Implantação do Núcleo de Segurança do Paciente em Serviços de Saúde. Brasília: ANVISA. No prelo 2015.

103. Santana HT, Morelo L. Cultura de segurança em serviços de saúde. In: EAD Segurança do Paciente e Qualidade em Serviços de Saúde. No prelo 2015.

104. Brasil. Lei no. 9.782, de 26 de janeiro de 1999. Dispõe sobre a criação da Agência Nacional de Vigilância Sanitária. Diário Oficial da União, jan 1999; Seção 1. 
105. Brasil. Agência Nacional de Vigilância Sanitária. Relatório de Gestão do exercício de 2012. Brasília:ANVISA; 2012. p. 271.

106. Brasil. Agência Nacional de Vigilância Sanitária. Diretrizes para o Gerenciamento do Risco em Farmacovigilância. Disponível em: http://www.anvisa.gov.br.

107. Brasil. Ministério da Saúde. Secretaria de Gestão do Trabalho e da Educação na Saúde. Departamento de Gestão da Educação na Saúde. Direito sanitário e saúde pública / Ministério da Saúde, Secretaria de Gestão do Trabalho e da Educação na Saúde, Departamento de Gestão da Educação na Saúde; Márcio lorio Aranha (Org.). Brasília: Ministério da Saúde; 2003.

108. Costa EA. Vigilância Sanitária: proteção e defesa da saúde. $2^{\mathrm{a}}$ ed. São Paulo: Sobravime; 2004.

109. Costa E, Fernandes T, Pimenta TS. A vigilância sanitária nas políticas de saúde no Brasil e a construção da identidade de seus trabalhadores (19761999). Ciênc. saúde coletiva 2008; 13(3):995-1004.

110. Brasil. Ministério da Saúde. Portaria ํo. 196, de 24 de junho de 1983. Dispõe sobre o controle de prevenção das infecções hospitalares. Diário Oficial da União, jun 1983; Seção 1.

111. Brasil. Ministério da Saúde. Portaria oo. 930, de 27 de agosto de 1992. Expede, na forma dos anexos, normas para o controle das infecções hospitalares. Diário Oficial da União, ago 1992; Seção 1.

112. Brasil. Lei ํo. 9.431, de 06 de janeiro de 1997. Dispõe sobre a obrigatoriedade de manutenção de programas de controle de infecção hospitalar pelos hospitais do País. Diário Oficial da União, jan 1997; Seção 1. 
113. Ministério da Saúde (Brasil). Portaria no. 2616, de 12 de maio de 1998. Expede, na forma dos anexos I, II, III, IV e V, diretrizes e normas para a prevenção e o controle das infecções hospitalares. Diário Oficial da União, 15 ago 2012.

114. Brasil. Agência Nacional de Vigilância Sanitária. Portaria no. 1.218, de 14 de agosto de 2012 Institui na ANVISA a Comissão Nacional de Prevenção e Controle de Infecção Relacionada à Assistência à Saúde (CNCIRAS). Diário Oficial da União, 13 mai 1998.

115. Agência Nacional de Vigilância Sanitária [homepage na internet]. Programa Nacional de Prevenção e Controle de Infecções Relacionadas à Assistência à Saúde (PNPCIRAS) [acesso em 2013 set 24]. Disponível em: http:www.anvisa.gov.br.

116. Brasil. Agência Nacional de Vigilância Sanitária. Resolução da Diretoria Colegiada - RDC nํ. 50, de 21 de fevereiro de 2002. Dispõe sobre o Regulamento Técnico para planejamento, programação, elaboração e avaliação de projetos físicos de estabelecimentos assistenciais de saúde. Diário Oficial da União, 20 mar 2002; seção 1.

117. Brasil. Agência Nacional de Vigilância Sanitária. Resolução da Diretoria Colegiada - RDC №. 307, de 14 de novembro de 2002. Diário Oficial da União 18 de nov 2002; seção 1.

118. Sociedade Brasileira de Enfermeiros de Centro Cirúrgico, Recuperação anestésica e Central de Material Esterilizado. Práticas recomendadas. 5a ed. São Paulo: Sobecc; 2013.219p.

119. Costa EA. Risk and sanitary safety: analysis on medical product reprocessing in hospitals in Salvador, Northeastern Brazil. Rev Saude Publica 2012;46(5):800-7. 
120. Brasil. Agência Nacional de Vigilância Sanitária. Resolução da Diretoria Colegiada - RDC n‥ 156, de 11 de agosto de 2006. Dispõe sobre o registro, rotulagem e reprocessamento de produtos médicos, e dá outras providências (Revoga Resolução - RDC n³0, de 15 de fevereiro de 2006). Diário Oficial da União; 2006;14 ago).

121. Brasil. Agência Nacional de Vigilância Sanitária. Resolução RE no․ 2605 de 11 de Agosto de 2006. Estabelece a lista de produtos médicos enquadrados como de uso único proibidos de ser reprocessados (Revoga a Resolução RE no. 515, de 15 de fevereiro de 2006, publicada em 16 de fevereiro de 2006). Diário Oficial da União; 2006;14 ago.

122. Brasil. Agência Nacional de Vigilância Sanitária. Resolução RE no․ 2.606, de 11 de agosto de 2006. Dispõe sobre as diretrizes para elaboração, validação e implantação de protocolos de reprocessamento de produtos médicos e dá outras providências. Diário Oficial da União; 2006; 14 ago.

123. Brasil. Agência Nacional de Vigilância Sanitária. Resolução da Diretoria Colegiada - RDC n‥ 8, de 27 de fevereiro de 2009. Dispõe sobre as medidas para redução da ocorrência de infecções por Micobactérias de Crescimento Rápido - MCR em serviços de saúde. Diário Oficial da União; 2009; 02 mar.

124. World HealthOrganization (WHO). WHO guidelines on hand hygiene in health care. First global patient safety challenge. Clean care is safer care. Genebra: WHO Press; 2009.

125. World HealthOrganization (WHO). Hand hygiene in outpatient and homebased care and long-term care facilities: a guide to the application of the WHO multimodal hand hygiene improvement strategy and the "My Five Moments For Hand Hygiene" approach. Geneva: WHO Press; 2012. 
126. Gonçalves KJ, Graziano KU, Kawagoe JY. A systematic review of surgical hand antisepsis utilizing an alcohol preparation compared to traditional products. Rev Esc Enferm USP. 2012;46(6):1484-93.

127. Brasil. Agência Nacional de Vigilância Sanitária. Resolução da Diretoria Colegiada - RDC №. 199 de 26 de outubro de 2006. Institui a notificação simplificada de medicamentos por meio eletrônico disponível no site da ANVISA. Diário Oficial da União; 2006; 30 out.

128. Brasil. Agência Nacional de Vigilância Sanitária. Resolução da Diretoria Colegiada - RDC №. 4 de 30 de janeiro de 2014. Dispõe sobre os requisitos técnicos para a regularização de produtos de higiene pessoal, cosméticos e perfumes e dá outras providências. Diário Oficial da União 2014;31 jan.

129. Brasil. Agência Nacional de Vigilância Sanitária. Resolução da Diretoria Colegiada - RDC no. 15, de 15 de março de 2012. Dispõe sobre requisitos de boas práticas para o processamento de produtos para saúde e dá outras providências. Diário Oficial da União 2012; 19 mar; seção 1.

130. Brasil. Ministério da Saúde. Portaria № 941, de 17 de maio de 2013. Altera e acresce dispositivo ao art. $8^{\circ}$ da Portaria $\mathrm{n}^{\circ}$. 529/GM/MS, de $1^{\circ}$ de abril de 2013, que institui o Programa Nacional de Segurança do Paciente - PNSP. Diário Oficial da União 2013; 21 mai.

131. Resolução da Diretoria Colegiada - RDC n'. 53, de 14 de novembro de 2013. Altera o artigo 12 da RDC ํ․ 36/2013, prorrogando os prazos para a estruturação dos NSPs, elaboração do PSP e notificação mensal dos EA, contados a partir da data da publicação da norma. Diário Oficial da União 2013; 26 jul. 
132. Brasil. Ministério da Saúde. Portaria n. 2.095 de 24 de setembro de 2013. Aprova os Protocolos de Segurança do Paciente. Diário Oficial da União 2013; 25 set.

133. Ferraz, EM. A cirurgia segura em serviços de saúde. In: Agência Nacional de Vigilância Sanitária. Assistência Segura: uma reflexão teórica aplicada à prática. Série Segurança do Paciente e Qualidade em Serviços de Saúde. Brasília: ANVISA; 2013.

134. Organização Mundial de Saúde. Segundo desafio global para a segurança do paciente. Cirurgias seguras salvam vidas (Orientações para cirurgia segura da OMS). Organização Mundial da Saúde. Ministério da Saúde. Agência Nacional de Vigilância Sanitária. Rio de Janeiro: Organização Pan-Americana da Saúde; 2010.

135. Brasil. Agência Nacional de Vigilância Sanitária. Manual de Critérios Nacionais de Infecções Relacionadas à Assistência à Saúde - Sítio Cirúrgico [Internet]. Brasília; acesso em 22 fev 2012. Disponível em: http://portal.anvisa.gov.br/wps/wcm/connect/35b4530049bef5c89d01bf6dcbd9 c63c/Crit\%C3\%A9rios+S\%C3\%ADtio+Cir\%C3\%BArgico.pdf?MOD=AJPERES

136. Brasil. Agência Nacional de Vigilância Sanitária. Manual de Indicadores Nacionais de Infecções Relacionadas à Assistência à Saúde [Internet]. Brasília; acesso em 21 fev 2012. Disponível em: http://portal.anvisa.gov.br/wps/wcm/connect/1ff4120047457e9b8a6ede3fbc4c 6735/INDICADORES+NACIONAIS+DE+INFEC\%C3\%87\%C3\%830++Setembro+2010+-+NOVO.pdf?MOD=AJPERES .

137. Brasil. Agência Nacional de Vigilância Sanitária. Cartaz Segurança do Paciente [Internet]. Brasília; acesso em 20 mar2014. Disponível em: 
138. Proqualis. Cirurgia Segura (DVD). Rio de Janeiro: Vídeo Saúde distribuidora da Fiocruz; 2011.

139. Bauer FL. Gestão de Risco e Segurança Hospitalar. São Paulo: Martinari; 2009.

140. Associação dos Enfermeiros de Sala de Operações Portugueses (AESOP). Enfermagem Perioperatória. Da Filosofia à Prática de Cuidados. Loures: Lusodidacta. 2006; 356 p.

141. Rebelo SMSRS. Segurança do Doente no Bloco Operatório. [Dissertação]. [Coimbra]: Escola Superior de Enfermagem de Coimbra; 2013. 178 p.

142. Ferraz EM. A XXI century exigence. Rev Col Bras Cir. 2009;36(4):281-282.

143. Weiser TG, Regenbogen SE, Thompson KD, Haynes AB, Lipsitz SR, Berry $W R$, et al. An estimation of the global volume of surgery: a modelling strategy based on available data. Lancet. $2008 \mathrm{Jul}$ 12; 372(9633):139-144.

144. Moura GMSS, Magalhães AMM. Eventos adversos relacionados à assistência em serviços de saúde: principais tipos. In: Agência Nacional de Vigilância Sanitária. Assistência Segura: uma reflexão teórica aplicada à prática. Série Segurança do Paciente e Qualidade em Serviços de Saúde. Brasília: ANVISA; 2013.

145. World HealthOrganization (WHO). Conceptual framework for the international classification for patient safety. Version 1.1. Final Technical Report. WHO; 2009.

146. Fragata JIG. Erros e acidentes no bloco operatório: revisão do estado da arte. Rev Port Saúde Pública. 2010;Vol Temat(10):17-26. 
147. Wilson RM RW, Gibberd RW, Harrison BT, Newby L, Hamilton JD, et al. The quality in Australian health care study. Med J Aust. 1995 Nov 6; 163:458-471.

148. Vincent C, Neale G, Woloshynowych M. Adverse events in British hospitals: preliminary retrospective record review. BMJ. 2001;322(7285):517-9.

149. Davis P, Lay-Yee R, Briant R, Ali W, Scott A, Schug S. Adverse events in New Zealand public hospitals I: occurrence and impact. $\mathrm{N} Z$ Med $\mathrm{J}$ 2002;115(1167):U271.

150. Baker GR, Norton PG, Flintoft V, Blais R, Brown A, Cox J, et al. The Canadian Adverse Events Study: the incidence of adverse events among hospital patients in Canada. CMAJ 2004;170(11):1678-86.

151. Mendes W, Travassos C, Martins M, Noronha JC. Revisão dos estudos de avaliação da ocorrência de eventos adversos em hospitais. Rev Bras Epidemiol 2005; 8(4): 393-406.

152. Sousa P, Uva AS, Serranheira F, Nunes C, Leite ES. Estimating the incidence of adverse events in Portuguese hospitals: a contribution to improving quality and patient safety. BMC Health Serv Res 2014;14:311.

153. Mendes W MM, Rozenfeld S, Travassos C. The assessment of adverse events in Brazilian hospitals. Int J Qual Health Care 2009; 21(4):279-284.

154. Centers for Disease Control and Prevention (CDC). Estimates of healthcareassociated infections; 2007.

155. Leape LL, Brennan TA, Laird N, Lawthers AG, Localio R,. Barnes BA, et al. The nature of adverse events in hospitalized patients. Results of the Harvard Medical Practice Study II. N Engl J Med 1991; 377-384. 
156. Kirkland KB, Briggs JP, Trivette SL, Wilkinson WE, Sexton DJ. The impact of surgical-site infections in the 1990s: attributable mortality, excess length of hospitalization, and extra costs. Infect Control Hosp Epidemiol 1999;20(11):725-30.

157. Centers for Disease Control and Prevention. Surgical Site Infection (SSI) Event [Accessed 2015 may 15]. Available from: http://www.cdc.gov/nhsn/PDFs/pscManual/9pscSSlcurrent.pdf?agree=yes\&ne $\mathrm{xt}=$ Accept

158. Velasco E, Thuler LC, Martins CA, Dias LM, Conalves VM. Risk factors for infectious complications after abdominal surgery for malignant disease. Am $\mathrm{J}$ Infect Control. 1996;24:1-6.

159. Smyth ETM, Emmerson AM. Surgical site infection surveillance. J Hosp Infect 2000;45:173-84.

160. Mangram AJ, Horan TC, Pearson ML, Silver LC, Jarvis WR. Guideline for Prevention of Surgical Site Infection, 1999. Centers for Disease Control and Prevention (CDC) Hospital Infection Control Practices Advisory Committee. Am J Infect Control 1999;27(2):97-132; quiz 3-4; discussion 96.

161. Horan TC, Culver DH, Gaynes RP, Jarvis WR, Edwards JR, Reid CR. Nosocomial infections in surgical patients in the United States, January 1986June 1992. National Nosocomial Infections Surveillance (NNIS) System. Infect Control Hosp Epidemiol. 1993;14:73-80.

162. Smyth ET, Mcllvenny G, Enstone JE, Emmerson AM, Humphreys $H$, Fitzpatrick $F$, et al. Four country healthcare associated infection prevalence survey 2006: overview of the results. J Hosp Infect 2008;69(3):230-48. 
163. Franco LMC. Infecção de sítio cirúrgico em pacientes submetidos a procedimentos ortopédicos com implante, em um hospital público de Belo Horizonte, Minas Gerais [Dissertação]. [Belo Horizonte]: Universidade Federal de Minas Gerais; 2013.147p.

164. Bode LGM, Kluytmans JAJW, Wertheim HFL, Bogaers D, VandenbrouckeGrauls CMJE, Roosendaal R, et al. Preventing surgical-site infections in nasal carriers of Staphylococcus aureus. N Engl J Méd. 2010;362:9-17.

165. Nichols RL. Preventing surgical site infections: a surgeon's perspective. Emerg Infect Dis 2001;7(2):220-4.

166. Ferraz EM, Ferraz AAB, Bacelar TS, D' Albuquerque HST, Vasconcelos MDMM, Leão CS. Controle de infecção em cirurgia geral - Resultado de um estudo prospectivo de 23 anos e 42.274 cirurgias. Col Bras Cirur. 2000;28(1): 17-26.

167. Oliveira AC, Ciosak SI, D'Lorenzo C. Post-discharge surveillance and its impact on surgical site infection incidence. Rev Esc Enferm USP. 2007;41(4):653-9.

168. Myhall CG, editor. Hospital Epidemiology and Infection Control. 3rd ed. Philadelphia: Lippincott Williams \& Wilkins;2004.

169. Sasaki VDM, Romanzini AE, de Jesus APM, de CarvalhoE, Gomes JJ, Damiano VB. Vigilância de infecção de sítio cirúrgico no pós-alta hospitalar de cirurgia cardíaca reconstrutora. Texto contexto - enferm. [serial on the Internet]. 2011 June [cited 2014 Sep 24];20(2):328-332. Available from: http://www.scielo.br/scielo.php?script=sci_arttext\&pid=S0104-.

170. de Oliveira AC, Ciosak SI. Surgical site infection in a university hospital: postrelease surveillance and risk factors. Rev Esc Enferm USP2007;41(2):258-63. 
171. Bilimoria KY, Cohen ME, Ingraham AM, Bentrem DJ, Richards K, Hall BL, et al. Effect of postdischarge morbidity and mortality on comparisons of hospital surgical quality. Ann Surg 2010;252(1):183-90.

172. Runciman W, Hibbert $P$, Thomson $R$, Schaaf TV, Sherman H, Lewalle P. Towards an International Classification for Patient Safety: key concepts and terms. Int J Qual Health Care 2009, 21(1):18-26.

173. Waeschle RM, Bauer M, Schmidt CE. Errors in medicine: Causes, impact and improvement measures to improve patient safety. Anaesthesist 2015;64(9):689-704.

174. Reason J. Human error: models and management. BMJ 2000;320(7237):76870.

175. Verdaasdonk EG, Stassen LP, Widhiasmara PP, Dankelman J. Requirements for the design and implementation of checklists for surgical processes. Surg Endosc 2009 Apr;23(4):715-26.

176. Perneger TV. The Swiss cheese model of safety incidents: are there holes in the metaphor? BMC Health Serv Res 2005;5:71.

177. Catchpole K. Spreading human factors expertise in healthcare: untangling the knots in people and systems. BMJ Qual Saf 2013;22(10):793-7.

178. Fragata JIG. Erro médico: A segurança dos doentes - Indicador de qualidade em saúde. Revista Portuguesa de Medicina Geral e Familiar nov 2010; 26(6): 564-70. 
179. Weinbroum AA, Ekstein P, Ezri T. Efficiency of the operating room suite. Am J Surg 2003;185(3):244-50.

180. Plsek PE, Greenhalgh T. Complexity science: The challenge of complexity in health care. BMJ 2001;323(7313):625-8.

181. Gibbs VC. Thinking in three's: changing surgical patient safety practices in the complex modern operating room. World J Gastroenterol 2012;18(46):6712-9.

182. Booij LH. Conflicts in the operating theatre. Curr Opin Anaesthesiol. $2007 ; 20(2): 152-6$.

183. de Vries EN, Ramrattan MA, Smorenburg SM, Gouma DJ, Boermeester MA. The incidence and nature of in-hospital adverse events: a systematic review. Qual Saf Health Care Jun 2008;17(3):216-23.

184. Brock D, Abu-Rish E, Chiu CR, Hammer D, Wilson S, Vorvick L, et al. Interprofessional education in team communication: working together to improve patient safety. Postgrad Med J. 2013;89(1057):642-51.

185. Wetzel CM, Kneebone RL, Woloshynowych M, Nestel D, Moorthy K, Kidd J, et al. The effects of stress on surgical performance. Am J Surg. 2006;191(1):510.

186. Wetzel CM, Black SA, Hanna GB, Athanasiou T, Kneebone RL, Nestel D, et al. The effects of stress and coping on surgical performance during simulations. Ann Surg. 2010;251(1):171-6.

187. Arora S, Sevdalis N, Nestel D, Tierney T, Woloshynowych M, Kneebone R. Managing intraoperative stress: what do surgeons want from a crisis training program? Am J Surg. 2009;197(4):537-43. 
188. Arora S, Sevdalis N, Nestel D, Woloshynowych M, Darzi A, Kneebone R. The impact of stress on surgical performance: a systematic review of the literature. Surgery 2010 Mar; 147(3):318-30 e-.

189. Gawande AA, Studdert DM, Orav EJ, Brennan TA, Zinner MJ. Risk factors for retained instruments and sponges after surgery. N Engl J Med 2003 Jan 16; 348(3):229-35.

190. Kawano T, Taniwaki M, Ogata K, Sakamoto M, Yokoyama M. Improvement of teamwork and safety climate following implementation of the WHO surgical safety checklist at a university hospital in Japan. J Anesth. 2014;28(3):467-70.

191. Classen D, Evans RS, Pestotnik SL, Horn SD, Menlove RL, Burke JP. The timing of prophylactic administration of antibiotics and the risk of surgicalwound infection. N Engl J Med 1992 Jan 30; 326(5):281-6.

192. ECDC Technical Report. Systematic review and evidence-based guidance on perioperative antibiotic prophylaxis. Stockholm: ECDC; 2013.

193. Minnesota Departmenf of Health. Adverse health events in Minnesota. Fith annual public report: 2009. Minnesota: Minnesota Department of Health; 2009.

194. Yule S, Flin R, Paterson-Brown S, Maran N. Non-technical skills for surgeons in the operating room: a review of the literature. Surgery 2006;139(2):140-9.

195. The National Quality Forum. Safe Practices for Better Healthcare 2010 update. Washington: The National Quality Forum; 2010.

196. Koeckeritz JL, Hopkins KV, Merrill AS. ILEUM: Interactive learning can be effective using mnemonics. Nurse Educ 2004;29(2):75-9. 
197. Hales B, Terblanche M, Fowler R, Sibbald W. Development of medical checklists for improved quality of patient care. Int J Qual Health Care 2008;20(1):22-30.

198. Hales BM, Pronovost PJ. The checklist--a tool for error management and performance improvement. J Crit Care 2006 Sep;21(3):231-5.

199. Winters BD, Gurses AP, Lehmann H, Sexton JB, Rampersad CJ, Pronovost PJ. Clinical review: checklists - translating evidence into practice. Crit Care 2009;13(6):210.

200. Weiser TG, Berry WR. Review article: perioperative checklist methodologies. Can J Anaesth. 2013;60(2):136-42.

201. Pronovost P, Needham D, Berenholtz S, Sinopoli D, Chu H, Cosgrove S, et al. An intervention to decrease catheter-related bloodstream infections in the ICU. N Engl J Med. 2006;355(26):2725-32.

202. McConnell DJ, Fargen KM, Mocco J. Surgical checklists: A detailed review of their emergence, development, and relevance to neurosurgical practice. Surg Neurol Int. 2012; 3: 2.

203. Stahl K, Palileo A, Schulman CI, Wilson K, Augenstein J, Kiffin C, et al. Enhancing patient safety in the trauma/surgical intensive care unit. J Trauma 2009;67(3):430-3; discussion 3-5.

204. Semel ME, Resch S, Haynes AB, Funk LM, Bader A, Berry WR, et al. Adopting a surgical safety checklist could save money and improve the quality of care in U.S. hospitals. Health Aff. 2010 Sept; 29(9): 1593-99.

205. Gawande A. The checklist manifesto: how to get things right. New York: Metropolitan Books; 2009. 
206. Askarian M, Kouchak F, Palenik, CJ. Effect of Surgical Safety Checklists on Postoperative Morbidity and Mortality Rates, Shiraz, Faghihy Hospital, a 1Year Study. Q Manage Health Care 2011 Oct-Dec; 20(4):293-97.

207. van Klei WA, Hoff RG, van Aarnhem EE, Simmermacher RK, Regli LP, Kappen $\mathrm{TH}$, et al. Effects of the introduction of the WHO "Surgical Safety Checklist" on in-hospital mortality: a cohort study. Ann Surg 2012;255(1):44-9.

208. Birkmeyer JD. Strategies for improving surgical quality-checklists and beyond. N Engl J Med 2010;363(20):1963-5.

209. de Vries EN, Prins HA, Crolla RM, den Outer AJ, van Andel G, van Helden $\mathrm{SH}$, et al. Effect of a Comprehensive Surgical Safety System on Patient Outcomes. N Engl J Med 2010 Nov 11; 363(20):1928-37.

210. Tsai T, Boussard $T$, Welton, M, Morton, J. Does a surgical safety checklist improve patient safety culture and outcomes? In: American College of Surgeons Annual Clinical Congress. 2010 Oct 3-7; Washington D.C.: Journal of American College of Surgeons.

211. Takala RSK, Pauniaho SL, Kotkansalo A, Helmio P, Blomgren K, Helminen M, et al. A pilot study of the implementation of WHO Surgical Checklist in Finland: improvements in activities and communication. Acta Anaesthesiol Scand 2011 Nov; 55(10):1206-14.

212. Thomassen O. Implementation of safety checklists in medicine. Not as simple as it sounds [Dissertation]. [Bergen]:University of Bergen; 2012. 70p.

213. Patient safety: surgical safety Web map. Geneva: World Health Organization. [cited 2014 Aug 20] Available from: http://maps.cga.harvard.edu:8080/Hospital/\#). 
214. Schlack WS, Boermeester MA. Patient safety during anaesthesia: incorporation of the WHO safe surgery guidelines into clinical practice. Curr Opin Anaesthesiol 2010 Dec;23(6):754-823(6):754-758.

215. Seiden SC, Barach P. Wrong-side/wrong-site, wrong-procedure, and wrongpatient adverse events: Are they preventable? Arch Surg 2006 Sep;141:93139.

216. Joint Commission International. Patient Safety Goals Created. Joint Commission Perspectives 2006; 26(2):8.

217. American College of Surgeons. Statement on ensuring correct patient, correct site, and correct procedure surgery. Bulletin of the American College of Surgeons 2002; 87(12).

218. Ouro-Bang'na Maman AF, Tomta K, Ahouangbévi S, Chobli M. Deaths associated with anaesthesia in Togo, West Africa. Tropical Doctor. 2005 Oct $1 ; 35(4): 220-22$.

219. Arbous MS, Meursing A.E, van Kleef JW, de Lange JJ, Spoormans HH, Touw $P$, et al. Impact of anesthesia management characteristics on severe morbidity and mortality. Anesthesiology. 2005 Feb; 102 (2):257-68.

220. Cooper JB, Newbower RS, Ronald S, Long CD, McPeek B. Preventable anesthesia mishaps: a study of human factors. Anesthesiology $1978 \mathrm{Dec}$; 49(6):399-406.

221. Webb RK, Currie M, Morgan CA, Williamson JA, Mackay P, Russell WJ, et al. The Australian Incident Monitoring Study: an analysis of 2000 incident reports. Anaesth Intensive Care 1993 Oct; 21(5):520-8. 
222. Paix $A D$, Williamson JA, Runciman WB. Crisis management during anaesthesia: difficult intubation. Qual Saf Health Care 2005; 14(3):e5.

223. Crosby ET, Cooper RM, Douglas MJ, Doyle DJ, Hung OR, Labrecque P, et al. The unanticipated difficult airway with recommendations for management. Can J Anaesth. 1998; 45(8):757-76.

224. Rotondo MF, Schwab CW, McGonigal MD, Phillips GR, Fruchterman TM, Kauder DR, et al. Damage control: an approach for improved survival in exsanguinating penetrating abdominal injury. J Trauma 1993 Sep; 35(3):37582; discussion 382-3.

225. Nichols $P$, Copeland T, Craib IA, Hopkins P, Bruce, DG. Learning from error: identifying contributory causes of medication errors in Australian hospital. Med J. Aust 2008; 88:276-79.

226. Roughead EE, Semple SJ. Medication safety in acute care in Australia: where are we now? Part 1: a review of the extent and causes of medication problems 2002-2008. Aust New Zealand Health Policy 2009 Aug 11; 6:18.

227. Bratzler D W, Houck PM. Antimicrobial prophylaxis for surgery: an advisory statement from the National Surgical Infection Prevention Project. Clin Infect Dis $2004 ; 38(12): 1706-15$.

228. Makary MA, Epstein J, Pronovost PJ, Millman EA, Hartmann EC, Freischlag JA. Surgical specimen identification errors: a new measure of quality in surgical care. Surgery 2007 Apr; 141(4):450-55.

229. Sexton JB, Thomas EJ, Helmreich RL. Error, stress, and teamwork in medicine and aviation: cross sectional surveys. BMJ 2000;320:745-9. 
230. Greenberg CC, Regenbogen SE, Studdert DM, Lipsitz SR, Rogers SO, Zinner $\mathrm{MJ}$, et al. Patterns of communication breakdowns resulting in injury to surgical patients. J Am Coll Surg 2007 Apr; 204(4):533-40.

231. Joint Commission. Sentinel event statistics, 31 December 2006. [cesso em Jun 2012]. Disponível em: http://www.jointcommission.org/SentinelEvents/Statistics.

232. Gouvêa CSD, Travassos C. Indicadores de segurança do paciente para hospitais de pacientes agudos: revisão sistemática. Cad Saude Publica 2010 jun; 26(6):1061-1078.

233. Yuan CT, Walsh D, Tomarken JL, Alpern R, Shakpeh J, Bradley EH. Incorporating the World Health Organization Surgical Safety Checklist into Practice at Two Hospitals in Liberia. Jt Comm J Qual Patient Saf 2012 Jun;38(6):254-60.

234. Melekie TB, Getahun GM. Compliance with Surgical Safety Checklist completion in the operating room of University of Gondar Hospital, Northwest Ethiopia. BMC Res Notes 2015; 8:361.

235. Hayes C. Surgical safety checklist: improved patient safety through effective teamwork. Healthc Q 2012;15 Spec No:57-62.

236. Patient Safety Indicator Reporting: Ontario Totals. Toronto; 2011. Available from: http://www.hqontario.ca/Public-Reporting/Patient-Safety/Informationabout-Patient-Safety-Quality-Indicators.

237. Fourcade A, Blache JL, Grenier C, Bourgain J, Minvielle E. Barriers to staff adoption of a surgical safety checklist. BMJ Qual Saf. 2012;21(3):191-197. 
238. Lepänluoma M, Takala R, Kotkansalo A, Rahi M, Ikonen TS. Surgical safety checklist is associated with improved operating room safety culture, reduced wound complications, and unplanned readmissions in a pilot study in neurosurgery. Scand J Surg 2014;103(1):66-72.

239. Bashford T, Reshamwalla S, McAuley J, Allen NH, McNatt Z, Gebremedhen YD. Implementation of the WHO Surgical Safety Checklist in an Ethiopian Referral Hospital. Patient Saf Surg 2014;8:16.

240. Direcção Geral da Saúde (DGS). Circular Normativa n. 16/DQS/DQCO. Cirurgia Segura Salva Vidas. Lisboa: DGS; 2010.15 p.

241. Sewell M, Adebibe M, Jayakumar P, Jowett C, Kong K, Vemulapalli K, et al. Use of the WHO surgical safety checklist in trauma and orthopaedic patients. Int Orthop 2011;35(6):897-901.

242. Urbach DR, Govindarajan A, Saskin R, Wilton AS, Baxter NN. Introduction of surgical safety checklists in Ontario, Canada. $N$ Engl $J$ Med 2014;370(11):1029-38.

243. Cunha ALSM, Salman FC, Silva SC, Arap SS. In: Anais do IX Congresso Internacional de Qualidade em Serviços e Sistemas de Saúde; 2009 São Paulo, Brasil. São Paulo:QualiHosp; 2009. p.326.

244. Freitas MR, Antunes AG, Lopes BN, Fernandes FdaC, Monte L de C, Gama ZA. Assessment of adherence to the WHO surgical safety checklist in urological and gynecological surgeries at two teaching hospitals in Natal, Rio Grande do Norte State, Brazil. Cad Saude Publica 2014;30(1):137-48.

245. Anger J, Letizio N, Orel M, Souza Junior JLS, Santos, MM. A preoperative checklist in esthetic plastic surgery. Rev Bras Cir Plast 2011; 26(3):525-29. 
246. Croti UA, Jenkins KJ, Braile, DM. Checklist em Cirurgia Cardíaca Pediátrica no Brasil: uma adaptação útil e necessária do International Quality Improvement Collaborative for Congenital Heart Surgery in Developing Countries. Rev Bras Cir Cardiovasc 2011;26(3):511-15.

247. Delgado Hurtado JJ, Jiménez X, Peñalonzo MA, Villatoro C, de Izquierdo S, Cifuentes M. Acceptance of the WHO Surgical Safety Checklist among surgical personnel in hospitals in Guatemala city. BMC Health Serv Res 2012;12:169.

248. Makary MA, Holzmueller CG, Thompson D, et al. Operating room briefings: working on the same page. Jt Comm J Qual Patient Saf. 2006;32:351-5.

249. O'Connor P, Reddin C, O'Sullivan M, O'Duffy F, Keogh I. Surgical checklists: the human factor. Patient Saf Surg 2013;7(1):14.

250. Conley DM, Singer SJ, Edmondson L, Berry WR, Gawande AA. Effective surgical safety checklist implementation. J Am Coll Surg 2011;212(5):873-9.

251. Mahajan R. The WHO surgical checklist. Best Pract Res Clin Anaesthesiol $2011 ; 161-8$.

252. Fudickar A, Hörle K, Wiltfang J, Bein B. The effect of the WHO Surgical Safety Checklist on complication rate and communication. Dtsch Arztebl Int 2012;109(42):695-701.

253. Garnerin P, Ares M, Huchet A, Clergue F. Verifying patient identity and site of surgery: improving compliance with protocol by audit and feedback. Qual Saf Health Care 2008; 17:454-458.

254. Kasatpibal N, Senaratana W, Chitreecheur J, Chotirosniramit N, Pakvipas P, Junthasopeepun P. Implementation of the World Health Organization surgical 
safety checklist at a university hospital in Thailand. Surg Infect (Larchmt) 2012 Feb;13(1):50-6.

255. Khorshidifar A, Kadkhodaee H, Zamen Z. Degree of Observance of the WHO Surgical Safety Checklist. Trauma Mon 2012;17(3):315-8.

256. van Klei WA, Hoff RG, van Aarnhem EE, Simmermacher RK, Regli LP, Kappen $\mathrm{TH}$, et al. Effects of the introduction of the WHO "Surgical Safety Checklist" on in-hospital mortality: a cohort study. Ann Surg. 2012 Jan; 255(1):44-9.

257. Maziero ECS. Avaliação da implantação do programa cirurgia segura em um Hospital de ensino. [Dissertação]. [ Curitiba]: Universidade Federal do Paraná; 2012. $106 p$.

258. Kearns RJ, Uppal V, Bonner J, Robertson J, Daniel M, McGrady EM. The introduction of a surgical safety checklist in a tertiary referral obstetric centre. BMJ Qual Saf; 2011 Sep;20(9):818-22.

259. Soria-Aledo V, Da Silva ZA, Saturno PJ, Grau-Polan M, Carrillo-Alcaraz A. Difficulties in implementing a surgical check list in operating theatres. Cir Esp 2012;90(3):180-5.

260. Mascherek AC, Schwappach DL, Bezzola P. Frequency of use and knowledge of the WHO-surgical checklist in Swiss hospitals: a cross-sectional online survey. Patient Saf Surg 2013;7(1):36.

261. Brasil. Agência Nacional de Vigilância Sanitária [homepage na internet]. Projeto: Pacientes pela segurança do paciente em serviços de saúde [acesso em 18 set 2014]. Disponível em: http:www.anvisa.gov.br. 
262. Russ SJ, Rout S, Caris J, Moorthy K, Mayer E, Darzi A, et al. The WHO surgical safety checklist: survey of patients' views. BMJ Qual Saf 2014;0:1-8.

263. Joint Commission [homepage na internet]. Universal protocol for preventing wrong site, wrong procedure, wrong person surgery. [acessado 2014 set 10]. Available from: http://www.jointcommission.org/standards_information/up.aspx

264. Brasil. Agência Nacional de Vigilância Sanitária [homepage na internet]. Folder: Você sabia que pode colaborar para um cuidado mais seguro e com qualidade nos serviços de saúde? [acessado 2014 set 18]. Disponível em: http:www.anvisa.gov.br.

265. Dimick JB, Weeks WB, Karia RJ, Das S, Campbell DA Jr. Who pays for poor surgical quality? Building a business case for quality improvement. J Am Coll Surg 2006;202(6):933-7. 


\section{APÊNDICE A}

ACOMPANHAMENTO DA LISTA DE VERIFICAÇÃO DE SEGURANÇA CIRÚRGICA

\section{Acompanhamento da LVSC}

Dados pré e perioperatório

*1. Nome do hospital

Hospital 1

Hospital 2

Hospital 3

*2. Número do questionário

3. Nome do responsável pelo preenchimento da LVSC

4. Data do procedimento cirúrgico.

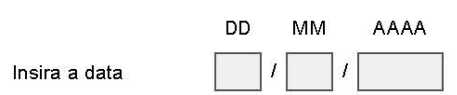

5. Registro do paciente

*6. Nome do paciente

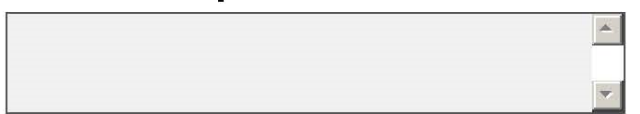

7. Data de nascimento do paciente

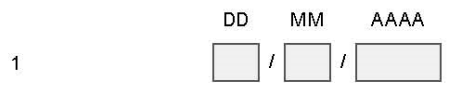

8. Sexo do paciente

O Feminino

O Masculino

\section{Telefones para contato}

(DDD) Telefone, Nome do

contato

(DDD) Telefone, Nome do

contato

(DDD) Telefone, Nome do

contato

* 10. Tempo de internação

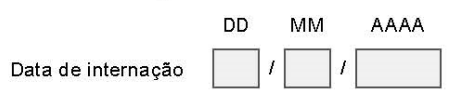

11. Doença que motivou a cirurgia 


\section{Acompanhamento da LVSC}

*12. Tricotomia

Feita com aparador

C Feita com lâmina

C Não realizada

Não se aplica

\section{Intervalo da tricotomia}

C Menos de 02 horas antes do início da cirurgia

( 2 ou mais horas antes do início da cirurgia

\section{Antissepsia cirúrgica das mãos}

Realizada por todos profissionais

Realizada apenas por parte dos profissionais

C Não realizada

\section{Paramentação cirúrgica}

Completa em todos profissionais

Completa em apenas parte dos profissionais

Incompleta

C Não utilizada

\section{Drenagem cirúrgica}

C Com sistema fechado

C Não realizada

Não se aplica

Outra (especifique)

17. . O profissional de enfermagem confirma verbalmente o nome do procedimento com o cirurgião?
C Sim

Não 


\section{Acompanhamento da LVSC}

Dados pré e perioperatório (continuação)

18. Procedimento cirúrgico realizado

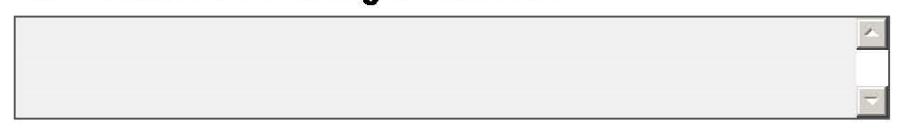

19. Classificação da cirurgia

O Limpa

C Potencialmente Contaminada

O Contaminada

O Infectada

\section{Tipo de anestesia}

C Anestesia geral

Anestesia raquidiana

Anestesia peridural

C Anestesia local

Outro (especifique) 
Acompanhamento da LVSC

\section{ANTES DA INDUĢÃO ANESTÉSICA}

21. Existência de pelo menos 02 mecanismos de identificação do paciente (ex: pulseira de identificação e $n^{\circ}$ de identidade)

C Sim

○ Não

22. O paciente confirmou sua identidade, sítio cirúrgico, procedimento e consentimento?

C $\operatorname{sim}$

C Não

23. O sítio cirúrgico está demarcado?

o sim

○ Não

Não se aplica

24. Foi colocado um oxímetro no pulso do paciente?

O Sim

○ Não

25. 0 oxímetro de pulso está funcionando?

C $\operatorname{sim}$

○ Não

26. O paciente possui alguma alergia conhecida?

O sim

○ Não

27. Há dificuldade aérea?

O Sim e equipamento disponível

C Sim mas equipamento não disponivel

C Não

28. Há risco de aspiração?

O Sim

ก Não 
Acompanhamento da LVSC

29. Há risco de perda sanguínea maior ou igual a $500 \mathrm{~mL}$ ?

. Sim e COM presença de pelo menos 2 cateteres venosos periféricos ou 01 cateter venoso central

Sim e SEM presença de pelo menos 2 cateteres venosos periféricos ou 01 cateter venoso central

O Não

30. Os membros da equipe cirúrgica se apresentaram pelo nome e função?

O Sim

Não

31. Os membros da equipe cirúrgica confirmaram verbalmente a identificação do paciente?

O Sim

Não

32. Os membros da equipe cirúrgica confirmaram verbalmente o local da cirurgia?

O Sim

ก Não

33. Os membros da equipe cirúrgica confirmaram verbalmente o procedimento cirúrgico?

O Sim

Não

\section{Foi realizada a profilaxia antimicrobiana?}

Mais de 60 minutos antes da incisão

Com 60 minutos ou menos antes da incisão

Não realizada

C Não se aplica

35. As etapas críticas foram discutidas pelo cirurgião com a equipe?

C Sim

○ Não

36. O anestesiologista discutiu com a equipe os riscos potenciais de complicações anestésicas?

C $\operatorname{Sim}$

Não 
Acompanhamento da LVSC

\section{ANTES DA INDUGÃO GIRÚRGIGA}

37. A esterilização dos artigos foi confirmada (incluindo resultados do indicador)?

O Sim

C Năo

38. Há questões relacionadas ao não funcionamento dos equipamentos?

O $\operatorname{sim}$

○ Não

39. As imagens essenciais estão disponíveis?

O Sim

○ Não

40. Permanência do circulante na sala cirúrgica durante todo o período da cirurgia

O sim

○ Nåo

41. Permanência do cirurgião principal na sala cirúrgica durante todo o período da cirurgia

o sim

○ Năo

42. Permanência do anestesiologista na sala cirúrgica durante todo o período da cirurgia

o sim

○ Não 
Acompanhamento da LVSC

\section{ANTES DO PAGIENTE SAIR DA SALA DE OPERACÃO}

43. O profissional de enfermagem confirmou verbalmente o procedimento cirúrgico realizado com o cirurgião?

C $\operatorname{sim}$

○ Não

44. O profissional de enfermagem confirmou verbalmente a contagem dos artigos com o cirurgião?

$\begin{array}{lcc} & \text { Sim } & \text { Não } \\ \text { Compressas } & 0 & 0 \\ \text { Instrumentais } & 0 & 0 \\ \text { Agulhas } & 0 & 0\end{array}$

45. O profissional de enfermagem confirma verbalmente a identificação da amostra para anatomia patológica com o cirurgião?
O Sim
○ Não
O Não se aplica

46. Foi informado o cuidado principal para a recuperação deste paciente?

$\begin{array}{lcc} & \text { Sim } & \text { Não } \\ \text { Pelo cirurgião } & 0 & 0 \\ \text { Pelo anestesiologista } & 0 & 0 \\ \begin{array}{l}\text { Pela equipe de } \\ \text { enfermagem }\end{array} & 0 & 0\end{array}$

47. Duração da cirurgia

Horas

Minutos

\begin{tabular}{|l|}
\hline \\
\hline
\end{tabular}




\section{Acompanhamento da LVSC}

\section{Dados pós-operatório}

\section{Comprometimento renal agudo}
Até $24 \mathrm{~h}$ após a cirurgia
Entre $24 h$ e 7 dias após a cirurgia
C Entre 8 e 30 dias após a cirurgia
Não ocorreu

49. Sangramento maior do que 4 unidades de concentrado de hemácias nas primeiras 72 horas após a cirurgia

O Sim

○ Não

\section{Parada cardíaca}
Até $24 \mathrm{~h}$ após a cirurgia
Entre $24 \mathrm{~h}$ e 7 dias após a cirurgia
- Entre 8 e 30 dias após a cirurgia
C Não ocorreu

\section{Coma de duração de 24 horas ou mais}

O sim

○ Não

\section{Trombose venosa profunda}

Até $24 \mathrm{~h}$ após a cirurgia

Cntre 24h e 7 dias após a cirurgia

Entre 8 e 30 dias após a cirurgia

Não ocorreu

\section{Infarto do miocárdio}

A Até $24 h$ após a cirurgia

Cntre $24 h$ e 7 dias após a cirurgia

- Entre 8 e 30 dias após a cirurgia

O Năo ocorreu 


\section{Acompanhamento da LVSC}

54. Intubação não planejada

Até $24 \mathrm{~h}$ após a cirurgia

Entre $24 \mathrm{~h}$ e 7 dias após a cirurgia

Entre 8 e 30 dias após a cirurgia

C Não ocorreu

55. Uso do respirador por 48 horas ou mais

O Sim

○ Não

\section{Pneumonia}

C Sim

○ Não

57. Embolia pulmonar

Até $24 h$ após a cirurgia

Entre $24 \mathrm{~h}$ e 7 dias após a cirurgia

- Entre 8 e 30 dias após a cirurgia

C Não ocorreu

\section{Acidente vascular cerebral}

A Até $24 \mathrm{~h}$ após a cirurgia

- Entre 24h e 7 dias apos a cirurgia

- Entre 8 e 30 dias após a cirurgia

C Não ocorreu

\section{Ruptura da sutura do sítio cirúrgico}
Até $24 \mathrm{~h}$ após a cirurgia
Entre $24 \mathrm{~h}$ e 7 dias após a cirurgia
Entre 8 e 30 dias após a cirurgia
C Não ocorreu

\section{Sepse}

Até $24 h$ após a cirurgia

Entre $24 h$ e 7 dias após a cirurgia

C Entre 8 e 30 dias após a cirurgia

C Não ocorreu 


\section{Acompanhamento da LVSC}

\section{Choque séptico}

Até 24 h após a cirurgia

Entre $24 \mathrm{~h}$ e 7 dias após a cirurgia

Entre 8 e 30 dias após a cirurgia

C Não ocorreu

62. Síndrome da resposta inflamatória sistêmica

Até 24 h após a cirurgia

Entre $24 \mathrm{~h}$ e 7 dias após a cirurgia

Entre 8 e 30 dias após a cirurgia

Não ocorreu

63. Retorno não planejado à sala de operação

○ sim

○ Não

\section{Falência de enxerto vascular}

D Durante

C Após

C Não houve

65. Infecção de sítio cirúrgico - ISC

Foi percebida uma infecção até $24 \mathrm{~h}$ após a cirurgia

Foi percebida uma infecção entre 24 h e 7 dias após a cirurgia

Foi percebida uma infecção entre o $7^{\circ}$ e $030^{\circ}$ dia após a cirurgia

C Não houve infecção

66. Infecção do trato urinário

C Sim

○ Não

67. Retenção urinária

C sim

C Não 


\section{Acompanhamento da LVSC}
68. Óbito
O Na Entrada
Durante a Cirurgia
Na Pausa Cirúrgica
No pós operatório imediato (até 24 horas após a cirurgia)
Após 24 horas
Não Ocorreu Óbito

69. Outra(s) complicação(ões):

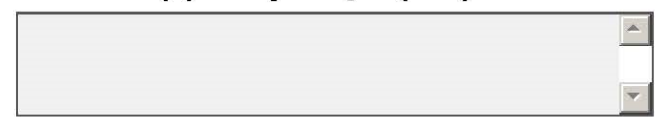

70. Unidade para qual o (a) paciente foi encaminhado após Recuperação pós anestésica
O Unidade na qual estava internado anteriormente
Unidade de Terapia Intensiva - UTI
Transferido para outra instituição de saúde
Outra unidade do hospital.

71. Data de alta do paciente da internação pós-cirúrgica

Data de alta do
paciente




\section{APÊNDICE B}

\section{QUESTIONÁRIO SOBRE ATITUDES E OPINIÕES DE SEGURANÇA EM SERVIÇOS DE SAÚDE I}

\section{Atitudes de Segurança em Serviços de Saúde I}

\section{A. PERFIL DO RESPONDENTE}

Esta pesquisa objetiva estudar as atitudes e opiniões de

- Chefes (médicos e de enfermagem) do Centro Cirúrgico e da Recuperação Pós-anestésica;

- Equipe Cirúrgica (cirurgião, anestesista, instrumentador, enfermeiro, técnico de enfermagem e auxiliar de enfermagem).

Sua participação na pesquisa é voluntária, porém é de extrema importância para a elaboração de estratégias para melhoria da segurança em serviços de saúde.

Não é necessário o fomecimento de dados pessoais. São apenas algumas perguntas. Participe!

Unidade Hospitalar:

Hospital 1

Hospital 2

Hospital 3

Número do questionário:

\section{Gênero}

C Masculino

C Feminino
Data de nascimento

Data de nascimento $\square, \square, \square$, AAAA

Número de anos de experiência na área de saúde (informe o número de anos completos. Se for menor que "1", informe "0".)

Número de anos de experiência de trabalho nessa unidade hospitalar (informe o número de anos completos. Se for menor que "1", informe "0".)

\section{A1. Qual a sua ocupação nessa unidade hospitalar?}
Cirurgião
Residente de anestesiologia
Residente de Enfermagem
Residente de cirurgia
Instrumentador
Técnico de Enfermagem
Anestesiologista
Enfermeiro
Auxiliar de Enfermagem

Outro (especifique) 


\section{B. ATITUDES E OPINIÕES SOBRE SEGURANÇA CIRÚRGICA}

B1. Se você fosse tratado(a) como paciente nesse hospital, sentiria-se em segurança?
C Sim
Não
SEM RESPOSTA

B2. Como você avalia a necessidade de verificações ou checagens na sala de operação antes do procedimento cirúrgico?

Desnecessárias $O$ Impraticáveis $O$ Importantes $O$ Indispensáveis $O$ sEM REsPosta

B3. Seus colegas de trabalho já o(a) encorajaram a reportar qualquer preocupação que tenha relacionada à segurança dos pacientes?
C Sim
( Não
SEM RESPOSTA

B4. Como se dá a comunicação com a equipe frente a algum problema durante o cuidado ao paciente na sala de operação?
Muito fácil
Fácil
Difícil
Impossivel
SEM RESPOSTA

B5. Você acha que os profissionais de saúde trabalham em conjunto, como uma equipe bem integrada?
C Sim
Não
SEM RESPOSTA

Com que frequência os profissionais de saúde ignoram regras ou normas sobre segurança cirúrgica estabelecidas na instituição, tais como:

$\begin{array}{lcccccc} & \text { Nunca } & \text { Raramente } & \text { Às vezes } & \text { Quase sempre } & \text { Sempre } & \text { SEM RESPOSTA } \\ \text { B6. Higiene das mãos } & 0 & 0 & 0 & 0 & 0 & 0 \\ \text { B7. Normas e Rotinas } & 0 & 0 & 0 & 0 & 0 & 0 \\ \text { B8. Técnica Cirúrgica } & 0 & 0 & 0 & 0 & 0 & 0\end{array}$




\section{APÊNDICE C}

\section{QUESTIONÁRIO SOBRE ATITUDES E OPINIÕES DE SEGURANÇA EM SERVIÇOS DE SAÚDE II}

\section{Atitudes de Segurança em Serviços de Saúde I}

\section{A. PERFIL DO RESPONDENTE}

Esta pesquisa objetiva estudar as atitudes e opiniões de

- Chefes (médicos e de enfermagem) do Centro Cirúrgico e da Recuperação Pós-anestésica;

- Equipe Cirúrgica (cirurgião, anestesista, instrumentador, enfermeiro, técnico de enfermagem e auxiliar de enfermagem).

Sua participação na pesquisa é voluntária, porém é de extrema importância para a elaboração de estratégias para melhoria da segurança em serviços de saúde.

Não é necessário o fomecimento de dados pessoais. São apenas algumas perguntas. Participe!

Unidade Hospitalar:

Hospital 1

Hospital 2

Hospital 3

Número do questionário:

\section{Gênero}

Masculino

Feminino
Data de nascimento

Data de nascimento $\square, \square, \square$

Número de anos de experiência na área de saúde (informe o número de anos completos. Se for menor que "1", informe "0".)

Número de anos de experiência de trabalho nessa unidade hospitalar (informe o número de anos completos. Se for menor que "1", informe "0".)

\section{A1. Qual a sua ocupação nessa unidade hospitalar?}
Cirurgião
Residente de anestesiologia
Residente de Enfermagem
Residente de cirurgia
Instrumentador
Técnico de Enfermagem
Anestesiologista
Enfermeiro
Auxiliar de Enfermagem

Outro (especifique) 


\section{B. ATITUDES E OPINIÕES SOBRE SEGURANÇA CIRÚRGICA}

B1. Se você fosse tratado(a) como paciente nesse hospital, sentiria-se em segurança?
C Sim
Não
SEM RESPOSTA

B2. Como você avalia a necessidade de verificações ou checagens na sala de operação antes do procedimento cirúrgico?

Desnecessárias $O$ Impraticáveis $O$ Importantes $O$ Indispensáveis $O$ sEM REsPosta

B3. Seus colegas de trabalho já o(a) encorajaram a reportar qualquer preocupação que tenha relacionada à segurança dos pacientes?
C Sim
( Não
SEM RESPOSTA

B4. Como se dá a comunicação com a equipe frente a algum problema durante o cuidado ao paciente na sala de operação?
Muito fácil
Fácil
Difícil
Impossivel
SEM RESPOSTA

B5. Você acha que os profissionais de saúde trabalham em conjunto, como uma equipe bem integrada?
C Sim
Não
SEM RESPOSTA

Com que frequência os profissionais de saúde ignoram regras ou normas sobre segurança cirúrgica estabelecidas na instituição, tais como:

$\begin{array}{lcccccc} & \text { Nunca } & \text { Raramente } & \text { Às vezes } & \text { Quase sempre } & \text { Sempre } & \text { SEM RESPOSTA } \\ \text { B6. Higiene das mãos } & 0 & 0 & 0 & 0 & 0 & 0 \\ \text { B7. Normas e Rotinas } & 0 & 0 & 0 & 0 & 0 & 0 \\ \text { B8. Técnica Cirúrgica } & 0 & 0 & 0 & 0 & 0 & 0\end{array}$




\section{APLICAÇÃO DA LISTA DE VERIFICAÇÃO DE SEGURANÇA ...}

C1. Em relação a usabilidade da lista de verificação de segurança cirúrgica (LVSC), você a considera:

Fácil de usar/preencher

Difícil de usar/preencher

Sem resposta

C2. Em relação ao preenchimento, você considera que a LVSC é um instrumento:

Breve e rápido

Extenso e demorado

SEM REsposta

C3. Se você fosse se submeter a uma cirurgia, gostaria que a LVSC fosse utilizada?
Sim
Não
SEM RESPOSTA

C4. A comunicação foi melhorada pela utilização da LVSC?
Sim
Não
SEM RESPOSTA

C5. A LVSC ajuda a evitar erros na sala de operação?
C Sim
Não
SEM RESPOSTA

C6. A LVSC tem contribuído para desenvolver uma cultura de segurança cirúrgica na instituição?
C Sim
C Não
SEM RESPOSTA 


\section{APÊNDICE D}

\section{AUTOAVALIAÇÃO DA ATENÇÃO CIRÚRGICA E ANESTÉSICA EM SERVIÇOS DE SAÚDE}

Este questionário objetiva avaliar a estrutura funcional, os recursos humanos, as condições organizacionais e a segurança do paciente no Centro Cirúrgico do estabelecimento de saúde participante do estudo. O questionário deve ser respondido pelos gerentes e líderes do Centro Cirúrgico e Recuperação Anestésica e equipes cirúrgicas que atuam no hospital. A conclusão do questionário leva cerca de 20 minutos. Os dados de identificação serão mantidos em sigilo. Sua participação na pesquisa é totalmente voluntária.

Instruções para preenchimento do roteiro de Autoavaliação da Atenção Cirúrgica e Anestésica em Serviços de Saúde:

-IDENTIFICAÇÃO: preencher o campo com os dados do hospital. -ESTRUTURA FUNCIONAL, RECURSOS HUMANOS, CONDIÇÕES ORGANIZACIONAIS e SEGURANÇA DO PACIENTE: para cada questão, marque com "X" a alternativa que demonstra a realidade encontrada no estabelecimento de saúde, de acordo com o seguinte:

Sim: item efetuado.

Não: item não efetuado.

NSA: Não se aplica ao estabelecimento.

\section{A. IDENTIFICAÇÃO}

- Nome do Hospital

\section{ESTRUTURA FUNCIONAL}

\begin{tabular}{|l|l|l|l|}
\hline \multicolumn{1}{|c|}{ ITENS } & Sim & Não & NSA \\
\hline $\begin{array}{l}\text { 1. Existência de pelo menos 01 lavabo cirúrgico para cada 02 } \\
\text { salas operatórias. }\end{array}$ & & \\
\hline $\begin{array}{l}\text { 2. Existência de lavabos cirúrgicos com torneiras de acionamento } \\
\text { com o cotovelo, pé, joelho ou célula fotoelétrica para realização da }\end{array}$ & & & \\
\hline
\end{tabular}


antissepsia cirúrgica das mãos.

3. Disponibilização de antisséptico líquido para antissepsia cirúrgica das mãos

4. Sala operatória com controle individual de temperatura, filtros de ar específicos e pressão positiva

5. Norma de restrição da circulação de pessoas na sala operatória.

6. Mecanismo autônomo de manutenção de portas fechadas na sala operatória.

7. Documentação de procedimentos de limpeza e desinfecção no Centro Cirúrgico.

\section{RECURSOS HUMANOS}

8. Permanência do enfermeiro na unidade durante todo o período de funcionamento do Centro Cirúrgico.

9. Permanência do enfermeiro na Unidade de Recuperação Pósanestésica durante todo o período de funcionamento do Centro Cirúrgico.

10. Permanência do circulante na sala cirúrgica durante todo o período da cirurgia

11. Permanência do cirurgião principal na sala cirúrgica durante todo o período da cirurgia

12. Permanência do anestesiologista na sala cirúrgica durante todo o período da cirurgia.

\section{SEGURANÇA DO PACIENTE}

13. Orientações para estimular a participação do paciente na assistência prestada

14. Existência de pelo menos 02 mecanismos de identificação do paciente

15. Atendimento pré-anestésico aos pacientes cirúrgicos por anestesiologistas na enfermaria ou no Centro Cirúrgico

16. Atendimento pós-anestésico aos pacientes cirúrgicos por anestesiologistas na enfermaria ou Recuperação Pós-anestésica.

17. Registro de questionamento aos pacientes de possíveis alergias a medicamentos

18. Orientações para administração segura de medicamentos.

19. Orientações para administração segura de sangue e hemocomponentes.

20. Cuidados com materiais esterilizados que são mantidos na 


\begin{tabular}{|l|l|l|l|}
\hline $\begin{array}{l}\text { embalagem do processo, fechada e datados até o momento da } \\
\text { utilização. }\end{array}$ & & \\
\hline $\begin{array}{l}\text { 21. Registro do monitoramento de indicadores de infecção do sítio } \\
\text { cirúrgico. }\end{array}$ & & & \\
\hline $\begin{array}{l}\text { 22. Ações de prevenção de eventos adversos associados aos } \\
\text { cuidados à saúde no Centro Cirúrgico. }\end{array}$ & & & \\
\hline $\begin{array}{l}\text { 23. Registro de eventos adversos associados aos cuidados à } \\
\text { saúde. }\end{array}$ & & & \\
\hline 24. Monitoramento do tempo médio de atraso no início da cirurgia. & & & \\
\hline 25. Monitoramento do tempo médio na Recuperação Anestésica. & & & \\
\hline 26. Acompanhamento da taxa de reinternação cirúrgica & & & \\
\hline 27. Vigilância pós-alta de pacientes cirúrgicos. & & & \\
\hline
\end{tabular}




\section{APÊNDICE E}

\section{TERMO DE CONSENTIMENTO LIVRE E ESCLARECIDO (TCLE)}

O Senhor (a) está sendo convidado a participar de uma pesquisa do Curso de PósGraduação em Ciências da Saúde intitulada: "Acompanhamento da aplicação da Lista de Verificação de Segurança Cirúrgica da Organização Mundial de Saúde para a Segurança do Paciente e Qualidade em Serviços de Saúde do Distrito Federal", que tem como objetivo principal acompanhar o processo de aplicação da Lista de Verificação de Segurança Cirúrgica em hospitais públicos da Rede Sentinela do Distrito Federal, utilizando-se as diretrizes da Organização Mundial de Saúde para a segurança cirúrgica em serviços de saúde. O tema escolhido se justifica pelo fato de que a lista de verificação de segurança cirúrgica pode prevenir as falhas de segurança durante $o$ ato cirúrgico, evitando danos e injúrias à saúde das pessoas e a internação prolongada do paciente nos serviços de saúde, mas ainda são necessários outros estudos. A coleta dos dados da investigação será dividida em 2 fases (Fase 1 os procedimentos cirúrgicos serão acompanhados prospectivamente pelo pesquisador, no período de agosto de 2012 a outubro de 2012; Fase 2 - será realizada a implementação da lista de verificação da segurança cirúrgica no período de novembro de 2012 a janeiro de 2013). Concomitantemente, para alcançar os objetivos do estudo, nas fases 1 e 2 do estudo serão aplicados os seguintes questionários individuais com perguntas pré-estabelecidas sobre segurança cirúrgica: Diagnóstico Situacional do Centro Cirúrgico do Estabelecimento de Saúde (será respondido pelos chefes de enfermagem do Centro Cirúrgico, contendo 27 questões, levando em média 20 minutos para a conclusão do questionário); Autoavaliação da Atenção Cirúrgica e Anestésica (será respondido pelos gestores, diretores e líderes do hospital, contendo 25 questões, levando em média 20 minutos para a conclusão do questionário) e Atitudes de Segurança Cirúrgica (será respondido pela equipe do Centro Cirúrgico e líderes do hospital, contendo 12 questões, levando em média 5 minutos para a conclusão do questionário). Os dados de identificação serão confidenciais e os nomes reservados. O benefício direto do estudo será para o estabelecimento de saúde, para 0 paciente e para os profissionais que atuam na instituição, pois o projeto está voltado para a melhoria da segurança e da qualidade da assistência em serviços de saúde. Espera-se que a aplicação do instrumento da Organização Mundial de Saúde possa prevenir danos e complicações cirúrgicas aos pacientes nos serviços de saúde participantes. No final do estudo será feita a avaliação da intervenção e os resultados serão apresentados e entregues à diretoria do hospital para conhecimento e aprimoramento das ações. Os resultados encontrados ao final da pesquisa serão publicados na forma de artigo original em um periódico indexado. O trabalho está sendo realizado por Heiko Thereza Santana sob a supervisão e orientação da Professora Doutora Maria do Socorro Nantua Evangelista.

Os dados obtidos serão utilizados somente para este estudo, sendo os mesmos armazenados pela pesquisadora principal durante 05 (cinco) anos e após totalmente destruídos (conforme preconiza a Resolução 196/96).

Eu recebi as informações sobre os objetivos e a importância desta pesquisa de forma clara e concordo em participar do estudo. Declaro que também fui informado: 
- Da garantia de receber resposta a qualquer pergunta ou esclarecimento acerca dos assuntos relacionados a esta pesquisa.

- De que minha participação é voluntária e terei a liberdade de retirar o meu consentimento, a qualquer momento e deixar de participar do estudo, sem que isto traga prejuízo para a minha vida pessoal e nem para o atendimento prestado a mim.

- Da garantia que não serei identificado quando da divulgação dos resultados e que as informações serão utilizadas somente para fins científicos do presente projeto de pesquisa.

- Sobre o projeto de pesquisa e a forma como será conduzido e que em caso de dúvida ou novas perguntas poderei entrar em contato com a pesquisadora Maria do Socorro N. Evangelista (telefone 61 32138053, e-mail socorrok@unb.br e endereço QI 27, conj.10, casa 08, Lago Sul, Brasília - DF).

- Também que, se houverem dúvidas quanto a questões éticas, poderei entrar em contato com o Comitê de Ética em Pesquisa (CEP/SES/DF) por meio do telefone (061) 3325-4955.

Declaro que recebi cópia deste Termo de Consentimento Livre e Esclarecido, ficando outra via com a pesquisadora. $O$ pesquisador e o sujeito da pesquisa deverão rubricar todas as folhas.

Brasília, de de 20

Nome:

Assinatura do Sujeito de Pesquisa

Data:

Nome:

Assinatura do pesquisador responsável

Data: 
ANEXOS 


\section{ANEXO A}

LISTA DE VERIFICAÇÃO DE SEGURANÇA CIRÚRGICA DA ORGANIZAÇÃO MUNDIAL DE SAÚDE

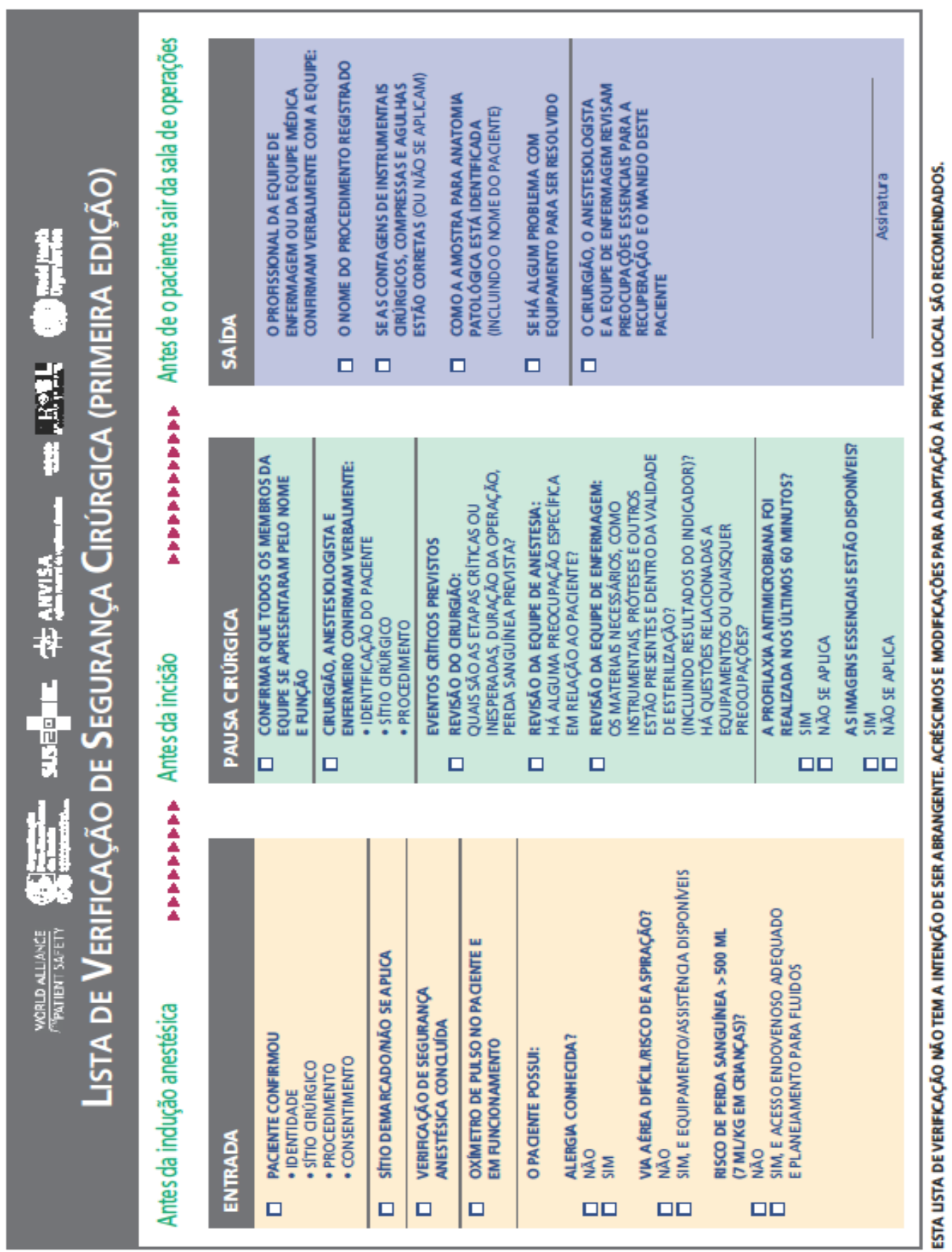




\section{ANEXO B}

\section{AUTORIZAÇÃO}

\section{- L ANVISA}

Agência Nacional de Vigilância Sanitária

Of.125/2013 - GGTES/ANVISA.

Em 26 de agosto de 2013.

Ao Senhor,

Professor Francisco de Assis Rocha Neves

Coordenador do Programa de Pós-Graduação em Ciências da Saúde

Universidade de Brasília - UnB

Campus Universitário Darcy Ribeiro

CEP: 70910-900 Brasília (DF)

Assunto: Utilização do banco de dados da Agência Nacional de Vigilância Sanitária referentes a "Cirurgias Seguras Salvam Vidas em Serviços de Saúde"

Senhor Coordenador,

Informo, para fins de documentação neste Programa de Pós-Graduação, que foi autorizada a utilização do banco de dados da Gerência Geral de Tecnologia em Serviços de Saúde - GGTES, da Agência Nacional de Vigilância Sanitária - Anvisa referente ao Projeto "Cirurgias Seguras Salvam Vidas em Serviços de Saúde", para uso na tese de doutorado da aluna Heiko Thereza Santana.

Atenciosamente,

Deana

DIANA CARMEM ALMEIDA NUNES DE OLIVEIRA

Gerente Geral

Diana Carment of a ce Utivetra

SIAPE 1558252

GGTESIANVISA 


\title{
ANEXO C
}

\section{COMITÊ DE ÉTICA EM PESQUISA}

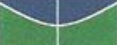 \\ Universidade de Brasiiia \\ Faculdade de Ciências da Saúde \\ Comitê de Ética em Pesquisa - CEP/FS

\section{PROCESSO DE ANÁLISE DE PROJETO DE PESOUISA}

Registro do Projeto no CEP: 185/12

Título do Projeto: “Acompanhamento da aplicação da lista de verificação da segurança cirúrgica da organização mundial de saúde para a segurança do paciente e qualidade em serviços de saúde."

Pesquisador Responsável: Heiko Thereza Santana

Data de Entrada: 21/11/2012

Com base na Resolução 196/96, do CNS/MS, que regulamenta a ética em pesquisa com seres humanos, o Comitê de Ética em Pesquisa com Seres Humanos da Faculdade de Ciências da Saúde da Universidade de Brasília, após análise dos aspectos éticos e do contexto técnico-científico, resolveu APROVAR o projeto 185/12 com o título: "Acompanhamento da aplicação da lista de verificação da segurança cirúrgica da organização mundial de saúde para a segurança do paciente e qualidade em serviços de saúde." analisado na $10^{2}$ Reunião Ordinária, realizada no dia 13 de novembro de 2012.

A pesquisadora responsável fica, desde já, notificada da obrigatoriedade da apresentação de um relatório semestral e relatório final sucinto e objetivo sobre o desenvolvimento do Projeto, no prazo de 1 (um) ano a contar da presente data (item VII.13 da Resolução 196/96).

Brasília, 13 de novembro de 2012

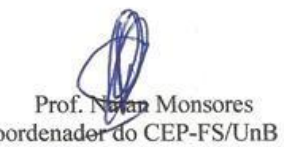

Comité de Ética em Pesquisa com Seres Humanos - Faculdade de Ciências da Saúd

Universidade de Brasilia - Campus Universitánio Darcy Ribeiro - CEP: 70.910-900

Telefone: (61)-3107-1947 Email: cepfs@unb. br 


\section{ANEXO D}

\section{SUBMISSÃO DE ARTIGO 1}

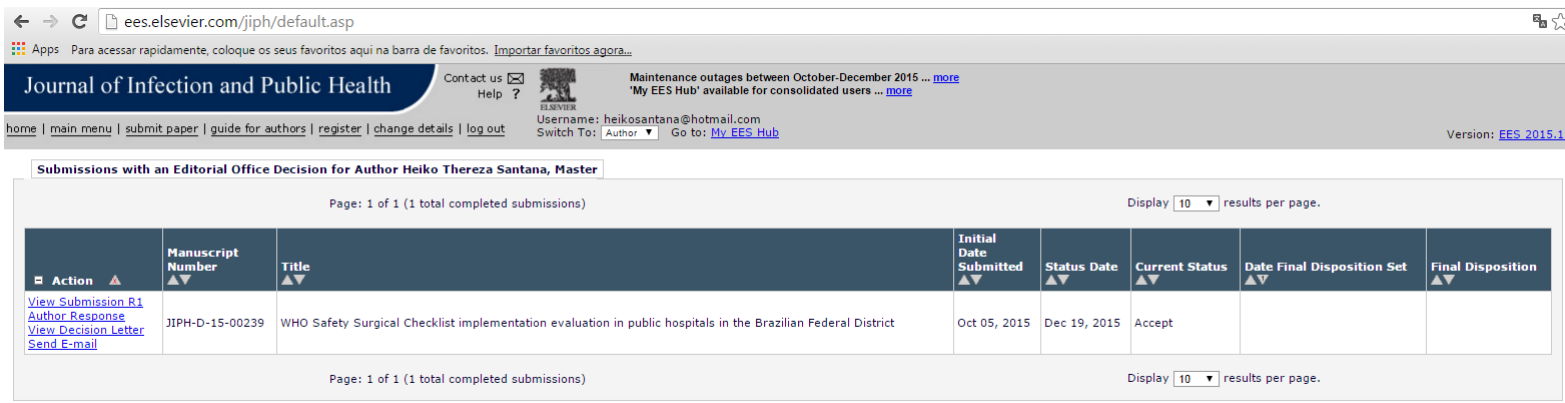

\footnotetext{
Gax Outlook.com - heikosante $\times$

$\leftarrow \rightarrow \mathrm{C}$ 回 Microsoft Corporation [Us] https://col126.mail.live.com/?tid=cm5FdsxnGm5RG6NwAiZMHWEA2\&fid=flinbox

::: Apps Para acessar r rapidamente, coloque os seus favoritos aqui na barra de favoritos. Importar favoritos agora...

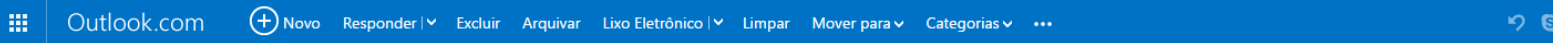

\begin{tabular}{|c|c|c|}
\hline Pesquisar no email & م & Your Submission \\
\hline Pastas & c & \multirow{3}{*}{$\begin{array}{l}\text { Journal of Infection and Public Health Adicionar aos contatos 19/12/2015 } \\
\text { Para: heikosantana@ hotmail.com, heiko.santana@anvisa.gov.br ₹ }\end{array}$} \\
\hline Caixa de Entrada 4390 & & \\
\hline \multicolumn{2}{|l|}{ Arquivo Morto } & \\
\hline \multicolumn{2}{|l|}{ Lixo 48} & Ms. Ref. No.: JIPH-D-15-00239R1 \\
\hline \multicolumn{2}{|l|}{ Rascunhos 193} & Title: WHO Safety Surgical Checklist implementation evaluation in public hospitals in the Brazilian Federal District \\
\hline \multicolumn{2}{|l|}{ Enviados } & \\
\hline \multicolumn{2}{|l|}{ Excluidos } & Dear Mrs. Heiko Thereza Santana, \\
\hline \multirow{6}{*}{\multicolumn{2}{|c|}{ Nova pasta }} & $\begin{array}{l}\text { I am pleased to inform you that your paper "WHO Safety Surgical Checklist implementation evaluation in public hospitals in the Brazilian Federal District" has been accepted for } \\
\text { publication in Journal of Infection and Public Health. }\end{array}$ \\
\hline & & Thank you for submitting your work to Journal of Infection and Public Health. \\
\hline & & Yours sincerely, \\
\hline & & Hanan H Balkhy, MD \\
\hline & & Editor in Chief \\
\hline & & Journal of Infection and Public Health \\
\hline
\end{tabular}
}




\section{ANEXO E}

\section{SUBMISSÃO DE ARTIGO 2}

\begin{tabular}{lr}
\hline BMC & $\begin{array}{r}\text { emEditorial } \\
\text { Manager }\end{array}$ \\
Research Notes & $\begin{array}{l}\text { Manager } \\
\text { Role: Author }\end{array}$ \\
MOME * LOGOUT * HELP * REGISTER * UPDATE MY INFORMATION * JOURNAL OVERVIEW &
\end{tabular}

\section{Author Main Menu}

Alternate Contact Information

Unavailable Dates
New Submissions

Submit New Manuscript

Submissions Sent Back to Author (0)

Incomplete Submissions ( 0 )

Submissions Waiting for Author's Approval (0)

Submissions Being Processed (0)

Revisions

Submissions Needing Revision (0)

Revisions Sent Back to Author (0)

Incomplete Submissions Being Revised (0)

Revisions Waiting for Author's Approval (0)

Revisions Being Processed (1)

Declined Revisions (0)

Completed 


\section{ANEXO F}

SUBMISSÃO DE ARTIGO 3

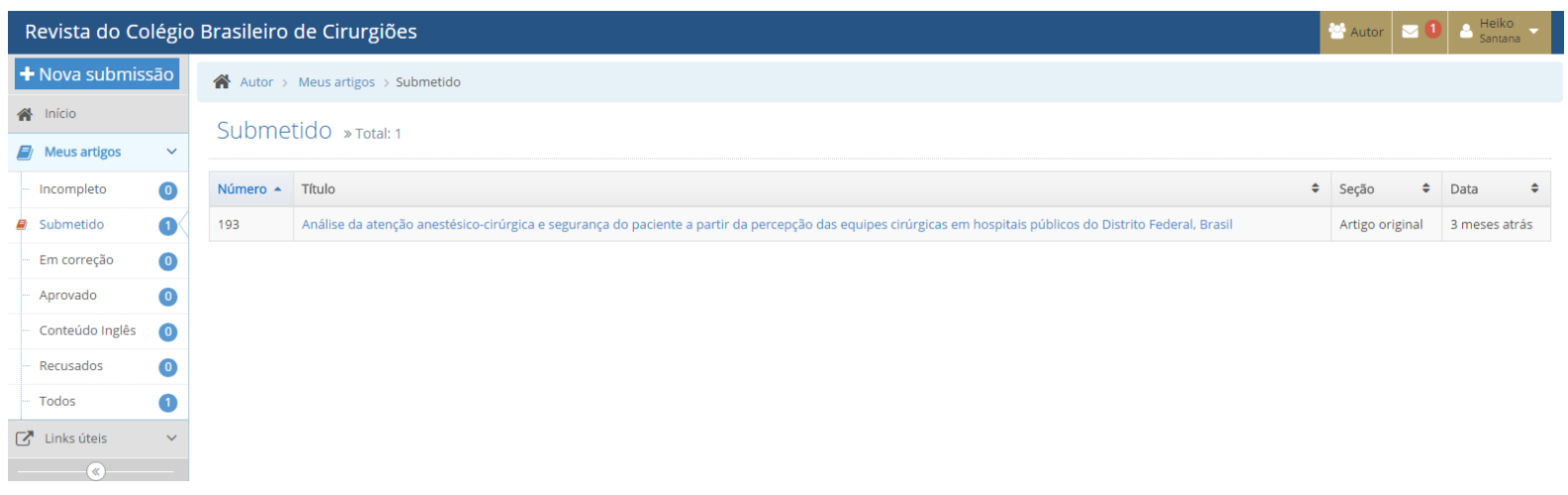

